Aus der Klinik für Allgemein-, Viszeral- und Kinderchirurgie

(Prof. Dr. med. M. Ghadimi)

des Zentrums Chirurgie

der Medizinischen Fakultät der Universität Göttingen

\title{
Immunhistochemische Analyse der p16-Expression im Rektumkarzinom: Vergleich von Patienten mit und ohne neoadjuvante Radiochemotherapie
}

\author{
INAUGURAL - DISSERTATION \\ zur Erlangung des Doktorgrades \\ der Medizinischen Fakultät der \\ Georg-August-Universität Göttingen
}

\author{
vorgelegt von \\ Ute Boczek \\ aus \\ Hildesheim
}

Göttingen 2017 
Dekan:

Referent/in:

Ko-Referent/in:

Drittreferent/in:
Prof. Dr. rer. nat. H. K. Kroemer

Prof. Dr. med. T. Liersch

Prof. Dr. rer. nat. T. Beißbarth

Datum der mündlichen Prüfung:

29.05.2018 


\section{Eigenständigkeitserklärung}

Hiermit erkläre ich, die Dissertation mit dem Titel „Immunhistochemische Analyse der p16Expression im Rektumkarzinom: Vergleich von Patienten mit und ohne neoadjuvante Radiochemotherapie“ eigenständig angefertigt und keine anderen als die von mir angegebenen Quellen und Hilfsmittel verwendet zu haben.

Göttingen, 


\section{Inhaltsverzeichnis}

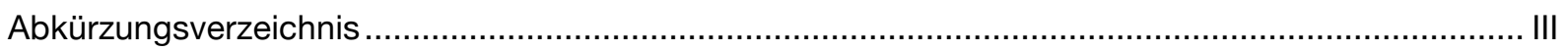

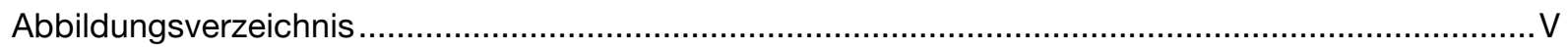

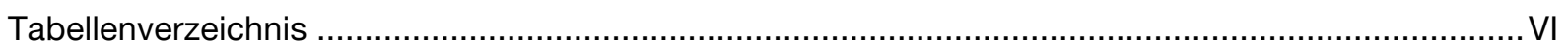

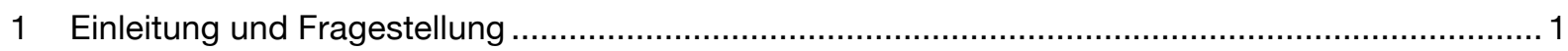

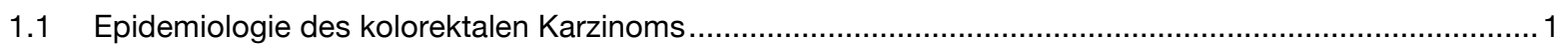

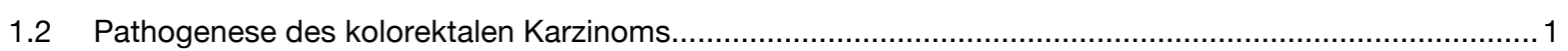

1.3 Risikofaktoren für das Auftreten eines kolorektalen Karzinoms .......................................................

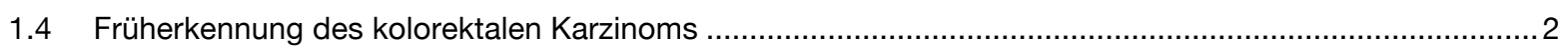

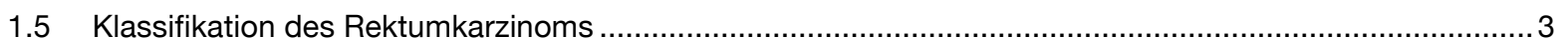

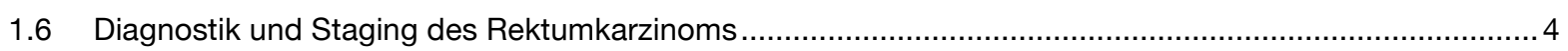

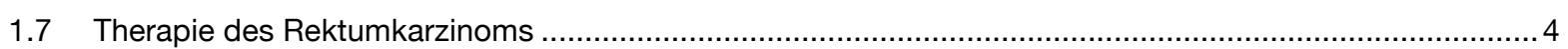

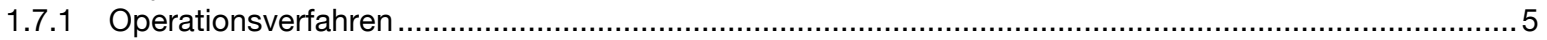

1.7.2 Multimodale Therapie des lokal fortgeschrittenen Rektumkarzinoms …..........................................

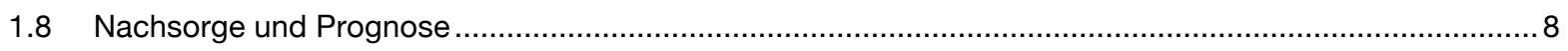

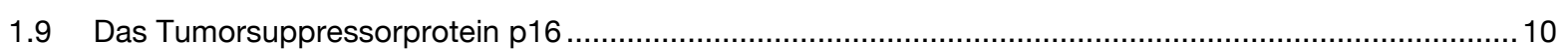

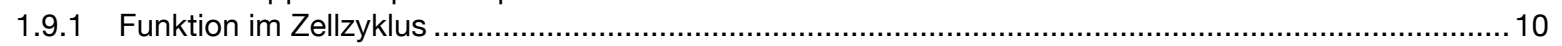

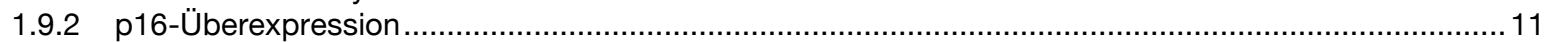

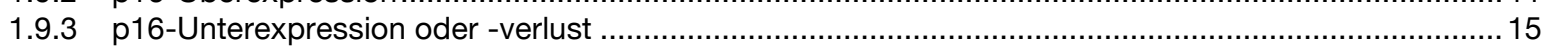

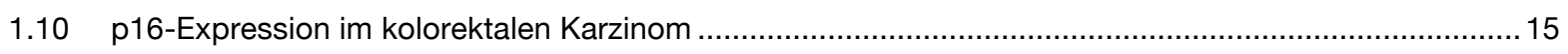

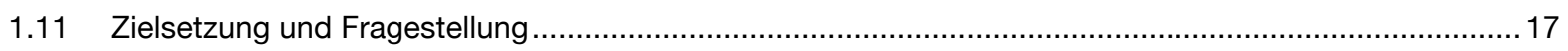

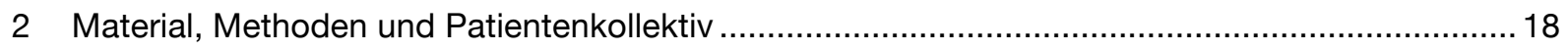

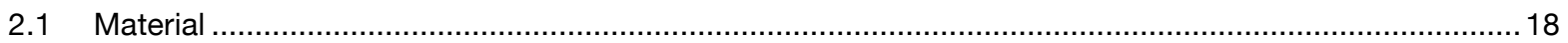

2.2 Grundprinzipien der Immunhistochemie und immunhistochemischer Färbevorgang ................................18

2.3 Mikroskopische Auswertung der immunhistochemischen Färbung ....................................................21

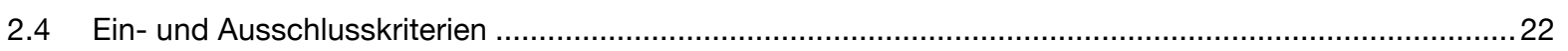

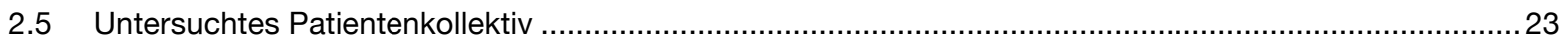

2.5.1 Präoperatives Staging und neoadjuvante Therapie ...........................................................................2 23

2.5.2 OP-Verfahren, histopathologisches Staging und adjuvante Therapie ..................................................26

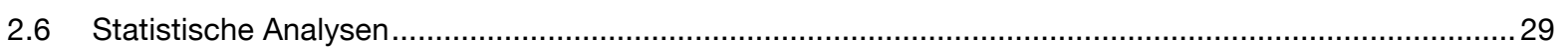

2.7 Erhebung der Patientendaten und Literaturrecherche ........................................................................... 30

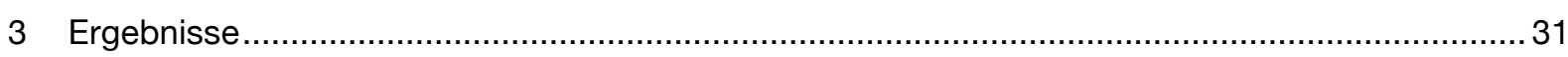

3.1 p16-Expression in den prätherapeutischen Biopsien ....................................................................

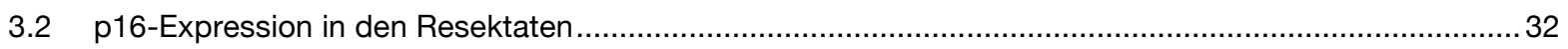

3.3 p16-Expression bei neoadjuvant behandelten vs. primär resezierten Rektumkarzinomen..........................36

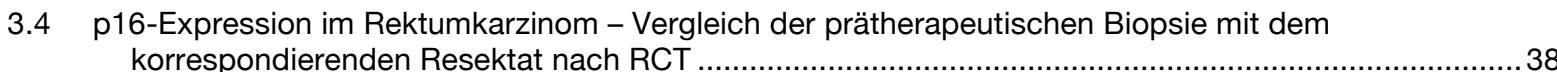

3.5 Korrelation der immunhistochemischen p16-Färbung der Biopsien und Resektate mit klinischen und histopathologischen Parametern.................................................................................................. 38

3.5.1 Korrelation der p16-Färbung mit dem Patientenalter ............................................................................ 39

3.5.2 Korrelation der p16-Scores des Karzinomanteils mit dem (y)pT-, dem (y)pN- und dem (y)pUICC-

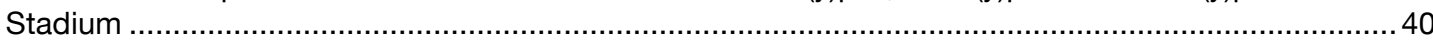


3.5.3 Korrelation des p16-Scores mit dem postoperativen Grading des Rektumkarzinoms.......................42

3.5.4 Korrelation der p16-Scores der prätherapeutischen Biopsie und des Resektates mit dem TRG .........42

3.6 Analysen des p16-Expressionsmusters und der p16-Stromafärbung..............................................43

3.6.1 Häufigkeit von homogen angefärbten Tumorarealen im Karzinomanteil des Resektates.....................43

3.6.2 Korrelation des p16-Expressionsmusters des Resektates mit dem TRG ............................................4

3.6.3 Häufigkeiten der p16-Stromafärbegrade im Vergleich zwischen den unterschiedlichen Behandlungsgruppen .................................................................................................... 44

3.6.4 Korrelation der p16-Stromafärbung mit dem p16-Score des Karzinomanteils nach Rektumresektion. 45

3.6.5 Korrelation der p16-Stromafärbung des Resektates mit dem TRG nach Rektumresektion .................45

3.7 Korrelation der p16-Expression mit Überlebensparametern .............................................................46

3.7.1 Korrelation des p16-Scores im Karzinomanteil der Resektate mit Überlebensparametern..................46

3.7.2 Korrelation des p16-Scores (Karzinomanteil/Adenomanteil) mit Überlebensparametern......................46

3.7.3 Korrelation der p16-Stromafärbung mit Überlebensparametern ..................................................4 47

3.7.4 Korrelation des p16-Expressionsmusters des Resektates mit Überlebensparametern......................47

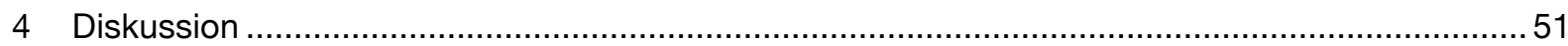

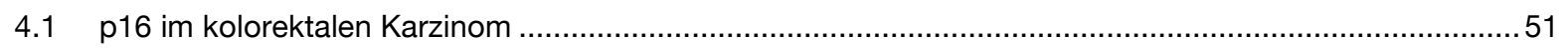

4.1.1 Vergleichbarkeit von Untersuchungen zur p16-Expression im KRK ...........................................5

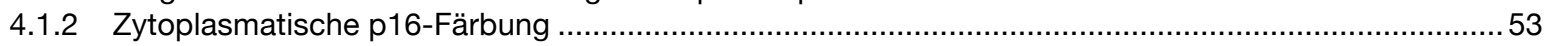

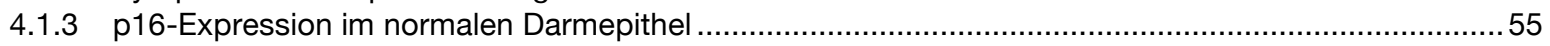

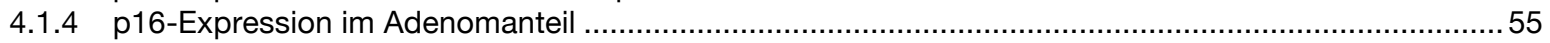

4.1.5 p16-Expression im nicht vorbehandelten primären kolorektalen Karzinom....................................56

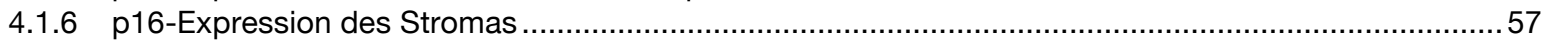

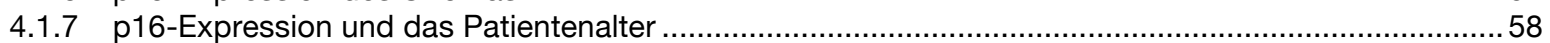

4.1.8 p16-Expression und das histopathologische Tumorgrading .......................................................59

4.1.9 p16-Expression und das pT-Stadium bzw. das Tumorstadium ....................................................59

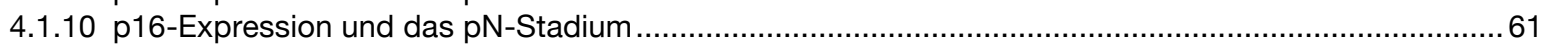

4.1.11 p16-Expressionsmuster - ein Unterscheidungskriterium..........................................................61

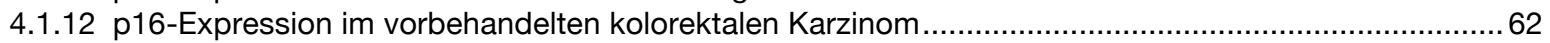

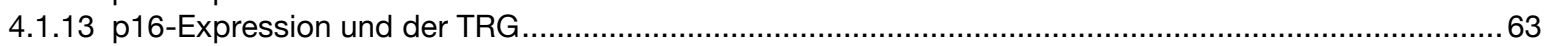

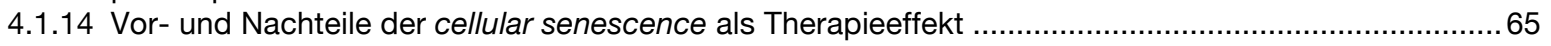

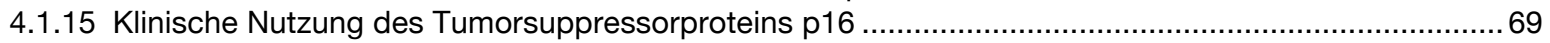

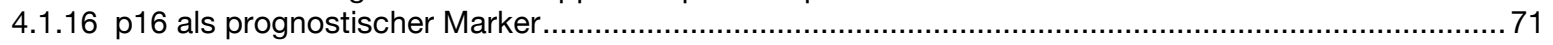

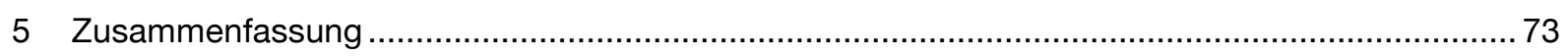

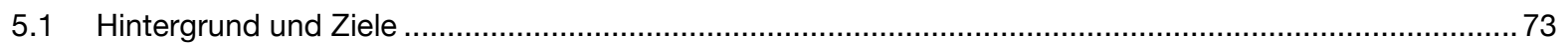

5.2 Methode

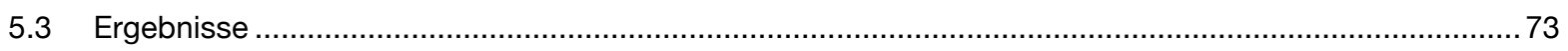

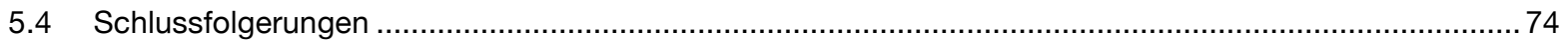

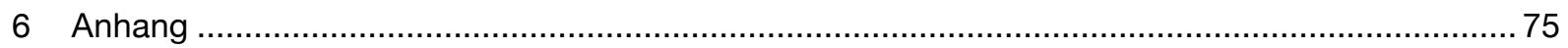

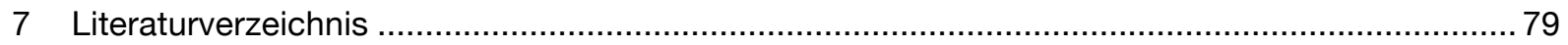




\section{Abkürzungsverzeichnis}

AIO

ATP

APC

APE

ARO

ARR

BRAF

CAO

CDK

CEA

CIMP

CIN

CRM

CSS

CT

CTx

$D A B$

DFG

DFS

DNA

FAP

FOBT

5-FU

HER-2

HNPCC

HPV

IL

JCCC

KFO

KRK

MAP

MAPK

MMR

MRT

NK-Zelle

OS

PME

Ras

RAS

RCT

rES

RT

SASP

SD
Arbeitsgemeinschaft Internistische Onkologie

Adenosintriphosphat

Adenomatöse Polyposis $\underline{\text { Coli }}$

Abdominoperineale Rektumexstirpation

Arbeitsgemeinschaft Radiologische Onkologie

Anteriore Rektumresektion

B-rapidly-accelerated-fibrosarcoma-Gen

Chirurgische Arbeitsgemeinschaft für Onkologie

Cyclin-dependent kinase (Cyclin-abhängige Kinase)

Carcinoembryonales Antigen

CpG island methylator phenotype

Chromosomal instability (Chromosomale Instabilität)

Circumferential resection margin (Zirkumferentieller Resektionsrand)

Cancer specific survival (Krebsspezifisches Überleben)

Computertomographie

Chemotherapie

Diaminobenzidin

Deutsche Forschungsgemeinschaft

Disease free survival (Krankheitsfreies Überleben)

Deoxyribonucleicacid (Desoxyribonukleinsäure)

Familiäre adenomatöse Polyposis

Fecal occult blood test (Test auf okkultes Blut im Stuhl)

5-Fluorouracil

Human epidermal growth factor receptor 2

(Humaner epidermaler Wachstumsfaktorrezeptor 2)

Hereditary non-polyposis colorectal cancer

(Hereditäres nonpolypöses kolorektales Karzinom)

Humanes Papillomvirus

Interleukin

Japanese Classification of Colorectal Carcinoma

(Japanische Klassifikation Kolorektaler Karzinome)

Klinische Forschergruppe

Kolorektales Karzinom

MUTHY-assoziierte Polyposis

Mitogen-activated-protein-kinase (Mitose-aktivierte-Proteinkinase)

Mismatch repair

Magnetresonanztomographie

Natural-Killer-Zelle (Natürliche Killerzelle)

Overall survival (Gesamtüberleben)

Partielle mesorektale Exzision

Rat-sarcoma-Protein

Rat-sarcoma-Gen

Radiochemotherapie

Rektale Endosonographie

Radiotherapie

Senescence-associated-secretory-phenotype

Standard deviation (Standardabweichung) 


\begin{tabular}{|c|c|}
\hline TARR & Tiefe anteriore Rektumresektion \\
\hline TEM & Transanale endoskopische Mikrochirurgie \\
\hline TME & Totale mesorektale Exzision \\
\hline TNM & Klassifikationssystem maligner Tumoren: \\
\hline & 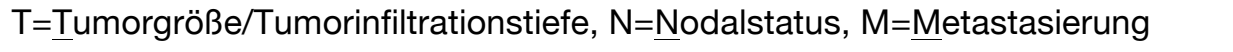 \\
\hline CTNM & TNM-Klassifikation nach klinischen Stagingergebnissen $(\mathrm{c}=\underline{c}$ linical) \\
\hline pTNM & TNM-Klassifikation nach histopathologischem Befund ( $\mathrm{p}=$ pathological) \\
\hline урTNM & $\begin{array}{l}\text { TNM-Klassifikation nach histopathologischem Befund nach } \\
\text { neoadjuvanter Therapie }\end{array}$ \\
\hline TRG & Tumorregressionsgrad \\
\hline TTR & Time to recurrence (Zeit bis zum Rezidiv) \\
\hline UICC & Union internationale contre le cancer (Internationale Vereinigung gegen Krebs) \\
\hline UMG & Universitätsmedizin Göttingen \\
\hline GF & Vascular endothelial growth factor (Vaskulärer endothelialer Wachstumsfaktor) \\
\hline
\end{tabular}




\section{Abbildungsverzeichnis}

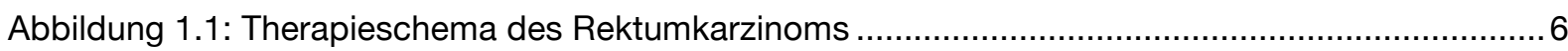

Abbildung 1.2: Therapieregime der CAO/ARO/AIO-94-Studie.....................................................

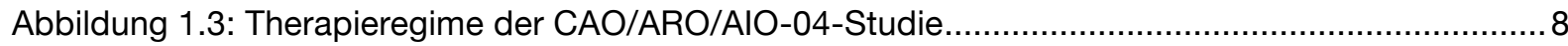

Abbildung 1.4: Funktion des Tumorsuppressorproteins p16 im Zellzyklus.....................................10

Abbildung 1.5: Auslöser einer erhöhten p16-Expression .......................................................... 12

Abbildung 2.1: Spektrum der beobachteten p16-Färbeintensitäten bei Rektumkarzinomzellen ..........21

Abbildung 2.2: Beispielbilder zur Bewertung des p16-Expressionsmusters.....................................22

Abbildung 2.3: Beispielbilder zur Gradeinteilung der Stromafärbung der Gewebeschnitte ..................22

Abbildung 3.1: Häufigkeitsverteilung der p16-Expression im Karzinomanteil der Biopsien $(n=40)$..... 32

Abbildung 3.2: Häufigkeitsverteilung der p16-Expression im Karzinomanteil der Rektumresektate

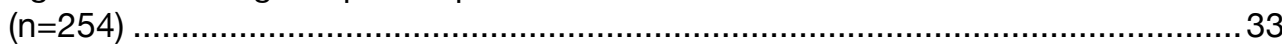

Abbildung 3.3: Vier Beispiele stark gefärbter Tumorzellcluster an der Tumorinvasionsfront................34

Abbildung 3.4: Häufigkeitsverteilung der p16-Expression im Adenomanteil der Rektumresektate

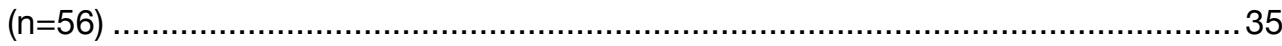

Abbildung 3.5: Normales Darmepithel mit vereinzelt angefärbten Zellen in Kryptennähe ....................35

Abbildung 3.6: Häufigkeitsverteilung der p16-Expression in normalem Darmepithel der

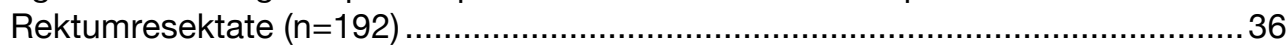

Abbildung 3.7: p16-Score der Karzinomanteile der Resektate in Korrelation zur präoperativen

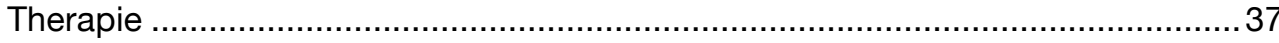

Abbildung 3.8: p16-Scores im Resektatgewebe nach neoadjuvanter Therapie vs. Kontrollgruppe.... 37

Abbildung 3.9: Vergleich der p16-Scores im Karzinomanteil der prätherapeutischen Biopsien und dem Karzinomgewebe der korrespondierenden Rektumresektate nach neoadjuvanter RCT

Abbildung 3.10: Korrelation der p16-Scores mit dem Patientenalter .................................................. 39

Abbildung 3.11: Grad der Stromafärbung in Korrelation zum Patientenalter bei OP ........................... 39

Abbildung 3.12: Korrelation der p16-Scores des Karzinomanteils mit dem postoperativen (y)pTStadium des Rektumresektates ........................................................................ 40

Abbildung 3.13: Korrelation der p16-Scores des Karzinomanteils mit dem postoperativen (y)pN-

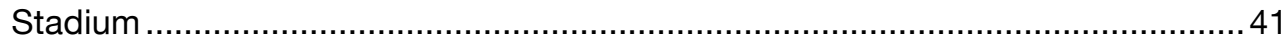

Abbildung 3.14: Korrelation des p16-Scores des neoadjuvant behandelten Rektumkarzinomgewebes mit dem postoperativen TRG .................................... 42

Abbildung 3.15: Korrelation der Stromafärbung mit dem p16-Score des Karzinomanteils der Resektate nach Rektumresektion

Abbildung 3.16: Vergleich der p16-Expression von Adenom- und korrespondierenden Karzinomanteilen ..................................................................................... 47

Abbildung 3.17: Korrelation des p16-Scores der Resektate mit TTR und CSS ................................ 48

Abbildung 3.18: Korrelation der unterschiedlichen Gruppen der Resektate mit Adenom- und Karzinomanteil mit den Überlebensparametern TTR und CSS.

Abbildung 3.19: Korrelation der Stromafärbung des Resektates mit den Überlebensparametern TTR und CSS

Abbildung 3.20: Vergleich von TTR und CSS zwischen Patienten mit und ohne homogen gefärbte Karzinomanteile.

Abbildung 4.1: Darstellung verschiedener Auswertungsmodelle der p16-Expression anhand des prozentual gefärbten Tumoranteils

Abbildung 4.2: Visualisierung der unterschiedlichen Auswertungsmethoden der immunhistochemischen p16-Färbung ............................................................5

Abbildung 4.3: Färbung des gleichen Ausschnittes eines Rektumkarzinom-Resektates mit p16, CD68, Vimentin und Aktin

Abbildung 4.4: Auswirkungen einer (Radio-)Chemotherapie und der daraus folgenden cellular senescence 


\section{Tabellenverzeichnis}

Tabelle 1.1: TNM-Klassifikation und UICC-Stadien bei kolorektalen Karzinomen ................................ 3

Tabelle 2.1: Übersicht über die verwendeten Materialien .............................................................20

Tabelle 2.2: Übersicht über das Biomaterial der Kohorten A, B und C .........................................24

Tabelle 2.3: Präoperative Parameter des Patientenkollektivs ........................................................25

Tabelle 2.4: Angewandte onkologische Operationsverfahren im Patientenkollektiv ............................26

Tabelle 2.5: Postoperative Parameter der histopathologischen Beurteilung .......................................2

Tabelle 2.6: Postoperative Behandlung der Patienten ................................................................ 28

Tabelle 3.1: Häufigkeit von homogen angefärbten Tumorarealen im Karzinomanteil des Resektates 43

Tabelle 3.2: Korrelation des p16-Expressionsmusters mit dem TRG nach präoperativer RCT ........... 44

Tabelle 3.3: Häufigkeiten der p16-Stromafärbegrade der Rektumresektate im Vergleich zwischen den unterschiedlichen Behandlungsgruppen ................................................. 44

Tabelle 3.4: Korrelation der Stromafärbegrade der Resektate mit dem TRG nach neoadjuvanter

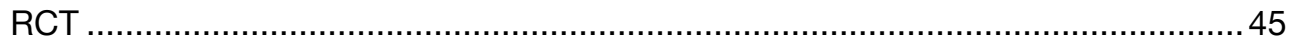

Tabelle 4.1: Tumorregression nach der Japanese Classification of Colorectal Carcinoma und nach dem TRG nach Dworak (1997) im Vergleich ...................................................... 64

Tabelle 4.2: Zusammenfassung der Unterschiede der Methodik zwischen der vorliegenden Arbeit, Kamoshida et al. (2004a) und Komuro et al. (2005) ............................................ 64

Tabelle 6.1: Übersicht über die Veröffentlichungen, die die immunhistochemische p16-Expression im KRK untersucht haben ........................................................................... 75 


\section{Einleitung und Fragestellung}

\subsection{Epidemiologie des kolorektalen Karzinoms}

Im Jahr 2012 erkrankten in Deutschland laut der Veröffentlichung „Krebs in Deutschland 2011/2012“ des Robert Koch-Instituts ca. 34.000 Männer und ca. 28.500 Frauen erstmals an einem kolorektalen Karzinom (KRK). Ein Drittel dieser KRK-Fälle war im Rektum lokalisiert (RKI und GEKID 2015). Im gleichen Jahr verstarben in Deutschland fast 26.000 Menschen an einem KRK, dabei war dieses Malignom bei Frauen die dritthäufigste, bei Männern sogar die zweithäufigste Ursache krebsbedingter Sterbefälle (RKI und GEKID 2015). Das mittlere Erkrankungsalter bei Erstdiagnose des KRK betrug bei Männern 72 Jahre und bei Frauen 75 Jahre (RKI und GEKID 2015). Allerdings bestehen fortgeschrittene Adenome und Karzinome in Screeningpopulationen von 50- bis 54-jährigen Patienten auch schon bei 8,6\% der koloskopierten Männer und 4,5\% der untersuchten Frauen (Brenner et al. 2017). Dementsprechend ist das KRK nicht nur eine Krebserkrankung des fortgeschrittenen Lebensalters, sondern betrifft auch schon Patienten im erwerbsfähigen Alter. Neben den offensichtlichen gesundheitlichen und psychosozialen Folgen, unter denen die erkrankten Patienten leiden, hat das KRK auch erhebliche wirtschaftliche Konsequenzen. Zum einen kommen auf das öffentliche Gesundheitssystem durch die teils erheblichen Behandlungskosten auch zukünftig bei derzeit annähernd gleichbleibenden Erkrankungszahlen enorme Ausgaben zu (Haug et al. 2014). Zum anderen entstehen insbesondere bei erkrankten Erwerbsfähigen durch deren Arbeitskraftausfall auch negative Folgen für die Gesamtwirtschaft (Luengo-Fernandez et al. 2013). Daher ist die klinischwissenschaftliche Auseinandersetzung mit der Verbesserung von Früherkennung, Therapie und molekularpathologisch-basierter Prognoseabschätzung des kolorektalen Karzinoms sowohl für das Wohlergehen einer Vielzahl von Patienten als auch aus ökonomischer Sicht sinnvoll.

\subsection{Pathogenese des kolorektalen Karzinoms}

Nach derzeitigem Kenntnisstand entwickelt sich ein KRK durch die klonale Expansion von Darmepithelzellen, die zuvor aufgrund somatischer Mutationen, oftmals über die Aktivierung von Onkogenen oder die Inaktivierung von Tumorsuppressorgenen, die Fähigkeit zu unkontrolliertem und infiltrativem Wachstum erworben haben (Fearon und Vogelstein 1990; Knudson 1985). Je nach Art der zugrundeliegenden Zellveränderung können verschiedene Wege der KRK-Entstehung unterschieden werden, wie der CIN- (chromosomal instability), der MMR- (mismatch repair) und der CIMP- (CpG island methylator phenotype) pathway (Colussi et al. 2013; Worthley und Leggett 2010). Der CIN ist der häufigste pathway der KRK-Entstehung. Hierbei entsteht aus hyperproliferativem Darmepithel zuerst ein Adenom, welches durch eine Ansammlung von Mutationen von u. a. APC (Adenomatöse Polyposis Coli-Gen), K-ras und p53 zu einem Karzinom transformiert (Colussi et al. 2013; Fearon und Vogelstein 1990). Durch Mutationen entstandene Funktionsverluste des $M M R$ Systems führen unter anderem zu einer Mikrosatelliteninstabilität, die vor allem bei der Genese der 
hereditären Karzinome des HNPCC-Syndroms eine bedeutende Rolle spielt, aber auch für ca. 15-20 \% aller sporadischen KRK verantwortlich ist (Poulogiannis et al. 2010). Der CIMP-pathway zeichnet sich durch eine epigenetische Instabilität aus, die durch die Methylierung von Promotoren $\operatorname{der} C p G$ islands zur Inaktivierung von Tumorsuppressorgenen führt. Hierbei entsteht das Karzinom über die vorherige Entwicklung eines sessilen serratierten Adenoms bzw. Polypens (Nazemalhosseini Mojarad et al. 2013; Snover 2011; Toyota et al. 1999).

\subsection{Risikofaktoren für das Auftreten eines kolorektalen Karzinoms}

Bei der Entstehung eines KRK wird zwischen begünstigenden endogenen und exogenen Faktoren unterschieden (Fearon und Vogelstein 1990; Lynch und de la Chapelle 2003; Pelser et al. 2014; Willett 1989). Endogene Faktoren umfassen vorbestehende Erkrankungen oder genetische Dispositionen der Patienten (Pox et al. 2013). Darunter fallen die Colitis ulcerosa als chronischentzündliche Darmerkrankung, das Vorliegen von großen oder multiplen Adenomen, eine positive Familienanamnese von KRK bei Verwandten ersten Grades und spezifische genetische Erkrankungen wie die FAP (familiäre adenomatöse Polyposis), die MUTYH-assoziierte Polyposis (MAP) und das HNPCC-Syndrom (hereditäres non-polypöses Kolonkarzinom) (Aarnio et al. 1995; Eaden et al. 2001; Goldgar et al. 1994; Johns und Houlston 2001; Lubbe et al. 2009; Lynch und Smyrk 1998; Samadder et al. 2015; van Stolk et al. 1998). Liegt einer dieser endogenen Risikofaktoren vor, sollten bei den betroffenen Personen regelmäßige Vorsorgeuntersuchungen frühzeitiger und engmaschiger als in der Normalbevölkerung durchgeführt werden (Pox et al. 2013). Als exogene Risikofaktoren für die Entstehung von KRK werden hoher Alkoholkonsum, körperliche Inaktivität, Nikotinabusus, hoher Fleischkonsum und Adipositas angesehen (Cho et al. 2004; Giovannucci 2001; Huxley et al. 2009; Ning et al. 2010; Pelser et al. 2014).

\subsection{Früherkennung des kolorektalen Karzinoms}

Ziel einer effektiven KRK-Vorsorge ist die frühzeitige Detektion von Polypen und Karzinomvorstufen sowie deren vollständige Entfernung. Langfristig wird damit eine Senkung der Inzidenz und Mortalität angestrebt. In Deutschland werden seit Jahresende 2002 die Kosten für eine komplette Vorsorgekoloskopie von den gesetzlichen Krankenkassen übernommen und den Versicherten ab dem 55. Lebensjahr angeboten. Bei einem unauffälligen Ergebnis in der Primärkoloskopie, einem durchschnittlichen familiären Risikoprofil sowie fortbestehender Beschwerdefreiheit sollte und kann nach 10 Jahren auch eine zweite komplette Koloskopie zu Lasten der gesetzlichen Krankenkassen in Anspruch genommen werden (Brenner et al. 2015; Krebsfrüherkennungs-Richtlinien 2002). Grundsätzlich hat die komplette endoskopische Kolondiagnostik neben der höchsten Sensitivität und Spezifität für die Adenom- und Karzinomerkennung auch den Vorteil, dass identifizierte Befunde unmittelbar per Biopsie gesichert oder sogar komplett abgetragen werden können. Zudem ist die Durchführung einer Vorsorgekoloskopie mit einer geringeren KRK-Mortalität assoziiert (Baxter et al. 
2012; Brenner et al. 2014; Jacob et al. 2012; Kahi et al. 2009; Pox et al. 2012; Zauber et al. 2008). Auch die Durchführung einer Sigmoidoskopie oder des FOBT (Fecal occult blood test, Test auf okkultes Blut im Stuhl) senken die KRK-Mortalität nachweislich; sie kommen jedoch ebenso wie die virtuelle Koloskopie, eine kontrastmittelgestützte CT-Untersuchung des Dickdarmes, als ScreeningMethode aufgrund ihrer geringeren Detektionsrate bzw. einer hohen Strahlenbelastung als Alternative nur bei Ablehnung der kompletten Koloskopie seitens des Patienten in Betracht (Fitzpatrick-Lewis et al. 2016; Hewitson et al. 2008; Lieberman et al. 2000; Pox et al. 2013).

\subsection{Klassifikation des Rektumkarzinoms}

Im Folgenden wird genauer auf das Adenokarzinom des Rektums (vereinfacht als „Rektumkarzinom“ bezeichnet) eingegangen, da es Gegenstand dieser Arbeit ist. Das Rektumkarzinom ist über die Lage des aboralen Tumorrandes im Bereich von 0-16 cm ab Anokutanlinie definiert (Sobin et al. 2002). Die Unterscheidung zwischen Kolon- und Rektumkarzinomen hat große therapeutische Relevanz, da Rektumkarzinome aufgrund ihrer anatomischen Lage und ihrer hohen Tendenz zu Lokalrezidiven einer anderen Therapie zugeführt werden müssen als Kolonkarzinome (Pilipshen et al. 1984; Pox et al. 2013). Mithilfe der starren Rektoskopie, dem zuverlässigsten Werkzeug zur genauen Höhenangabe von Rektumkarzinomen, werden die Tumoren gemäß ihrer Lokalisation gemessen von der Anokutanlinie bis zum aboralen Tumorrand in Tumoren des unteren $(<6 \mathrm{~cm})$, mittleren $(6$ bis $<12 \mathrm{~cm})$ und oberen (12-16 cm) Rektumdrittels unterschieden (Fielding et al. 1991; Paparo et al. 2014).

Neben der Höhenlokalisation ist die Bestimmung des präoperativen UICC-Stadiums des Karzinoms grundlegend für eine Therapieentscheidung (Gaedcke et al. 2011). Die Stadieneinteilung der UICC (Union internationale contre le cancer) ergibt sich aus der T- (Tumorinfiltrationstiefe), N(Nodalstatus) und M-Klassifikation (Fernmetastasierung) des vorliegenden Malignoms. Die Einteilung in ein UICC-Stadium kann präoperativ klinisch (cUICC), postoperativ histopathologisch (pUICC) und postoperativ histopathologisch nach einer neoadjuvanten Therapie (ypUICC) erfolgen (Sobin et al. 2011). Eine Übersicht über die einzelnen T-, N-, und M-Stadien und die sich daraus ergebenden UICC-Stadien ist in Tabelle 1.1 dargestellt.

Tabelle 1.1: TNM-Klassifikation und UICC-Stadien bei kolorektalen Karzinomen

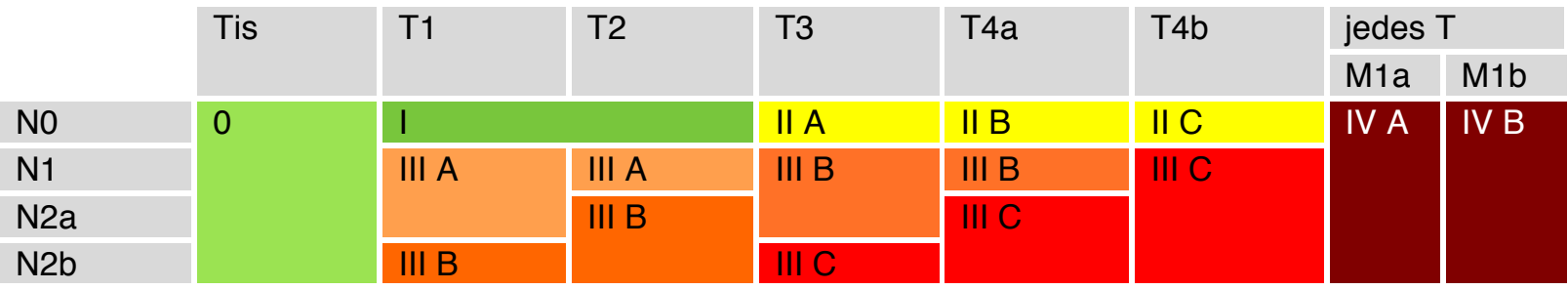

Eigene Darstellung nach Sobin et al. (2011). Die UICC-Stadien, die aus T-, N-, und M-Stadium hergeleitet werden, reichen von 0-IV B. Tis-Tumoren sind auf die Mucosa beschränkt, T1-Karzinome infiltrieren die Submukosa, T2-Stadien reichen bis über die Muscularis propria hinaus. Das pT3-Stadium wächst in die Subserosa hinein. Das T4-Stadium wird ebenso wie das N2- und das M1-Stadium noch in a und b unterteilt. T4a entspricht der Infiltration des viszeralen Peritoneums, T4b-Stadien infiltrieren andere Organe. Die Stadien N1, N2a und N2b beschreiben das Vorhandensein von jeweils 1-3, 4-6 bzw. >6 regionären Lymphknotenmetastasen von mindestens 12 untersuchten Lymphknoten. Die Unterscheidung von M1 betrifft die Anzahl der Organe, in denen Metastasen diagnostiziert werden. Im Stadium M1a ist nur ein Organ, im Stadium M1b ist mehr als ein Organ oder das Peritoneum betroffen (Pox et al. 2013; Sobin et al. 2011). 
Für darüber hinausgehende Informationen sei an dieser Stelle auf „TNM Classification of Malignant Tumours" von Sobin et al. (2011) verwiesen. Neben der pathologischen TNM-Klassifikation werden nach der Resektion des Tumors der Residualstatus $(\mathrm{R} 0=$ komplette Resektion, $\mathrm{R} 1=$ mikroskopisch nicht im Gesunden entfernt, R2=makroskopisch nicht im Gesunden entfernt), eine etwaige Lymph- (L0, L1) bzw. Blutgefäßinvasion (V0, V1) der Malignomzellen und das Grading (G0=gut differenziert, $\mathrm{G} 1=$ mäßig differenziert, $\mathrm{G} 3=$ =schlecht differenziert, G4=undifferenziert) angegeben (Hamilton et al. 2000; Pox et al. 2013).

\subsection{Diagnostik und Staging des Rektumkarzinoms}

Sofern Rektumkarzinome nicht im Rahmen von Früherkennungsmaßnahmen diagnostiziert werden, fallen sie aufgrund ihrer späten Symptomatik zumeist erst im lokal fortgeschrittenen Stadium auf (Hamilton et al. 2005; Stapley et al. 2006). Der diagnostisch-methodische „Goldstandard“ für die Diagnose eines malignen Prozesses im Rektum ist nach wie vor die starre Rektoskopie mit Gewinnung von Biopsien aus unterschiedlichen Arealen des Tumors. Zusätzlich zur Rektoskopie wird bei nicht stenosierenden Tumoren prätherapeutisch immer eine komplette Koloskopie durchgeführt, um weiter proximal gelegene, synchrone Zweitkarzinome (bis zu $4 \%$ der KRK-Fälle) und Polypen (bis zu 14 \% der KRK-Fälle) auszuschließen (Barillari et al. 1990; Chen und Sheen-Chen 2000; Pox et al. 2013). Zum weiteren lokoregionalen Staging des Rektumkarzinoms gehören die rektale Endosonographie (rES) zur Bestimmung der Tumorinfiltrationstiefe in die Rektumwand und das mesorektale Fettgewebe (uT-Stadium analog der TNM-Klassifikation) sowie zur Beurteilung des lokalen Nodalstatus (uN-Stadium analog der TNM-Klassifikation). Eine Magnetresonanztomographie (MRT) des kleinen Beckens mit rektaler Kontrastmittelfüllung erfolgt zur bestmöglichen Darstellung der pelvinen und mesorektalen Fasziensysteme in Korrelation zur Karzinomlage und -infiltrationstiefe (Kwok et al. 2000; Liersch et al. 2003; Pox et al. 2013; Puli et al. 2009). Zusätzlich zum lokoregionalen Staging wird eine Röntgen-Thorax-Aufnahme und eine Abdomensonographie zur Abklärung einer Fernmetastasierung sowie eine präoperative Bestimmung des Blutwertes für das carcinoembryonale Antigen (CEA) als Ausgangswert für spätere Verlaufskontrollen durchgeführt (Kwok et al. 2000; Levy et al. 2008; Pox et al. 2013). Bei metastasensuspekten Vorbefunden im Staging folgen weitere CT- oder MRT-Untersuchungen und bei Zweifeln an der Möglichkeit des Sphinktererhalts bei geplanter onkologischer Resektion wird oftmals eine Sphinktermanometrie durchgeführt (Beets-Tan 2003; Floriani et al. 2010; Gaedcke et al. 2011; Mainenti et al. 2010; Pox et al. 2013; Purkayastha et al. 2007; Quaia et al. 2006; Schmoll et al. 2012).

\subsection{Therapie des Rektumkarzinoms}

Die Therapie des Rektumkarzinoms reicht von einem rein operativen Vorgehen bei frühen, lokal begrenzten Tumorstadien bis hin zu multimodalen Konzepten bei lokal fortgeschrittenen oder bereits (fern-) metastasierten Tumoren. Eine nach Tumorstadien geordnete Übersicht über die Therapieregime 
findet sich in Abbildung 1.1. Im Folgenden werden die operativen Maßnahmen und die präoperative (neoadjuvante) Radiochemotherapie (RCT) bei lokal fortgeschrittenen Rektumkarzinomen im cUICC Stadium II und III beschrieben.

\subsubsection{Operationsverfahren}

Das Ziel jeder onkologischen Operation mit kurativem Anspruch ist die histopathologisch bestätigte komplette Resektion des Tumors und etwaiger infiltrierter Strukturen (R0-Status) (Nagtegaal et al. 2002). Grundsätzlich werden drei verschiedene Operationsverfahren unterschieden: die tiefe anteriore Rektumresektion (TARR) mit totaler mesorektaler Exzision (TME), die anteriore Rektumresektion (ARR) mit partieller mesorektaler Exzision (PME) und die abdominoperineale Exstirpation (APE) mit TME (Gaedcke et al. 2011; Smith et al. 1988). Der entscheidende Unterschied zwischen TARR mit TME und der ARR mit PME liegt in dem Ausmaß der Resektion des mesorektalen Weichgewebes und seiner Hüllfaszie, die bei der TME vollständig und bei der PME nur teilweise entfernt wird (Heald et al. 1982). Bei cUICC-II- und III-Karzinomen des mittleren und unteren Rektumdrittels ist grundsätzlich eine TME notwendig (Heald et al. 1982; Heald und Ryall 1986; Pilipshen et al. 1984; Pox et al. 2013). Ob im oberen Rektumdrittel eine PME gegenüber der TME als onkologisch gleichwertig angesehen werden kann, ist in der Literatur umstritten und wird gegenwärtig in der multizentrischen deutschen GAST-05-Studie (Studiennummer: ISRCTN35198481, DFG-geförderte Phase-II b-Studie) geprüft (Liersch et al. 2009). Die APE ist im Gegensatz zu den anderen beiden Verfahren keine kontinenzerhaltende Operation und beinhaltet neben der Resektion des Schließmuskelapparates und von Anteilen der Beckenbodenmuskulatur auch die Anlage eines definitiven Descendostomas (Nagtegaal et al. 2005; West et al. 2008). Sie ist indiziert, wenn zum Operationszeitpunkt eine Sphinkterinfiltration des Tumors vorliegt, der Tumor weniger als $1 \mathrm{~cm}$ vom Sphinkter entfernt ist oder die Sphinkterfunktion schon präoperativ schwach ist (Perry und Connaughton 2007; Pox et al. 2013; Schmoll et al. 2012). 


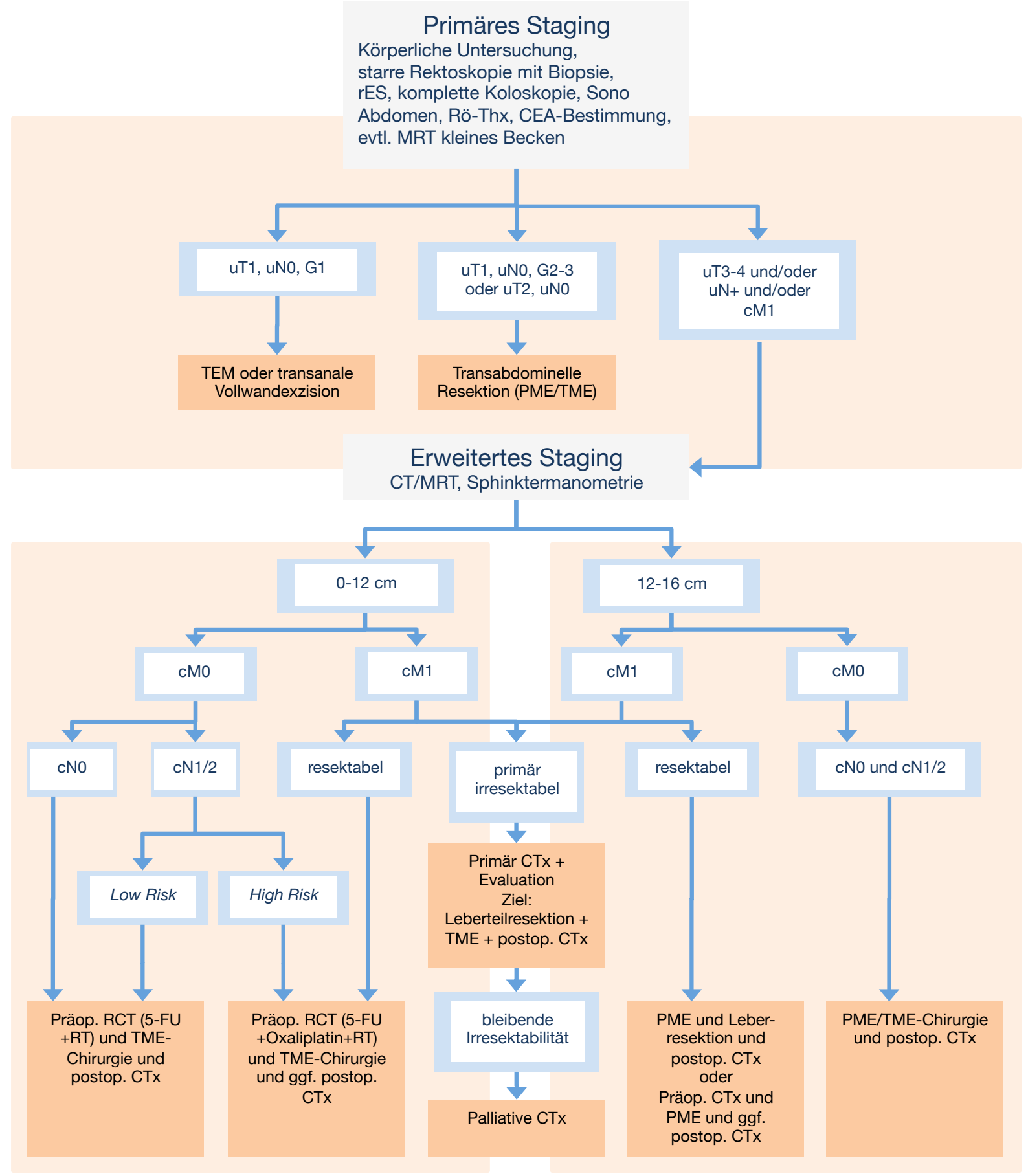

\section{Abbildung 1.1: Therapieschema des Rektumkarzinoms}

Eigene Darstellung nach Gaedcke et al. (2011). Low Risk und High Risk entsprechend klinischer Beurteilung. Die Sphinktermanometrie kann in einigen Fällen zur Entscheidungsfindung bei der Frage nach sphinktererhaltender Operation führen, wird aber nicht generell empfohlen (Pox et al. 2013). Die Therapie von resektablen Lebermetastasen wird noch nicht einheitlich durchgeführt. Bei diesem Schema handelt es sich um Therapiempfehlungen (Gaedcke et al. 2011). Die Zugabe von Oxaliplatin zur neoadjuvanten RCT in High-Risk-Fällen ist ebenfalls noch nicht in die aktuelle deutsche S3-Leitlinie eingegangen (Pox et al. 2013). RCT (Radiochemotherapie), CTx (Chemotherapie), TME (Totale mesorektale Exzision), PME (Partielle mesorektale Exzision), 5-FU (5-Fluoruracil), Rö-Thx (Röntgen-Thorax), rES (rektale Endosonographie), TEM (Transanale endoskopische Mikrochirurgie), CT (Computertomographie), MRT (Magnetresonanztomographie). 


\subsubsection{Multimodale Therapie des lokal fortgeschrittenen Rektumkarzinoms}

In der Therapie des lokal fortgeschrittenen Rektumkarzinoms (cUICC-II- und III-Stadien) wurde durch die Einführung der adjuvanten Chemotherapie, der TME und der neoadjuvanten RCT eine deutlich verbesserte lokoregionäre Kontrolle und eine in geringerem Maße reduzierte Fernmetastasierungsrate erreicht (Czito und Willett 2007; Frykholm et al. 2001; Heald et al. 1982; Krook et al. 1991; MacFarlane et al. 1993; Sauer et al. 2004; Sauer et al. 2012; van Gijn et al. 2011). Um die Qualität der Therapie des Rektumkarzinoms deutschlandweit sicherzustellen und zu standardisieren, gibt es eine S3-Leitlinie „Kolorektales Karzinom“, in der die Evidenz für Vorsorge, Therapie und Nachsorge des Rektumkarzinoms beschrieben und Empfehlungen diesbezüglich ausgesprochen werden (Pox et al. 2013). Die derzeitige Standardtherapie für lokal fortgeschrittene Rektumkarzinome des unteren und mittleren Drittels sieht auf der Grundlage der deutschen CAO/ARO/AIO-94-Studie (Fördernummer der Krebshilfe: 70-587) eine neoadjuvante RCT mit 50,4 Gy und simultaner 5-Fluorouracil-Gabe (5-FU), eine nachfolgende Operation mit TME und eine adjuvante 5-FU-Chemotherapie (CTx) vor (Pox et al. 2013; Sauer et al. 2003) (siehe Abbildung 1.2). Diese CAO/ARO/AIO-94-Studie hat weltweit erstmals gezeigt, dass mit der neoadjuvanten RCT auch nach einem medianen Nachbeobachtungszeitraum von 134 Monaten eine anhaltend niedrigere Lokalrezidivrate $(7,1 \%$ vs. $10,1 \% ; \mathrm{p}=0,048)$ gegenüber der Kontrollgruppe, die statt der neoadjuvanten RCT eine postoperative RCT erhielt, erreicht werden kann (Sauer et al. 2012). Das DFS (Disease free survival, kranksheitsfreies Überleben) unterschied sich zwischen den beiden Studienarmen nicht (68,5\% Arm B vs. 67,5\% Arm A) (Sauer et al. 2012).

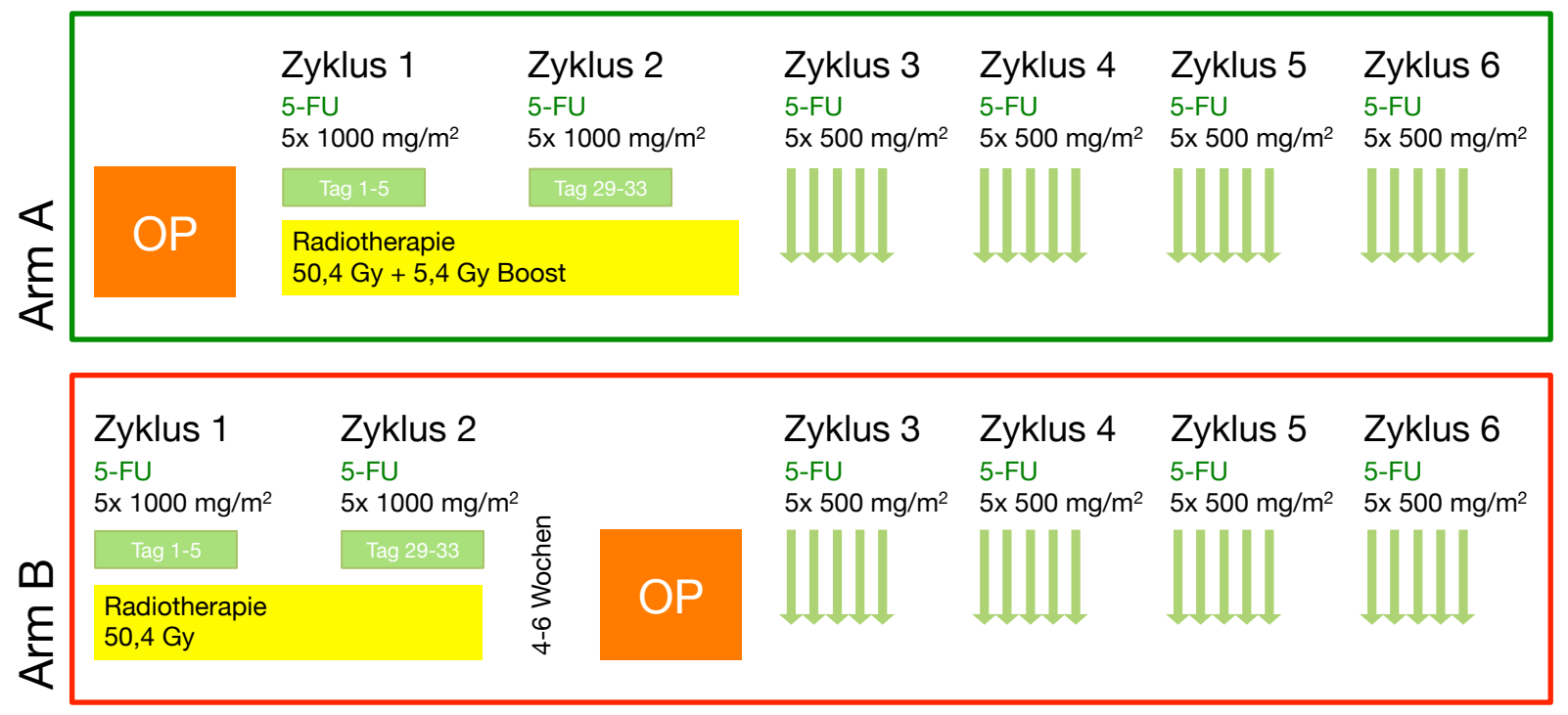

\section{Abbildung 1.2: Therapieregime der CAO/ARO/AIO-94-Studie}

Eigene Darstellung nach Sauer et al. (2003) und Sauer et al. (2004). Der Kontrollarm (Arm A) besteht aus einer adjuvanten RCT aus insgesamt sechs Zyklen. Die ersten zwei Zyklen 5-FU-Chemotherapie werden konkomitant zur Radiotherapie gegeben und entsprechen der neoadjuvanten RCT des Prüfarms mit dem einzigen Unterschied des zusätzlichen 5,4 GyBoosts auf das Tumorbett. Der Prüfarm (Arm B) beinhaltet eine neoadjuvante RCT mit 50,4 Gy in 28 Einzeldosen und konkomitanter Gabe von $1000 \mathrm{mg} / \mathrm{m}^{2}$ jeweils an Tag 1-5 und 29-33. Die adjuvante Therapie besteht aus vier Zyklen 5-FUBolus-Therapie an den Tagen 1-5 mit Beginn des nächsten Zyklus an Tag 29. Die Operation erfolgt immer als TME (Sauer et al. 2012). 5-FU (5-Fluorouracil), RCT (Radiochemotherapie). 
Die Nachfolgestudie CAO/ARO/AIO-04 (Studiennummer: NCT 00349076, randomisierte klinische Phase-III-Studie) zeigt im Vergleich zur CAO/ARO/AIO-94-Studie, dass durch eine zusätzliche Intensivierung der Systemtherapie mit Oxaliplatin (siehe Abbildung 1.3) die Rate an kompletter Tumorregression signifikant gesteigert werden kann (Rödel et al. 2012). Zudem besteht nach einem medianen Nachbeobachtungszeitraum von 50 Monaten ein signifikanter Unterschied $(p=0,03)$ im DFS zugunsten der Prüfkohorte (Rödel et al. 2015). Im bisherigen Beobachtungszeitraum hat sich kein Unterschied im overall survival (OS) der Patienten im Vergleich beider Therapieregime ergeben (88,0 \% Arm A vs. 88,7 \% Arm B, Hazard Ratio=0,96) (Rödel et al. 2015).
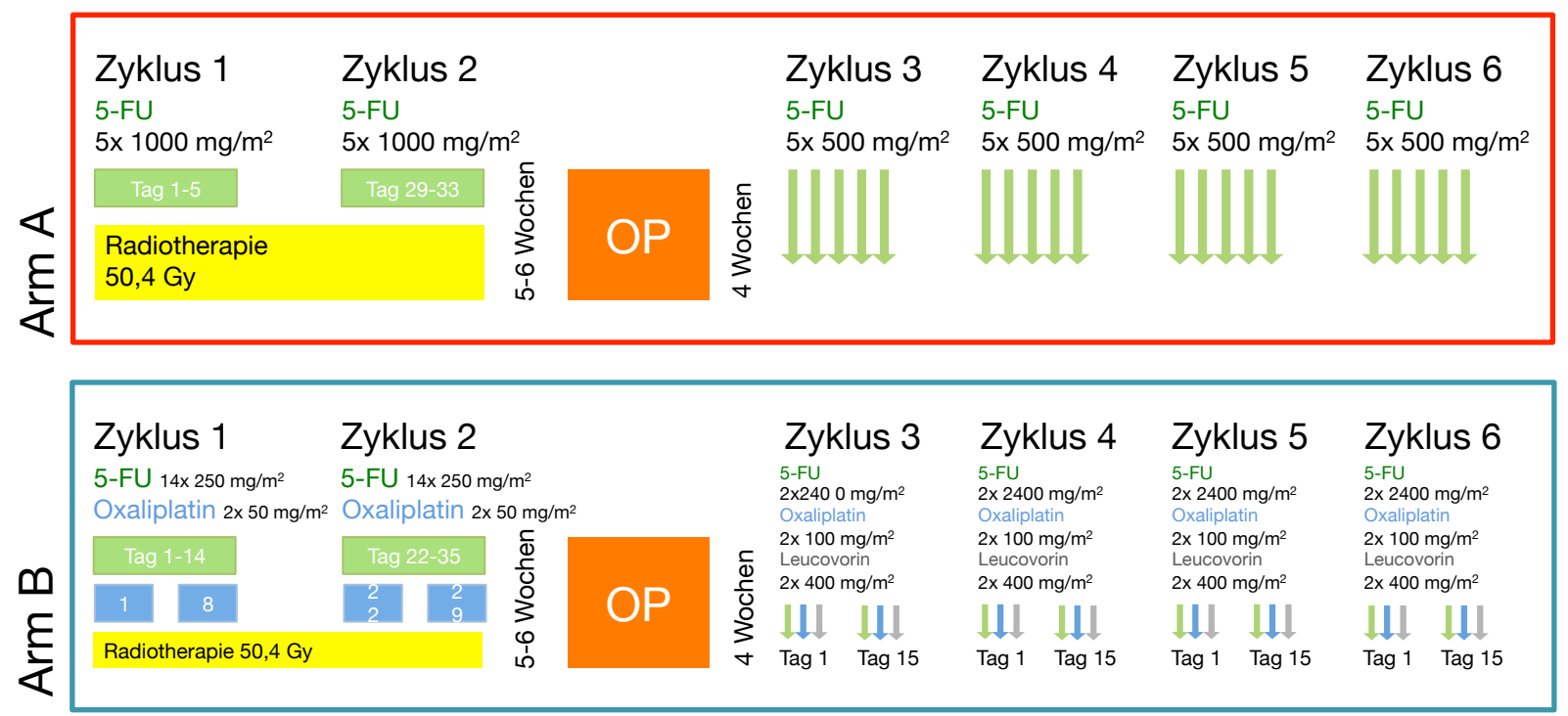

Abbildung 1.3: Therapieregime der CAO/ARO/AIO-04-Studie

Eigene Darstellung nach Rödel et al. (2012) und Rödel et al. (2015). Der Kontrollarm entspricht dem Prüfarm der CAO/ARO/AIO-94-Studie. Der Prüfarm hingegen umfasst eine mit vier zusätzlichen Einzelgaben Oxaliplatin intensivierte neoadjuvante RCT und eine aus vier Zyklen bestehende adjuvante Chemotherapie mit der Gabe von 5-FU (Tag 1-2, 15-16), Oxaliplatin und Leukovorin (Tag 1 und 15). Die Operation wird in allen Fällen als TME durchgeführt (Rödel et al. 2015). 5FU (5-Fluorouracil), RCT (Radiochemotherapie), TME (Totale mesorektale Exzision).

\subsection{Nachsorge und Prognose}

Nach Abschluss der Primärtherapie wird eine strukturierte Nachsorge zur frühzeitigen Erkennung von lokoregionären Rezidiven und Fernmetastasen durchgeführt (Pox et al. 2013). Dazu gehören neben einer kompletten Koloskopie und einer abdominellen Sonographie auch CEA-Bestimmungen, die in festgelegten Abständen postoperativ durchgeführt werden sollten (Pox et al. 2013).

Klinisch-pathologisch etablierte Faktoren für eine schlechtere Langzeitprognose sind unter anderem ein primär metastasiertes Tumorstadium, die Höhe des pT-Stadiums, ein nach neoadjuvanter RCT verbleibender positiver Nodalstatus, ein positiver circumferential resection margin (CRM, Zirkumferentieller Resektionsrand), intraoperative Tumorperforation, vaskuläre, perineurale oder lymphatische Tumorzellinvasion, Nachweis von Mikrosatelliteninstabilität in den Karzinomzellen, schlechte histologische Differenzierung und die Anzahl positiver Lymphknoten (Chan et al. 2005; Chapet et al. 2005; Schmoll et al. 2012; Sprenger et al. 2016). Auch der Tumorregressionsgrad (TRG) nach Dworak et al. (1997), der nach neoadjuvanter Therapie histopathologisch bestimmt wird, ist ein 
wichtiger prognostischer Marker. Das 5- und 10-Jahres-DFS liegt bei TRG 4 über $85 \%$, wohingegen es bei TRG 0 und 1 unter 65 \% liegt (Fokas et al. 2014; Rödel et al. 2005). Vor diesem Hintergrund besteht aus klinisch-therapeutischer Sicht die Notwendigkeit, prätherapeutische Parameter bzw. Biomarker als Prognosefaktor zu identifizieren, um Patienten eine möglichst gut verträgliche, an das individuelle Karzinom-Rezidiv-Risiko adaptierte multimodale Therapie zukommen zu lassen. 


\subsection{Das Tumorsuppressorprotein p16}

Das Thema der vorliegenden Dissertation ist die immunhistochemisch nachweisbare p16-Expression im Adenokarzinom des Rektums. Häufig gebrauchte Synonyme für das Tumorsuppressorprotein p16 sind p16INK4a (INK4=Inhibitor of CDK4), p16INK, INK4a, CDKN2 (Cyclin-dependent-kinaseinhibitor 2), CDK4I (Cyclin-dependent-kinase-4-Inhibitor), TP16 (Tumorsuppressorprotein 16) und MTS1 (Multiple Tumor Suppressor 1) (Chaubert et al. 1997; Foulkes et al. 1997; Hara et al. 1996; Reed et al. 1995; Serrano et al. 1993; Shapiro und Rollins 1996; Steiner et al. 2000). Zur Verbesserung der Lesbarkeit wird im Folgenden einheitlich der Terminus „p16“ verwendet.

\subsubsection{Funktion im Zellzyklus}

Das Tumorsuppressorprotein p16 ist im normalen Zellzyklus ein 156 Aminosäuren umfassendes, 16 kD schweres Protein, welches aus Exon 1 1 , 2 und 3 des CDKN2A-Gens besteht. Sein Genort liegt auf dem Chromosom 9p21 (Serrano 1997).

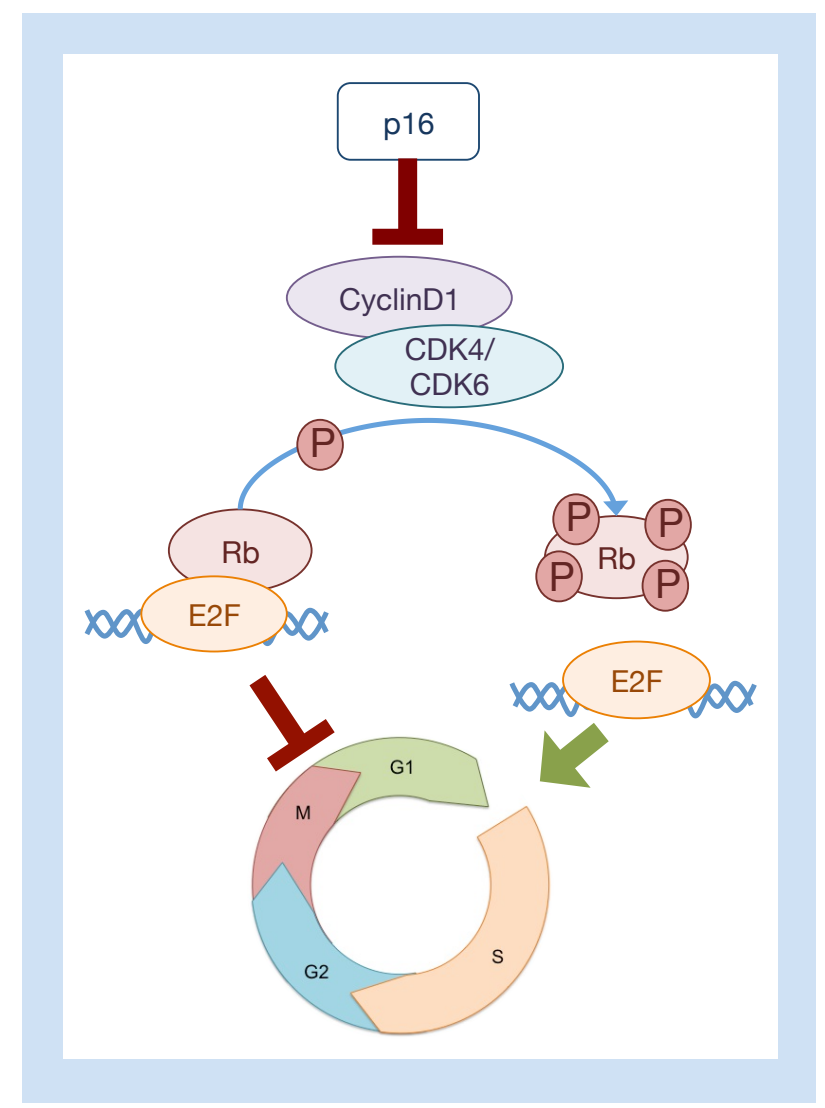

Abbildung 1.4: Funktion des Tumorsuppressorproteins p16 im Zellzyklus

Eigene schematische Darstellung modifiziert nach Romagosa et al. (2011) und Witkiewicz et al. (2011). Das Tumorsuppressorprotein p16 verhindert durch Hemmung des CDK4/CDK6 Komplexes die Phosphorylierung des Tumorsuppressorproteins $\mathrm{Rb}$ (Serrano et al. 1993). Rb ist ein Tumorsuppressorprotein, das die Transition von der G1-Phase in die S-Phase im Zellzyklus hemmt, sodass geschädigte DNA (deoxyribonucleicacid, Desoxyribonukleinsäure) nicht repliziert werden kann (Murphree und Benedict 1984; Weinberg 1995). Das hypophosphorylierte Rb bindet an Transkriptionsfaktorkomplexe der E2F-Familie, sogenannte „E2 promoter-binding-protein-dimerization Partner“ (E2F-DP), die aus Heterodimeren des E2F- und des DP-Proteins bestehen (Wu et al. 1995). Normalerweise aktivieren E2F-Komplexe die Transkription verschiedener Gene, die den Eintritt der Zelle in die S-Phase ermöglichen. Wird die E2F-Aktivität jedoch durch hypophosphoryliertes $\mathrm{Rb}$ gehemmt, so verbleibt die Zelle in der G1-Phase. In der Folge unterbleibt die DNAReplikation, die eigentlich in der S-Phase des Zellzyklus stattfinden würde (Weinberg 1995). 
Seine Wirkung entfaltet p16 über die Inhibition der CDK4 und CDK6 (Cyclin-dependent kinase, Cyclin-abhängige Kinase) im Retinoblastoma-pathway (Foulkes et al. 1997; Nevins 2001; Serrano 1997; Sridhar et al. 2006). Dabei verhindert p16 indirekt die Bindung von Cyclin D an CDK4 und CDK6 (siehe Abbildung 1.4), indem es durch Anbindung an diese Kinasen deren molekulare Enzymstruktur verändert. In der Folge ist die Bindungsstelle für Cyclin D unzugänglich. Zusätzlich setzt p16 die Aktivität des bereits gebildeten CDK4/6-Cyclin D-Komplexes durch Interaktion mit der ATP-Bindung (Adenosintriphosphatbindung) herab (Russo et al. 1998). Durch die verhinderte Komplexbildung der Kinasen mit Cyclin D mit nachfolgender Blockade der Enzymaktivität unterbleibt die Phosphorylierung des Retinoblastoma-Proteins (Rb) (Serrano 1997). Die Transkriptionsfaktoren der E2F-Familie verbleiben im Komplex mit dem hypophosphorylierten $\mathrm{Rb}$. Als Folge werden verschiedene, die Zellproliferation stimulierende Gene nicht mehr transkribiert (Li et al. 2011). Die Zelle verbleibt in der G1-Phase des Zellzyklus und geht nicht in die S-Phase über (siehe Abbildung 1.4). Die andauernde Erhöhung der p16-Expression kann zu einem permanenten Ausbleiben des Zellwachstums führen (Ohtani et al. 2004). Der p16-abhängige Zellzyklusarrest kann in diesen Fällen in eine cellular senescence (zelluläre Alterung/Altersschwäche) übergehen, die als irreversibler Zellzyklusarrest in der G1-Phase des Zellzyklus definiert ist (Larsson 2011; Ohtani et al. 2004). Der Mechanismus der cellular senescence wird als Tumorsuppressionsmechanismus des Organismus aufgefasst, da die betroffenen Zellen aus dem replizierenden Zellpool entfernt werden und so einer potentiellen Entartung der Zellen auf diese Weise vorgebeugt wird (Suzuki und Boothman 2008). Selbst auf ausgeprägte mitogene Reize hin tritt eine seneszente Zelle nicht wieder in den Zellzyklus ein (Alspach et al. 2013). Andererseits bleibt sie jedoch trotzdem noch metabolisch aktiv und entwickelt einen senescence-associated-secretory-phenotype (SASP). Dieser zeichnet sich durch die Sekretion verschiedener Moleküle aus, die in die zellumgebende extrazelluläre Matrix abgegeben werden (Coppe et al. 2010). Auf diese Weise von seneszenten Fibroblasten und Tumorzellen sezernierte Proteasen, Wachstumsfaktoren, Zytokine und Interleukine beeinflussen nicht nur die Wundheilung und Gewebealterung, sondern können tumorinhibitorische wie auch tumorfördernde Wirkung auf ihre Umgebung ausüben (Coppe et al. 2011; Demaria et al. 2014; Krishnamurthy et al. 2004; Krizhanovsky et al. 2008; Parrinello et al. 2005; Ressler et al. 2006; Roninson 2003).

\subsection{2 p16-Überexpression}

Eine Überexpression von p16 ist zumeist Folge einer erhöhten Transkription des p16-Gens (Li et al. 2011; Serrano 1997). Die gesteigerte Transkription kann durch unterschiedliche Stimuli ausgelöst werden, wie z. B. Telomerverkürzung, Akkumulation von DNA-Schäden, Aktivierung von Onkogenen, oxidativen Stress und Zell-Zell-Fusion (Burton und Krizhanovsky 2014; Chuprin et al. 2013; Collado et al. 2007; Gal und Krizhanovsky 2014; te Poele et al. 2002). Im Folgenden werden die wichtigsten Mechanismen erläutert, die zu einer Erhöhung der p16-Expression führen können (siehe Abbildung 1.5). 


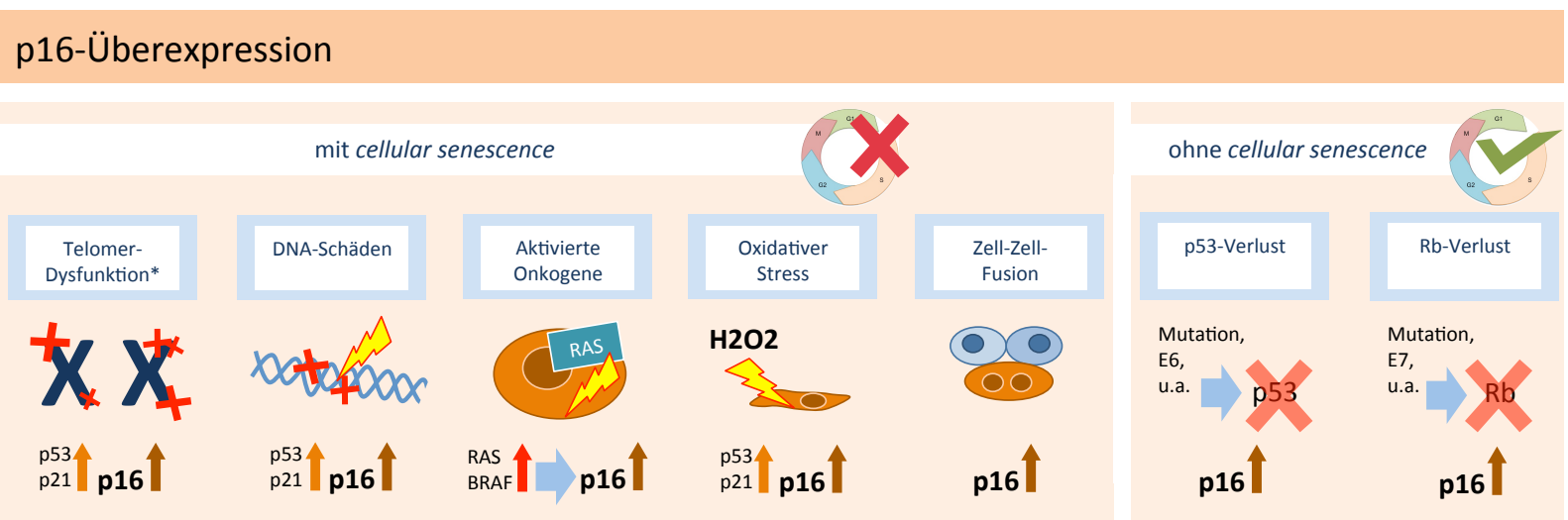

Abbildung 1.5: Auslöser einer erhöhten p16-Expression

Eigene Darstellung. Auf der linken Seite sind Ursachen angeführt, die zu einer vermehrten p16-Expression und einer damit verbundenen cellular senescence führen. Auf der rechten Seite sind der Verlust von p53 bzw. Rb dargestellt. Beide lösen zwar eine erhöhte p16-Expression der Zelle aus, führen aber nicht zu einem Zellzyklusarrest, da die tumorsuppressorische Funktion von p16 über die Funktion von Rb ausgeübt wird. Das Protein p53 wird zur Induktion des Zellzyklusarrestes benötigt. RAS (Rat-sarcoma-Gen).

\subsubsection{Telomerverkürzung und -dysfunktion}

Die genetisch determinierte cellular senescence (in dem Fall auch replicative senescence genannt) ist durch eine kontinuierliche Verkürzung und Veränderung der Telomere während der Zellteilung bedingt (Harley et al. 1990; Hayflick und Moorhead 1961; Robles und Adami 1998). Haben die Telomere eine kritische Länge erreicht oder hat sich ihre funktionelle Struktur verändert, wird über Zellzyklus-checkpoints das Tumorsuppressorgen p53 aktiviert und entweder die Apoptose oder der permanente Zellzyklusarrest eingeleitet (Collado et al. 2007; Gewirtz et al. 2008; Karlseder et al. 2002; Sherr und DePinho 2000). Bei der Einleitung der replicative senescence in vitro werden sowohl p16 als auch p21 unabhängig voneinander mit zunehmenden Zellteilungszyklen überexprimiert (Herbig et al. 2004). Mit der Zeit nimmt jedoch die p21-Expression im Gegensatz zur p16-Expression wieder ab, sodass vermutet wird, dass p21 zwar eine Rolle bei der Einleitung der cellular senescence spielt, aber p16 zur Aufrechterhaltung der replicative senescence benötigt wird (Alcorta et al. 1996).

Generell besteht ein großer Unterschied in der Art der Induktion und Aufrechterhaltung der replicative senescence zwischen verschiedenen Zellarten. Der Nachweis einer p16-Überexpression ist abhängig von Zelltyp und Zeitpunkt der Analyse des Proteins, da p16 meist nicht am Anfang der replicative senescence überexprimiert wird (Jacobs und de Lange 2005; Shelton et al. 1999). Untersuchungen in vitro zeigen bei Vorliegen einer replicative senescence sehr häufig eine p16-Überexpression (Alcorta et al. 1996; Hara et al. 1996; Herbig et al. 2004; Jacobs und de Lange 2005; Loughran et al. 1996; Palmero et al. 1997). Auch in vivo steigt die p16-Expression im Mausmodell in epithelialen und stromalen Zellen mit dem zunehmenden Alter des Versuchstieres an, sodass auch hier eine stattgefundene Einleitung der cellular senescence durch zunehmende Zellteilungen angenommen wird (Krishnamurthy et al. 2004). 


\subsubsection{Aktivierung von Onkogenen}

Die Beobachtung, dass onkogenes Ras (Rat-sarcoma-Protein) einen der replicative senescence ähnlichen Zustand induziert, prägte den Begriff oncogene-induced senescence (Collado et al. 2007). Das Protein Ras hat grundsätzlich eine wichtige Funktion innerhalb des Zellzyklus beim Übergang von der G0- auf die G1-Phase und hat durch Aktivierung seiner downstream targets (wie z. B. des MAPK-Weges, mitogene-activated-protein-kinase) die Proliferation der jeweiligen Zelle zur Folge. Ist Ras dauerhaft aktiviert, führt dies zu einem anhaltenden Wachstumsstimulus auf die betroffene Zelle (Lin et al. 1998). Dieser wird allerdings antiproliferativ mit einer Erhöhung der p16- und p53Expression und einer darauffolgenden cellular senescence beantwortet, wodurch eine weitere unkontrollierte Zellproliferation bis hin zur Malignomentstehung verhindert wird. Ohne die Expression von p16 und p53 wird die Balance zwischen notwendiger Zellproliferation und Tumorsuppression nicht mehr aufrechterhalten und es entsteht ein maligner Tumor mit Invasionspotential (Bringold und Serrano 2000; Serrano 1997). Auch ein mutiertes BRAF (B-rapidlyaccelerated-fibrosarcoma-Gen) kann einen irreversiblen Zellzyklusarrest mit vermehrter p16Expression zur Folge haben (Kriegl et al. 2011; Michaloglou et al. 2005).

\subsubsection{Inaktivierung oder Verlust von Rb}

Neben aktivierten Onkogenen führt auch der Verlust von Rb aufgrund eines Feedbackmechanismus zur erhöhten Expression von p16 in Tumorzellen (Romagosa et al. 2011; Sherr und Roberts 1995). Bei funktionslosem oder fehlendem $\mathrm{Rb}$ ist eine p16-Überexpression allerdings nicht immer mit einer cellular senescence verbunden, da p16 seine Funktion über die von Rb ausübt (Bringold und Serrano 2000; Okamoto et al. 1994; Serrano 1997; Sherr und Roberts 1995). Nur wenn der Zellzyklusarrest schon vor Verlust von Rb eingetreten ist, kann er in einigen Fällen auch ohne Rb-Funktion durch p16 aufrechterhalten werden (Beausejour et al. 2003). Unter anderem wird ein Rb-Funktionsverlust durch die hemmende Interaktion des Virusproteins E7 der high-risk-Humanen Papillomaviren (HPV) mit Rb verursacht (Liu et al. 2006; Yim und Park 2005; zur Hausen 1996). Dadurch kommt es bei einer HPVInfektion zu einer Erhöhung der p16-Expression ohne Zellzyklusarrest (Ishikawa et al. 2006; Narisawa-Saito und Kiyono 2007).

\subsubsection{Inaktivierung oder Verlust von p53}

Zur Einleitung einer cellular senescence wird unabhängig vom auslösenden Stimulus das Tumorsuppressorprotein p53 benötigt (Saretzki 2010). Ohne p53-Funktion wird weder nach wiederholten Zellteilungen noch bei Vorliegen einer onkogenen RAS-Mutation oder nach Exposition von Wasserstoffperoxid, DNA-schädigenden Chemotherapeutika oder ionisierender Strahlung eine cellular senescence ausgelöst (Chen et al. 1998; Saretzki et al. 1999; Schmitt et al. 2002; Serrano et al. 1997; Suzuki et al. 2001). Eine Reaktivierung der Expression von p53 ermöglicht in ursprünglich p53defizienten Tumorzellen die Induktion einer cellular senescence und damit einhergehend eine Tumorregression (Ventura et al. 2007; Xue et al. 2007). Ein intaktes p53 ist also für die Induktion der 
cellular senescence durch p16 notwendig (Itahana et al. 2003; Schmitt et al. 2002). Für die Aufrechterhaltung eines einmal erreichten Zellzyklusarrestes scheint jedoch p16 verantwortlich zu sein. Eine alleinige Inaktivierung von p53 während der cellular senescence führt nicht zu einem erneuten Eintritt in den Zellzyklus (Beausejour et al. 2003). Bei Inaktivierung von p53 und noch nicht eingetretener cellular senescence wird p16 als Reaktion auf eine Chemotherapie vielfach überexprimiert, löst jedoch keinen Zellzyklusarrest aus (Schmitt et al. 2002). Auch eine HPVInfektion kann durch die durch das Virusprotein E6 beschleunigte Degradation von p53 zu einer erhöhten p16-Expression ohne cellular senescence führen (Crook et al. 1991; Sano et al. 1998b; Yim und Park 2005).

\subsubsection{Oxidativer Stress}

Oxidativer Stress kann in Form von vermehrt vorhandenen reaktiven Sauerstoffspezies (ROS) wie Wasserstoffperoxid, Superoxiden oder Hydroxylradikalen menschlichen Zellen schaden. Zu den oxidativen Schäden gehören die Reaktion der ROS mit Proteinen, die zur Erhöhung des intrazellulären Kalziums oder direktem Schaden an der $\mathrm{Na}+/ \mathrm{K}+$-ATPase führen und DNA-Schäden, die z. B. durch die Oxidation von Guaninen hervorgerufen werden (Chen 2000; Finkel und Holbrook 2000; Halliwell 2007). In vitro wurde an Fibroblasten unter Wasserstoffperoxidgabe gezeigt, dass oxidativer Stress in seiner Gesamtheit eine cellular senescence auslösen kann (Chen und Ames 1994; Chen et al. 1998). Diese cellular senescence geht wie die genetisch determinierte replicative senescence mit einer kurzzeitigen p53-Erhöhung und einer nachfolgenden Steigerung der p21- und p16-Expression einher (Chen et al. 1998; Chen 2000).

\subsubsection{Induktion von DNA-Schäden}

Eine Zelle kann auf irreparable DNA-Schäden ihres Genoms auf zwei verschiedene Arten reagieren, um die weitere Proliferation der Zelle zu verhindern. Entweder wird die Apoptose der Zelle eingeleitet oder sie geht in ein Stadium der cellular senescence über (Robles und Adami 1998). Epitheliale Tumorzellen gehen dabei nach DNA-schädigender Therapie eher in einen permanenten Zellzyklusarrest, während Malignome des blutbildenden Systems und Keimzelltumoren eher die Apoptose einleiten (Suzuki und Boothman 2008). Die beiden Tumorsuppressorgene p53 und p21 werden nach Applikation von ionisierenden Strahlen oder DNA-schädigender CTx (z.B. Bleomycin oder Etoposid) genauso wie im Übergang zu einer replicative senescence überexprimiert. Dabei nehmen die Proteinlevel von p21 und p53 nach einigen Tagen ab und werden für die Erhaltung der cellular senescence nicht mehr benötigt (Robles und Adami 1998; Suzuki et al. 2001; te Poele et al. 2002). Das Expressionslevel von p16 nimmt nach mehreren Tagen stark zu, bleibt konstant hoch und sorgt für die Aufrechterhaltung der cellular senescence (Le et al. 2010; Robles und Adami 1998; Suzuki et al. 2001; te Poele et al. 2002). Im Mausmodell verblieb p16 nach Bestrahlung über einen Beobachtungszeitraum von 45 Wochen auf einem gesteigerten Expressionslevel (Le et al. 2010). Neben der erhöhten p16-Expression gibt es auch alternative p16-unabhängige Mechanismen der 
kurzfristigen Aufrechterhaltung einer cellular senescence, auf die hier nicht näher eingegangen werden soll (Chang et al. 1999; Chang et al. 2002; Gewirtz et al. 2008; te Poele et al. 2002). In den meisten Fällen wird p16 nach DNA-schädigenden Stimuli wie nach Gabe von Chemotherapeutika und/oder Radiotherapie in vitro und in vivo überexprimiert. In vivo kann p16 somit als Zeichen der Irreversibilität des Zellzyklusarrestes dienen (Beausejour et al. 2003; Le et al. 2010; Schmitt et al. 2002; Suzuki et al. 2001; te Poele et al. 2002). Unter Beachtung einiger Zustände, in denen das Protein auch ohne Einleitung eines Zellzyklusarrestes überexprimiert wird (siehe Kapitel 1.9.2.3 und 1.9.2.4), kann p16 daher als Surrogatmarker für eine durch RCT- oder CTx-induzierte cellular senescence angesehen werden. Die starke immunhistochemisch nachweisbare Expression könnte als potentiell prognostischer Biomarker eine Blockade der Tumorprogression darstellen. Konkret könnte die p16Expression, die nach Applikation gängiger Chemotherapeutika wie Oxaliplatin und 5-FU und auch Radiotherapie auftritt, zur zukünftigen, an den einzelnen Patienten adaptierten Therapiestratifizierung oder zum Therapiemonitoring genutzt werden (Gewirtz et al. 2008; Schmitt et al. 2002).

\subsection{3 p16-Unterexpression oder -verlust}

Das p16-Gen ist in vielen Tumorentitäten deletiert oder mutiert, sodass es vermindert oder gar nicht exprimiert wird und seine physiologische Funktion verloren geht (Nobori et al. 1994). Die Veränderung des Gens kann sowohl durch eine Keimbahnmutation, eine somatische Mutation als auch durch eine vermehrte Methylierung des Promotors bedingt sein, welche das Ablesen des zugehörigen DNA-Abschnittes verringert (Li et al. 2011; Shima et al. 2011). Für den Verlust der Proteinfunktion innerhalb des Zellzyklus ist ein Verlust beider Allele notwendig (Li et al. 2011; Romagosa et al. 2011; Serrano 1997). Inaktivierende Keimzellmutationen führen $\mathrm{zu}$ einem erhöhten Risiko der Karzinomentstehung, insbesondere in Form des Pankreaskarzinoms oder des malignen Melanoms (Foulkes et al. 1997; Mantelli et al. 2002; Read et al. 2016; Soura et al. 2016). Eine durch somatische Mutationen des CDKN2A-Gens hervorgerufene p16-Unterexpression wird in zahlreichen Tumorentitäten beobachtet: z. B. beim Pankreaskarzinom, Ösophaguskarzinom, malignem Melanom, bei Plattenepithelkarzinomen im Kopf- und Halsbereich, Mammakarzinomen, Harnblasenkarzinomen und auch KRK (Li et al. 2011).

\subsection{0 p16-Expression im kolorektalen Karzinom}

Die immunhistochemische p16-Expression wurde im kolorektalen Karzinom bereits mehrfach untersucht. Dabei waren jedoch die Methoden der Auswertung der immunhistochemischen Färbung sehr heterogen, nicht standardisiert und es wurden sowohl Rektum- als auch Kolonkarzinome in die Analysen einbezogen. Zudem gibt es widersprüchliche Aussagen zur Korrelation der p16-Expression und der Prognose der Patienten (Cui et al. 2004; Shima et al. 2011). Relative Einigkeit herrscht darüber, dass die p16-Expression im distalen Kolonabschnitt (Colon sigmoideum und Colon descendens) höher ist als im proximalen Abschnitt (Colon ascendens und Colon transversum) (Deschoolmeester et al. 2010; Lam et al. 2008). Damit übereinstimmend ist die Promotor- 
Methylierung in proximalen Kolonabschnitten gegenüber den distalen Kolonabschnitten signifikant höher (Burri et al. 2001). Diese Beobachtung bestätigt, dass proximale und distale Tumoren eine unterschiedliche Tumorbiologie und Expressionen von zellzyklusregulierenden Proteinen aufweisen (Brule et al. 2015; McKay et al. 2002; Minoo et al. 2010). Die vorliegende Arbeit analysiert und vergleicht deshalb nur Rektumkarzinome und ist die bisher größte immunhistochemische p16Expressionsanalyse, die ausschließlich an Rektumkarzinomen durchgeführt wurde (siehe Anhang, Tabelle 6.1). Es wurde bisher nur eine Studie publiziert, welche überhaupt die p16-Expression in neoadjuvant behandelten Rektumkarzinomresektaten analysiert hat. Diese wies nach, dass nach neoadjuvanter Monotherapie mit 5-FU eine erhöhte p16-Expression mit einer höheren Ansprechrate des Tumors im Sinne einer Tumorregression verbunden war (Kamoshida et al. 2004a). Eine Recherche nach Publikationen, die die heutige Standardtherapie des lokal fortgeschrittenen Rektumkarzinoms, die RCT, und die p16-Expression im Rektumkarzinom thematisieren, war bis zum Zeitpunkt der Abgabe dieser Dissertation ergebnislos. 


\subsection{Zielsetzung und Fragestellung}

Die vorliegende Dissertation untersucht die p16-Expression in Rektumkarzinomen mittels Immunhistochemie. Zuerst werden prätherapeutische Biopsien $(n=40)$ von neoadjuvant behandelten Rektumkarzinomen auf p16 hin untersucht. Es soll analysiert werden, ob die p16-Expression der Biopsie eine prädiktive Aussage über das Ansprechen auf eine neoadjuvante RCT treffen kann oder mit anderen klinischen und pathologischen Parametern korreliert. Zusätzlich wird in einer großen Kohorte neoadjuvant behandelter Patienten $(n=156)$ im Vergleich zu einer Kontrollgruppe ohne Vorbehandlung ( $\mathrm{n}=98)$ eine mögliche p16-Induktion durch die neoadjuvante RCT untersucht. Im Anschluss wird analysiert, ob es eine Korrelation der p16-Expression der Resektate mit klinischen und histopathologischen Parametern wie dem (y)pUICC-Stadium und dem TRG sowie der time to recurrence (TTR) und dem cancer specific survival (CSS) gibt.

Sämtliche Untersuchungen haben im Rahmen der DFG-geförderten klinischen Forschergruppe 179 (KFO 179; Sprecher: Prof. Dr. med. M. Ghadimi; Biological Basis of Individual Tumor Response in Patients with Rectal Cancer, www.kfo179.de) im Teilprojekt 5a (Projektleiter: Prof. Dr. med. T. Liersch; Prädiktive und prognostische Biomarker beim lokal fortgeschrittenen Rektumkarzinom; siehe Ethikvotum der Medizinischen Fakultät Göttingen, Antragsnummer 9/8/08) stattgefunden.

Im Detail prüft die vorliegende Arbeit die folgende Annahmen:

1. Die p16-Expression der Biopsien bzw. der Resektate korreliert mit dem TRG des korrespondierenden Resektates.

2. Die p16-Expression der Rektumkarzinomresektate ist nach neoadjuvanter RCT signifikant höher als nach primärer Tumorresektion.

3. Die Höhe der p16-Expression korreliert positiv mit der TTR und dem CSS. 


\section{Material, Methoden und Patientenkollektiv}

\subsection{Material}

In der vorliegenden Arbeit wurden 40 prätherapeutische Biopsien und 254 Operationsresektate von insgesamt 261 konsekutiven Patienten mit einem Rektumkarzinom immunhistochemisch auf die Expression von p16 untersucht (siehe Tabelle 2.2). Die dazu notwendigen Biomaterialien, die im Rahmen der Routinediagnostik nach Standardprozeduren Formalin-fixiert und in Paraffin eingebettet worden sind, wurden vom Institut für Pathologie der UMG (Direktoren: Herr Prof. Dr. med. P. Ströbel und Prof. Dr. med. H.-J. Radzun, Universitätsmedizin Göttingen) bereitgestellt. Die immunhistochemischen p16-Färbungen erfolgten im klinischen KFO-Forschungslabor (Arbeitsgruppenleiter: Herr Prof. Dr. med. T. Liersch) der Klinik für Allgemein-, Viszeral- und Kinderchirurgie (Direktor: Herr Prof. Dr. med. M. Ghadimi) durch Frau B. Jünemann. Die Analyse der Färbungen erfolgte unter enger Kooperation, Supervision und Kontrolle von Frau Oberärztin Dr. med. J. Kitz (Institut für Pathologie, UMG) durch die Autorin dieser Arbeit.

\subsection{Grundprinzipien der Immunhistochemie und immunhistochemischer Färbevorgang}

Eine immunhistochemische Färbung weist direkt und spezifisch das Vorhandensein von einzelnen Proteinen in histologischen Schnitten nach, beruhend auf einer Antigen-Antikörper-Reaktion. Dafür wird ein Antikörper benötigt, der spezifisch an das gesuchte Epitop bindet. Dieser primäre, spezifische Antikörper bildet wiederum ein Epitop für einen sekundären Antikörper, der mit einem enzymatischen Farb-Detektionssystem gekoppelt ist. Infolge einer enzymatischen Reaktion, bei der eine Farbreaktion am Ort des sekundären Antikörpers stattfindet, kann das gesuchte Antigen für lichtmikroskopische Auswertungen sichtbar gemacht werden.

Bei den p16-Färbungen wurde als Detektionssystem die Polymerkonjugat-Methode angewandt. Dabei trägt ein Polysaccharid mehrere sekundäre Antikörper und mehrere Enzymmoleküle. Ein derartiger Komplex führt zu einer Farbverstärkung und einer verbesserten Auswertbarkeit in der immunhistochemischen Analyse. Das Detektionsenzym bei den p16-Färbungen war Meerrettichperoxidase. Sie bildet aus den ihr zur Verfügung gestellten Substraten 3,3'Diaminobenzidin (DAB) und Wasserstoffperoxid durch Oxidation einen unlöslichen, braunen Farbstoff.

Die Paraffinblöcke mit den jeweils standardisiert eingebetteten Rektumresektaten bzw. Rektumbiopsien wurden mit einem Schlittenmikrotom in ca. $2 \mu \mathrm{m}$ dünne Schnitte geschnitten und mittels eines Wasserbades auf adhäsive Objektträger aufgebracht. Die Färbung wurde an diesen Gewebeschnitten vorgenommen, die zuvor ca. 12 Stunden bei $37^{\circ} \mathrm{C}$ in einem Brutschrank getrocknet wurden. 
Zur bestmöglichen Vergleichbarkeit der immunhistochemischen Färbung wurden die Schnitte nach einem standardisierten Protokoll mit dem BenchMark XT-Färbeautomaten (siehe Tabelle 2.1) gefärbt.

Der Färbevorgang wurde nach folgendem Protokoll ausgeführt:

1. Auslösen des Paraffins mit EZ Prep bei $75^{\circ} \mathrm{C}$

2. Antigendemaskierung mit $C C 1$ bei $100^{\circ} \mathrm{C}$ für 60 Minuten

3. Auftragen des Inhibitors bei $37^{\circ} \mathrm{C}$, Inkubation für 4 Minuten

4. Aufgeben des spezifischen Antikörpers (Konzentration 1:200) bei $37^{\circ} \mathrm{C}$, Inkubation für 60 Minuten

5. Auftragen des Multimer Ig, Inkubation für 8 Minuten

6. Zugabe von DAB (Diaminobenzidin) und $\mathrm{H}_{2} \mathrm{O}_{2}$, Inkubation für 8 Minuten

7. Zugabe von Copper, Inkubation für 4 Minuten

8. Gegenfärbung mit Hämatoxylin, Inkubation für 12 Minuten

9. Auftragen des Bluing Reagenz, Inkubation für 8 Minuten

Zwischen den einzelnen Handlungsschritten wurden die Schnitte mittels gerätespezifischer Pufferlösung (BenchMark XT-Färbeautomat, siehe Tabelle 2.1) gewaschen.

Nach dem Färbevorgang wurden die Schnitte mittels aufsteigender Alkoholreihe entwässert, und nach einem zweiminütigen Xylol-Bad wurde der Schnitt per Vitro Clud mit einem Deckglässchen eingedeckt. Die für die immunhistochemische Färbung verwendeten Materialien werden in Tabelle 2.1 zusammengefasst. Als spezifischer Antikörper wurde ein monoklonaler Mausantikörper (JC8; Santa Cruz Biotechnology, Inc., USA, siehe Tabelle 2.1) genutzt, der an full length human recombinant p16 bindet (Sawicka et al. 2013). Die Spezifität des Antikörpers wurde zuvor von Frau B. Jünemann im oben genannten KFO-Labor der Klinik für Allgemein-, Viszeral- und Kinderchirurgie (KFO 179, Teilprojekt 5a) vor dem Färben der Rektumgewebe an zwei bekannt p16-positiven CervixkarzinomGewebeproben getestet. Das Färbeergebnis entsprach der bei dieser Entität zu erwartenden positiven Färbung der Malignomzellen in Quantität und Qualität (Sano et al. 1998a). Diese Voruntersuchungen wurden von Frau Oberärztin Dr. med. J. Kitz supervidiert und mitbeurteilt.

Zusätzlich wurden mehrere Gewebeschnitte eines repräsentativen Rektumresektates mit den in Tabelle 2.1 aufgeführten Antikörpern für Aktin, Vimentin und CD68 nach jeweils etabliertem Standard des Instituts für Pathologie der UMG gefärbt und die Expression analysiert (Azumi und Battifora 1987; Rizeq et al. 1994; Warnke et al. 1989). 
Tabelle 2.1: Übersicht über die verwendeten Materialien

\section{Verwendete Materialien}

Adhäsive Objektträger Starfrost

\section{Ethanol $99 \%$ \\ Deckgläser}

\section{Färbeautomat BenchMark XT}

Mikroskop Axio Imager II

Mikrotomklingen Feather

Schlittenmikrotom Microm HM430

Substanzen für den Färbeautomat

BenchMark XT:

- EZ Prep

- $\quad$ LCS

- Reaction Buffer

- CC1 (Cell Conditioner)

- Antibody Diluent

- Hämatoxilin II

- $\quad$ Bluing Reagent

Wärmeschrank

UltraView Universal DAB Detection Kit, enthält:

- Inhibitor

- $\quad$ Mutimer lg

- $\mathrm{DAB}$

- $\mathrm{H}_{2} \mathrm{O}_{2}$

- Copper

Vitro Clud - Eindeckmittel

\section{Wärmeplatte}

Xylol

p16-Antikörper: p16 (JC8): sc-56330

Aktin-Antikörper: Clone 1A4 (Ready-to-Use), IR611

Vimentin-Antikörper: Clone V9 (Ready-to-Use),

IR630

CD68-Antikörper: Clone KP1 (Ready-to-Use), IR609

\section{Hersteller, Firma, etc.}

Engelbrecht Medizin \& Labortechnik GmbH, Edermünde, Deutschland

Chemie Vertrieb, Hannover, Deutschland

Gerhard Menzel GmbH, Braunschweig,

Deutschland

Ventana Medical Systems, Tucson, Arizona, USA

Carl Zeiss Microlmaging GmbH Deutschland

Pfm, Köln, Deutschland

MICROM International, Walldorf, Deutschland

Ventana Medical Systems, Tucson, Arizona, USA

Memmert GmbH, Schwabach, Deutschland

Ventana Medical Systems, Mannheim, Deutschland

R. Langenbrinck - Labor- und Medizintechnik, Emmendingen, Deutschland

Medax \& Nagel, Kiel, Deutschland

Mallinckrodt Baker B.V., Deventer, Niederlande

Santa Cruz Biotechnology, Inc., Dallas, Texas, USA

Dako Denmark A/S, Glostrup, Dänemark

Dako Denmark A/S, Glostrup, Dänemark

Dako Denmark A/S, Glostrup, Dänemark 


\subsection{Mikroskopische Auswertung der immunhistochemischen Färbung}

Die immunhistochemisch gefärbten Gewebeschnitte der Biopsien und der Rektumresektate wurden nach der Anleitung und unter der Kontrolle von Frau Oberärztin Dr. med. J. Kitz (Institut für Pathologie der UMG) analysiert. Bei allen fraglichen Schnitten wurde die Analyse in direkter Absprache mit ihr angefertigt und ein Konsens erzielt.

Nach der Durchmusterung des Gewebeschnittes unter 2,5- und 10-facher Vergrößerung erfolgte die Bewertung der p16-Färbung. Die Färbeintensität wurde mittels vier verschiedener Grade $(0,1,2$ und 3) erfasst. Grad 0 entsprach keiner Färbung und Grad 3 einer tiefdunklen Färbeintensität (siehe Abbildung 2.1). In den vereinzelten Fällen, in denen die Färbeintensität des Kernes nicht der des Zytoplasmas entsprach, erfolgte die Zuordnung zu einem Färbegrad anhand der Kernfärbung.

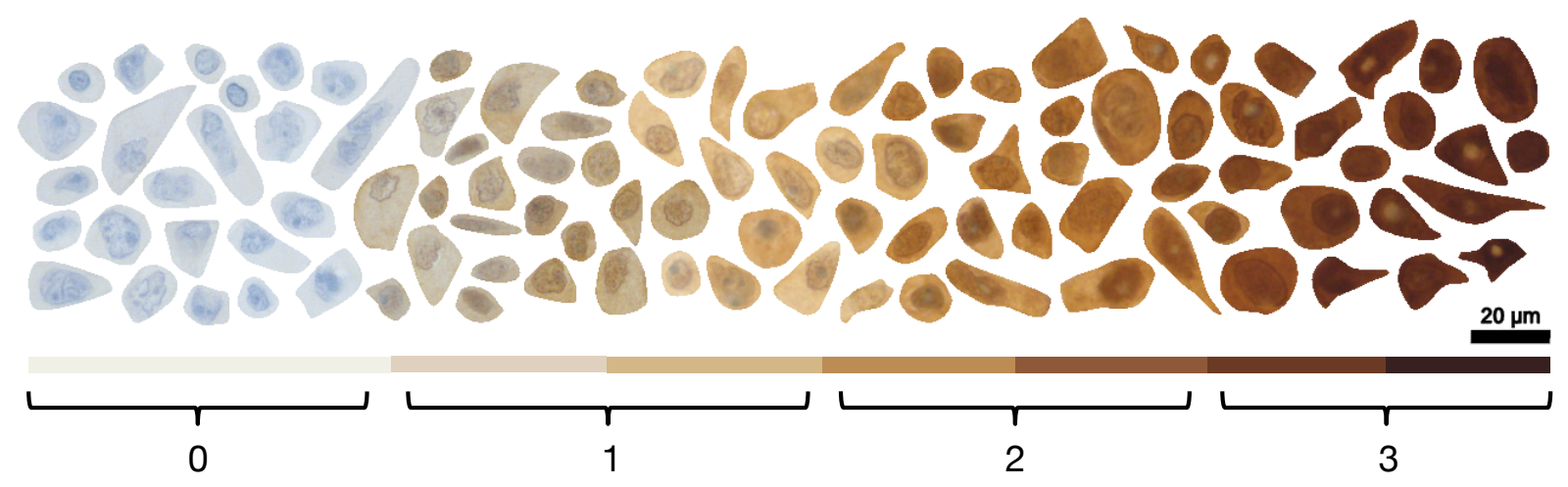

Abbildung 2.1: Spektrum der beobachteten p16-Färbeintensitäten bei Rektumkarzinomzellen

Auffällig ist eine relative Übereinstimmung zwischen der Färbeintensität des Zytoplasmas und des Zellkernes. Dadurch wird die Einteilung in die Färbegrade 0-3 wie abgebildet möglich. Original 40 -fache Vergrößerung. Die Zellen wurden aus repräsentativen Gewebeschnitten nach vorherigem automatischen Weißabgleich fotografiert, mit einem Bildbearbeitungsprogramm (Silhouette Studio, Version 2.7.0) ausgeschnitten und ihrer Färbeintensität nach angeordnet.

Der Anteil des normalen Darmepithels, der Adenomanteil und der Karzinomanteil des Resektates des gesamten Gewebeschnittes wurden jeweils separat begutachtet. Der Anteil der in den jeweiligen Färbegraden angefärbten Zellen wurde einzeln abgeschätzt und deren Anteil am Gesamttumoranteil in Prozent angegeben, z. B. wie folgt:

\begin{tabular}{|c|c|c|c|c|c|}
\hline Färbeintensität & 0 & 1 & 2 & 3 & \\
\hline \multicolumn{5}{|c|}{ Prozentsatz der in dieser Intensität gefärbten Zellen in \% } & \\
\hline Normales Darmepithel & 95 & 5 & 0 & 0 & $=100$ des normalen Darmepithels \\
\hline Adenomanteil & 40 & 40 & 20 & 0 & $=100$ des Adenomanteils \\
\hline Karzinomanteil & 30 & 20 & 10 & 40 & $=100$ des Karzinomanteils \\
\hline
\end{tabular}

Diese Angaben dienten als Grundlage für die Berechnung von immunhistochemischen p16-Scores (Näheres hierzu siehe Kapitel 2.6). 
Bei der Bestimmung des p16-Expressionsmusters wurde zwischen einer durchgehend mosaikartigen

Färbung der Karzinomareale und dem Vorliegen von homogen angefärbten Tumorarealen unterschieden (Beispielbilder siehe Abbildung 2.2).
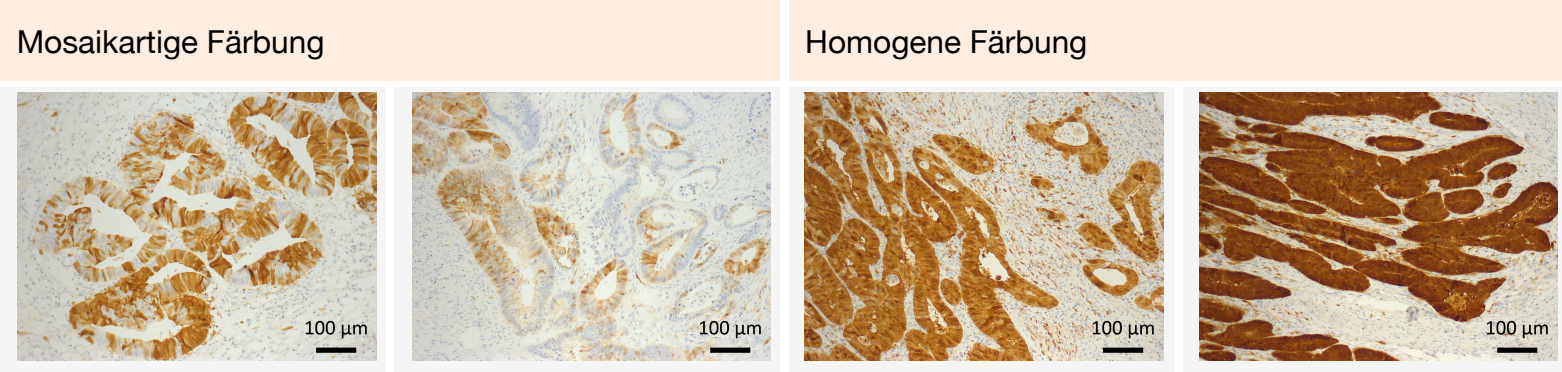

Abbildung 2.2: Beispielbilder zur Bewertung des p16-Expressionsmusters 10 -fache Vergrößerung.

Bei der Auswertung der p16-Färbung wurde in den angefertigten Gewebeschnitten auch eine spezifische Färbung des Stromas beobachtet. Die Stromafärbung wurde in 4 Grade unterteilt, die abhängig von der Menge der angefärbten Zellen im Gewebeschnitt waren, nicht von der Färbeintensität. Grad 0 entsprach hierbei einer fehlenden Stromafärbung, Grad 1 der Anfärbung vereinzelter Zellen, Grad 2 einer deutlichen Anfärbung, die problemlos bei 2,5-facher Vergrößerung zu erkennen war und Grad 3 der massiven Anfärbung von Stromazellen (siehe Beispielbilder Abbildung 2.3). Diese Gradeinteilung erfolgte pro Gewebeschnitt auf Basis des mikroskopischen Blickfeldes in 10-facher Vergrößerung, welches die stärkste Stromafärbung des gesamten Gewebeschnittes aufwies. Waren beispielsweise in einem Schnitt sowohl Grad 1 als auch Grad 3 gefärbte Blickfelder in 10-facher Vergrößerung vorhanden, wurde die Stromafärbung des Schnittes insgesamt als Grad 3 gewertet.

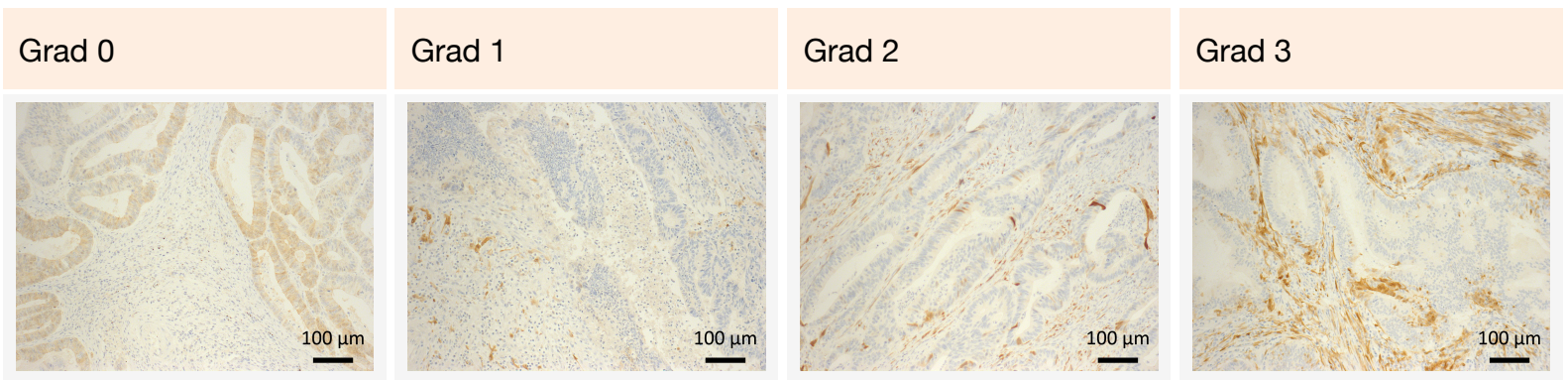

Abbildung 2.3: Beispielbilder zur Gradeinteilung der Stromafärbung der Gewebeschnitte 10 -fache Vergrößerung.

\subsection{Ein- und Ausschlusskriterien}

Voraussetzung für den Einschluss in das Untersuchungskollektiv war das Vorliegen von in Paraffin eingebettetem Biomaterial. Zusätzlich musste in den jeweiligen Gewebeschnitten sowohl der Biopsien als auch der Resektate invasiv wachsendes Tumorgewebe (Karzinom) und eine ausreichende Tumorzellzahl ( $>30$ Zellen) für eine valide p16-Analyse vorhanden sein. Bei alleinigem Vorliegen von Adenomanteilen oder normalem Darmepithel blieb das Biomaterial in den Analysen unberücksichtigt. Das Biomaterial musste von Rektumkarzinompatienten stammen, die entweder mit 5-FU und 
Radiotherapie oder mit 5-FU, Oxaliplatin und Radiotherapie vorbehandelt oder primär reseziert worden waren. Biomaterial wurde aus den Analysen ausgeschlossen, sofern bei den dazugehörigen Patienten lokoregionär makroskopisch keine komplette Karzinomresektion (R2-Status der Resektion) erfolgt war. Ein histopathologisch bestätigter R1-Status oder ein positiver CRM war kein Ausschlusskriterium. Der Nachweis von synchronen, potentiell resektabel erscheinenden Fernmetastasen war ebenfalls kein Ausschlusskriterium.

\subsection{Untersuchtes Patientenkollektiv}

Unter Einhaltung oben genannter Kriterien wurde Biomaterial von insgesamt 261 Patienten untersucht, von denen entweder nur die Biopsie $(n=7)$, allein das Resektat ( $n=221)$ oder eine Biopsie mit korrespondierendem Resektat $(n=33)$ analysiert wurden. Im Folgenden wird das gesamte Patientenkollektiv ( $\mathrm{n}=261$ ) beschrieben, unabhängig davon ob nur eine Biopsie, allein ein Resektat oder Biopsie und Resektat von dem jeweiligen Patienten untersucht worden ist. Dadurch beinhaltet das Kollektiv auch Patienten, die nach erfolgter neoadjuvanter RCT einen TRG 4 im Sinne einer Komplettremission aufwiesen. Von diesen Patienten konnte gemäß der Einschlusskriterien selbstverständlich nur die präoperative Biopsie analysiert werden (siehe Kapitel 2.5.2).

Das Patientenkollektiv wurde zwischen den Jahren 2000 und 2013 entsprechend ihrem Tumorstadium und ihren Nebenerkrankungen nach der jeweils aktuellsten multimodalen Therapiestrategie behandelt. Die Patienten hatten prätherapeutisch im Rahmen der KFO 179 (www.kfo179.de) schriftlich in die immunhistochemische Analyse ihres entnommenen Biomaterials, in die Auswertung ihrer Daten zum Diagnosezeitpunkt sowie auch in die Erhebung von krankheitsbezogenen Langzeit-Nachsorgedaten eingewilligt (siehe Ethikvotum der Medizinischen Fakultät Göttingen, Antragsnummer 9/8/08). Die neoadjuvant behandelten Patienten wurden in der UMG und vereinzelt in kooperierenden Kliniken innerhalb oder analog der CAO/AIO/ARO-94-Studie (nur Arm B) und CAO/AIO/ARO-04-Studie (Arm A und B) multimodal präoperativ behandelt (Rödel et al. 2007; Rödel et al. 2012; Rödel et al. 2015; Sauer et al. 2004; Sauer et al. 2012). Eine primäre Resektion des Rektumkarzinoms erfolgte in oder analog der GAST-05-Studie (Liersch et al. 2009). Insgesamt wurde Karzinomgewebe enthaltendes Biomaterial von 81 Frauen (31\%) und 180 Männern (69\%) im Alter von 35 bis 87 Jahren analysiert.

\subsubsection{Präoperatives Staging und neoadjuvante Therapie}

Wie in Tabelle 2.2 dargestellt, gliedert sich das Patientenkollektiv entsprechend der durchgeführten Therapiestrategien in drei verschiedene Kohorten. Kohorte A, deren Patienten neoadjuvant mit 5-FU und kombinierter Radiotherapie therapiert wurden $\left(\mathrm{n}_{\text {Gesamt }}=101\right)$, Kohorte $\mathrm{B}$, deren Patienten mit 5-FU, Oxaliplatin und Radiotherapie intensivierter behandelt wurden $\left(\mathrm{n}_{\text {Gesamt }}=62\right)$ und die Kohorte $\mathrm{C}$ ohne neoadjuvante Vorbehandlung $\left(\mathrm{n}_{\text {Gesamt }}=98\right)$. In den meisten Analysen werden die Kohorten A und B zu einer neoadjuvant behandelten Kohorte $A B$ zusammengefasst $\left(n_{\text {Gesamt }}=163\right)$. Alle analysierten Biopsien stammen von neoadjuvant behandelten Patienten (siehe Tabelle 2.2). 
Tabelle 2.2: Übersicht über das Biomaterial der Kohorten A, B und C

\begin{tabular}{|c|c|c|c|c|}
\hline & Kohorte A & Kohorte B & Kohorte C & Gesamt \\
\hline Präoperative Therapie & 5-FU + RT & $\begin{array}{l}\text { 5-FU + Oxaliplatin + } \\
\text { RT }\end{array}$ & keine & \\
\hline \multirow[t]{2}{*}{$\mathbf{n}_{\text {Resektate }}$} & 94 & 62 & 98 & 254 \\
\hline & \multicolumn{2}{|c|}{ Kohorte AB: 156} & & \\
\hline \multirow[t]{2}{*}{$\mathbf{n}_{\text {Biopsien }}$} & $25^{\star}$ & 15 & 0 & 40 \\
\hline & \multicolumn{2}{|c|}{ Kohorte AB: 40} & & \\
\hline \multirow[t]{2}{*}{$\mathbf{n}_{\text {Gesamt }}$} & 101 & 62 & 98 & 261 \\
\hline & \multicolumn{2}{|c|}{ Kohorte AB: 163} & & \\
\hline
\end{tabular}

*davon sieben ohne korrespondierendes Resektat. $\mathrm{n}_{\text {Gesamt }}=$ Patientenzahl der Resektate und Biopsien, $\mathrm{n}_{\text {Biopsien }}=$ Patientenzahl der Biopsien, $\mathrm{n}_{\text {Resektate }}=$ Patientenzahl der Resektate, 5-FU (5-Fluorouracil), RT (Radiotherapie).

In den Patientenkohorten A und B waren die Rektumkarzinome überwiegend im unteren und mittleren Drittel ( $\mathrm{n}=66$ bzw. $\mathrm{n}=90$ ) lokalisiert; lediglich bei sieben Patienten lag das Rektumkarzinom im oberen Rektumdrittel. Im Gegensatz dazu waren in der primär operierten Kohorte C 94,9 \% der Karzinome $(n=93)$ im oberen Rektumdrittel lokalisiert. Die Tumorlokalisation im Rektum unterscheidet sich in den drei verglichenen Kohorten daher signifikant (siehe Tabelle 2.3, $<<0,001$ ).

Die prätherapeutischen cUICC-Stadien verteilten sich wie folgt: 2,3\% cUICC-Stadium I ( $n=6), 23,7 \%$ cUICC-Stadium II ( $\mathrm{n}=62), 67,4 \%$ cUICC-Stadium III ( $\mathrm{n}=176)$ sowie 5\% cUICC-Stadium IV ( $\mathrm{n}=13)$. Ein cUICC-Stadium I lag nur bei Patienten der Kohorte C vor. Bei vier Patienten konnte kein cUICCStadium festgestellt werden (1,5\%): In einem Fall standen die Staging-Informationen nicht zur Verfügung, bei zwei Patienten war der Lymphknotenstatus im CT und/oder in der Endosonographie bei Vorliegen eines T3-Stadiums nicht sicher beurteilbar; bei dem vierten Patienten konnte aufgrund der Notwendigkeit einer sofortigen OP aufgrund eines mechanischen Ileus kein präoperatives Staging durchgeführt werden. Zwischen den einzelnen Patientenkohorten besteht ein signifikanter Unterschied in der Verteilung der cUICC-Stadien $(\mathrm{p}=0,013)$.

Endosonographisch wurde ein positiver Lymphknotenstatus in 92 Fällen $(35,2 \%)$ und ein negativer Lymphknotenstatus in 152 Fällen (58,2 \%) erhoben. Bei zehn Patienten wurde keine Endosonographie durchgeführt, sondern das cUICC-Stadium durch den MRT- bzw. CT-Befund bestimmt. Bei sieben Patienten war aus technischen Gründen, z. B. aufgrund einer nicht passierbaren intraluminalen Tumorstenose endosonographisch keine Angabe zum Nodalstatus möglich. Diese konnte letztlich in sechs Fällen durch eine MRT bzw. CT bestimmt werden. Das uT-Stadium verteilte sich folgendermaßen: 5,7\% uT2 (n=15), 85,8\% uT3 (n=224) und 4,6\% uT4 (n=12). Die neoadjuvante Therapie wurde in $83,4 \%$ der Fälle $(n=136)$ vollständig verabreicht. Bei 15 Patienten $(13,5 \%)$ erfolgte eine Dosisreduktion aufgrund von therapiebedingten Nebenwirkungen oder aufgrund dosislimitierender Komorbidität (siehe Tabelle 2.3). 
Tabelle 2.3: Präoperative Parameter des Patientenkollektivs

\begin{tabular}{|c|c|c|}
\hline \multicolumn{3}{|c|}{ Art der präoperativen Therapie } \\
\hline $5-F U+R T$ & $\begin{array}{l}\text { 5-FU + Oxaliplatin } \\
+\mathbf{R T}\end{array}$ & keine \\
\hline$\%$ & $\%$ & $\mathrm{n}$ \\
\hline
\end{tabular}

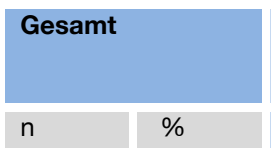

p-Wert*

Patientenzahl

$$
101
$$

62

98

261

100

\section{Geschlecht}

\begin{tabular}{|c|l|l|l|l|l|l|l|l|l|} 
weiblich & 31 & 30,7 & 18 & 29,0 & 32 & 32,7 & 81 & 31,0 & \\
männlich & 70 & 69,3 & 44 & 71,0 & 66 & 67,3 & 180 & 69,0 & 0,886
\end{tabular}

Alter bei OP in Jahren

\begin{tabular}{r|l|l|l|l|l|l|l|l|l|} 
Min.-Max./Mittelwert & $35-82$ & 63,0 & $41-80$ & 61,6 & $38-87$ & 67,5 & $35-87$ & 64,3 & 0,129 \\
\hline Höhenlokalisation des Tumors ab ano & & & & & & & \\
\hline $0-6 \mathrm{~cm}$ & 44 & 43,6 & 22 & 35,5 & 1 & 1,0 & 67 & 25,7 & \\
\hline $6-12 \mathrm{~cm}$ & 52 & 51,5 & 38 & 61,3 & 4 & 4,1 & 94 & 36,0 & \\
\hline $12-16 \mathrm{~cm}$ & 5 & 5,0 & 2 & 3,2 & 93 & 94,9 & 100 & 38,3 & 0,000 \\
\hline
\end{tabular}

uT-Stadium

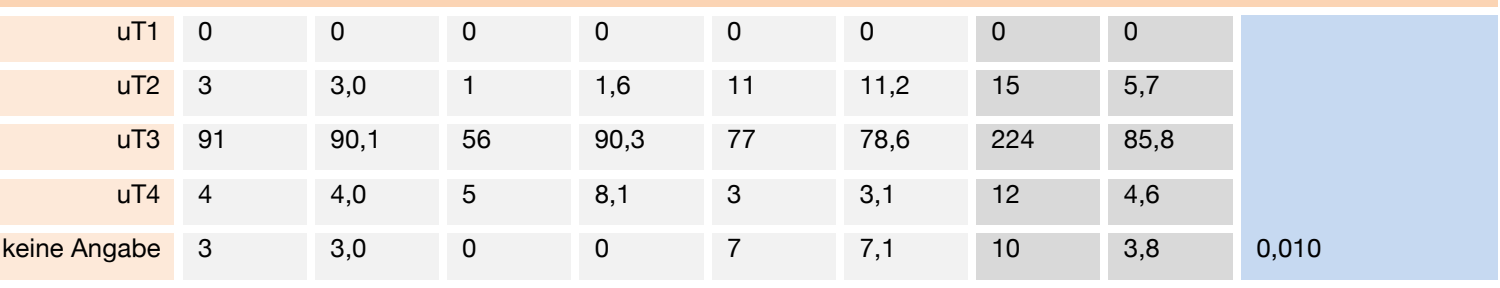

uN-Stadium

\begin{tabular}{|r|l|l|l|l|l|l|l|l|}
\hline uN- & 33 & 32,7 & 18 & 29,0 & 41 & 41,8 & 92 & 35,2 \\
\hline uN+ & 63 & 62,4 & 42 & 67,7 & 47 & 48,0 & 152 & 58,2 \\
\hline keine Angabe & 5 & 5,0 & 2 & 3,2 & 10 & 10,2 & 17 & 6,5 \\
\hline
\end{tabular}

0,073

cUICC-Stadium

\begin{tabular}{|c|c|c|c|c|c|c|c|c|c|c|}
\hline 0 & & 0 & 0 & 0 & 0 & 0 & 0 & 0 & 0 & \\
\hline I & & 0 & 0 & 0 & 0 & 6 & 6,1 & 6 & 2,3 & \\
\hline II & & 24 & 23,8 & 11 & 17,7 & 27 & 27,5 & 62 & 23,7 & \\
\hline & A & 22 & 21,8 & 10 & 16,1 & 26 & 26,5 & 58 & 22,2 & \\
\hline & B & 2 & 2,0 & 1 & 1,6 & 1 & 1,0 & 4 & 1,5 & \\
\hline II & & 74 & 73,3 & 46 & 74,2 & 56 & 57,1 & 176 & 67,4 & \\
\hline & A & 4 & 4,0 & 0 & 0 & 7 & 7,1 & 11 & 4,2 & \\
\hline & B & 67 & 66,3 & 43 & 69,4 & 48 & 49,0 & 158 & 60,5 & \\
\hline & C & 3 & 3,0 & 3 & 4,8 & 1 & 1,0 & 7 & 2,7 & \\
\hline 川 & & 2 & 2,0 & 5 & 8,1 & 6 & 6,1 & 13 & 5,0 & \\
\hline keine $A$ & & 1 & 1,0 & 0 & 0 & 3 & 3,1 & 4 & 1,5 & 0,013 \\
\hline Neoadjuva & erap & e vo & lig geg & & & & & & & \\
\hline ja, komplet & & 85 & 84,2 & 51 & 82,3 & $x$ & $x$ & 136 & 83,4 & \\
\hline nein, reduz & & 14 & 13,9 & 11 & 17,7 & $x$ & $\mathrm{x}$ & 25 & 15,3 & \\
\hline keine Anga & & 2 & 2,0 & 0 & 0 & $\mathrm{x}$ & $\mathrm{x}$ & 2 & 1,2 & $0,445^{\star \star}$ \\
\hline
\end{tabular}

*asymptotische Signifikanz (2-seitig) des Chi-Quadrat-Test nach Pearson, **Berechnung ohne Kohorte C. 5-FU (5Fluorouracil), RT (Radiotherapie), x (nicht zutreffend). 


\subsubsection{OP-Verfahren, histopathologisches Staging und adjuvante Therapie}

Die durchgeführten onkologischen OP-Verfahren umfassten die anteriore Rektumresektion (ARR), die tiefe anteriore Rektumresektion (TARR) und die abdominoperineale Rektumexstirpation (APE) (siehe Kapitel 1.7.1). Zwischen den drei unterschiedlichen Kohorten besteht aufgrund der unterschiedlichen Höhenlokalisationen der Rektumkarzinome ein Unterschied in den jeweils angewandten OPVerfahren $(p<0,001)$. Das am häufigsten angewandte OP-Verfahren war die TARR (Kohorte A: $n=66$, 65,3 \%; Kohorte B: $n=45,72,6 \%$; Kohorte C: $n=59,60,2 \%$ ). Die APE erfolgte in der Kohorte A in 34 Fällen (33,7 \%), in der Kohorte B in 15 Fällen (24,2 \%) und in der Kohorte C in einem Fall (1 \%). Eine ARR fand in der Kohorte AB nur in Einzelfällen statt (Kohorte A: n=1, 1,0 \%; Kohorte B: n=2, 3,2 \%). In der Kohorte $\mathrm{C}$ wurde eine ARR bei 38 Patienten (38,8 \%) durchgeführt (siehe Tabelle 2.4).

Tabelle 2.4: Angewandte onkologische Operationsverfahren im Patientenkollektiv

\begin{tabular}{|c|c|c|c|c|c|c|c|c|}
\hline \multicolumn{6}{|c|}{ Art der präoperativen Therapie } & & & \\
\hline \multicolumn{2}{|c|}{ 5-FU + RT } & \multicolumn{2}{|c|}{$\begin{array}{l}\text { 5-FU + Oxaliplatin } \\
+ \text { RT }\end{array}$} & \multicolumn{2}{|c|}{ keine } & \multicolumn{2}{|c|}{ Gesamt } & \multirow[t]{2}{*}{ p-Wert } \\
\hline $\mathrm{N}$ & $\%$ & $n$ & $\%$ & N & $\%$ & $\mathrm{n}$ & $\%$ & \\
\hline 101 & & 62 & & 98 & & 261 & 100 & \\
\hline 34 & 33,7 & 15 & 24,2 & 1 & 1,0 & 50 & 19,2 & \\
\hline 66 & 65,3 & 45 & 72,6 & 59 & 60,2 & 170 & 65,1 & \\
\hline 1 & 1,0 & 2 & 3,2 & 38 & 38,8 & 41 & 15,7 & $<0,001$ \\
\hline
\end{tabular}

*asymptotische Signifikanz (2-seitig) des Chi-Quadrat-Test nach Pearson. 5-FU (5-Fluorouracil), RT (Radiotherapie), APE (Abdominoperineale Rektumexstirpation), TARR (Tiefe anteriore Rektumresektion), ARR (Anteriore Rektumresektion).

Bei 253 Patienten wurde eine vollständige onkologische Resektion im Gesunden (R0-Status der Resektion) durchgeführt. Bei acht Patienten wurde histopathologisch ein R1-Status der Resektion festgestellt (3,1\%). Die Mehrheit der Rektumkarzinome war mäßig differenziert (G2) ( $\mathrm{n}=180$; $69,0 \%)$; in 24 Resektaten (9,2\%) lag eine G2- bis 3-Differenzierung und in 56 Resektaten $(21,5 \%)$ eine reine G3-Differenzierung vor. In einem Fall ( $\mathrm{n}=1 ; 0,4 \%)$ stellte der befundende Pathologe eine prognostisch besonders ungünstige schlechte Differenzierung des Rektumkarzinomgewebes (G3-4) fest $(n=1 ; 0,4 \%)$. Bei $22 \%$ der Karzinome wurde postoperativ ein (y)pUICC-Stadium I ( $n=58)$ und bei jeweils einem Drittel der Patienten ein Stadium II ( $\mathrm{n}=87 ; 33,3 \%$ ) bzw. III ( $\mathrm{n}=90 ; 34,4 \%)$ diagnostiziert (siehe Tabelle 1.1). Der Anteil an metastasierten Patienten betrug postoperativ 9,2\% $(n=24)$ im Gegensatz zur prätherapeutischen Einschätzung ( $n=13 ; 5,0 \%)$. Diese Änderung lässt sich am ehesten durch okkulte Metastasen während des Stagings erklären. Die Behandlungsgruppen unterscheiden sich bezüglich der Verteilung des Tumorgradings $(\mathrm{p}=0,022)$, des $(\mathrm{y}) \mathrm{pN}-$ Stadiums $(\mathrm{p}=0,029)$, des (y)pT-Stadiums $(\mathrm{p}=0,031)$ und des (y)pUICC-Stadiums $(\mathrm{p}=0,015$, siehe Tabelle 2.5$)$. 
Tabelle 2.5: Postoperative Parameter der histopathologischen Beurteilung

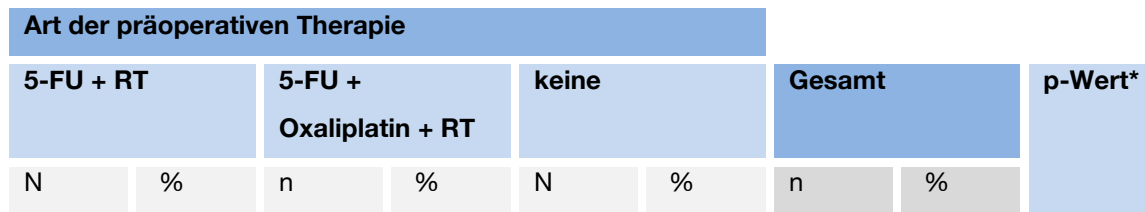

Patientenzahl

\begin{tabular}{|l|l|l|l|l|}
\hline 101 & 62 & 98 & 261 & 100
\end{tabular}

R-Status

\begin{tabular}{|l|l|l|l|l|l|l|l|l|l|} 
R0 & 100 & 99,0 & 60 & 96,8 & 93 & 94,9 & 253 & 96,9 & \\
\hline R1 & 1 & 1,0 & 2 & 3,2 & 5 & 5,1 & 8 & 3,1 & 0,242 \\
\hline
\end{tabular}

Grading des Tumors

\begin{tabular}{|c|c|c|c|c|c|c|c|}
\hline 0 & 0 & 0 & 0 & 0 & 0 & 0 & 0 \\
\hline 68 & 67,3 & 42 & 67,7 & 70 & 71,4 & 180 & 69,0 \\
\hline 16 & 15,8 & 6 & 9,7 & 2 & 2,0 & 24 & 9,2 \\
\hline 16 & 15,8 & 14 & 22,6 & 26 & 26,5 & 56 & 21,5 \\
\hline 1 & 1,0 & 0 & 0 & 0 & 0 & 1 & 0,4 \\
\hline
\end{tabular}

(y)pT-Stadium

\begin{tabular}{|l|l|l|l|l|l|l|l|l|} 
T0 & 2 & 2,0 & 0 & 0 & 0 & 0 & 2 & 0,8 \\
\hline T1 & 9 & 8,9 & 3 & 4,8 & 2 & 2,0 & 14 & 5,4 \\
\hline T2 & 32 & 31,7 & 18 & 29,0 & 17 & 17,3 & 67 & 25,7 \\
\hline T3 & 50 & 49,5 & 37 & 59,7 & 66 & 67,3 & 153 & 58,6 \\
\hline T4 & 8 & 7,9 & 4 & 6,5 & 13 & 13,3 & 25 & 9,6
\end{tabular}

031

(y) $\mathrm{pN}-$ Stadium

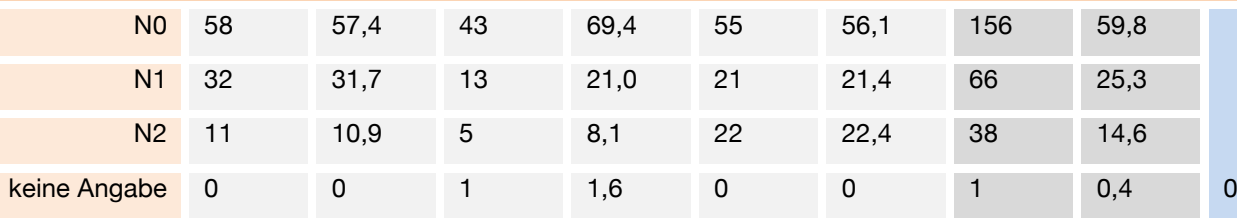

(y)pUICC-Stadium

\begin{tabular}{|c|c|c|c|c|c|c|c|c|c|}
\hline 0 & & 2 & 2,0 & 0 & 0 & 0 & 0 & 2 & 0,8 \\
\hline I & & 26 & 25,7 & 19 & 30,6 & 13 & 13,3 & 58 & 22,2 \\
\hline II & & 26 & 25,8 & 21 & 33,8 & 40 & 40,8 & 87 & 33,3 \\
\hline & A & 23 & 22,8 & 19 & 30,6 & 36 & 36,7 & 78 & 29,9 \\
\hline & B & 3 & 3,0 & 2 & 3,2 & 4 & 4,1 & 9 & 3,4 \\
\hline III & & 39 & 38,7 & 15 & 24,2 & 36 & 36,7 & 90 & 34,4 \\
\hline & A & 11 & 10,9 & 1 & 1,6 & 3 & 3,1 & 15 & 5,7 \\
\hline & B & 24 & 23,8 & 12 & 19,4 & 21 & 21,4 & 57 & 21,8 \\
\hline & C & 4 & 4,0 & 2 & 3,2 & 12 & 12,2 & 18 & 6,9 \\
\hline IV & & 8 & 7,9 & 7 & 11,3 & 9 & 9,2 & 24 & 9,2 \\
\hline
\end{tabular}

0,015

TRG nach Dworak (1997)

\begin{tabular}{|c|c|c|c|c|c|c|c|c|c|}
\hline 0 & 0 & 0 & 0 & 0 & $x$ & $x$ & 1 & 0,6 & \\
\hline 1 & 17 & 16,8 & 10 & 16,1 & $x$ & $x$ & 25 & 15,3 & \\
\hline 2 & 40 & 39,6 & 22 & 35,5 & X & $x$ & 61 & 37,4 & \\
\hline 3 & 42 & 41,6 & 30 & 48,4 & $x$ & $x$ & 74 & 45,4 & \\
\hline 4 & 2 & 2,0 & 0 & 0 & $x$ & $x$ & 2 & 1,2 & $0,506^{\star \star}$ \\
\hline
\end{tabular}

*asymptotische Signifikanz (2-seitig) des Chi-Quadrat-Test nach Pearson, **Berechnung ohne Kohorte C. 5-FU (5Fluorouracil), RT (Radiotherapie), TRG (Tumorregressionsgrad), x (nicht anwendbar). 
Die neoadjuvant therapierten Karzinome zeigten eine unterschiedliche Tumorregression. Der Großteil der Rektumkarzinome hatte einen TRG 2 ( $n=61 ; 37,4 \%)$ und TRG $3(n=74 ; 45,4 \%)$ nach Dworak et al. (1997). Zwei Rektumkarzinome (1,2\%) zeigten eine vollständige Tumorregression, einem TRG von 4 entsprechend. Diese zwei Fälle gehörten zu den insgesamt sieben Patienten, bei denen für die Analysen allein die tumortragende, prätherapeutische Biopsie berücksichtigt werden konnte (siehe Kapitel 2.5). In 25 Fällen wurde ein TRG 1 (15,3\%) nachgewiesen. In einem Fall (0,6 \%) ließ sich keinerlei RCT-induzierte Tumorregression beobachten.

Die Mehrheit der Patienten ( $\mathrm{n}=212 ; 81,2 \%$ ) wurde nach ihrer operativen Therapie gemäß der S3Leitlinien-Empfehlung Tumorstadien-adaptiert einer adjuvanten Chemotherapie zugeführt. Neben der Zytostatikakombination von 5-FU und Oxaliplatin wurden fünf Patienten (1,9 \%) erweitert behandelt: Vier Patienten (bereits in einem metastasierten Tumorstadium) erhielten zusätzlich gegen EGFR(Cetuximab) bzw. VEGF-Rezeptoren (Bevacizumab) gerichtete Antikörper. Einer Patientin wurde aufgrund von 5-FU-indizierten Koronarspasmen während der neoadjuvanten RCT im weiteren Verlauf allein nur Oxaliplatin parallel zur Radiotherapie verabreicht. Bei 49 Patienten (18,8 \%) erfolgte keine postoperative (adjuvante) Chemotherapie aufgrund des ausdrücklichen Patientenwunsches, des Vorliegens eines prognostisch sehr günstigen pUICC-I-Stadiums, bestehender Kontraindikationen wie protrahierten Wundheilungsstörungen, voranschreitender Multimorbidität oder aufgrund des Toxizitätsprofils (siehe Tabelle 2.6).

Tabelle 2.6: Postoperative Behandlung der Patienten

\begin{tabular}{|c|c|c|c|c|c|c|c|c|}
\hline \multicolumn{9}{|c|}{ Art der präoperativen Therapie } \\
\hline \multicolumn{2}{|c|}{$5-F U+R T$} & \multicolumn{2}{|c|}{$\begin{array}{l}\text { 5-FU + } \\
\text { Oxaliplatin + RT }\end{array}$} & \multicolumn{2}{|c|}{ keine } & \multicolumn{2}{|c|}{ Gesamt } & \multirow[t]{2}{*}{ p-Wert* } \\
\hline $\mathrm{n}$ & $\%$ & $\mathrm{~N}$ & $\%$ & $\mathrm{n}$ & $\%$ & $\mathrm{n}$ & $\%$ & \\
\hline
\end{tabular}

\begin{tabular}{|c|c|c|c|c|c|c|c|c|c|}
\hline \multicolumn{10}{|l|}{ Patientenzahl } \\
\hline & 101 & & 62 & & 98 & & 261 & 100 & \\
\hline \multicolumn{10}{|c|}{ Art der Nachbehandlung } \\
\hline 5-FU mono & 82 & 81,2 & 2 & 3,2 & 3 & 3,1 & 87 & 33,3 & \\
\hline 5-FU + Oxaliplatin & 8 & 7,9 & 53 & 85,5 & 59 & 60,2 & 120 & 46,0 & \\
\hline Andere & 1 & 1,0 & 0 & 0 & 4 & 4,1 & 5 & 1,9 & \\
\hline Keine & 10 & 9,9 & 7 & 11,3 & 32 & 32,7 & 49 & 18,8 & $<0,001$ \\
\hline
\end{tabular}

*asymptotische Signifikanz (2-seitig) des Chi-Quadrat-Test nach Pearson. 5-FU (5-Fluorouracil), RT (Radiotherapie). 


\subsection{Statistische Analysen}

Die p16-Expression in den einzelnen Resektaten wurde mittels der lichtmikroskopischen Begutachtung der immunhistochemisch gefärbten Gewebeschnitte ermittelt. Dabei wurde eine Auswertungsmethode genutzt, die auch als gewichteter Histologie-Score oder kurz H-Score etabliert ist und sowohl die immunhistochemische zelluläre Färbeintensität als auch den jeweiligen prozentualen Anteil gefärbter Zellen berücksichtigt (Detre et al. 1995; Edwards et al. 2004; Fraser et al. 2003; Kirkegaard et al. 2006; Numata et al. 2013). Die prozentuale Verteilung der Färbeintensität von Grad 0 bis Grad 3 wurde wie folgt in einen H-Score, im Folgenden p16-Score genannt, umgerechnet:

$$
(\% \operatorname{Grad} 0 \times 0)+(\% \operatorname{Grad} 1 \times 1)+(\% \operatorname{Grad} 2 \times 2)+(\% \operatorname{Grad} 3 \times 3)=\mathrm{p} 16-\text { Score }
$$

Zum Beispiel:

\begin{tabular}{|c|c|c|c|c|c|}
\hline \multirow[b]{2}{*}{ Färbeintensität } & \multicolumn{4}{|c|}{ Karzinomanteil } & \multirow[t]{2}{*}{ p16-Score } \\
\hline & 0 & 1 & 2 & 3 & \\
\hline $\begin{array}{l}\text { Prozentsatz der in dieser } \\
\text { Intensität gefärbten Zellen (in } \\
\text { schwarz) }\end{array}$ & $30 \times 0$ & $20 \times 1$ & $10 \times 2$ & $40 \times 3$ & $=160$ \\
\hline
\end{tabular}

Jedes untersuchte Gewebe erhielt je einen p16-Score zwischen 0 und 300 für den Anteil des normalen Darmepithels, des Adenoms und des Karzinoms als Ausgangswert für weitergehende Analysen. Im Folgenden wird der Begriff „,p16-Score“ für den errechneten Färbescore des Karzinomanteils genutzt. Bezieht sich ein p16-Score auf den Adenom- oder den normalen Darmepithelanteil der Biopsie oder des Resektates, so wird dies explizit erwähnt.

Die Korrelationsanalysen zwischen dem p16-Score und den klinisch-pathologischen Parametern TRG, Grading, Patientenalter, (y)pT- und (y)pN-Stadium erfolgten mit dem Korrelationstest Kendall's Tau (Stuart 2006). Der Vergleich der Verteilung der p16-Scores in normalem Darmepithel, Adenomanteilen und Karzinomgewebe wurde mit dem Wilcoxon-Vorzeichen-Rang-Test durchgeführt (Bortz et al. 2008). Die Überlebensparameter TTR und CSS sowie die korrespondierenden Überlebenskurven wurden nach der Kaplan-Meier-Methode mittels Log-Rang-Test bestimmt (Bland und Altman 1998, 2004). Das Kollektiv wurde hierfür anhand des Medianwertes des p16-Scores aller Resektate in zwei Gruppen geteilt. Mit dem Chi-Quadrat-Test nach Pearson und der Yates' Kontinuitätskorrektur wurde die Verteilung der klinisch-pathologischen Parameter in den Patientenkohorten A, B und C miteinander verglichen (Pearson 1900; Yates 1934). Die TTR wurde als Zeit vom OP-Datum bis zum Auftreten eines Lokalrezidivs oder einer Fernmetastasierung berechnet; das Versterben von Patienten und ein Lost-to-Follow-Up wurden bei der Berechnung nicht als Ereignis angesehen, sondern zensiert. Das CSS wurde definiert als Zeit vom OP-Datum bis zum Auftritt eines KRK-bedingten Todes; bei dieser Analyse wurde der Auftritt von Lokalrezidiven oder Fernmetastasen, ein Lost-to-Follow-Up und der nicht-KRK bedingte Tod zensiert (Birgisson et al. 
2011). Die p-Werte $<0,05$ wurden als statistisch signifikant angesehen. Der Chi-Quadrat-Test nach Pearson wurde mit IBM SPSS Statistics (IBM Corp. Released 2013. IBM SPSS Statistics for Windows, Version 22.0. Armonk, NY: IBM Corp.) berechnet. Alle anderen Analysen wurden mit der frei erhältlichen statistischen Software R (https://www.r-project.org/; Version 3.2.3) von Prof. Dr. T. Beißbarth, Gruppenleiter für statistische Bioinformatik (Institut für Medizinische Statistik der UMG, Direktor: Herr Prof. Dr. rer. nat. T. Friede) in enger gemeinsamer Kooperation durchgeführt.

\subsection{Erhebung der Patientendaten und Literaturrecherche}

Die Patientendaten wurden mithilfe der Patientenakten im Rahmen der KFO 179 erhoben. Aktuelle krankheitsbezogene Follow-Ups wurden im Rahmen von regelmäßigen Nachsorgeuntersuchungen an der UMG erhoben oder bei ärztlichen Kollegen aus der ambulanten Versorgung erfragt. Für die Diskussion der Untersuchungsergebnisse erfolgte eine ausführliche PubMed-Recherche (Stand: April 2016) mit den kombinierten Suchbegriffen „p16INK4a“, „p16“, „colorectal cancer“, „rectal cancer“ und „cellular senescence“. Des Weiteren wurden die Literaturverzeichnisse der gefundenen Publikationen auf Relevanz für die vorliegende Arbeit hin überprüft und ggf. genutzt. Daraufhin wurde eine Übersicht über die bisher erfolgten Untersuchungen zur immunhistochemischen p16Expression im KRK erstellt (siehe Anhang, Tabelle 6.1). 


\section{Ergebnisse}

Die immunhistochemische Färbung des Tumorsuppressorproteins p16 führte sowohl zu einer nukleären als auch zytoplasmatischen Anfärbung der histologischen Gewebeschnitte in unterschiedlicher Intensität. Dabei wurde beobachtet, dass eine intensive Kernfärbung fast immer mit einer intensiven zytoplasmatischen Färbung assoziiert war (siehe Abbildung 2.1). Nur in vereinzelten Karzinomzellen wich die nukleäre Färbung deutlich von der dazugehörigen zytoplasmatischen Färbung ab. Daher wurden nukleäre und zytoplasmatische Färbung nicht getrennt voneinander ausgewertet, sondern die Positivität der Zelle als Gesamtheit von gefärbtem Nukleus und Zytoplasma betrachtet. Aufgrund der vielfach heterogenen Färbung des Tumors sind häufig alle vier Färbeintensitäten in einem Präparat zu verschiedenen Anteilen vorhanden.

Im Folgenden wird die p16-Expression in den Biopsien und Resektaten sowohl als prozentualer Anteil an positiven Tumorzellen ohne Beachtung der Intensität als auch mit dem errechneten p16-Score (Wert zwischen 0 und 300, siehe Kapitel 2.6) angegeben, um die Vergleichbarkeit mit den Ergebnissen anderer Untersuchungen zu erleichtern. Der rein deskriptiven Darstellung der p16Expressionen folgt die Analyse des p16-Scores in Verbindung mit klinischen und histopathologischen Parametern. 


\section{1 p16-Expression in den prätherapeutischen Biopsien}

Im Karzinomanteil der 40 untersuchten Biopsien wurde in 37 Fällen (92,5\%) eine positive p16Expression nachgewiesen. Die beobachteten p16-Scores rangierten zwischen 0 und 135 bzw. der positive Tumoranteil des Karzinoms lag zwischen $0 \%$ und $80 \%$ (siehe Abbildung 3.1).

In 12 von 40 Biopsien waren zusätzlich zu den Karzinomanteilen auch Adenomanteile miterfasst worden. Die p16-Positivität hatte im Adenomanteil der Biopsien bei sehr geringer Fallzahl eine große Streubreite von $0 \%$ bzw. einem p16-Score von $0(n=4 ; 33 \%)$ bis hin zu einem maximalen positiven Adenomanteil von $45 \%$ bzw. einem p16-Score von 70 ( $n=1 ; 0,08 \%)$.
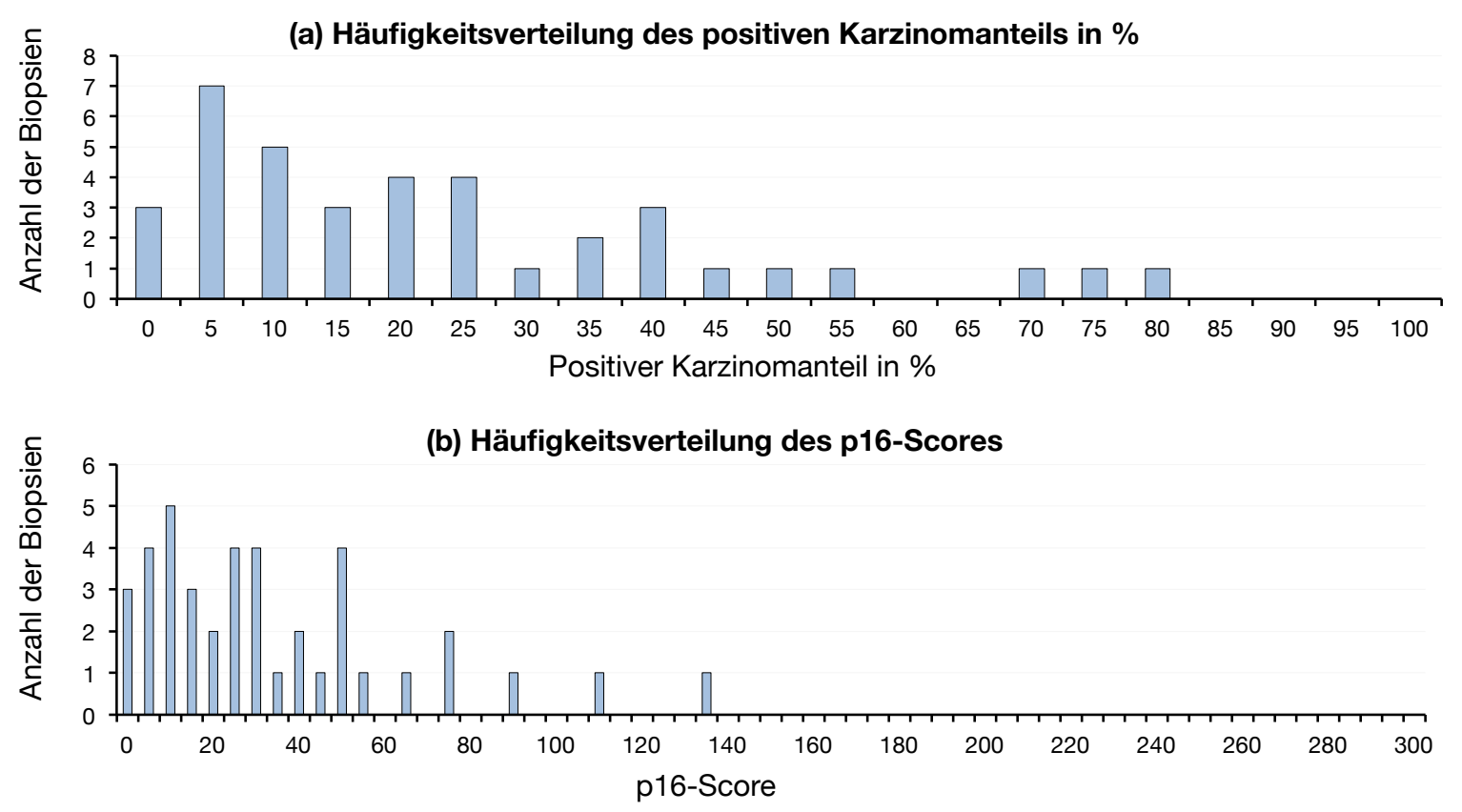

Abbildung 3.1: Häufigkeitsverteilung der p16-Expression im Karzinomanteil der Biopsien ( $n=40)$ (a): Häufigkeitsverteilung des positiven Karzinomanteils; (b): Häufigkeitsverteilung des p16-Scores.

Bei 24 von den 40 untersuchten Biopsien war normales Darmepithel miterfasst worden, das in 19 Fällen (79,2 \%) immunhistochemisch negativ für p16 ausfiel (p16-Score: 0). In vier Fällen (16,7 \%) lag ein positiver Anteil von $5 \%$ (p16-Score: 5) vor. In einem Fall (4,2\%) betrug der positive Färbeanteil $20 \%$. Die Biopsie mit dem positiven Anteil von $20 \%$ wies aufgrund ihrer verschiedenen Färbeintensitäten einen p16-Score von 30 auf (Berechnung des p16-Scores siehe Kapitel 2.6). Insgesamt betrachtet zeigte sich damit, dass das normale Darmepithel insgesamt nur sehr leicht oder gar nicht p16-positiv war.

\section{2 p16-Expression in den Resektaten}

In den 254 immunhistochemisch gefärbten Resektaten wurde die p16-Expression im Karzinomanteil, im Adenomanteil (falls vorhanden) und im angrenzenden normalen Darmepithel des Gewebeschnitts getrennt voneinander untersucht. Im Karzinomanteil der 254 untersuchten Resektate wurde in 95,3\% $(\mathrm{n}=242)$ eine positive p16-Expression nachgewiesen. Lediglich in 12 Resektaten zeigte sich keine p16Expression. In Abbildung 3.2 werden die Verteilungshäufigkeiten des positiven Karzinomanteils der 
Resektate in Prozent (a) und als p16-Scores (b) dargestellt. Die Verteilungsmuster ähneln sich stark, mit einer Häufung der Resektate zwischen $5 \%$ und $40 \%$ (p16-Score: 5-60) bzw. $75 \%$ und $100 \%$ (p16-Score: 100-200).

Unabhängig vom jeweiligen p16-Score fiel bei den Karzinomanteilen auf, dass kleine Tumorzellcluster häufig homogen und intensiv angefärbt waren. Größere Tumorzellcluster $(>10$ Zellen) desselben Gewebeschnittes wiesen eine eher mosaikartige p16-Positivität auf (siehe Abbildung 3.3).
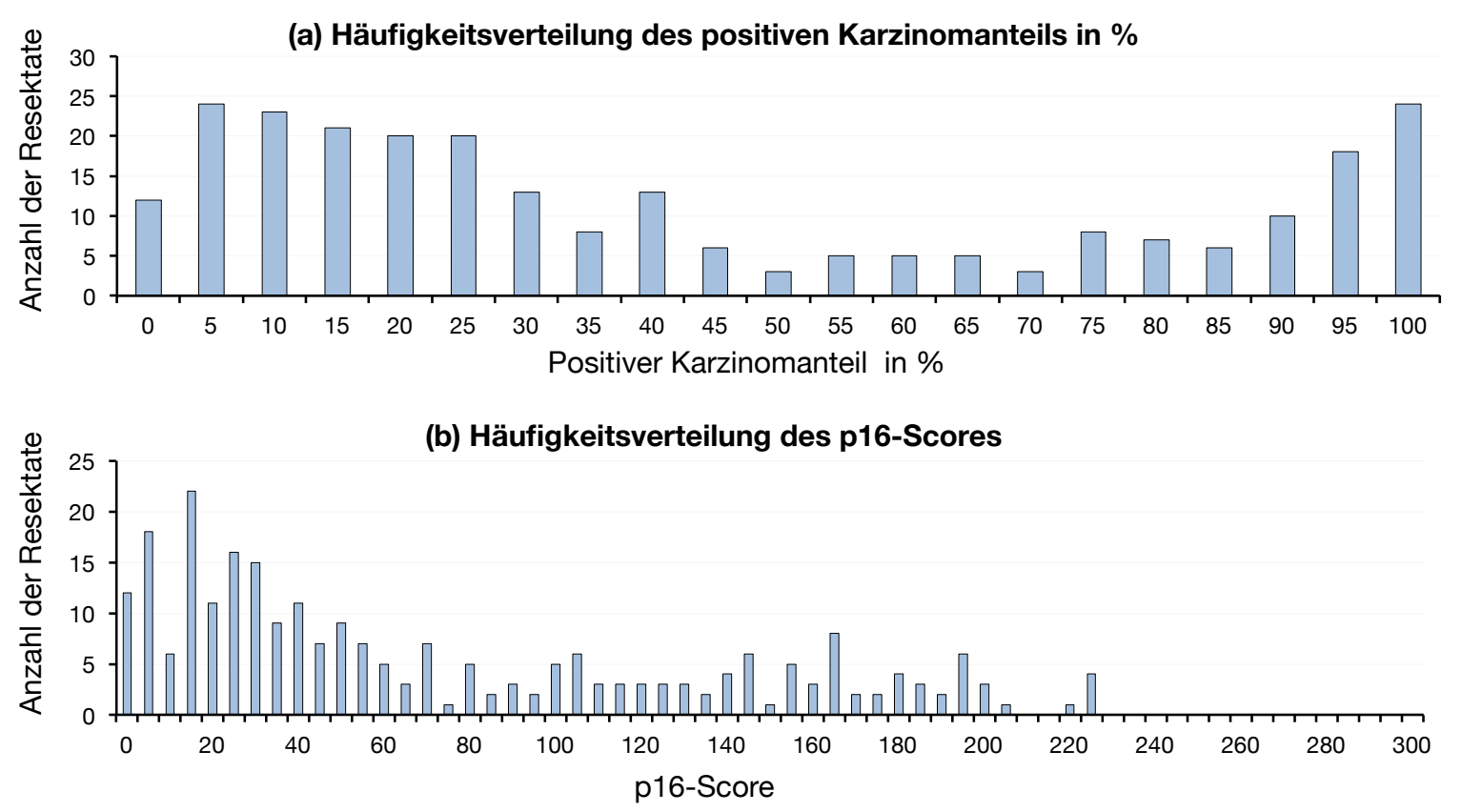

Abbildung 3.2: Häufigkeitsverteilung der p16-Expression im Karzinomanteil der Rektumresektate (n=254) (a): Häufigkeitsverteilung des positiven Karzinomanteils; (b): Häufigkeitsverteilung des p16-Scores. 
Stark gefärbte Tumorzellcluster an der Invasionsfront
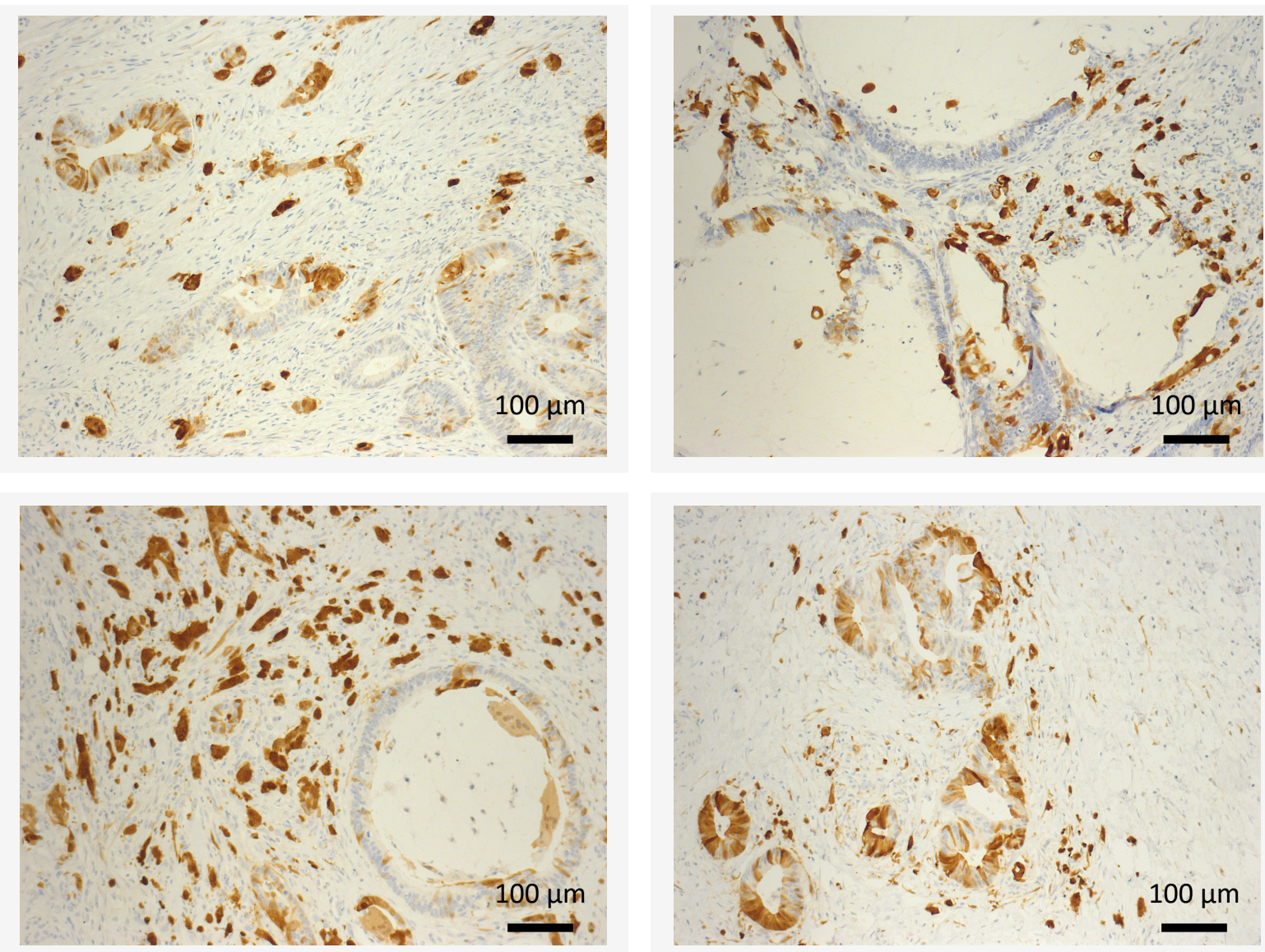

Abbildung 3.3: Vier Beispiele stark gefärbter Tumorzellcluster an der Tumorinvasionsfront

Jedes Bild stammt von je einem Rektumkarzinomresektat ohne präoperative Therapie. Die größeren Tumorzellcluster $(>10$ Zellen) sind deutlich schwächer und mosaikartig angefärbt. 10-fache Vergrößerung.

In 56 von 254 Resektaten (22\%) war ein relevanter Adenomanteil in den jeweiligen Gewebeschnitten sichtbar, der auch auf seine p16-Expression hin analysiert wurde. Die prozentuale Häufigkeitsverteilung der Adenomanteile wies zwei Gipfel auf: zwischen $5 \%$ und $30 \%$ sowie zwischen $70 \%$ und $100 \%$. Im Bereich des p16-Scores zeigte sich ebenfalls ein Gipfel zwischen 0 und 50; zwischen 90 bis 195 zeigte sich hingegen eine relative Gleichverteilung der Häufigkeiten (siehe Abbildung 3.4). 

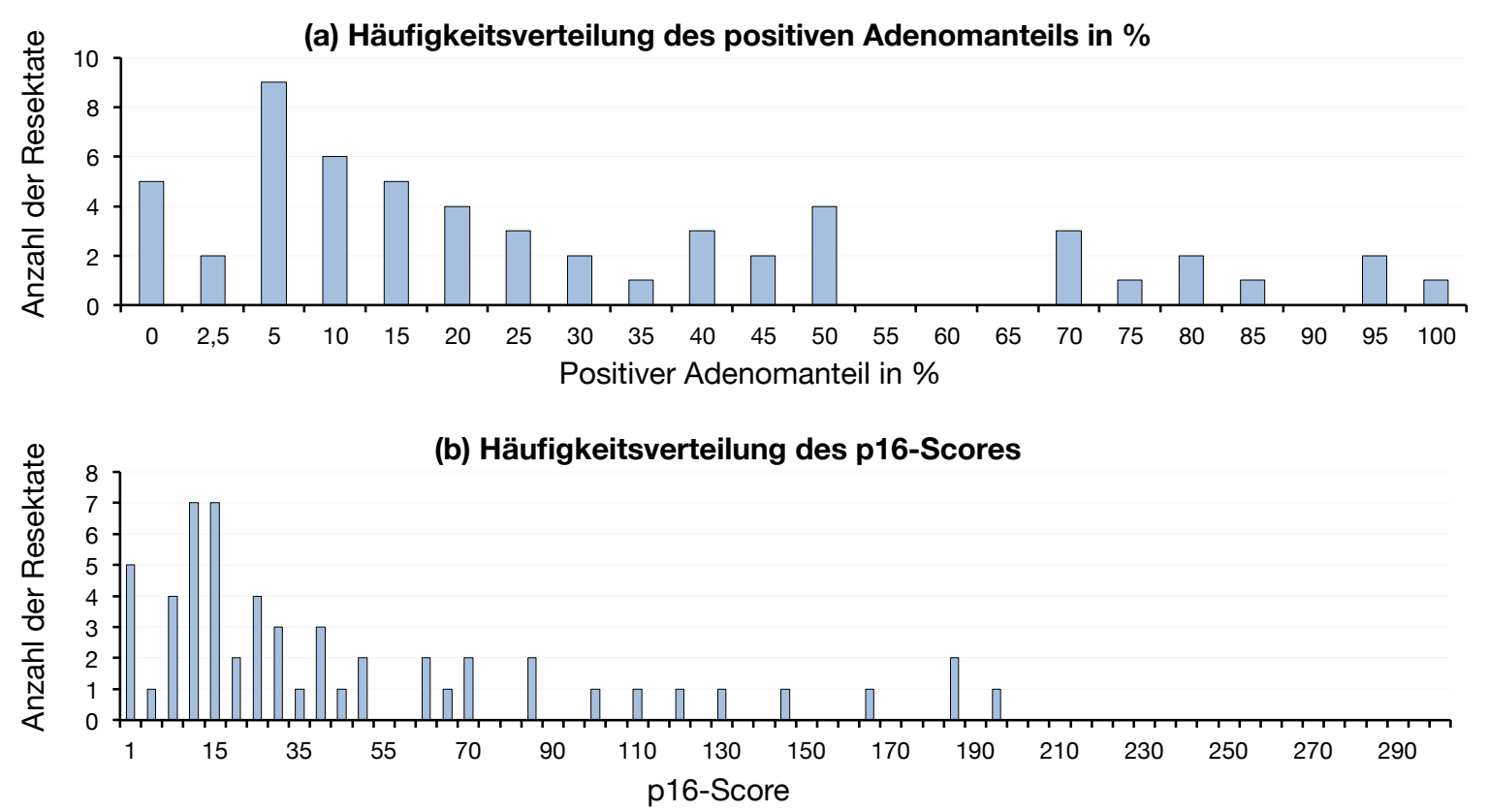

Abbildung 3.4: Häufigkeitsverteilung der p16-Expression im Adenomanteil der Rektumresektate $(n=56)$ (a): Häufigkeitsverteilung des positiven Adenomanteils; (b): Häufigkeitsverteilung des p16-Scores.

Bei 192 von 254 (75,6\%) Rektumresektaten wurde bei der p16-Färbung normales Darmepithel im Gewebeschnitt miterfasst. In 134 Fällen $(69,8 \%)$ zeigte sich keine p16-Expression. Auf den Gewebeschnitten waren Darmepithelanteile zu maximal 20\% positiv (p16-Score: 20) gefärbt (siehe Abbildung 3.6). Diese wenigen positiv gefärbten Zelle ließen sich kryptennah beobachten (siehe Abbildung 3.5).
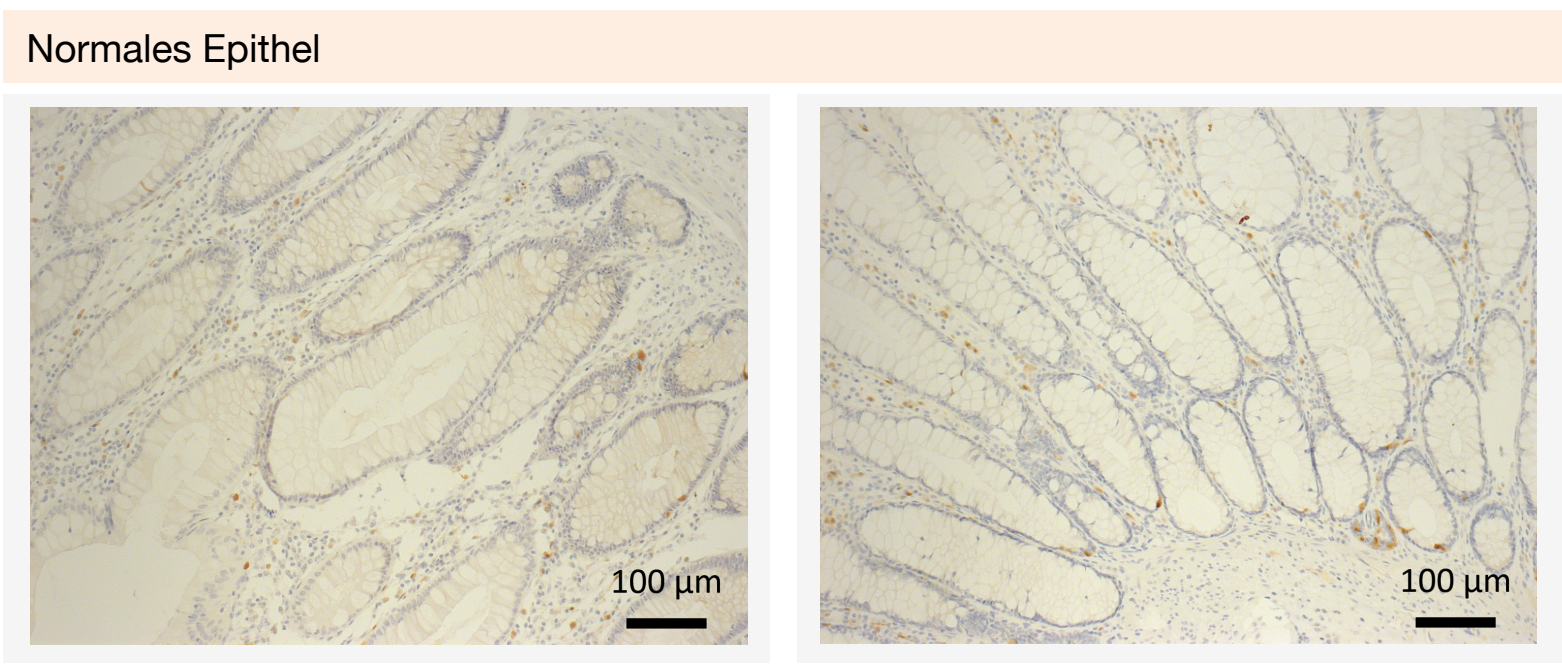

Abbildung 3.5: Normales Darmepithel mit vereinzelt angefärbten Zellen in Kryptennähe

Exemplarische Bilder von normalem Darmepithel aus zwei primär operierten Rektumresektaten. 10-fache Vergrößerung. 

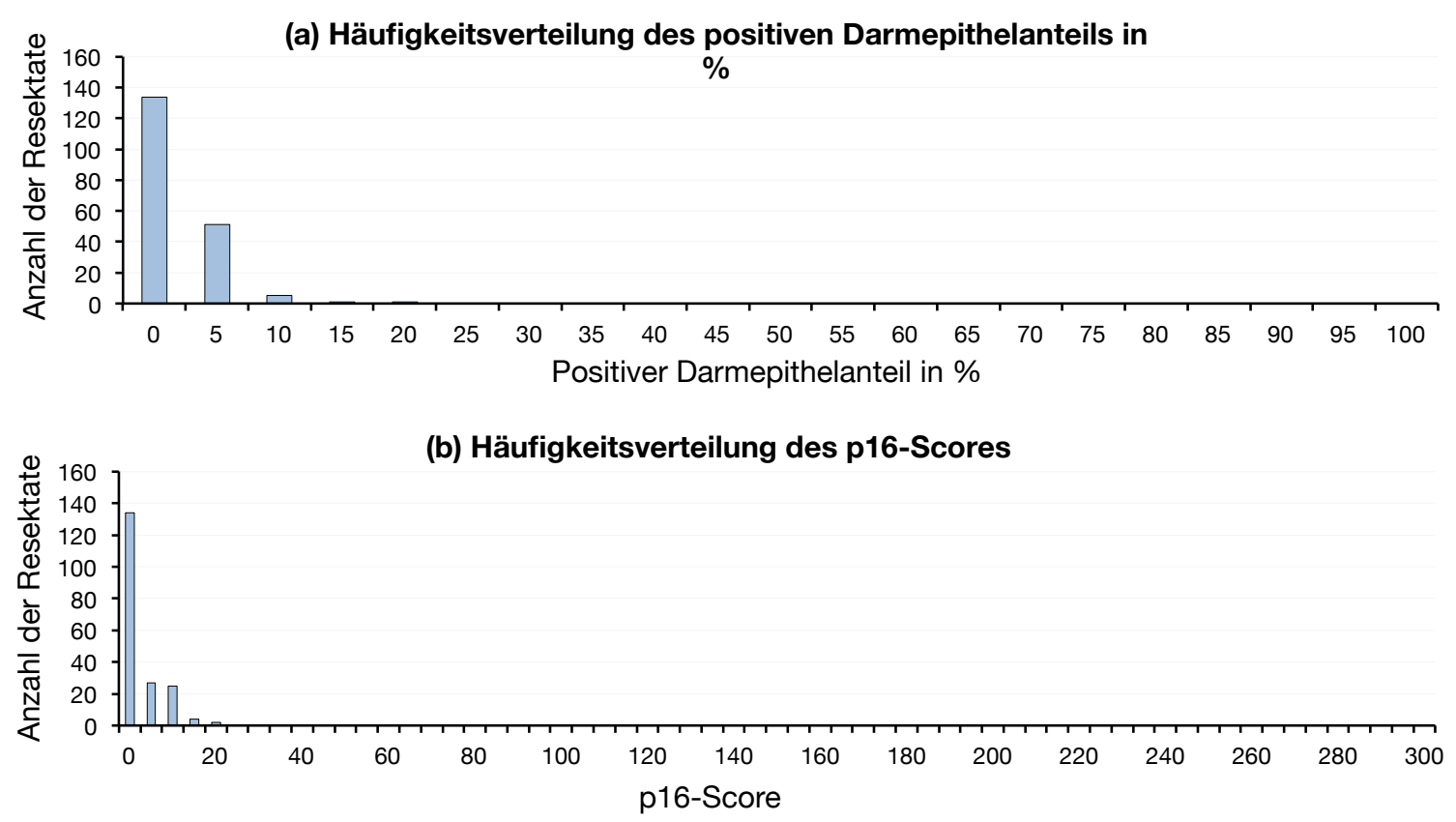

Abbildung 3.6: Häufigkeitsverteilung der p16-Expression in normalem Darmepithel der Rektumresektate $(n=192)$

(a): Häufigkeitsverteilung des positiven Darmepithelanteils; (b): Häufigkeitsverteilung des p16-Scores.

\section{3 p16-Expression bei neoadjuvant behandelten vs. primär resezierten Rektumkarzinomen}

Von den 98 primär resezierten Rektumkarzinomen (Kohorte C) zeigten 92,9\% eine p16-Positivität (definiert als mindestens $5 \%$ des Tumors gefärbt bzw. p16-Score $>0$ ). Von den neoadjuvant behandelten Patienten (Kohorte AB) waren 96,8 \% der Rektumkarzinome p16-positiv. Die ermittelten p16-Scores der resezierten Karzinomanteile lagen in der Kohorte A zwischen 0 und 225 (Mittelwert 96,6 \pm Standardabweichung (standard deviation, SD) 64,9), in der Kohorte B zwischen 0 und 220 (Mittelwert 102,1 \pm SD 63,3) und in der Kohorte C zwischen 0 und 180 (Mittelwert 29,8 \pm SD 31,8). Im Vergleich der p16-Scores zwischen den drei Patientenkohorten wird deutlich, dass in der Kohorte C $(n=98)$ signifikant niedrigere p16-Scores nachweisbar waren $(\mathrm{p}<0,001$; siehe Abbildung 3.7) gegenüber der neoadjuvant behandelten Kohorte AB ( $\mathrm{n}=156)$. Zwischen der Kohorte A (neoadjuvante RCT mit 5-FU und RT) und der Kohorte B (neoadjuvante RCT mit 5-FU, Oxaliplatin und RT) besteht kein Unterschied in den $\mathrm{p} 16-$ Scores $(\mathrm{p}=0,561$; siehe Abbildung 3.7). Demzufolge ist die - im Vergleich zur Kontrollkohorte C - erhöhte p16-Expression durch die neoadjuvante RCT induziert; sie ist aber unabhängig von der Zugabe von Oxaliplatin. Beim Vergleich der p16-Scores der Kohorte AB und der Kohorte $\mathrm{C}$ ergibt sich kein Unterschied in der p16-Färbung von normalem Darmepithel $(\mathrm{n}=192 ; \mathrm{p}=0,4)$. Im Vergleich der $\mathrm{p} 16$-Scores der Adenomanteile lassen sich allerdings signifikant höhere p16-Scores in den mit RCT neoadjuvant behandelten Gewebeproben beobachten $(\mathrm{n}=56$; $\mathrm{p}<0,001$, siehe Abbildung 3.8). Werden die p16-Scores der Adenom- bzw. Karzinomanteile innerhalb der Kohorte AB verglichen, so ergeben sich signifikant höhere p16-Scores der Karzinomanteile als p16-Scores der Adenomanteile ( $\mathrm{p}=0,027$; $\mathrm{p}$-Wert nicht abgebildet). Innerhalb der Kohorte $\mathrm{C}$ 
unterscheiden sich die p16-Scores der Adenomanteile nicht von den p16-Scores der Karzinomanteile $(\mathrm{p}=0,857 ; \mathrm{p}$-Wert nicht abgebildet).

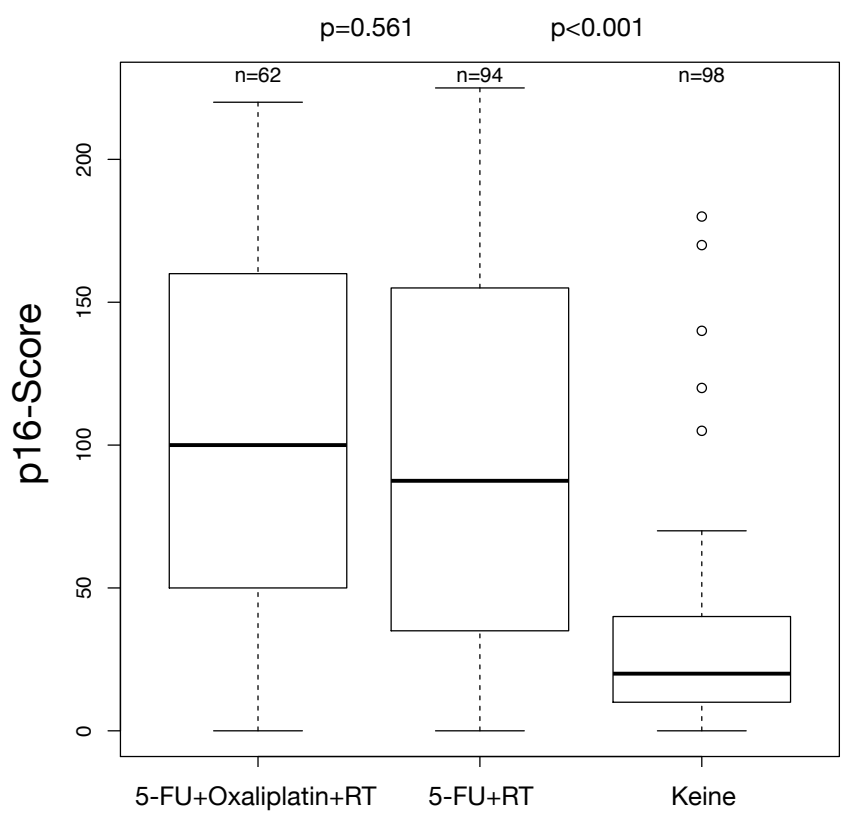

Abbildung 3.7: p16-Score der Karzinomanteile der Resektate in Korrelation zur präoperativen Therapie Zwischen der Vorbehandlung mit 5-FU+Radiotherapie (Kohorte A) und 5-FU+Oxaliplatin+Radiotherapie (Kohorte B) gibt es keinen signifikanten Unterschied in der Höhe der p16-Scores $(p=0,561)$. Beim Vergleich der p16-Scores zwischen der Gesamtgruppe der neoadjuvant behandelten Rektumkarzinome (Kohorte AB) und dem Karzinomgewebe von Patienten ohne präoperative Therapie (Kohorte $\mathrm{C}$, primäre Operation) zeigt sich eine signifikant höhere p16-Expression nach neoadjuvanter RCT (p-Wert $<0,001)$.

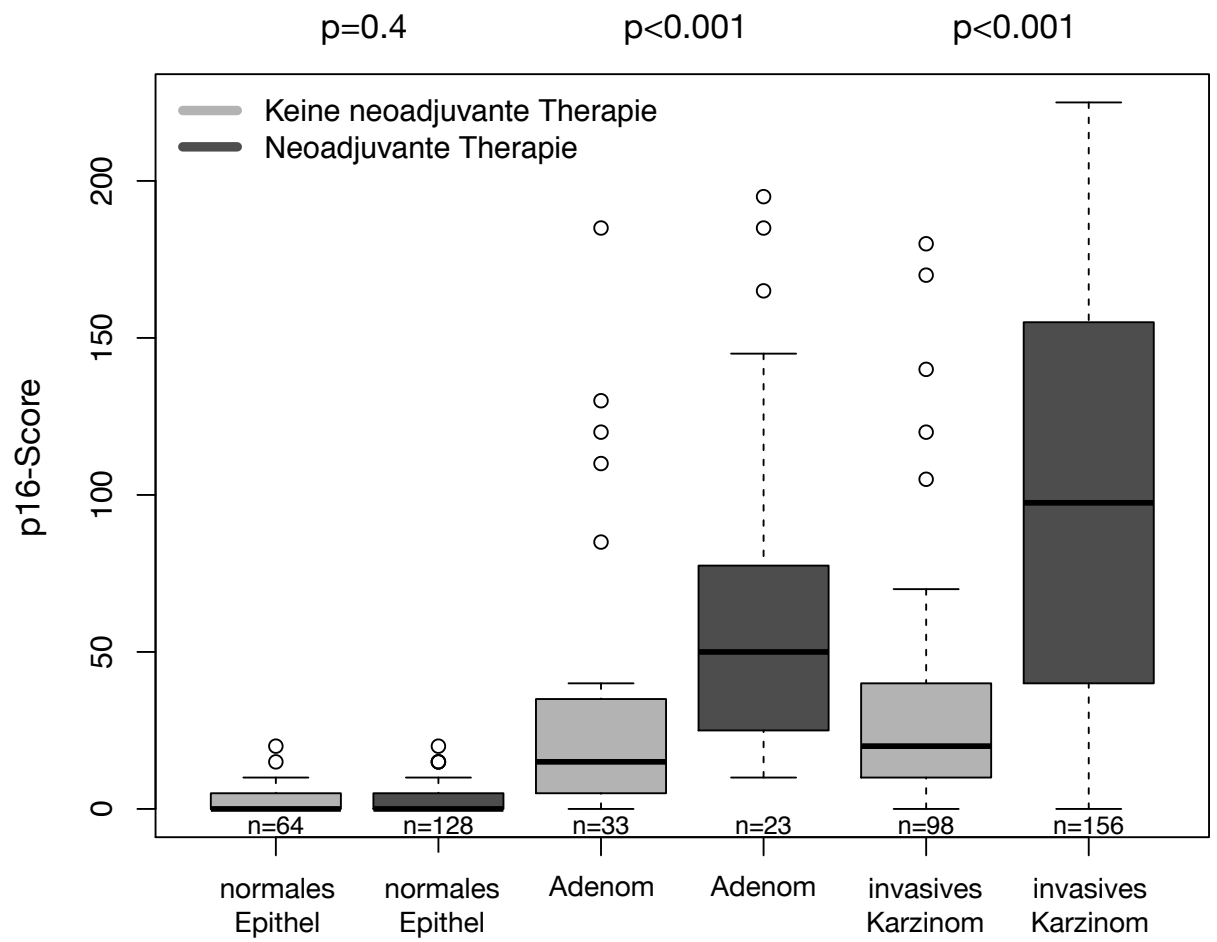

Abbildung 3.8: p16-Scores im Resektatgewebe nach neoadjuvanter Therapie vs. Kontrollgruppe

Die angegebenen p-Werte beziehen sich jeweils auf den Vergleich der p16-Scores einzelner Gewebeanteile zwischen Kohorte AB (neoadjuvante RCT) und Kohorte C (primär operiert, Kontrollgruppe). In normalem Darmepithel ist kein Unterschied zwischen den Patientengruppen festzustellen. Die p16-Scores der Adenomanteile und der Karzinomanteile sind hingegen jeweils in der neoadjuvant behandelten Kohorte $\mathrm{AB}$ signifikant höher als in der primär operierten Kohorte $\mathrm{C}$ (jeweils $\mathrm{p}<0,001$ ). 


\section{4 p16-Expression im Rektumkarzinom - Vergleich der prätherapeutischen Biopsie mit dem korrespondierenden Resektat nach RCT}

Von 33 der 40 analysierten Biopsien konnte auch das jeweils dazugehörige neoadjuvant behandelte Resektat analysiert werden. Im Vergleich der p16-Scores von Biopsie und Resektat zeigte sich ein signifikanter Unterschied ( $<00,001$; siehe Abbildung 3.9 (a)). Im Biopsiegewebe wurde mehrheitlich ein niedrigerer p16-Score als im korrespondierenden Resektatgewebe ermittelt (siehe Abbildung 3.9 (b)).
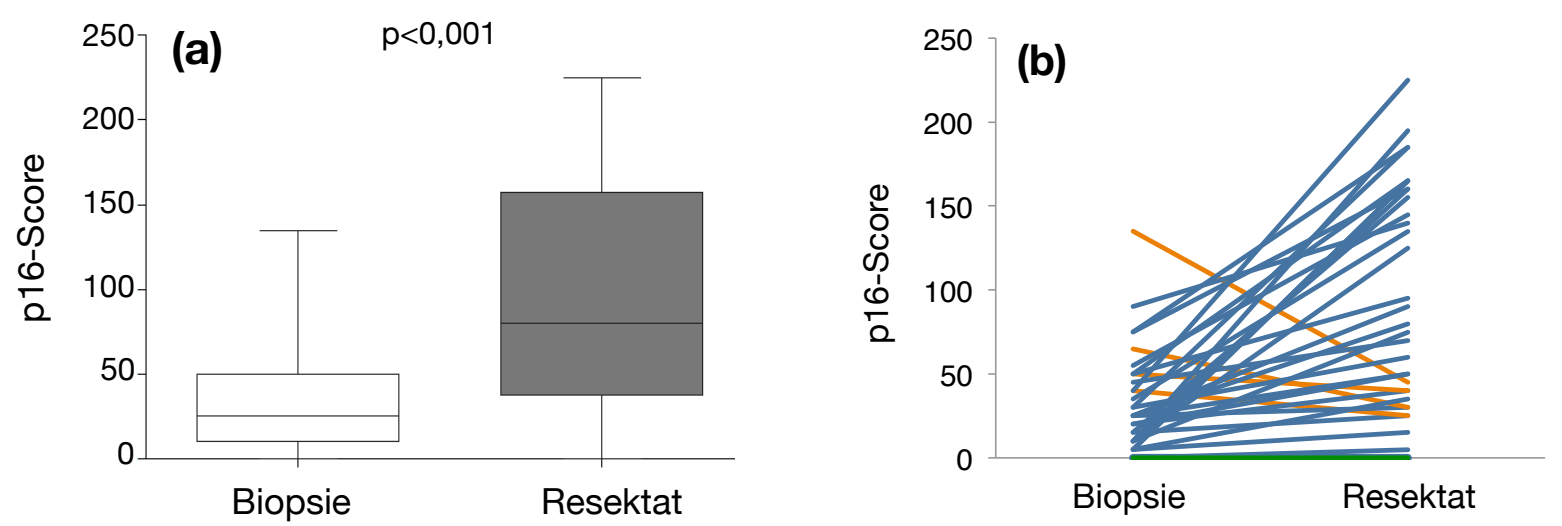

Abbildung 3.9: Vergleich der p16-Scores im Karzinomanteil der prätherapeutischen Biopsien und dem Karzinomgewebe der korrespondierenden Rektumresektate nach neoadjuvanter RCT

(a): Gesammelte p16-Scores der Biopsie und des Resektates im Vergleich; (b): Der p16-Score der Biopsie ist mit einer Linie mit dem p16-Score des korrespondierenden Rektumresektates verbunden. Aufteilung in Patienten, deren p16-Score im Resektat höher (blau), gleich (grün) oder niedriger (orange) ist als in der dazugehörigen Biopsie (n=33).

Zusammenfassend wird infolge einer neoadjvuanten RCT die p16-Expression, ablesbar am p16-Score im Vergleich zwischen prätherapeutischer Biopsie und korrespondierendem Rektumresektat, bei 28 von 33 Patienten $(84,9 \%)$ hochreguliert. Bei fünf Patienten $(15,1 \%)$ ließ sich dieser Effekt nicht beobachten, bei vier von diesen war der p16-Score im Rektumkarzinomresektat geringer als im p16Score der prätherapeutischen Biopsie, bei einem Patienten war sowohl in der Biopsie als auch im Rektumkarzinomresektat keine p16-Expression nachweisbar (siehe Abbildung 3.9).

\subsection{Korrelation der immunhistochemischen p16-Färbung der Biopsien und Resektate mit klinischen und histopathologischen Parametern}

Im folgenden Abschnitt werden die p16-Scores der prätherapeutischen Biopsien und Rektumresektate getrennt nach den Patientenkohorten $\mathrm{AB}$ und $\mathrm{C}$ (siehe Kapitel 2.5.1) mit den klinischen und histopathologischen Parametern Patientenalter, (y)pT-Stadium, (y)pN-Stadium, (y)pUICC-Stadium, histopathologischem Grading und TRG abgeglichen. 


\subsubsection{Korrelation der p16-Färbung mit dem Patientenalter}

Die p16-Scores der Biopsien und der Gesamtheit der Rektumresektate zeigen keinen Zusammenhang mit dem Patientenalter zum Operationszeitpunkt ( $\mathrm{p}=0,85$ bzw. $\mathrm{p}=0,23$; siehe Abbildung 3.10). Die p16-Expression des Karzinomanteils scheint altersunabhängig zu sein.

Im Gegensatz dazu korreliert der Grad der Stromafärbung in den Gewebeschnitten der Rektumresektate mit dem Patientenalter bei OP ( $p=0,02$, siehe Abbildung 3.11). Je älter der Patient zum Operationszeitpunkt war, desto stärker ließ sich das Stroma im Resektatgewebe mit dem p16Antikörper anfärben (siehe Abbildung 3.11 und Kapitel 4.1.6).

(a) Biopsien

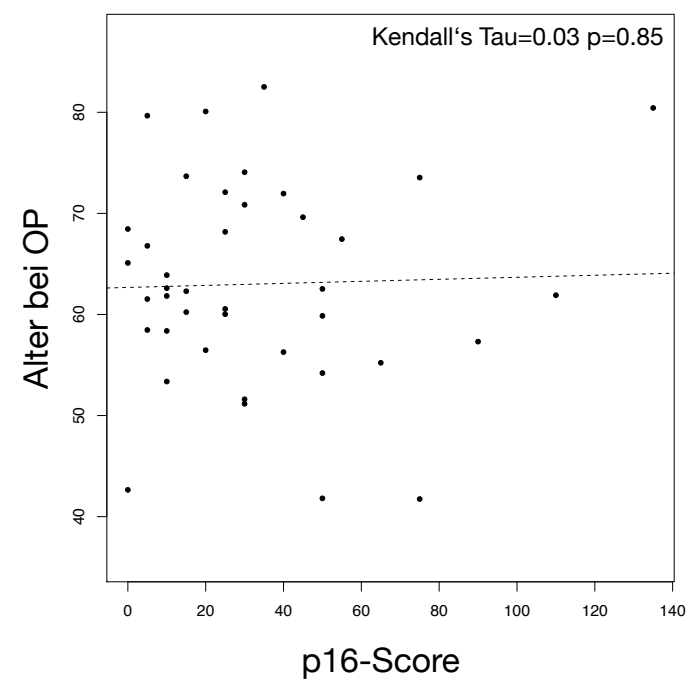

(b) Resektate

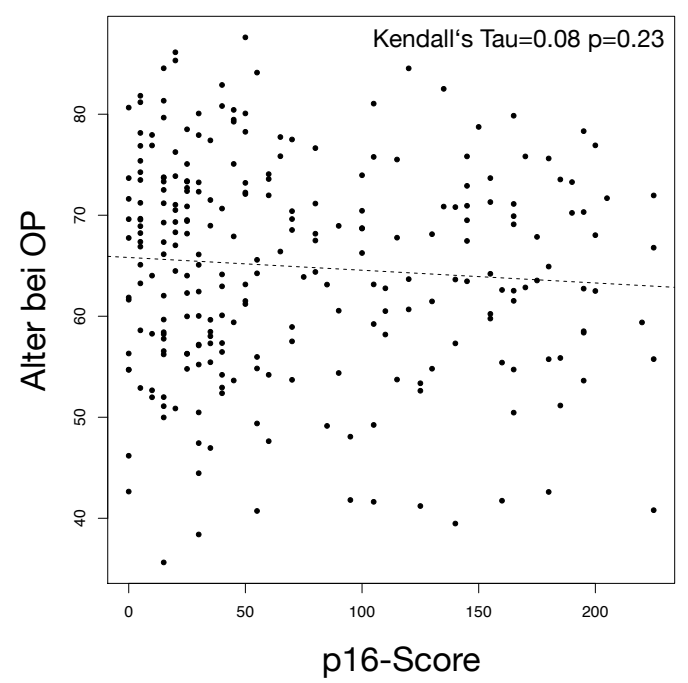

Abbildung 3.10: Korrelation der p16-Scores mit dem Patientenalter

(a) Korrelation des p16-Scores des Karzinomanteils der prätherapeutischen Biopsien ( $\mathrm{n}=40)$ mit dem Patientenalter; (b) Korrelation des p16-Scores des Karzinomanteils der Rektumresektate $(n=254)$ mit dem Patientenalter. In die Analyse wurden alle Resektate unabhängig von ihrer Vorbehandlung einbezogen (Kohorte A, B und C).

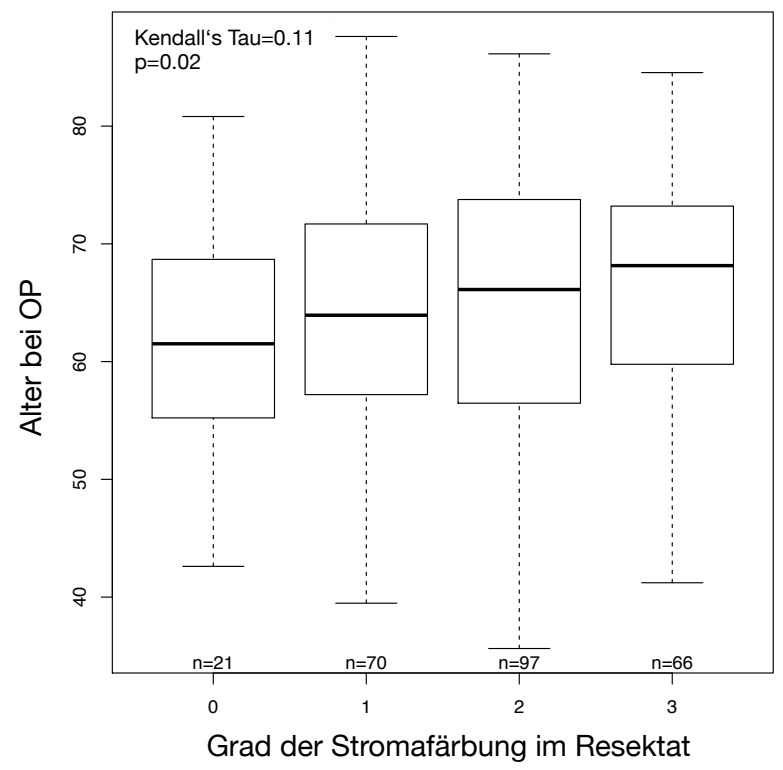

Abbildung 3.11: Grad der Stromafärbung in Korrelation zum Patientenalter bei OP 


\subsubsection{Korrelation der p16-Scores des Karzinomanteils mit dem (y)pT-, dem (y)pN- und dem (y)pUICC-Stadium}

(a) Biopsien

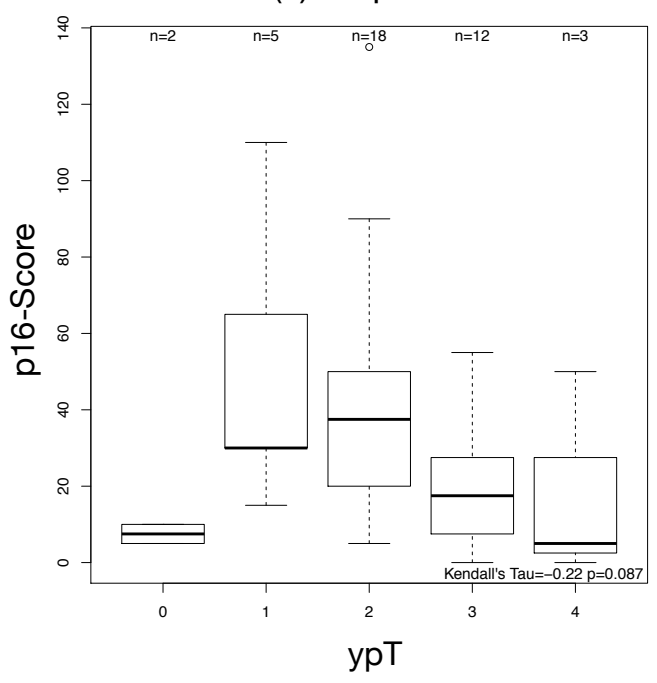

(c) Kohorte AB

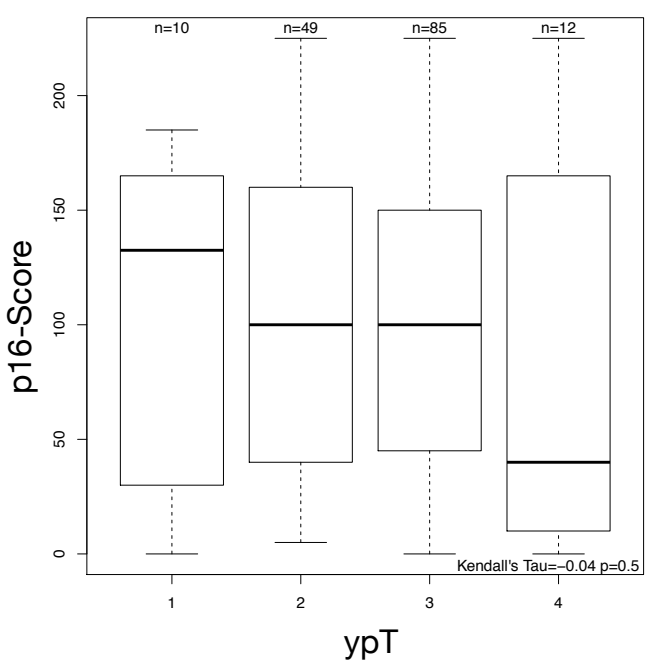

(b) Alle Resektate

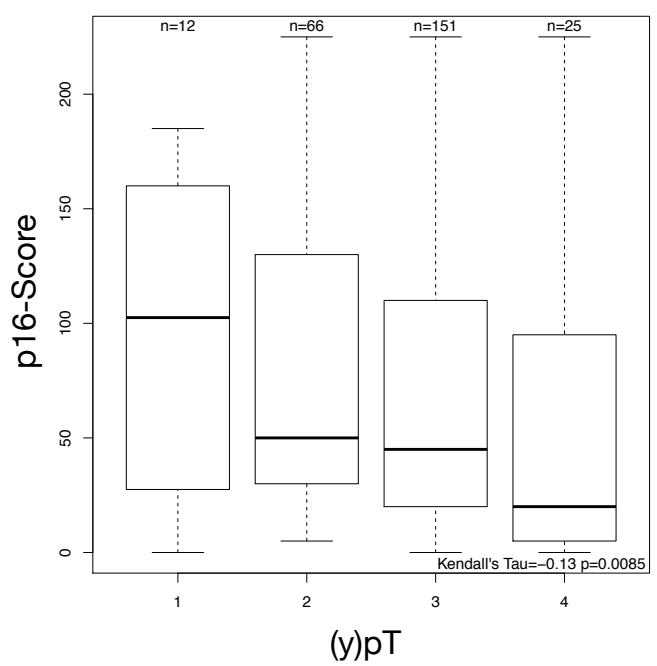

(d) Kohorte C

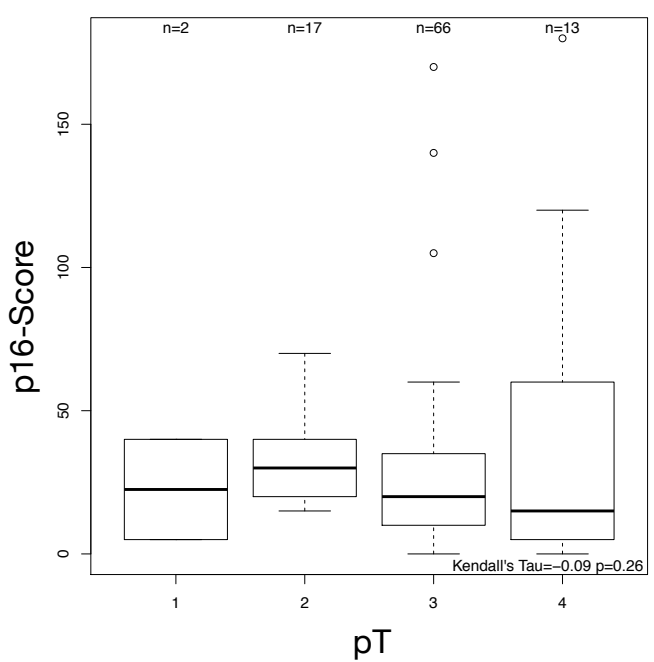

Abbildung 3.12: Korrelation der p16-Scores des Karzinomanteils mit dem postoperativen (y)pT-Stadium des Rektumresektates

(a) Karzinomgewebe der prätherapeutischen Biopsien ( $\mathrm{n}=40$ ); (b) Karzinomgewebe der Rektumresektate aller Patienten, Kohorte A, B und C (n=254); (c) Karzinomgewebe der Rektumresektate von den neoadjuvant mit RCT behandelten Patienten, Kohorte AB ( $\mathrm{n}=156)$; (d) Karzinomgewebe der Rektumresektate der primär operierten Patienten, Kohorte C $(n=98) . y=$ nach neoadjuvanter Therapie, $\mathrm{p}=$ histopathologisch erhobener Befund.

Es gibt keinen signifikanten Zusammenhang zwischen dem p16-Score der prätherapeutischen Biopsie und dem ypT-Stadium nach Rektumresektion ( $\mathrm{p}=0,087$, siehe Abbildung 3.12(a)). Tendenziell ist ein niedriger p16-Score mit einem höheren ypT-Stadium assoziiert. Ein signifikanter Zusammenhang besteht zwischen der Höhe des p16-Scores des Karzinomanteils aller Resektate und dem (y)pTStadium ( $\mathrm{p}=0,009$, siehe Abbildung 3.12(b)).

Bei der Betrachtung der einzelnen Kohorten $\mathrm{AB}$ und $\mathrm{C}$ ist kein Unterschied festzustellen ( $\mathrm{p}=0,5 \mathrm{bzw}$. $\mathrm{p}=0,26$, siehe Abbildung 3.12 (c) und (d); siehe Kapitel 4.1.9). 
(a) Biopsien

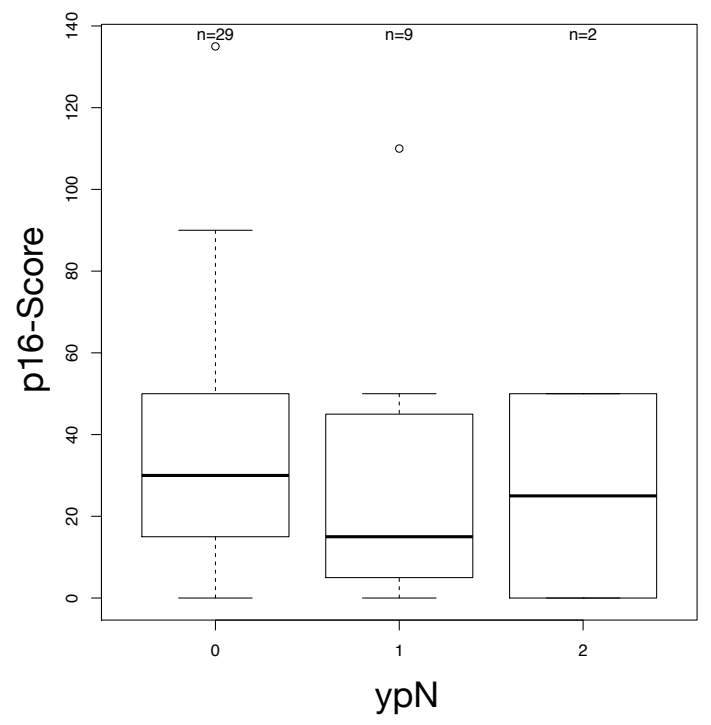

(c) Kohorte AB

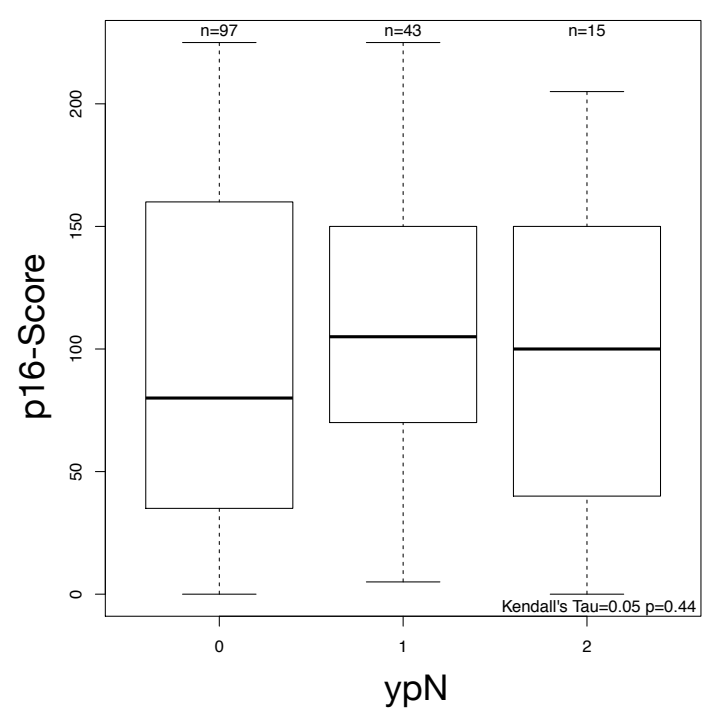

(b) Alle Resektate

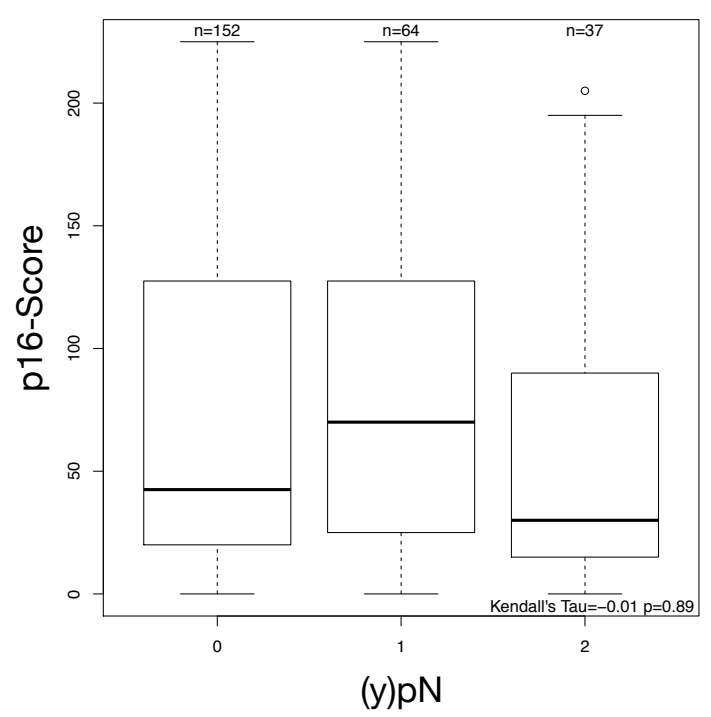

(d) Kohorte C

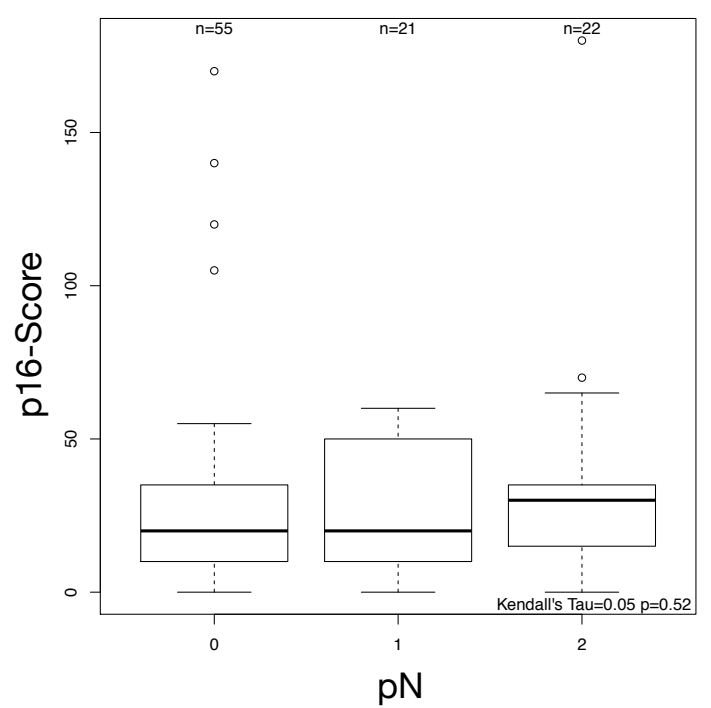

Abbildung 3.13: Korrelation der p16-Scores des Karzinomanteils mit dem postoperativen (y)pN-Stadium (a) Karzinomgewebe der prätherapeutischen Biopsien ( $\mathrm{n}=40)$; (b) Karzinomgewebe der Rektumresektate aller Patienten, Kohorte A, B und C ( $\mathrm{n}=254)$; (c) Karzinomgewebe der Rektumresektate von den neoadjuvant mit RCT behandelten Patienten, Kohorte AB ( $\mathrm{n}=155)$; (d) Karzinomgewebe der Rektumresektate der primär operierten Patienten, Kohorte C $(n=98) . y=$ nach neoadjuvanter Therapie, $p=$ histopathologisch erhobener Befund.

Zwischen dem postoperativ ermittelten Lymphknotenstatus und dem p16-Score des Karzinomanteils der Biopsien sowie dem p16-Score des Karzinomanteils der Resektate besteht kein Zusammenhang ( $\mathrm{p}=0,49$ bzw. 0,89; siehe Abbildung 3.13 (a) und (b)). Auch bei der Analyse der einzelnen Kohorten $\mathrm{AB}$ und $\mathrm{C}$ lässt sich kein Unterschied nachweisen ( $\mathrm{p}=0,44$ bzw. 0,52; siehe Abbildung 3.13 (c) und (d)). Wie diese Ergebnisse erwarten lassen, ergibt sich keine Abhängigkeit zwischen dem (y)pUICCStadium und dem p16-Score aus den Biopsien bzw. den Resektaten (Biopsien: p=0,33; alle Resektate: $\mathrm{p}=0,49$; Kohorte $\mathrm{AB}: \mathrm{p}=0,74$; Kohorte $\mathrm{C}: \mathrm{p}=0,91$; nicht abgebildet). 


\subsubsection{Korrelation des p16-Scores mit dem postoperativen Grading des Rektumkarzinoms}

Ebenso wie das (y)pUICC-Stadium zeigt auch das postoperative Grading keinen Zusammenhang mit den $\mathrm{p} 16-$ Scores der Karzinomanteile der Biopsien $(\mathrm{p}=0,11)$ und den $\mathrm{p} 16$-Scores der Karzinomanteile der Rektumresektate (alle Resektate: $\mathrm{p}=0,67$; Kohorte AB: $p=0,28$; Kohorte $\mathrm{C}: \mathrm{p}=0,2$ ).

\subsubsection{Korrelation der p16-Scores der prätherapeutischen Biopsie und des Resektates mit dem TRG}

(a) Biopsien

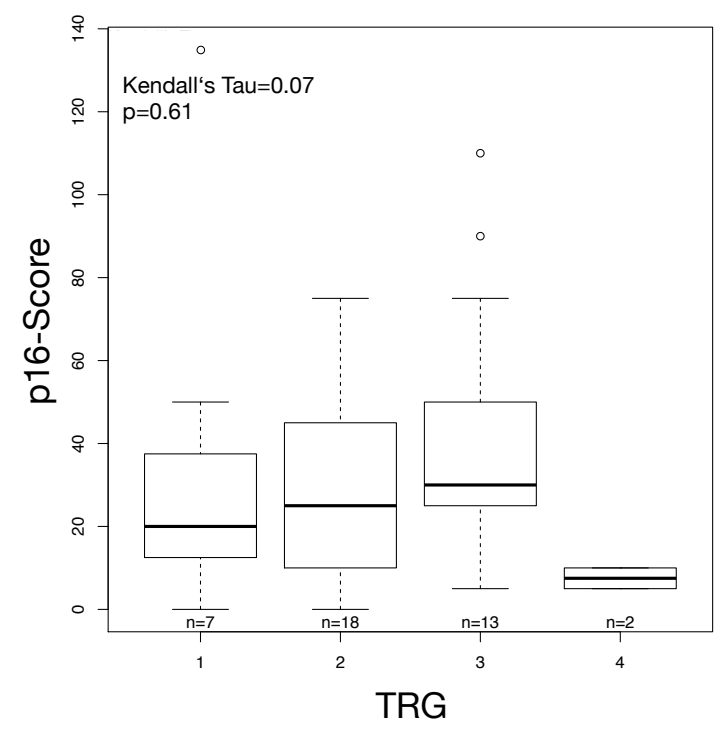

(c) Biopsien

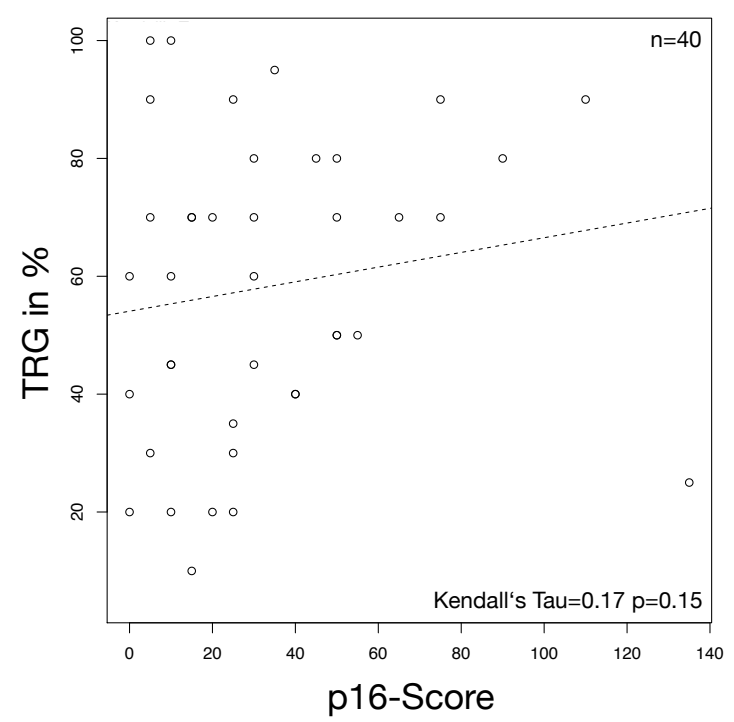

(b) Kohorte AB

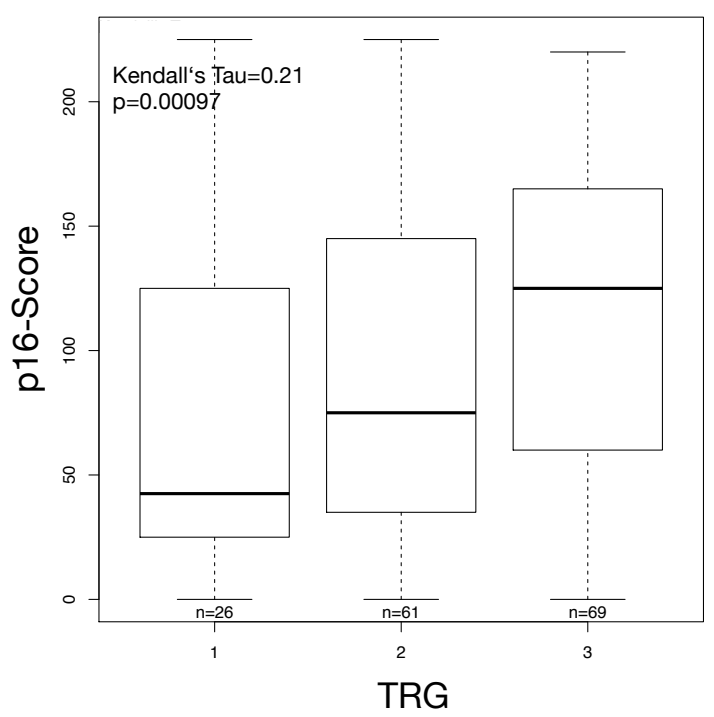

(d) Kohorte AB

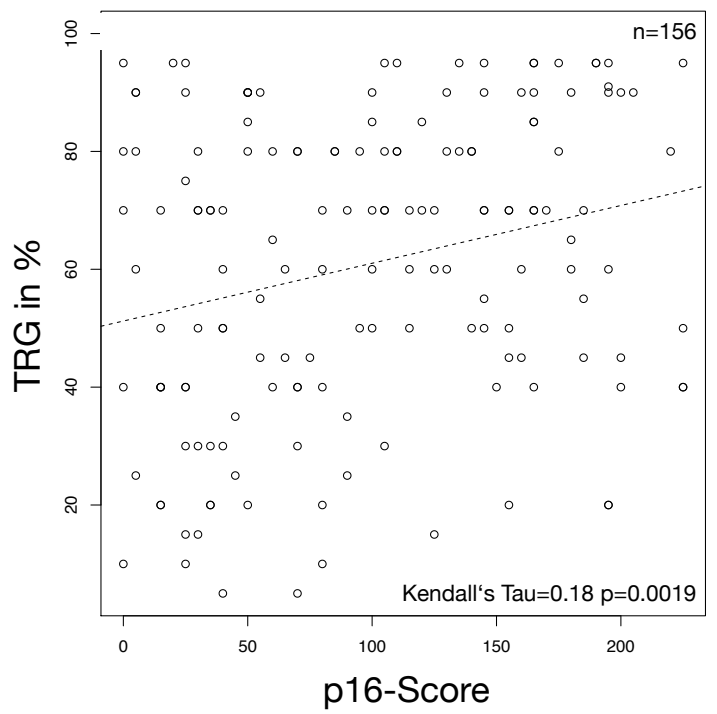

Abbildung 3.14: Korrelation des p16-Scores des neoadjuvant behandelten Rektumkarzinomgewebes mit dem postoperativen TRG

(a) Korrelation des p16-Scores der prätherapeutischen Biopsie mit dem TRG des dazugehörigen Rektumresektates nach neoadjuvanter RCT; (b) Korrelation des p16-Scores der neoadjuvant behandelten Rektumresektate der Kohorte AB mit dem TRG des residuellen Rektumkarzinoms; (c) Korrelation des p16-Scores der Biopsie mit dem TRG in Prozent des dazugehörigen Resektates. (d) Korrelation des p16-Scores des Resektates der Kohorte AB mit dem TRG in Prozent des Resektates. TRG (Tumorregressionsgrad). 
Es ergibt sich kein relevanter Zusammenhang zwischen den jeweiligen p16-Scores aller für eine p16Analyse verfügbaren prätherapeutischen Biopsien $(n=40)$ mit dem postoperativ bestimmten TRG des dazugehörigen Resektates ( $\mathrm{p}=0,61$; siehe Abbildung 3.14). Wird der TRG nicht in Graden, sondern in Prozent angegeben, so zeigt sich ein Trend zu einem möglichen Zusammenhang mit dem p16-Score der Biopsien ( $\mathrm{p}=0,15$; siehe Abbildung 3.14).

Innerhalb der Kohorte AB der neoadjuvant behandelten Rektumkarzinome ( $\mathrm{n}=156)$ wird die positive Korrelation zwischen den p16-Scores des Karzinomanteils der Resektate mit dem unabhängig bestimmten histopathologischen TRG deutlich: Je höher der p16-Score, desto höher ist auch der TRG, d. h. desto besser ist die RCT-induzierte Tumorregression ( $\mathrm{p}<0,001$; siehe Abbildung 3.14). Die genannte Korrelation bestätigt sich auch, wenn der postoperativ ermittelte TRG in Prozent angegeben wird ( $\mathrm{n}=156, \mathrm{p}=0,002$; siehe Abbildung 3.14).

\subsection{Analysen des p16-Expressionsmusters und der p16- Stromafärbung}

Zusätzlich zum p16-Score wurde das Vorhandensein von homogen angefärbten Tumorarealen und der Grad der Stromafärbung in den Rektumresektaten dokumentiert. Eine positive Färbung des stromalen Gewebes ließ sich oftmals direkt an den Karzinomanteil angrenzend beobachten. Die Stromafärbung innerhalb eines Gewebeschnittes war teilweise sehr heterogen verteilt. In den Gewebeschnitten der neoadjuvant behandelten Kohorte AB waren bei hohem RCT-induziertem TRG auch stromale Areale ohne Karzinomanteil stark angefärbt.

\subsubsection{Häufigkeit von homogen angefärbten Tumorarealen im Karzinomanteil des Resektates}

Beim Vergleich der p16-Expressionsmuster, d. h. des Vorhandenseins einer homogenen Anfärbung im Karzinomanteil ergibt sich ein signifikanter Unterschied zwischen den Patientenkohorten: Während in $51,28 \%$ der Gewebeschnitte aus Rektumresektaten der neoadjuvant behandelten Kohorte AB homogen angefärbte Tumoranteile nachweisbar sind, zeigen in den Gewebeschnitten der Kohorte C nur 5,10\% der Rektumresektate homogen gefärbte Karzinomareale ( $<<0,001$; siehe Tabelle 3.1).

Tabelle 3.1: Häufigkeit von homogen angefärbten Tumorarealen im Karzinomanteil des Resektates

\begin{tabular}{|c|c|c|c|c|c|}
\hline \multirow[b]{3}{*}{ Vorbehandlung } & \multicolumn{4}{|c|}{ Expressionsmuster } & \multirow[b]{2}{*}{$\mathrm{p}$-Wert } \\
\hline & \multicolumn{2}{|c|}{ nicht homogen } & \multicolumn{2}{|c|}{ homogen } & \\
\hline & $\mathrm{n}$ & $\%$ & $\mathrm{n}$ & $\%$ & \\
\hline Kohorte $A B$ & 76 & 48,72 & 80 & 51,28 & \\
\hline Kohorte C & 93 & 94,90 & 5 & 5,10 & $<0,001^{*}$ \\
\hline
\end{tabular}

Absolute und relative Verteilung des Vorhandenseins homogen angefärbter Karzinomareale im Resektat abhängig von der Gabe einer Vorbehandlung (Kohorte AB: präoperative RCT, Kohorte C: keine präoperative RCT). *Chi-Quadrat-Test nach Pearson mit Yates' Kontinuitätskorrektur. 


\subsubsection{Korrelation des p16-Expressionsmusters des Resektates mit dem TRG}

Es besteht kein Zusammenhang zwischen dem Vorhandensein von homogenen Anteilen im Karzinomanteil der neoadjuvant behandelten Resektate (Kohorte AB, n=156) und der Höhe des TRG $(\mathrm{p}=0,343 ;$ siehe Tabelle 3.2).

Tabelle 3.2: Korrelation des p16-Expressionsmusters mit dem TRG nach präoperativer RCT

\begin{tabular}{|c|c|c|c|c|c|}
\hline \multirow[b]{3}{*}{ TRG } & \multicolumn{4}{|c|}{ Expressionsmuster } & \multirow[b]{2}{*}{$p$-Wert } \\
\hline & \multicolumn{2}{|c|}{ nicht homogen } & \multicolumn{2}{|c|}{ homogen } & \\
\hline & $\mathrm{n}$ & $\%$ & $\mathrm{n}$ & $\%$ & \\
\hline 0 & 0 & 0 & 0 & 0 & \\
\hline 1 & 16 & 21,05 & 10 & 12,50 & \\
\hline 2 & 29 & 38,16 & 32 & 40,00 & \\
\hline 3 & 31 & 40,79 & 38 & 47,50 & \\
\hline 4 & 0 & 0 & 0 & 0 & $0,3428^{\star}$ \\
\hline
\end{tabular}

Absolute und relative Häufigkeit des Vorhandenseins homogen angefärbter Tumorareale im Karzinomanteil des Resektates abhängig vom TRG in der neoadjuvant behandelten Kohorte AB ( $\mathrm{n}=156)$. *Chi-Quadrat-Test nach Pearson. TRG (Tumorregressionsgrad).

\subsubsection{Häufigkeiten der p16-Stromafärbegrade im Vergleich zwischen den unterschiedlichen Behandlungsgruppen}

Es zeigt sich kein relevanter Unterschied in der Verteilung der Stromafärbegrade der Gewebeschnitte der Rektumresektate in Bezug auf die Art der präoperativen Therapie (Kohorte A, B und C; p=0,714; siehe Tabelle 3.3).

Tabelle 3.3: Häufigkeiten der p16-Stromafärbegrade der Rektumresektate im Vergleich zwischen den unterschiedlichen Behandlungsgruppen

\begin{tabular}{|c|c|c|c|c|c|c|c|}
\hline \multirow[b]{3}{*}{ Stroma } & \multicolumn{6}{|c|}{ Art der Vorbehandlung } & \multirow[b]{2}{*}{$\mathrm{p}$-Wert } \\
\hline & \multicolumn{2}{|c|}{$5-\mathrm{FU}+\mathrm{RT}$} & \multicolumn{2}{|c|}{ 5-FU+Oxaliplatin+RT } & \multicolumn{2}{|c|}{ keine } & \\
\hline & $\mathrm{n}$ & $\%$ & $\mathrm{n}$ & $\%$ & $\mathrm{n}$ & $\%$ & \\
\hline 0 & 5 & 5,3 & 8 & 12,9 & 8 & 8,2 & \\
\hline 1 & 19 & 30,9 & 14 & 22,6 & 27 & 27,6 & \\
\hline 2 & 36 & 38,3 & 25 & 40,3 & 36 & 36,7 & \\
\hline 3 & 24 & 25,5 & 15 & 24,2 & 27 & 27,6 & $0,714^{*}$ \\
\hline
\end{tabular}

*p-Wert nach dem exakten Test nach Fisher. 5-FU (5-Fluorouracil), RT (Radiotherapie). 


\subsubsection{Korrelation der p16-Stromafärbung mit dem p16-Score des Karzinomanteils nach Rektumresektion}

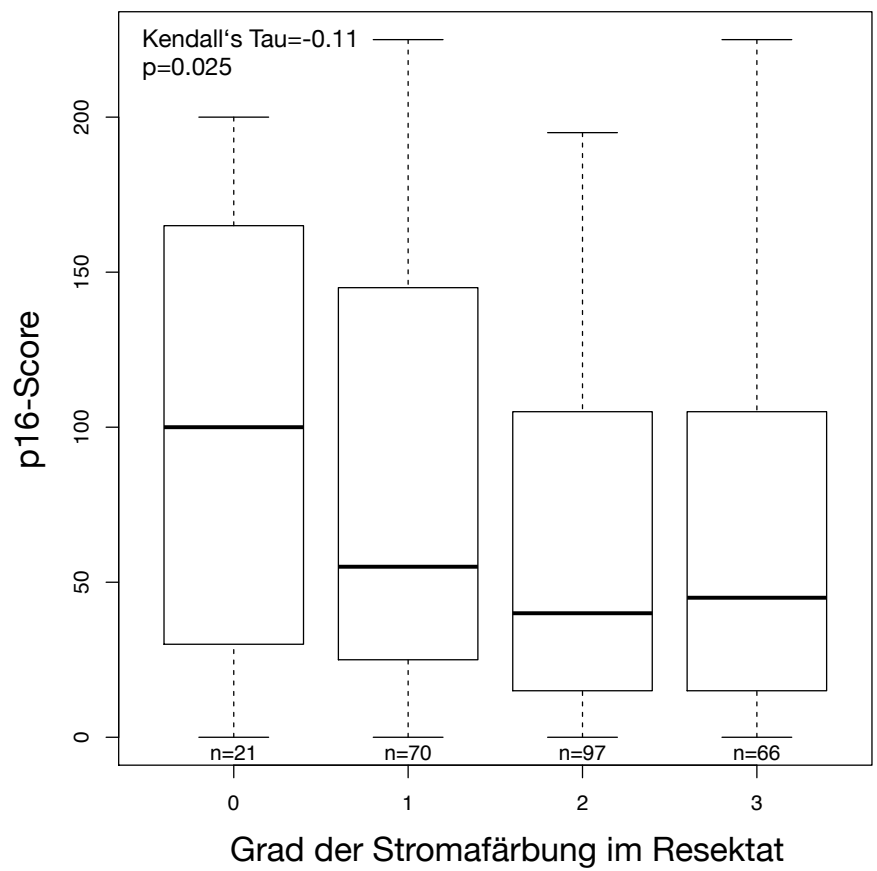

Abbildung 3.15: Korrelation der Stromafärbung mit dem p16-Score des Karzinomanteils der Resektate nach Rektumresektion

Der Grad der Stromafärbung auf den Gewebeschnitten der Rektumresektate korreliert signifikant mit dem p16-Score des Karzinomanteils ( $p=0,025)$. Ein höherer Grad der Stromafärbung geht mit einem niedrigeren p16-Score einher, also einer geringeren Färbung der Karzinomanteile (siehe Abbildung 3.15 und Kapitel 4.1.6). Für die Berechnung des p16-Scores siehe Kapitel 2.6.

\subsubsection{Korrelation der p16-Stromafärbung des Resektates mit dem TRG nach Rektumresektion}

Der Grad der Stromafärbung im Resektat korreliert nicht signifikant mit dem TRG des Resektates $(\mathrm{p}=0,079$; siehe Tabelle 3.4). Es scheint somit kein Zusammenhang zwischen dem am TRG ablesbaren Ansprechen des Rektumkarzinoms auf die neoadjuvante RCT und einer erhöhten p16-Expression in stromalen Zellen zu geben.

Tabelle 3.4: Korrelation der Stromafärbegrade der Resektate mit dem TRG nach neoadjuvanter RCT

\begin{tabular}{|c|c|c|c|c|c|c|c|c|c|c|}
\hline \multirow[b]{3}{*}{ Stromafärbegrad } & \multicolumn{10}{|c|}{ TRG } \\
\hline & \multicolumn{2}{|l|}{0} & \multicolumn{2}{|l|}{1} & \multicolumn{2}{|l|}{2} & \multicolumn{2}{|l|}{3} & \multicolumn{2}{|c|}{4} \\
\hline & $\mathrm{n}$ & $\%$ & $\mathrm{n}$ & $\%$ & $\mathrm{n}$ & $\%$ & $n$ & $\%$ & $n$ & $\%$ \\
\hline 0 & 0 & - & 1 & 7,69 & 4 & 30,77 & 8 & 61,54 & 0 & - \\
\hline 1 & 0 & - & 6 & 13,95 & 15 & 34,88 & 22 & 51,16 & 0 & - \\
\hline 2 & 0 & - & 11 & 18,03 & 26 & 42,62 & 24 & 39,34 & 0 & - \\
\hline 3 & 0 & - & 8 & 20,51 & 16 & 41,03 & 15 & 38,46 & 0 & - \\
\hline
\end{tabular}

Dargestellt ist die absolute und relative Häufigkeit der Stromafärbegrade in Abhängigkeit vom TRG. Die Prozentangaben geben den relativen Anteil der TRGs innerhalb eines Stromafärbegrades an. Kendall's Tau (Rangkorrelationskoeffizient): tau=-0,12460; $\mathrm{p}=0,079$. TRG (Tumorregressionsgrad). 


\subsection{Korrelation der p16-Expression mit Überlebensparametern}

Abschließend wurde die prognostische Bedeutung der p16-Expression anhand der Überlebensparameter TTR und CSS untersucht und exemplarisch dargestellt. In die Überlebensanalysen wurden nur Patienten eingeschlossen, von denen ein Rektumresektat vorlag und der residuelle Karzinomanteil den im Kapitel 2.4 beschriebenen Einschlusskriterien entsprach. Dementsprechend wurde aufgrund fehlenden vitalen Karzinomgewebes kein Patient mit einem TRG 4 eingeschlossen. Diese Patienten haben per se eine exzellente Langzeitprognose (Fokas et al. 2014; Rödel et al. 2005). Zudem wurden Überlebensanalysen allein auf der Grundlage der untersuchten Biopsien wegen der niedrigen Fallzahl $(n=40)$ nicht durchgeführt.

\subsubsection{Korrelation des p16-Scores im Karzinomanteil der Resektate mit Überlebensparametern}

Die p16-Scores aller Resektate wurden anhand des Medianwertes $(47,5)$ in zwei Gruppen, eine mit hoher p16-Expression und eine mit niedriger p16-Expression, unterteilt, die dann mithilfe einer Kaplan-Meier-Kurve miteinander verglichen wurden (siehe Kapitel 2.6). Es gibt keinen Unterschied zwischen der TTR und dem CSS der beiden Gruppen unabhängig davon, ob alle Resektate oder einzelne Kohorten betrachtet werden (TTR: alle Resektate: $p=0,55$; Kohorte AB: $p=0,68$; Kohorte C: $\mathrm{p}=0,54$; CSS: alle Resektate: $\mathrm{p}=0,71$; Kohorte AB: $\mathrm{p}=0,98$; Kohorte $\mathrm{C}: \mathrm{p}=0,65$; siehe Abbildung 3.17). Dementsprechend ergibt sich kein Zusammenhang zwischen dem p16-Score bzw. der p16-Expression der Karzinomzellen und dem Zeitintervall bis zur Diagnose von Fernmetastasen, einem lokoregionären Rezidiv oder dem tumorbedingten Tod.

\subsubsection{Korrelation des p16-Scores (Karzinomanteil/Adenomanteil) mit Überlebensparametern}

Bei der Analyse der p16-Expression der Adenomanteile fiel auf, dass manche Adenome stärker angefärbt waren als die dazugehörigen Karzinomanteile. Diese Beobachtung wird in Abbildung 3.16 exemplarisch dargestellt. Es kann vermutet werden, dass ein (teilweiser) Verlust des Tumorsuppressorproteins p16 im Verlauf der Adenom-Karzinom-Sequenz zu einem aggressiveren biologischen Verhalten des Malignomgeschehens führt (siehe Kapitel 1.2 und Kapitel 1.9.3). Daher wurde analysiert, ob ein im Vergleich zum dazugehörigen Karzinom stärker gefärbter Adenomanteil einen positiven prognostischen Faktor darstellen könnte. Hierzu wurden alle Resektate berücksichtigt, die zusätzlich zum Karzinomanteil auch einen Adenomanteil enthielten und in zwei Gruppen geteilt. Eine Gruppe ( $\mathrm{n}=31)$ bestand aus den Resektaten, in denen der Karzinomanteil einen höheren p16Score aufwies als der Adenomanteil. In der zweiten Gruppe $(\mathrm{n}=25)$ wiederum wies der Adenomanteil entweder einen höheren oder zumindest gleichen p16-Score auf wie der dazugehörige Karzinomanteil. In der Auswertung ergab sich kein signifikanter Unterschied zwischen beiden Gruppen, weder in der TTR noch im CSS ( $\mathrm{p}=0,09$ bzw. $\mathrm{p}=0,25$; siehe Abbildung 3.18). 

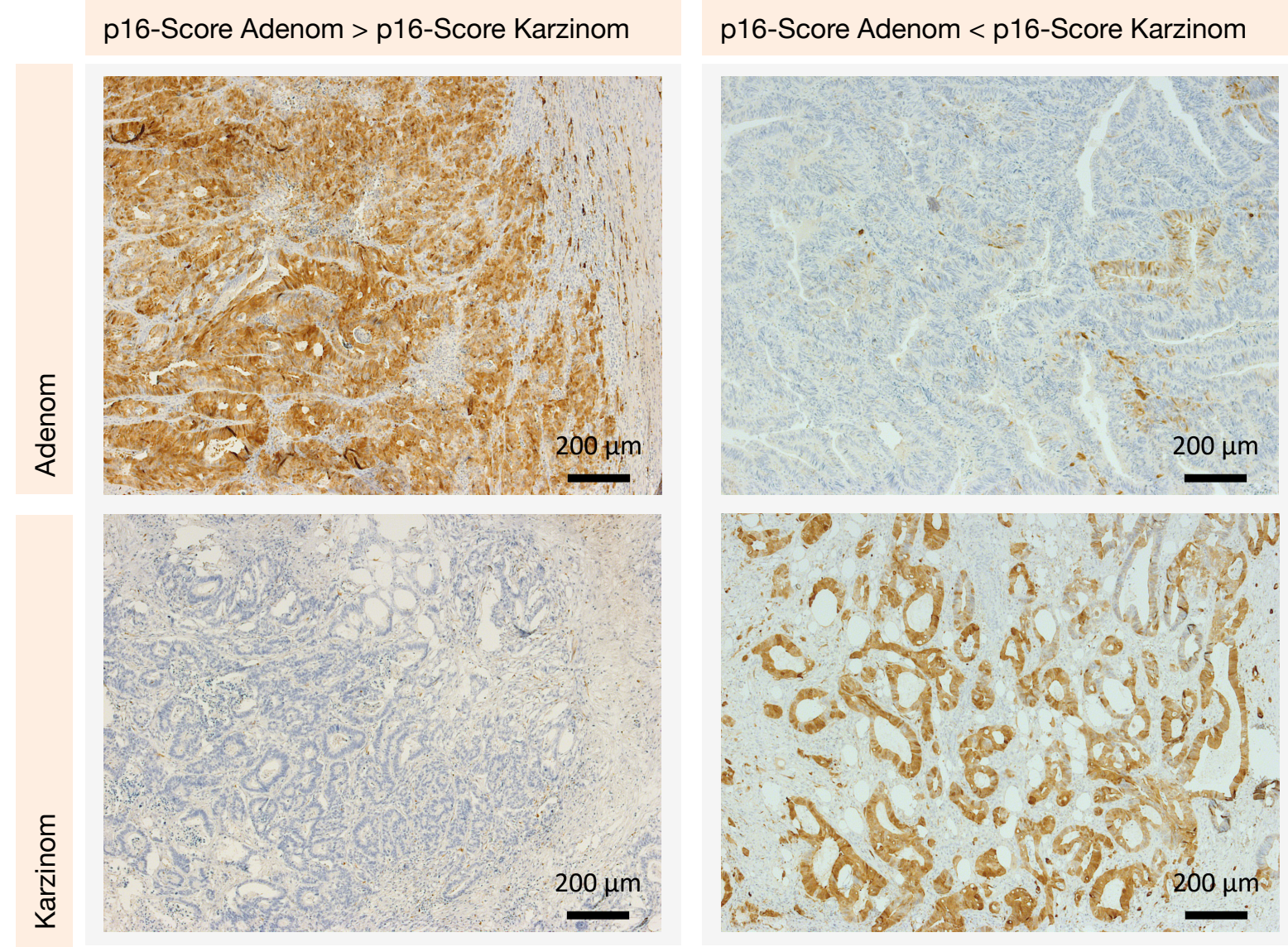

Abbildung 3.16: Vergleich der p16-Expression von Adenom- und korrespondierenden Karzinomanteilen Exemplarische Darstellung an Gewebeschnitten von zwei primär operierten Rektumkarzinomen. Links: high-gradeAdenomanteile mit hohem p16-Score im Vergleich zum Karzinom aus demselben Gewebeschnitt. Rechts: Adenomanteile, nur vereinzelt schwach p16- gefärbt im Vergleich zum korrespondierenden Karzinomanteil aus demselben Gewebeschnitt. 5fache Vergrößerung.

\subsubsection{Korrelation der p16-Stromafärbung mit Überlebensparametern}

Die Stromafärbegrade zeigen keine Korrelation zur TTR ( $\mathrm{p}=0,91$; Abbildung 3.19) oder zum CSS $(\mathrm{p}=0,54$; Abbildung 3.19). Für die Berechnung wurden die vier verschiedenen Stromafärbegrade zu zwei Kategorien zusammengefasst: Stromafärbegrad 0-1 entsprechen einer lichtmikroskopisch gar nicht oder schwer auffindbaren Stromafärbung, Stromafärbegrad 2-3 entsprechen einer sehr leicht auffindbaren Stromafärbung.

\subsubsection{Korrelation des p16-Expressionsmusters des Resektates mit Überlebensparametern}

Innerhalb des Kollektivs der neoadjuvant behandelten Patienten besteht keine signifikante Korrelation zwischen der Präsenz homogen gefärbter Karzinomanteile und der TTR oder dem CSS ( $p=0,41$ bzw. $\mathrm{p}=0,19$; siehe Abbildung 3.20). Allenfalls eine Tendenz für ein besseres CSS $(\mathrm{p}=0,19)$ zeigt sich bei jenen Patienten $(n=80)$, in deren Rektumresektat homogen gefärbte Karzinomanteile nachweisbar waren, gegenüber jenen Patienten mit mosaikartig gefärbten Karzinomanteilen im Rektumresektat ( $\mathrm{n}=76$; siehe Abbildung 3.20). 
(a) Alle Resektate
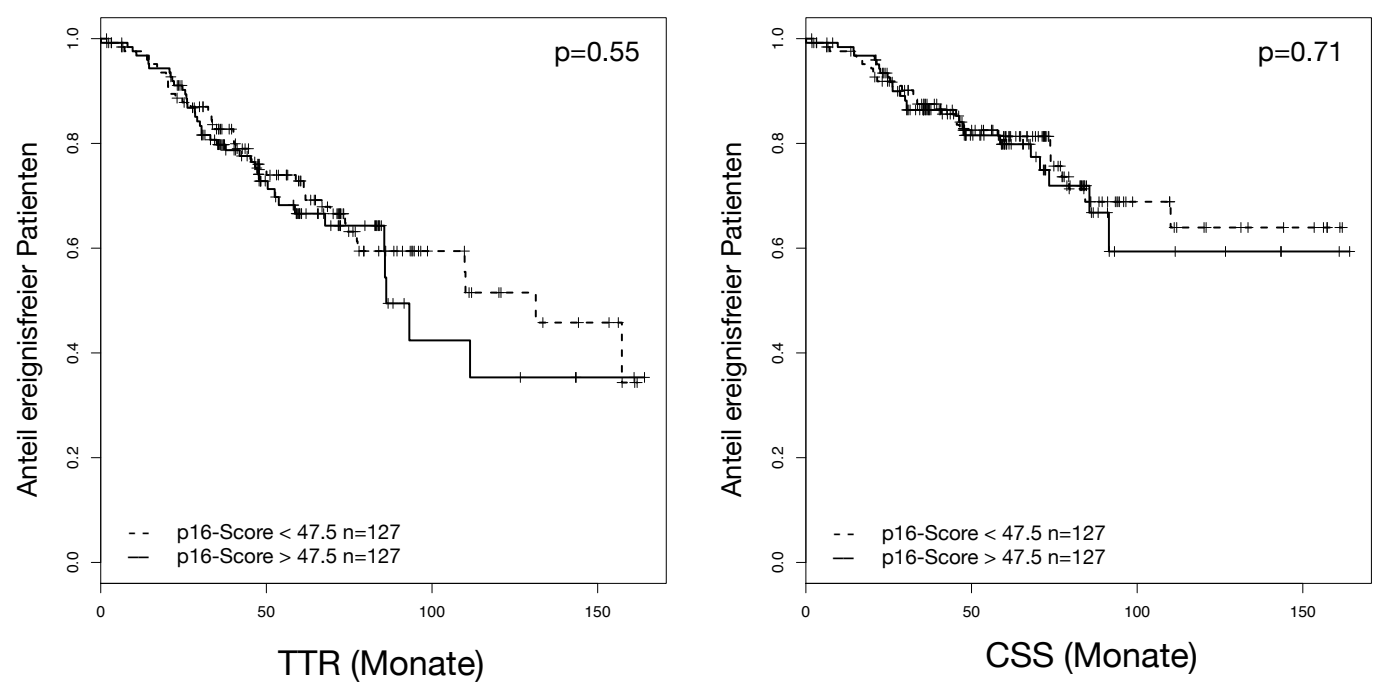

(b) Kohorte $A B$
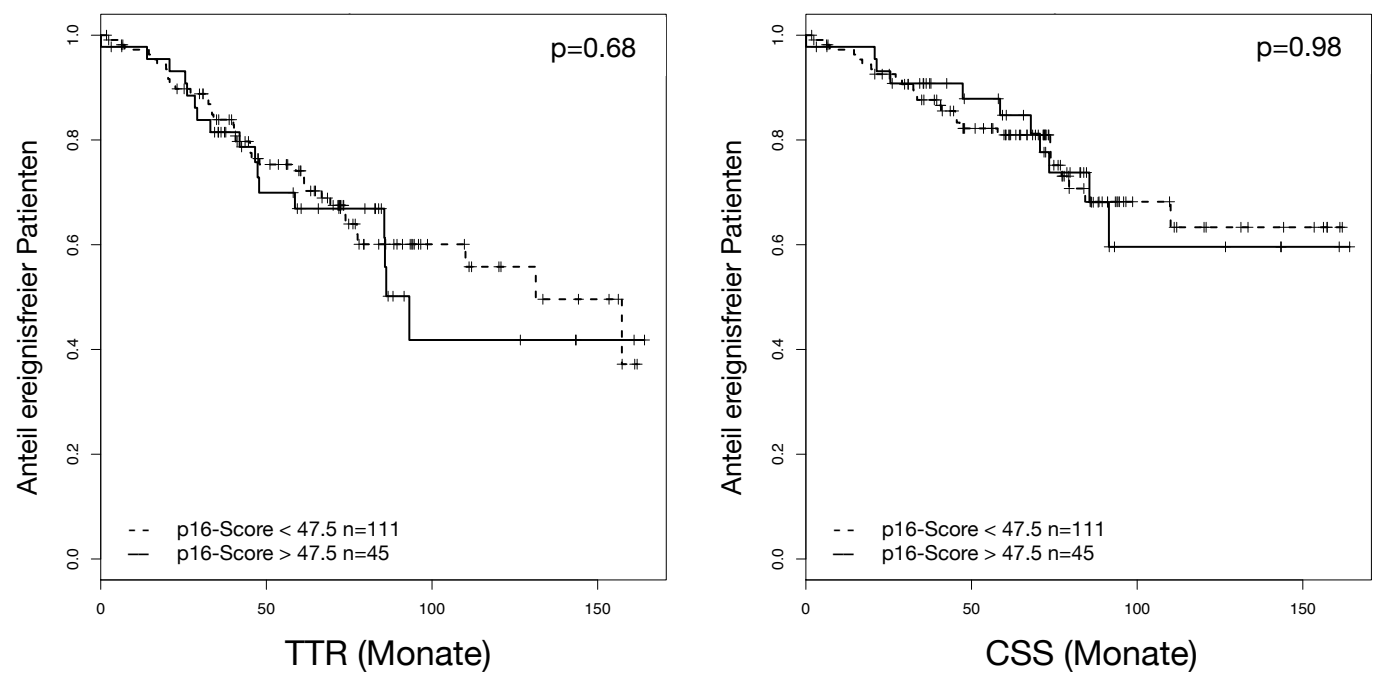

(c) Kohorte C
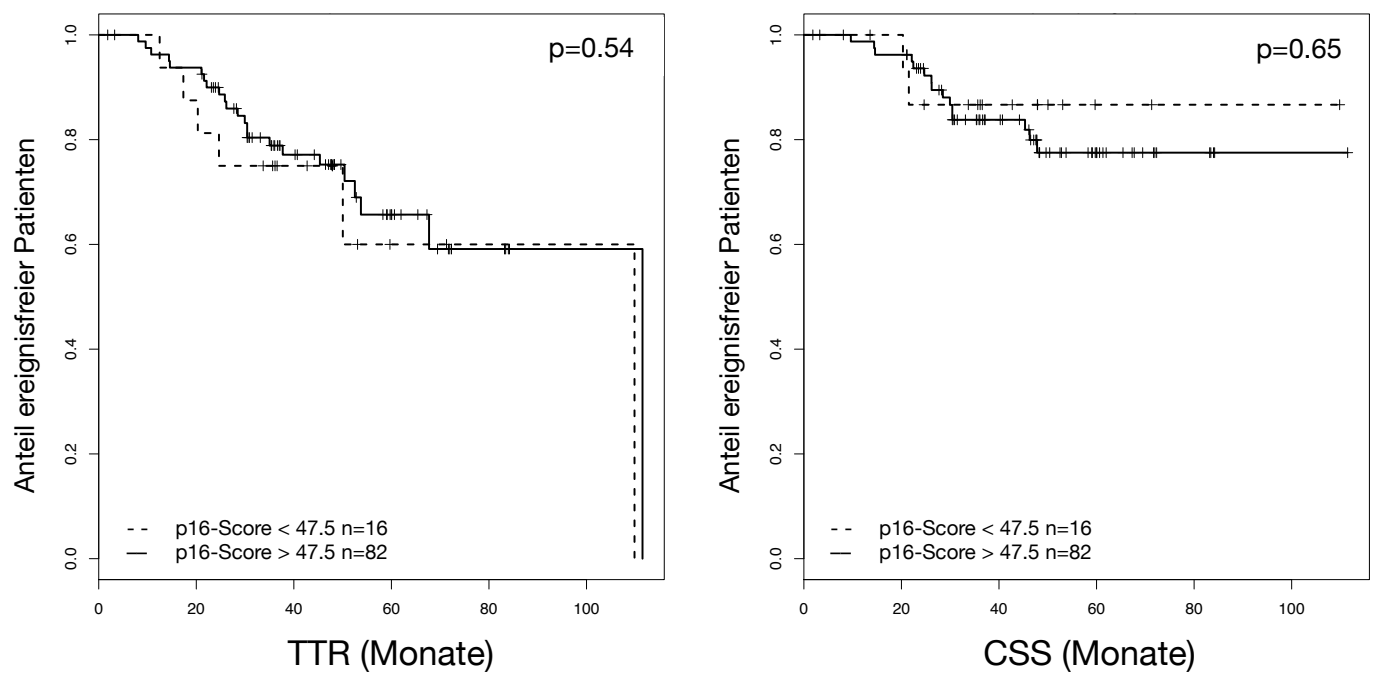

Abbildung 3.17: Korrelation des p16-Scores der Resektate mit TTR und CSS

Links: Time to recurrence (TTR). Rechts: Cancer specific survival (CSS) im Vergleich zwischen hohem und niedrigem p16Score (siehe Kapitel 2.6). Von oben nach unten: (a) Analysen für alle Resektate, (b) Analyse für die Resektate der neoadjuvant behandelten Kohorte AB, (c) Analyse für Patienten ohne neoadjuvante RCT, Kohorte C. 

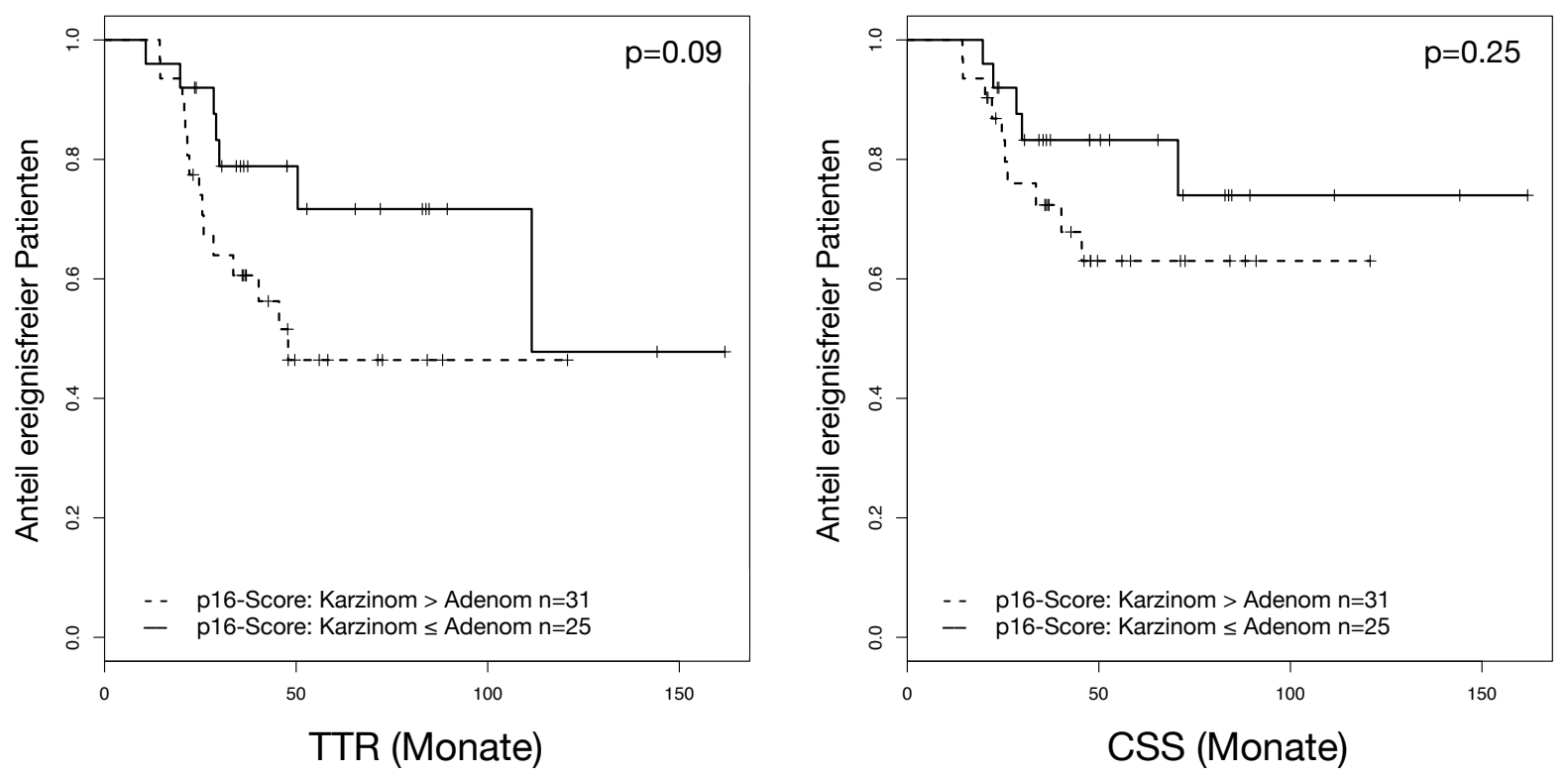

Abbildung 3.18: Korrelation der unterschiedlichen Gruppen der Resektate mit Adenom- und Karzinomanteil mit den Überlebensparametern TTR und CSS

Time to recurrence (TTR) und cancer specific survival (CSS) im Vergleich zwischen der Gruppe von Resektaten, deren Adenomanteil eine geringere p16-Expression als der dazugehörige Karzinomanteil aufwies $(n=31)$ und der Gruppe von Resektaten, deren Karzinomanteil einen geringeren oder gleichen p16-Score wie der dazugehörige Adenomanteil aufwiesen $(n=25)$.
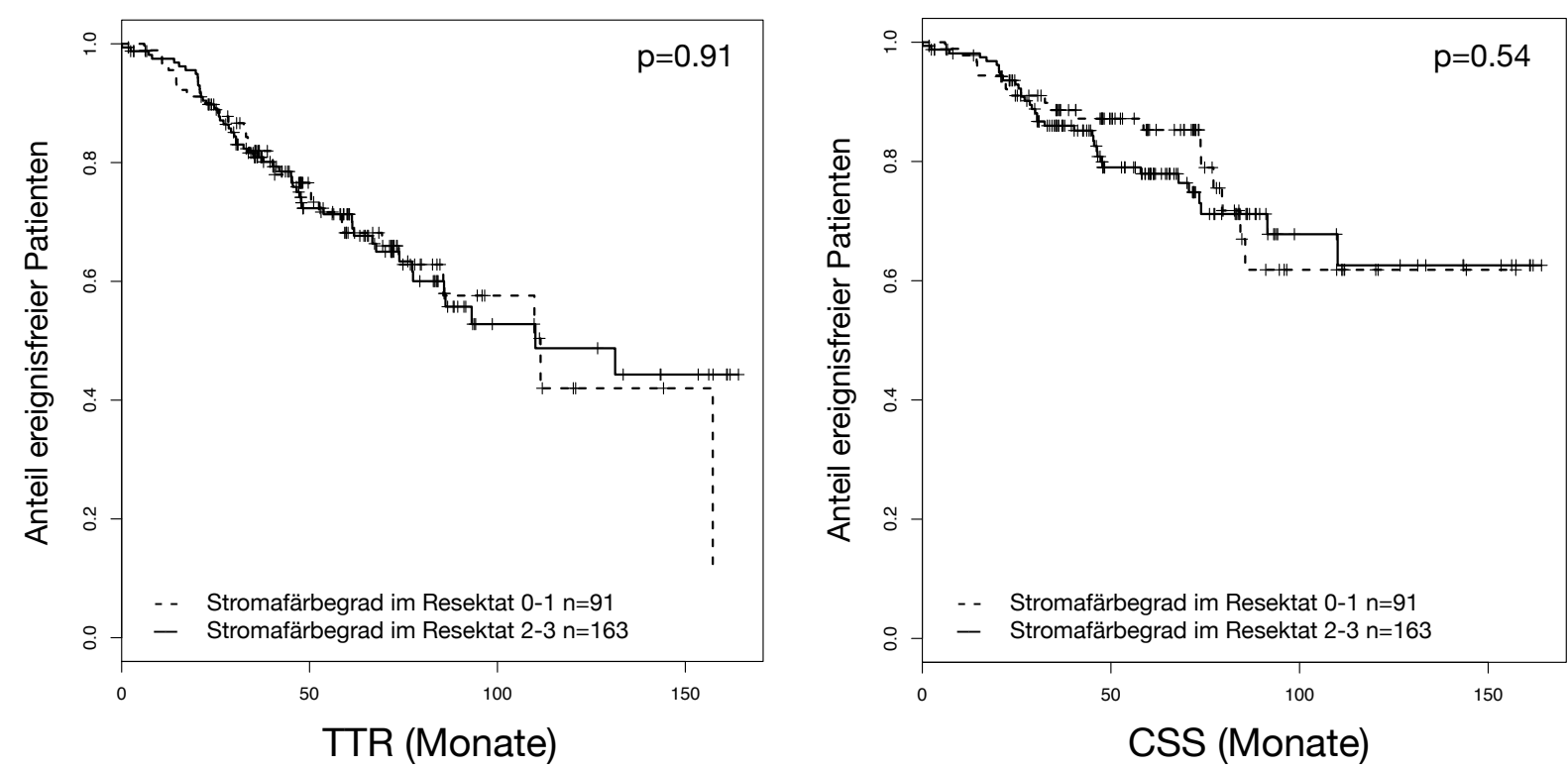

Abbildung 3.19: Korrelation der Stromafärbung des Resektates mit den Überlebensparametern TTR und CSS

Time to recurrence (TTR) und cancer specific survival (CSS) im Vergleich zwischen niedrigen (Grad 0-1) und hohen Stromafärbegraden (Grad 2-3) innerhalb der Gesamtkohorte aller Rektumresektate (Kohorte AB und C). 

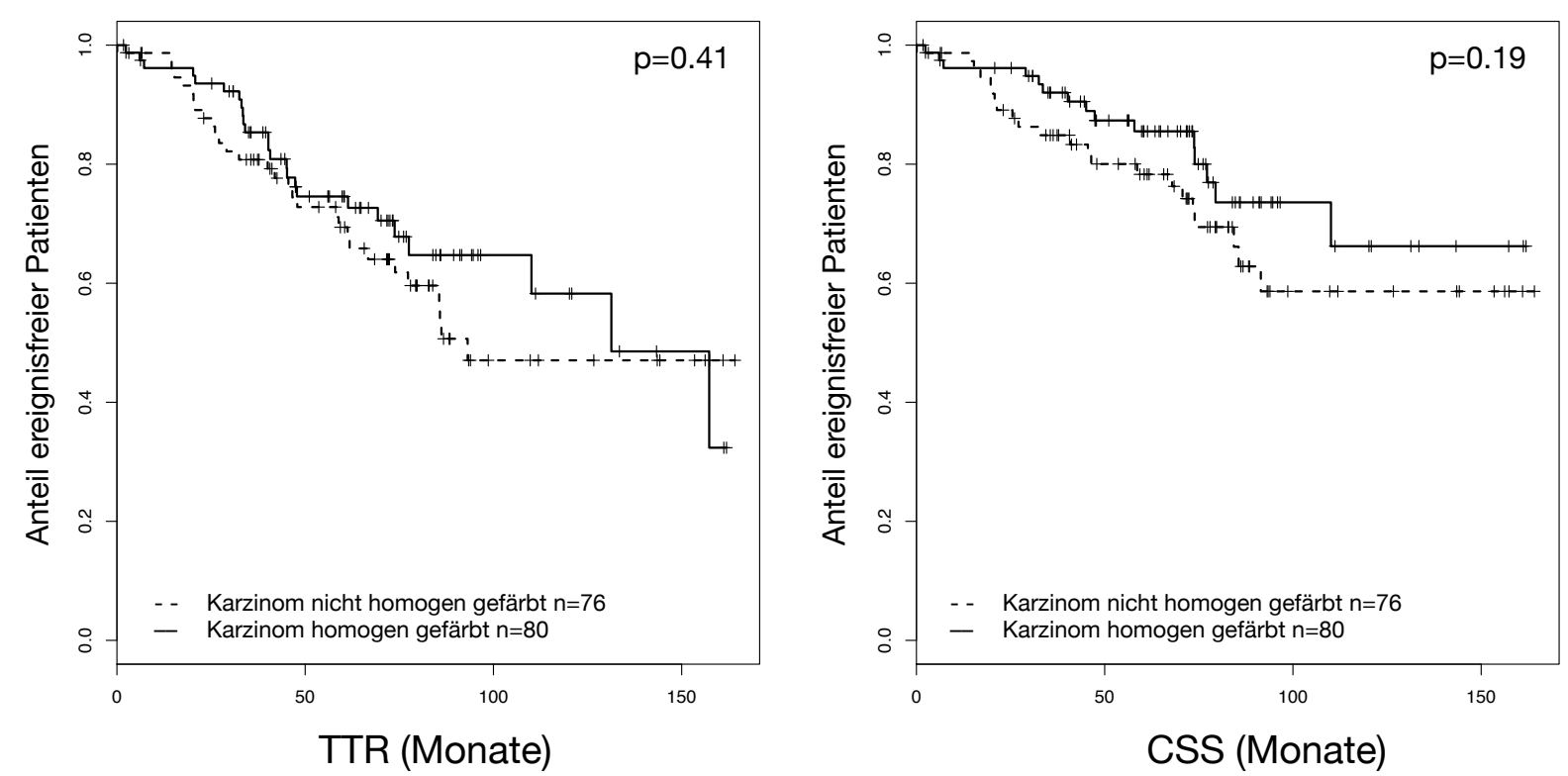

Abbildung 3.20: Vergleich von TTR und CSS zwischen Patienten mit und ohne homogen gefärbte Karzinomanteile

Time to recurrence (TTR) und cancer specific survival (CSS) im Vergleich zwischen den Gruppen mit oder ohne homogenen Karzinomanteil in der neoadjuvant behandelten Gruppe der Resektate (Kohorte AB). 


\section{Diskussion}

\section{1 p16 im kolorektalen Karzinom}

Im Folgenden werden die dargestellten Methoden und Ergebnisse im Zusammenhang mit bereits veröffentlichten Forschungsergebnissen (PubMed-Recherche, Stand: April 2016, siehe Anhang, Tabelle 6.1) diskutiert. Abschließend wird ein Ausblick auf mögliche klinische Anwendungen der p16-Immunhistochemie beim Rektumkarzinom gegeben.

\subsubsection{Vergleichbarkeit von Untersuchungen zur p16-Expression im KRK}

Fast alle im Folgenden diskutierten Studien legen zur Auswertung der p16-Expression allein die nukleäre Färbung zugrunde. Das ebenfalls angefärbte Zytoplasma (siehe Kapitel 2.3) wurde nicht in die Analyse einbezogen (siehe Übersicht in Abbildung 4.2, z. B. Kriegl et al. (2011), Cui et al. (2004), Tada et al. (2003), Shima et al. (2011)). Viele der Studien teilen die Karzinomgewebe anhand des prozentualen Anteils der angefärbten Zellen in Gruppen ein, die sie miteinander vergleichen (siehe Übersicht in Abbildung 4.1., z. B. Kamoshida et al. (2004b), Lam et al. (2008)). Ähnlich wie die vorliegende Dissertation analysieren vier Studien nicht nur den positiven prozentualen Tumoranteil, sondern auch die Färbeintensität der Zellen. Die Arbeiten bestimmen jedoch die Färbeintensität des Präparates allgemein, d.h. einem Präparat wurde nur eine Färbeintensität zugeordnet (Deschoolmeester et al. 2010; Jie et al. 2007; Wassermann et al. 2009; Zhao et al. 2003). Nur zwei Arbeitsgruppen nehmen die Unterteilung in Gruppen anhand des immunhistochemischen Expressionsmusters vor (Kriegl et al. 2011; Tada et al. 2003). Eine Übersicht über die unterschiedlichen Analyseverfahren zeigt die Abbildung 4.2.

Selbst unter den Arbeiten, die ihre Analysen anhand des prozentual gefärbten Tumoranteils vornehmen, gibt es große Unterschiede. Einige vergleichen dichotom zwischen „hoher“ und „niedriger“ p16-Expression, die jeweiligen cut-offs unterscheiden sich allerdings. Andere Arbeitsgruppen teilen die gefärbten Resektate in mehr als zwei Gruppen auf, wobei die Anzahl der Gruppen und die Grenzen zwischen den verschiedenen Untersuchungsgruppen ebenfalls sehr uneinheitlich sind. Eine Übersicht über die unterschiedlich gesetzten Prozentgrenzen des gefärbten Tumoranteils und die Einteilung in dadurch resultierende Gruppen von Resektaten ist in Abbildung 4.1 dargestellt. Nur zwei der Arbeitsgruppen analysierten den gefärbten Tumoranteil, wie die hier vorliegende Dissertation, kontinuierlich bzw. in 5 \%-Schritten (Dai et al. 2000; Jung et al. 2001). 


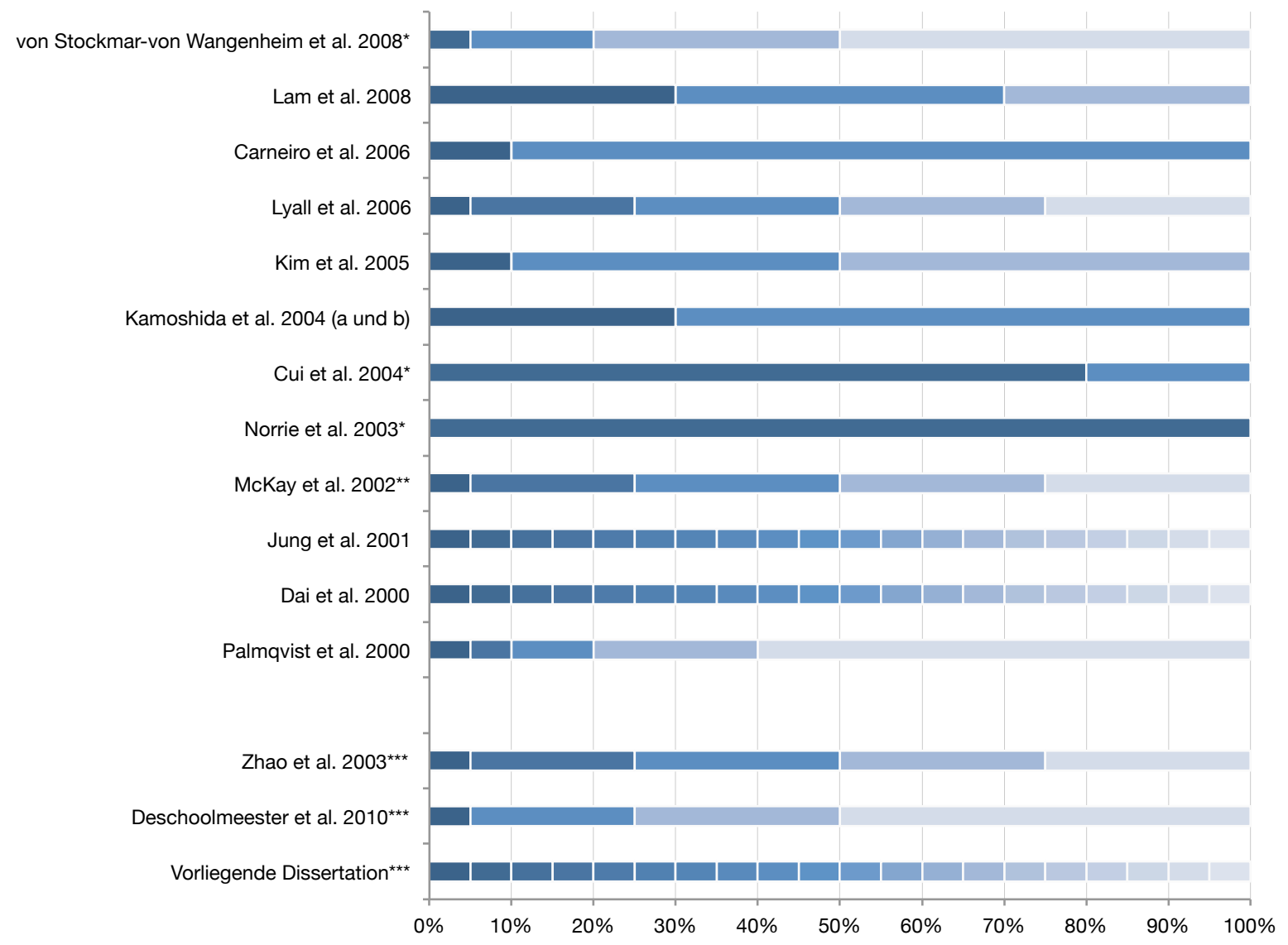

Abbildung 4.1: Darstellung verschiedener Auswertungsmodelle der p16-Expression anhand des prozentual gefärbten Tumoranteils

Aufgeführt sind die Arbeiten, die den immunhistochemisch gefärbten Tumoranteil (semi-)quantitativ analysieren. *Zusätzlich zu den aufgeführten Einteilungen besteht noch eine Gruppe mit $0 \%$ Färbung. **Zuerst Einteilung in fünf verschiedene Expressionsgruppen, in der statistischen Analyse erfolgte eine dichotome Einteilung ***In diesen drei Arbeiten wurde ein Score aus gefärbtem Tumoranteil und Färbeintensität ermittelt. Dargestellt ist nur die semiquantitative Einteilung des positiven Tumoranteils.

In den bisher vorliegenden Arbeiten bestehen erhebliche Unterschiede in der immunhistochemischen Auswertung der p16-Expression. Allein eindeutig hohe bzw. besonders niedrige p16-Expressionen erlauben eine begrenzte Vergleichbarkeit der Ergebnisse. Folglich ist ein einheitlicher Bewertungsscore $\mathrm{zu}$ fordern, mit dessen Hilfe die p16-Expression tatsächlich sinnvoll studienübergreifend verglichen werden kann. Die Anforderungen an den Score beinhalten eine klare Systematik in der methodischen Vorgehensweise und eine gute Reproduzierbarkeit, die möglichst in Panelbefundungen durch mehrere Pathologen verblindet evaluiert wird, wie dies beispielhaft bei der Etablierung des HER-2-Scores (Human epidermal growth factor receptor 2; beim Magen- und Rektumkarzinom) erfolgte (Bang et al. 2010; Conradi et al. 2013; Rüschoff et al. 2010; Styczen et al. 2015).

In der vorliegenden Dissertation wird ein p16-Score genutzt, der sowohl das Ausmaß des gefärbten Tumoranteils als auch die Färbeintensität der positiv gefärbten Tumoranteile berücksichtigt (siehe Kapitel 2.6). Im Ergebnisteil der Dissertation wird die Verteilung des p16-Scores der Verteilung des prozentualen positiv gefärbten Tumoranteils gegenübergestellt (siehe Abbildung 3.2). Es zeigt sich, 
dass mit dem p16-Score die Gesamtmenge des im Tumor vorhandenen Proteins besser abgebildet werden kann. Davon ausgehend, dass mit einer größeren Menge p16 auch eine vermehrte tumorsuppressorische Funktion des Proteins einhergeht, bietet sich der p16-Score aufgrund seiner Aussagekraft für mögliche klinische Anwendungsmöglichkeiten, z. B. zur Therapiestratifizierung an.

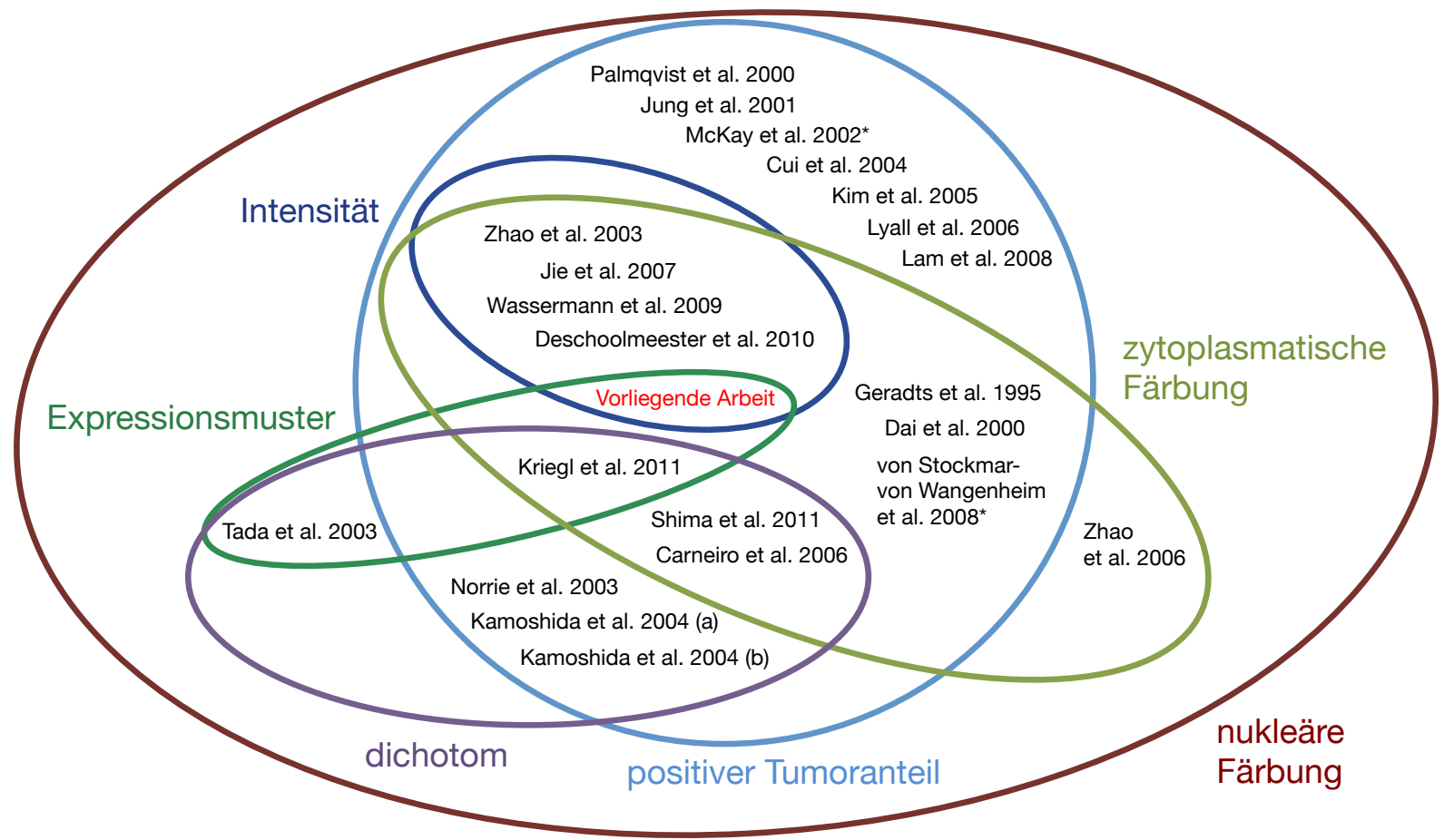

Abbildung 4.2: Visualisierung der unterschiedlichen Auswertungsmethoden der immunhistochemischen p16-Färbung

Eigene Darstellung. Die Abbildung gibt einen Überblick über bisherige Veröffentlichungen zur p16-Färbung und deren Untersuchungsschwerpunkte (siehe Anhang, Tabelle 6.1). Jede farbige Ellipse beinhaltet die Erstautoren der Studien, die das in derselben Farbe dargestellte Kriterium angewandt haben. Eine Arbeit, die mehrere Kriterien angewandt hat, befindet sich daher in mehreren Ellipsen. Die Größe der Ellipsen hat keine inhaltliche Bedeutung. *Ursprünglich detaillierte Einteilung der p16-Färbung anhand des gefärbten Tumoranteils, allerdings erfolgte die statistische Analyse nur mit dichotomer Einteilung.

\subsubsection{Zytoplasmatische p16-Färbung}

Die überwiegende Mehrheit der bisherigen Publikationen beschreibt sowohl eine zytoplasmatische als auch eine nukleäre p16-Färbung (Carneiro et al. 2006; Cui et al. 2004; Deschoolmeester et al. 2010; Kim et al. 2005; Kriegl et al. 2011; Lam et al. 2008; McKay et al. 2002; Norrie et al. 2003; Palmqvist et al. 2000; Tada et al. 2003; von Stockmar-von Wangenheim et al. 2008; Zhao et al. 2003; Zhao et al. 2006). Die Hälfte der Veröffentlichungen wertet allerdings nur die nukleäre Färbung der Tumorzellen aus, teilweise mit der Begründung, dass p16 funktionell nur im Zellkern relevant sei (siehe Übersicht in Abbildung 4.2, z. B. Palmqvist et al. (2000)). Von anderen Tumorentitäten und zellzyklusregulierenden Proteinen ist bekannt, dass eine zytoplasmatische Lokalisation der Proteine durchaus Auswirkungen auf klinisch-pathologische Parameter haben kann. So ist z. B. eine hohe zytoplasmatische p16-Expression im Mammakarzinom mit schnellerer Tumorprogression verbunden (Emig et al. 1998). In gastrointestinalen Stromatumoren ist eine hohe zytoplasmatische p16Expression mit einem signifikant kürzeren DFS assoziiert (Haller et al. 2010). Im KRK ist eine zusätzliche zytoplasmatische p53-Expression mit einem schlechteren OS vergesellschaftet als eine 
rein nukleäre p53-Expression (McKay et al. 2002). Diese Beispiele zeigen, dass zytoplasmatische Färbungen von vorwiegend nukleären Proteinen nicht immer als unwichtig oder als Artefakt eingestuft werden können, sondern bei den Analysen berücksichtigt werden sollten (McKay et al. 2002). In der hier vorliegenden Dissertation wird die p16-Färbung in ihrer Gesamtheit im Zytoplasma und im Nukleus berücksichtigt, wie dies z. B. auch Carneiro et al. (2006), Dai et al. (2000), Deschoolmeester et al. (2010), Jie et al. (2007) und Wassermann et al. (2009) taten. Die Ähnlichkeit der Intensität von nukleärer und dazugehöriger zytoplasmatischer p16-Positivität wird, wie in der vorliegenden Arbeit, auch explizit in zwei weiteren Veröffentlichungen erwähnt (Cui et al. 2004; Palmqvist et al. 2000). Im Unterschied dazu beschreiben Zhao et al. (2006) auch eine rein zytoplasmatische Färbung von Tumorzellen ohne nukleäre Färbung, die mit dem Voranschreiten der Adenom-Karzinom-Sequenz zunähme, sodass in der zytoplasmatischen p16-Expression ein früher Biomarker für die Entartung von Darmepithelzellen zu sehen sei (Zhao et al. 2006). Diese Aussage kann von den Ergebnissen der vorliegenden Arbeit, mit den umfassenden p16-Expressionsanalysen an normalen Darmepithel, an Adenomen und Karzinomen, nicht bestätigt werden. Eine rein zytoplasmatische p16-Färbung konnte nur in vernachlässigbar wenigen Zellen bei wenigen Tumoren beobachtet werden (siehe Kapitel 3). Die Autoren Zhao et al. (2003) sehen in der von ihnen beobachteten fast ausschließlich zytoplasmatischen Lokalisation von p16 einen Funktionsverlust des Tumorsuppressorproteins als Zeichen der Tumorentstehung. Andere Arbeitsgruppen deuten die zytoplasmatische Färbung hingegen als Zeichen einer ausgeprägten p16-Überexpression, vermuten dabei aber ebenfalls, dass die veränderte Lokalisation in der Zelle zur Pathogenese des KRK beitragen kann (Deschoolmeester et al. 2010; Lam et al. 2008).

Die aberrante p16-Lokalisation im Zytoplasma ist in ihrer Ätiologie noch nicht vollständig geklärt. Geradts et al. (1995) nahmen an, dass es sich bei der zytoplasmatischen Färbung um eine unspezifische Anfärbung handelte. Später konnte beobachtet werden, dass die Intensität der zytoplasmatischen Färbung von dem jeweils genutzten Antikörper und der Fixierung des Gewebes abhängig war, wobei auch Überlegungen aufkamen, dass p16 als leichtes Molekül (16kDa) auch in das Zytoplasma diffundieren und somit spezifisch dort nachgewiesen werden könnte (Ressler et al. 2006; Sawicka et al. 2013). Nilsson und Landberg zeigten 2006, dass p16 sowohl nukleär als auch zytoplasmatisch exprimiert wird und in den verschiedenen Kompartimenten in unterschiedlichen posttranslationalen p16-Modifikationen vorliegt, die beide Komplexe mit CDK4/6 bilden können. Die Arbeitsgruppe bewies letzlich, dass die immunhistochemische zytoplasmatische Darstellung von p16 spezifisch ist (Nilsson und Landberg 2006). Es wird mittlerweile angenommen, dass p16 im Zytoplasma mit anderen Proteinen interagiert und auch dort eine tumorsuppressorische Wirkung entfalten kann, indem es die Angiogenese und Zellinvasion hemmt (Romagosa et al. 2011). Wie das p16-Protein in das Zytoplasma gelangt, ist noch nicht abschließend geklärt. Diskutiert werden derzeit ein Transport des p16-CDK4/6-Komplexes über die Zellkernmembran, ein mutiertes p16, das durch 
die nukleäre Membran diffundiert, oder eine posttranslationale p16-Modifikation, die den Übergang in das Zytoplasma ermöglicht (Nilsson und Landberg 2006).

\subsection{3 p16-Expression im normalen Darmepithel}

Das normale Darmepithel wies in 96,4 \% der Fälle einen geringen p16-positiven Anteil (0\% oder 5\%) auf (siehe Kapitel 3.2). Übereinstimmend mit diesem Ergebnis beschrieben Kim et al. (2005), dass in ihren Untersuchungen weniger als $5 \%$ des normalen Darmepithels nukleär positiv angefärbt waren. Auch Zhao et al. (2003) fanden im normalen Darmepithel ebenfalls nur eine schwache nukleäre und moderate zytoplasmatische Färbung. Einige Veröffentlichungen berichten im normalen Epithel des Kolons und des Rektums über nahezu keine nennenswerte immunhistochemische Anfärbbarkeit von p16 (Carneiro et al. 2006; Kriegl et al. 2011; Lam et al. 2008). Andere Autoren hingegen beschreiben, übereinstimmend mit den Beobachtungen dieser Arbeit, vereinzelte p16-positiv angefärbte Zellen in den Krypten (siehe Abbildung 3.5) (Cui et al. 2004; Dai et al. 2000; Kamoshida et al. 2004a; Kamoshida et al. 2004b; Norrie et al. 2003; Palmqvist et al. 2000; Tada et al. 2003). Dai et al. (2000) mutmaßen hierbei, dass die wenigen Zellen, die in den Krypten p16 exprimieren, besonders anfällig für eine Entartung zu einem Darmkarzinom sein könnten. Insgesamt besteht jedoch Konsens, dass p16 im normalen Darmepithel nur wenig bis überhaupt nicht exprimiert wird.

\subsection{4 p16-Expression im Adenomanteil}

In dieser Arbeit wurden neben den Karzinomanteilen auch in 56 Fällen auf dem Gewebeschnitt mitabgebildete oberflächliche Adenomanteile der Tumoren analysiert. Von diesen 56 Fällen wiesen nur $5(8,9 \%)$ keine p16-Positivität auf (siehe Abbildung 3.4). Die Adenomanteile der primär operierten Rektumtumoren zeigten keinen höheren p16-Score als die dazugehörigen Karzinomanteile $(\mathrm{p}=0,857$; siehe Abbildung 3.8). Innerhalb der Kohorte der neoadjuvant behandelten Karzinome (Kohorte AB) waren die p16-Scores der invasiven Tumoranteile signifikant höher als die p16-Scores der Adenomanteile ( $\mathrm{p}=0,027$; siehe Abbildung 3.8).

Fünf Publikationen beschäftigen sich gezielt mit der p16-Expression von Adenomen (Carneiro et al. 2006; Dai et al. 2000; Kriegl et al. 2011; Tada et al. 2003; Zhao et al. 2006). Die Ergebnisse von Kriegl et al. (2011) werden im folgenden Ergebnisvergleich allerdings vernachlässigt, da es sich um eine spezielle Fallsammlung von BRAF-mutierten Adenomen und pT1-Karzinomen in sehr geringer Anzahl $(n=5)$ handelt. Carneiro et al. (2006) beschreiben $20 \%$ der von ihnen untersuchten Adenome als p16-positiv (definiert als: $>10 \%$ des Adenoms ist positiv gefärbt). Die Autoren fanden keine Korrelation zwischen der p16-Expression und dem Dysplasie-Grad oder der histologischen Klassifizierung (villös, tubulär, tubulovillös). Zudem ergab sich, wie in der vorliegenden Arbeit, ebenfalls kein signifikanter Unterschied in der p16-Positivität zwischen primär operierten Adenomen und Karzinomen (Carneiro et al. 2006). Im Gegensatz dazu beobachteten Tada et al. (2003) und Dai et al. (2000), dass Karzinome signifikant häufiger p16-positiv waren als Adenome. Zhao et al. (2006) 
beschrieben in den Karzinomen eine höhere zytoplasmatische p16-Färbung als in den dazugehörigen Adenomen (Zhao et al. 2006).

\subsubsection{Verlust der p16-Expressionsfähigkeit während der Adenom- Karzinom-Sequenz}

In den eigenen Untersuchungen an Gewebeschnitten fiel auf, dass unabhängig von einer neoadjuvanten Behandlung in einigen Fällen oberflächliche Adenomanteile im Vergleich zum invasiven Tumoranteil sehr stark angefärbt waren. Ebenso gab es Gewebeschnitte, in denen die Adenomanteile schwach und mosaikartig, der dazugehörige Karzinomanteil aber stärker angefärbt war (siehe Abbildung 3.16). Theoretisch ist zu erwarten, dass Patienten eine ungünstigere Tumorprognose aufweisen, sofern die Fähigkeit ihres Tumors, p16 zu exprimieren, beim Voranschreiten der AdenomKarzinom-Sequenz abgenommen hat. Um diese Vermutung zu überprüfen, wurden alle Tumoren mit Adenom- und Karzinomanteilen in zwei Gruppen aufgeteilt: eine Gruppe, in der der p16-Score des Adenoms genauso hoch oder höher war als der des Karzinoms und eine zweite Gruppe, in der der p16Score des Adenoms geringer war als der des Karzinoms. Die Überlebensparameter TTR und CSS beider Gruppen wurden berechnet und graphisch gegeneinander aufgetragen. Es zeigte sich für keine der beiden Gruppen ein signifikanter Überlebensvorteil ( $p=0,09$ bzw. $p=0,25$; siehe Abbildung 3.18). Anders als erwartet lässt sich daher vermuten, dass der teilweise erhebliche p16-Verlust beim Voranschreiten der Adenom-Karzinom-Sequenz keinen prognostischen Nachteil für die betroffenen Patienten darstellt.

\subsection{5 p16-Expression im nicht vorbehandelten primären kolorektalen Karzinom}

Die Rate an immunhistochemisch p16-positiv beurteilten Rektumkarzinomen liegt in dieser Arbeit in der primär operierten Kohorte C bei $92,9 \%$ (definiert als $\geq 5 \%$ des Karzinomanteils positiv gefärbt bzw. p16-Score $>0$, siehe Kapitel 3.3). In der Literatur werden in den Analysen Rektum- und Kolonkarzinome nicht gesondert betrachtet. Die Rate an p16-positiven KRK liegt je nach Studie bei $38 \%$ (Cui et al. 2004), 73,9 \% (McKay et al. 2002), $74 \%$ (Deschoolmeester et al. 2010), $75 \%$ (Shima et al. 2011), 81,5\% (Palmqvist et al. 2000), 91,9\% (Norrie et al. 2003), $94 \%$ (von Stockmar-von Wangenheim et al. 2008), 96,4\% (Kim et al. 2005), $98 \%$ (Tada et al. 2003), oder 98,6\% (Zhao et al. 2003). Somit ist eine im Gegensatz zum normalen Mucosaepithel stark erhöhte p16-Expression im primär operierten KRK die Regel. Die Unterschiede der Rate an p16-positiven Karzinomen zwischen den einzelnen Arbeiten beruhen u. a. auf unterschiedlichen Auswertungsverfahren der Immunhistochemie, z. B. der unterschiedlichen Definition von „,negativer“ und „positiver“ Färbung. In geringerem Maße könnte auch die Nutzung unterschiedlicher Antikörper zu den Unterschieden beigetragen haben.

Im Umkehrschluss zu den oben genannten Raten weisen dementsprechend KRK in Prozentsätzen von $1,4 \%$ (Zhao et al. 2003) bis $62 \%$ (Cui et al. 2004) eine negative p16-Färbung auf. Als Ursache für 
diesen p16-Verlust wird im KRK die Promotor-Hypermethylierung des CDKN2A-Gens verantwortlich gemacht, die laut Meta-Analyse in rund $23 \%$ der KRK nachgewiesen werden kann (Burri et al. 2001; Kamb et al. 1994; Okamoto et al. 1994; Xing et al. 2013).

\subsection{6 p16-Expression des Stromas}

Einige Publikationen berichten neben der immunhistochemischen Anfärbung der Darmepithelzellen auch über eine sporadische Anfärbung von stromalen Zellen wie Makrophagen, Fibroblasten und sogar Endothelzellen (Geradts et al. 1995; Kamoshida et al. 2004a; Kamoshida et al. 2004b; Norrie et al. 2003; Shima et al. 2011). Zum Teil werden in diesen Arbeiten die intensiv angefärbten Stromazellen als interne Positiv-Kontrolle genutzt und somit die stromale Färbung als spezifisch gewertet (Geradts et al. 1995; Norrie et al. 2003; Shima et al. 2011; Tada et al. 2003).

Die vorliegende Arbeit wertet erstmals die Färbung des Stromas gezielt aus. Die Häufigkeit und die Verteilung der Stromafärbung war in allen drei Kohorten ähnlich ( $\mathrm{p}=0,717$, siehe Tabelle 3.3.). Demzufolge scheint die Stromafärbung von einer neoadjuvanten RCT unbeeinflusst zu sein. Der Färbegrad des Stromas korrelierte unabhängig von der Vorbehandlung des Resektates mit dem Patientenalter ( $\mathrm{p}=0,02$, siehe Kapitel 3.5.1). Dieses Ergebnis entspricht Untersuchungen zur p16Expression an menschlicher Haut, in denen die Anzahl der p16-positiv-gefärbten Zellen der Dermis signifikant mit dem Patientenalter korrelierte (Ressler et al. 2006). In Gewebeschnitten der Rektumresektate war auffällig, dass jeweils nur einige Zellen des Stromas angefärbt waren und diese Zellen sich häufig in direkter Nähe zu Tumorzellclustern befanden. Die immunhistochemischen Färbungen auf Aktin, Vimentin und CD68 ergaben, dass es sich bei den im Stroma angefärbten Zellen wahrscheinlich um Makrophagen und Fibroblasten handelte (siehe Abbildung 4.3). Für eine genauere Abklärung der betroffenen Zellpopulationen sollten weitere, über die hier vorliegende Arbeit hinausgehende Analysen erfolgen.

Die p16-Expression des Stromas ist kein prognostischer Marker. Zwar zeigen Resektate mit einem höheren TRG auch eine höhere Stromafärbung. Diese Beobachtung ist jedoch nicht signifikant $(\mathrm{p}=0,08$; siehe Tabelle 3.4). Die Patientengruppe mit geringer Stromafärbung zeigt gegenüber der Gruppe mit einer starken Stromafärbung keinen Überlebensvorteil (siehe Abbildung 3.19). Dieser mögliche Überlebensvorteil war aufgrund der tumorfördernden Wirkung von seneszenten Fibroblasten durch ihren SASP (siehe Kapitel 1.9.1 und 4.1.14) erwartet worden (Krtolica und Campisi 2002).

In dieser Arbeit ergab sich eine inverse Korrelation zwischen dem Grad der Stromafärbung und dem p16-Score des Resektates ( $p=0,025$; siehe Abbildung 3.15). Es lässt sich vermuten, dass aktiviertes seneszentes Stroma bei der Malignomentwicklung proliferative Tumorzellen stimulierte (ablesbar an einem histopathologischen Grading 3, siehe Kapitel 4.1.14) und diese Zellen kein p16 mehr exprimieren konnten (siehe Kapitel 4.1.8). Gegen diese Hypothese spricht, dass keine Korrelation zwischen der p16-Expression und dem histopathologischen Tumorgrading beobachtet wurde (siehe Kapitel 4.1.8). Zur Klärung des tumorbiologischen Zusammenhangs zwischen der p16-Expression der 
Karzinomzellen und der p16-Expression des dazugehörigen Stromas bedarf es weiterer Untersuchungen innerhalb der Arbeitsgruppe des Teilprojektes 5 der KFO 179.

$$
\text { p16 }
$$

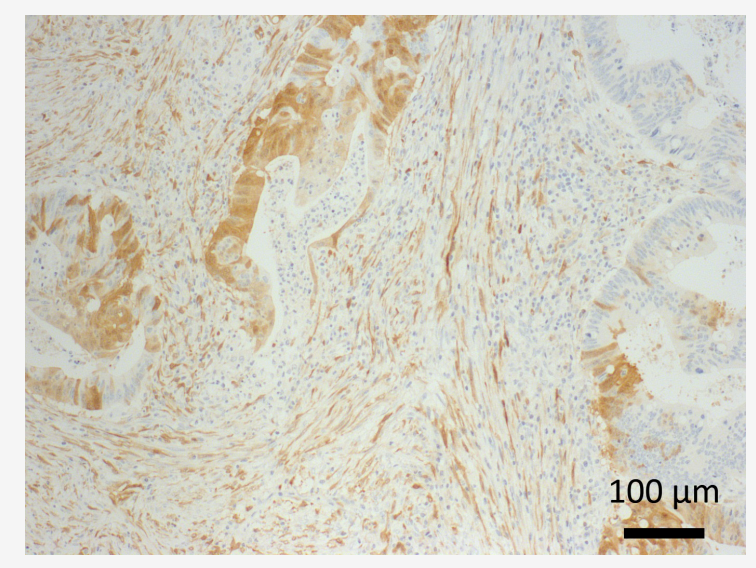

\section{Vimentin}

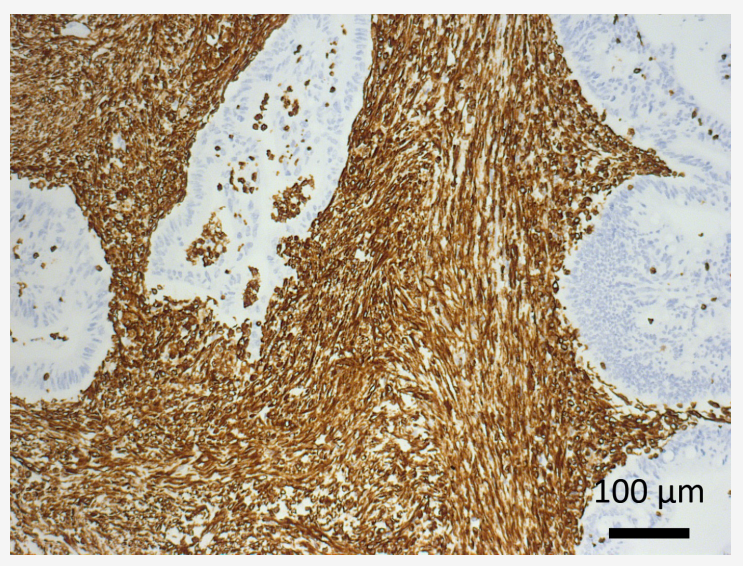

\section{68}

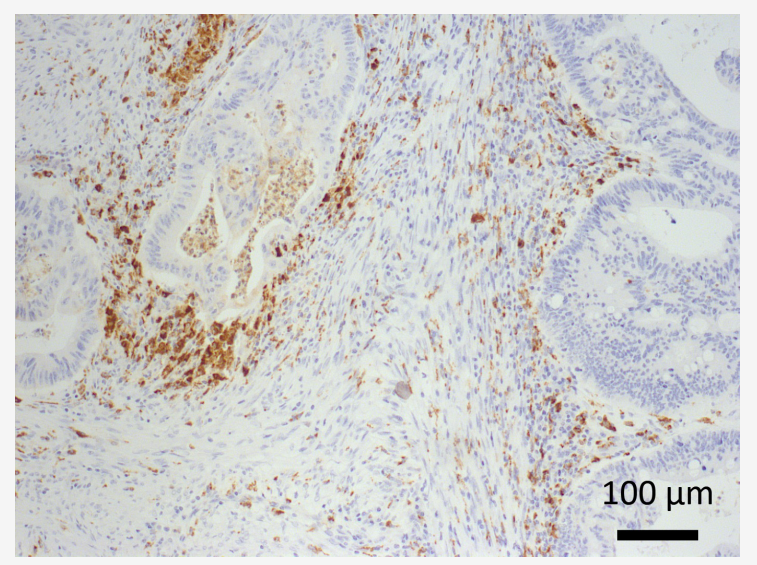

Aktin

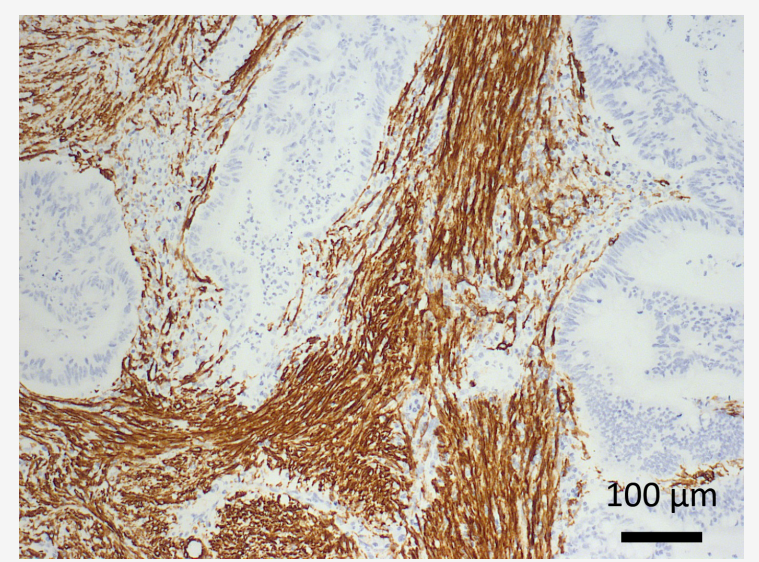

Abbildung 4.3: Färbung des gleichen Ausschnittes eines Rektumkarzinom-Resektates mit p16, CD68, Vimentin und Aktin

10-fache Vergrößerung, jeweils gleicher Ausschnitt. CD68 ist ein immunhistochemischer Marker für Makrophagen, monozytäre Zellen und granulozytäre Vorläuferzellen (Pulford et al. 1989). Vimentin ist ein Intermediärfilament, das als Marker für mesenchymale Zellen, wie Fibroblasten, genutzt wird (Eriksson et al. 2009). Der Aktin-Antikörper färbt $\alpha$ Glattmuskelaktin und dient so als Marker für glatte Muskulatur, Myofibroblasten und Myoepithelzellen (Skalli et al. 1986; Zarbo et al. 2000). Zu erkennen ist eine deutliche morphologische Ähnlichkeit der von p16, Vimentin und Aktin angefärbten Zellen; allerdings sind nicht alle Zellen p16-positiv, die eine Vimentin- und Aktinfärbung zeigen. Zusätzlich finden sich in der p16-Immunhistochemie neben spindelförmigen Zellen auch kleine rundere p16-positive Zellen, die den CD68-positiven Zellen morphologisch ähneln.

\subsection{7 p16-Expression und das Patientenalter}

Die p16-Expression wird durch verschiedene Stimuli induziert; unter anderem verursacht eine Telomerverkürzung eine Erhöhung der p16-Expression (siehe Kapitel 1.9.2). In vivo ist nachgewiesen, dass die Höhe der p16-Expression in humaner Dermis und Epidermis signifikant mit dem Alter korreliert (Ressler et al. 2006). In Epithel- und Stromazellen von Nagetieren ist ebenfalls eine positive Korrelation zwischen p16-Expression und Alter bekannt (Krishnamurthy et al. 2004). In humanen TZellen wurde ein Zusammenhang zwischen Alter und Höhe der p16-Expression nachgewiesen (Burd et al. 2013). Trotz dieser vermeintlich eindeutigen Abhängigkeit zwischen einer p16-Expression und 
Alterung fand sich in keiner der in diese Diskussion eingeflossenen Publikationen zur p16-Expression im KRK (siehe Tabelle 6.1), ebenso wenig wie in der vorliegenden Arbeit, eine signifikante Korrelation zwischen der Höhe der p16-Expression eines Karzinoms und dem Patientenalter (Cui et al. 2004; Deschoolmeester et al. 2010; Kamoshida et al. 2004a; Kamoshida et al. 2004b; Kim et al. 2005; Lam et al. 2008; McKay et al. 2002; Palmqvist et al. 2000; von Stockmar-von Wangenheim et al. 2008; Wassermann et al. 2009). Allerdings muss erwähnt werden, dass bisher in keiner Veröffentlichung die Färbung der Stromazellen systematisch analysiert wurde. Wie in Kapitel 4.1.6 gezeigt, hängt das Ausmaß der stromalen p16-Expression positiv mit dem Patientenalter zusammen. Dies ist gut vereinbar mit Untersuchungen, die ebenfalls eine Korrelation zwischen Alter und der p16Expressionshöhe in stromalen Zellen beobachteten (Krishnamurthy et al. 2004; Ressler et al. 2006). Mit zunehmenden Zellteilungen während des biologischen Alterungsprozesses steigt die p16Expression und kann nachfolgend eine cellular senescence im Sinne einer replicative senescence auslösen (siehe Kapitel 1.9.2.1). Aufgrund dieser Ergebnisse erscheint es sinnvoll, altersadaptierte Überlebensanalysen vorzunehmen, die den Zusammenhang zwischen stromaler p16-Expression und Prognoseparametern wie z. B. dem TRG und Grading prüfen.

\subsection{8 p16-Expression und das histopathologische Tumorgrading}

Die hier vorliegende Arbeit kann, wie die überwiegende Mehrzahl der bisherigen Veröffentlichungen, trotz einer relativ großen Anzahl $(\mathrm{n}=56)$ analysierter Gewebeschnitte von G3-Rektumkarzinomen, keinen Zusammenhang $(\mathrm{p}=0,67$; siehe Kapitel 3.5.3) zwischen dem histopathologischen Tumorgrading und dem p16-Score beobachten (Carneiro et al. 2006; Cui et al. 2004; Deschoolmeester et al. 2010; Kamoshida et al. 2004a; Kamoshida et al. 2004b; Kim et al. 2005; McKay et al. 2002; von Stockmar-von Wangenheim et al. 2008; Wassermann et al. 2009; Zhao et al. 2006). Einschränkend bleibt zu berücksichtigen, dass in zwei Publikationen schlecht differenzierte Malignome (G3, poorly differentiated) aus den Analysen ausgeschlossen worden waren (Kamoshida et al. 2004a; Kamoshida et al. 2004b). Demgegenüber stellten mehrere Arbeitsgruppen fest, dass eine niedrige oder fehlende p16-Expression gerade mit einem hohen - prognostisch ungünstigen - histopathologischen Tumorgrading (G3) einhergeht (Lam et al. 2008; Norrie et al. 2003; Palmqvist et al. 2000; Tada et al. 2003; Zhao et al. 2003). Der Verlust an p16-Tumorsuppressorfunktion kann zu einer damit verbundenen mutationsgenerierenden zellulären Hyperproliferation führen, in deren Folge bei der Karzinomentstehung zunehmend unreifere Karzinomzellen generiert werden (Norrie et al. 2003).

\subsection{9 p16-Expression und das pT-Stadium bzw. das Tumorstadium}

In der vorliegenden Arbeit korreliert eine geringe p16-Expression bei Betrachtung der gesamten Kohorte mit einem höheren pT-Stadium (siehe Abbildung 3.12, p=0,008). Betrachtet man die Kohorten $\mathrm{AB}$ und $\mathrm{C}$ getrennt, so ergibt sich jeweils keine Signifikanz, was als Fallzahlproblem gedeutet werden kann (siehe Abbildung 3.12, p=0,26 bzw. p=0,49). Das pUICC-Tumorstadium korreliert in keiner der Kohorten signifikant mit der p16-Expression (siehe Kapitel 3.5.2). 
In der bestehenden Literatur korreliert die p16-Expression in vielen Fällen nicht signifikant mit dem pT-Stadium oder dem Tumorstadium (Kamoshida et al. 2004a; Kamoshida et al. 2004b; Kim et al. 2005; McKay et al. 2002; Palmqvist et al. 2000; von Stockmar-von Wangenheim et al. 2008; Wassermann et al. 2009; Zhao et al. 2006). Dabei ist aber zu beachten, dass, wenn eine Analyse mit dem Tumorstadium nach Duke (A-D) oder UICC (I-IV) vorlag, oftmals keine zusätzliche alleinige Analyse des pT-Stadiums in Bezug auf die p16-Expression durchgeführt wurde (Sarma 1988; Sobin et al. 2002). Einige Arbeiten untersuchten statt des pT-Stadiums oder der Infiltrationstiefe auch nur die Korrelation mit der Tumorgröße (Cui et al. 2004; Kim et al. 2005). Es gibt nur wenige Arbeiten, die direkt das pT-Stadium analysieren.

Ergebnis dieser Arbeit ist eine signifikante Korrelation zwischen einer geringeren p16-Expression und einem höheren pT-Stadium (fortgeschrittenere Tumorinfiltration, siehe Tabelle 1.1). Dies deutet darauf hin, dass die Tumorsuppressorfunktion von p16 während der Entwicklung eines Karzinoms abnimmt und so erst durch den Wegfall seiner zellzyklusinhibierenden Funktion eine weitere Progression und Invasion ermöglicht (siehe Abbildung 1.4). Diese Theorie wird von Beobachtungen von Tada et al. (2003) unterstützt, die war zwar keine signifikante Korrelation zwischen Tumorgröße oder Tumorstadium und positiver p16-Expression beobachten konnten, aber in ihrer Untersuchung eine signifikante Korrelation zwischen einer p16-Negativität und der Invasionstiefe des Tumors beobachteten (Tada et al. 2003). Die Invasionstiefe in $\mathrm{cm}$ entspricht zwar nicht direkt dem pTStadium, welches durch die vom Karzinom infiltrierten histologischen Schichten definiert ist, sie ist aber eher mit dem pT-Stadium vergleichbar ist als die Tumorgröße (siehe Tabelle 1.1).

Auf der anderen Seite jedoch gibt es auch gegenteilige Beobachtungen. In der Arbeit von Zhao et al. (2003) korrelierte die Stärke der p16-Expression signifikant mit dem Tumorstadium. Lam et al. (2008) fanden auch eine positive Korrelation zwischen TNM-Stadium und der Höhe der p16-Expression, allerdings beobachteten sie in derselben Studie eine positive Korrelation von p16-Expression und pNStadium, sodass die positive Korrelation zwischen p16-Expression und TNM-Stadium auch ein Effekt des pN-Stadiums sein könnte.

Die hohe Fallzahl der vorliegenden Arbeit spricht dafür, dass es eine signifikante Korrelation zwischen einer geringen p16-Expression und dem pT-Stadium gibt. Dieser Effekt scheint jedoch nicht so bedeutend zu sein, dass er sich auf eine signifikante Korrelation zwischen p16-Expression und dem gesamten Tumorstadium ausweiten ließe. Die Mehrzahl der Veröffentlichungen stellte keine signifikante Korrelation zwischen p16-Expression und pT-Stadium bzw. Tumorstadium fest. Der größte Unterschied - neben der hohen Fallzahl der Gesamtkohorte - zwischen der bestehenden Literatur und der vorliegenden Arbeit ist die große Kohorte der neoadjuvant behandelten Karzinome, die in die Analyse einbezogen wurde. Am ehesten haben diese Resektate, die allgemein eine höhere p16-Expression als primär operierte Rektumkarzinome aufweisen, den Ausschlag zu einer signifikanten Korrelation mit dem pT-Stadium gegeben. 


\subsubsection{0 p16-Expression und das $\mathrm{pN}$-Stadium}

Wie bereits in Kapitel 4.1.9 erwähnt, beobachteten Lam et al. (2008) eine positive Korrelation der p16-Expression mit dem pN-Stadiums, d. h. je höher der Grad der p16-Expression, desto eher wurde eine Lymphknotenmetastasierung beobachtet. Im Gegensatz dazu beschrieben Tada et al. (2003) den Zusammenhang zwischen negativer p16-Expression (definiert als abwesende oder positive Färbung vereinzelter Zellen) im KRK und einer erhöhten Wahrscheinlichkeit für das Vorliegen einer lymphatischen Infiltration. Kim et al. (2005) beobachteten ebenfalls eine signifikante Korrelation von geringer nukleärer p16-Expression und erhöhter Inzidenz von Lymphknotenmetastasen. Eine andere Arbeitsgruppe konnte eine signifikante Korrelation zwischen einer geringen zytoplasmatischen p16Expression und einem erhöhten pN-Stadium beobachten; zwischen der Höhe der nukleären p16Expression und dem pN-Stadium fand sich in dieser Arbeit jedoch keine signifikante Korrelation (von Stockmar-von Wangenheim et al. 2008).

Die Mehrzahl der Arbeiten konnte jedoch keinen Hinweis auf einen Zusammenhang zwischen p16Expression und dem pN-Stadium finden (Cui et al. 2004; Deschoolmeester et al. 2010; Kamoshida et al. 2004a; Kamoshida et al. 2004b; Palmqvist et al. 2000; Wassermann et al. 2009). Die vorliegende Arbeit beobachtete ebenfalls weder in der Gesamtkohorte noch in der neoadjuvant behandelten bzw. der primär operierten Kohorte der untersuchten Rektumresektate eine Korrelation zwischen p16Expression und pN-Stadium (siehe Abbildung 3.13, p=0,89, p=0,44, bzw. p=0,52). Die p16Expression der Biopsien korrelierte ebenfalls nicht mit dem $\mathrm{pN}$-Stadium, sodass die immunhistochemische p16-Auswertung hierbei keinen diagnostischen Wert besitzt (siehe Abbildung $3.13, \mathrm{p}=0,49)$.

\subsubsection{1 p16-Expressionsmuster - ein Unterscheidungskriterium}

In den vorliegenden Analysen unterschieden sich nicht nur die Färbeintensität und der quantitative Anteil an gefärbten Karzinomzellen zwischen den einzelnen untersuchten Resektaten, sondern auch das Expressionsmuster von p16 teilweise deutlich. Folglich wurden zwei Expressionsmuster voneinander unterschieden: eine vorhandene homogene Färbung des Tumors und eine durchweg mosaikartige p16-Expression innerhalb des Karzinoms. In der Gruppe der neoadjuvant behandelten Patienten (Kohorte $\mathrm{AB}$ ) kamen signifikant häufiger homogen p16-angefärbte Areale im Karzinomanteil vor als in der primär operierten Kontrollgruppe (Kohorte $C)(p<0,001$; siehe Tabelle 3.1). Es ergab sich allerdings durch das p16-Expressionsmsuter kein prognostischer Vorteil für die Patienten.

In einigen Publikationen werden keine unterschiedlichen p16-Expressionsmuster beschrieben (Kamoshida et al. 2004a; Kamoshida et al. 2004b). Andere Arbeitsgruppen erwähnen die heterogene p16-Expression innerhalb der Tumoren, berücksichtigen diese aber nicht in ihren Analysen (Cui et al. 2004; Dai et al. 2000; Palmqvist et al. 2000; Wassermann et al. 2009). Tada et al. (2003) unterteilten ihr Kollektiv anhand des p16-Expressionsmusters in vier Subgruppen: Die p16-Expression war entweder diffus, nestartig, vereinzelt oder gar nicht vorhanden. Anhand der veröffentlichten 
Abbildungen von Tada et al. (2003) entsprechen die Subgruppen „nestartig“ und „vereinzelt“ der in dieser Dissertation definierten Kategorie „mosaikartig“, die Subgruppe „diffus“ entspricht der Kategorie „homogen“ (Tada et al. 2003). Es konnte auch von Tada et al. (2003) kein Einfluss des p16Expressionsmusters auf die Prognose der Patienten festgestellt werden.

Schon 1995 beobachteten Geradts et al., dass die immunhistochemische Färbung von Neoplasien auf p16 hin häufig ein mosaic pattern aufwies. Geradts postulierte, dass auch p16-positive Zelllinien teilweise Zellen mit p16-negativem Zellkern aufweisen könnten, da sich die Expression von p16 während der verschiedenen Zellzyklusphasen um ein Fünffaches unterscheide (Geradts et al. 1995). Dai et al. (2000) nehmen ebenfalls eine zellautonome Regulierung als Grund für die mosaikartige heterogene p16-Färbung an. Eine homogene Färbung kann im Umkehrschluss auf eine nichtzellautonome p16-Regulierung hindeuten, wie z. B. durch eine auf das Tumorgewebe wirkende neoadjuvante RCT. Diese löst als onkogener Stimulus eine cellular senescence und damit eine erhöhte p16-Expression im Tumorgewebe aus. So ließe sich auch erklären, dass in der neoadjuvant behandelten Kohorte AB signifikant mehr homogen p16-gefärbte Tumoranteile nachweisbar waren als in der primär operierten Kohorte C.

\subsubsection{2 p16-Expression im vorbehandelten kolorektalen} Karzinom

Ionisierende Strahlung verursacht u. a. DNA-Doppel- oder Einzelstrangbrüche, 5-FU wirkt als Antimetabolit und Hemmer der Thymidylatsynthase und Oxaliplatin führt über DNA-Quervernetzung zu einer verminderten zellulären Replikation und Transkription (Arango et al. 2004; Conradi et al. 2011; Li et al. 2001; Longley et al. 2003). Alle drei Bestandteile einer neoadjuvanten RCT verursachen demnach einen DNA-Schaden, der neben der Apoptose auch eine cellular senescence mit erhöhter p16-Expression einleiten kann (Arango et al. 2004; Eriksson und Stigbrand 2010).

Die vorliegende Arbeit zeigt erstmals an einer großen Kohorte von Rektumkarzinomen ( $n=254)$, dass präoperativ multimodal behandeltes Karzinomgewebe eine signifikant höhere p16-Expression aufweist als nicht vorbehandeltes Karzinomgewebe $(\mathrm{p}<0,001$; siehe Abbildung 3.8). Zu einem ähnlichen Ergebnis kamen auch Kamoshida et al. (2004a), die die bisher einzige Studie veröffentlichten, die sich mit der p16-Expression von neoadjuvant behandelten KRK beschäftigt. In dieser wurden insgesamt 37 mit 5-FU neoadjuvant chemotherapierte, lokal fortgeschrittene Karzinome mit 31 primär operierten, lokal fortgeschrittenen Karzinomen verglichen. Dabei wurde die p16Expression in „high“ ( $>30 \%$ des Tumors angefärbt) und „low“ ( $<30 \%$ des Tumors angefärbt) unterteilt. Die Arbeitsgruppe beobachtete einen signifikanten Unterschied $(\mathrm{p}=0,03)$ in der $\mathrm{p} 16-$ Expression zwischen respondern auf die neoadjuvante Therapie (definiert als TRG $1 \mathrm{~b}$ und 2 der Japanese Classification of Colorectal Carcinoma, JCCC) und den primär operierten Kontrollfällen (Kamoshida et al. 2004a). Die vorliegende Dissertation unterscheidet sich von Kamoshida et al. (2004a) in der Auswahl des Patientenkollektivs, der Fallzahl, der Art der präoperativen Therapie, der Auswertung der p16-Expression und der Art der Tumorregressionsanalyse (siehe Tabelle 4.2). Trotz 
einer eingeschränkten Vergleichbarkeit beider Untersuchungen bleibt die Beobachtung eindeutig, dass die jeweils angewandte neoadjuvante (Radio-)Chemotherapie eine erhöhte p16-Expression in den Resektaten induzierte.

Zusätzlich zu den Resektaten wurde in der vorliegenden Arbeit in 33 Fällen die p16-Expression der prätherapeutischen Biopsie und des Rektumresektates nach neoadjuvanter RCT verglichen. Es wurde beobachtet, dass die p16-Expression der Biopsien in 28 Fällen niedriger war als die des Resektates. In vier Fällen war die p16-Expression der Biopsie höher als die des Resektates, in einem Fall war der p16-Score sowohl in der Biopsie als auch im dazugehörigen Resektat 0 (siehe Abbildung 3.9). Am ehesten sind die vier Fälle, in denen die p16-Expression der Biopsie höher war als die des Resektates, auf die mosaikartige p16-Färbung der Karzinome zurückzuführen. Durch die Heterogenität der Tumoren ist eine Biopsie nicht zwangsläufig repräsentativ für den gesamten Tumor. Weniger wahrscheinlich ist das Vorliegen eines Unterschieds in der Tumorbiologie zwischen den Resektaten, deren p16-Expression durch die RCT hochreguliert bzw. herunterreguliert worden ist. Einer kleinen Subgruppe der Rektumkarzinome könnte es nicht möglich sein, ihre p16-Expression als Reaktion auf die RCT zu erhöhen. Zur Bestätigung dieser Hypothese wären Untersuchungen mit multiplen Biopsien notwendig, um eine Verfälschung des prätherapeutischen p16-Scores durch die Heterogenität der Tumoren möglichst gering zu halten. Dann wäre auch eine Antwort auf die Frage möglich, ob ein prognostischer Unterschied zwischen Rektumkarzinomen besteht, die p16 nach RCT höher bzw. niedriger exprimieren als prätherapeutisch. Von der vorliegenden Arbeit kann diese Frage aufgrund der vorliegenden niedrigen Fallzahl nicht valide beantwortet werden.

\subsubsection{3 p16-Expression und der TRG}

Es liegen zwei Untersuchungen vor, die sich ebenfalls mit der p16-Expression von neoadjuvant behandelten KRK beschäftigen. Komuro et al. (2005) analysierten lediglich die p16-Expression von prätherapeutischen Biopsien und untersuchten den Zusammenhang dieser mit der Tumorregression der dazugehörigen Resektate nach alleiniger präoperativer Radiotherapie (RT). Kamoshida et al. (2004a) untersuchten die p16-Expression prätherapeutischer Biopsien und ihrer korrespondierenden Resektate nach neoadjuvanter Chemotherapie. Die vorliegende Dissertation untersucht erstmals den Einfluss einer neoadjuvanten, multimodalen RCT auf die p16-Expression von Rektumkarzinomen in lokal fortgeschrittenen Tumorstadien. Für einen detaillierten Vergleich der drei Arbeiten siehe Tabelle 4.2. Kamoshida et al. (2004a) bewerteten die Chemotherapie-response auf die neoadjuvante 5-FUBehandlung nicht anhand des TRGs nach Dworak, sondern nach der Japanese Classification of Colorectal Carcinoma (JCCC, siehe Tabelle 4.1). Dabei klassifizierten sie Grad 0 und 1a (entsprechend dem TRG 0 und 1 nach Dworak) als „,non-responder“ und Grad 1b und 2 (TRG 2 und 3 nach Dworak) als „responder“. Eine komplette Tumorregression im Sinne eines Grad 3 (TRG 4 nach Dworak) konnte nicht beobachtet werden. Der Unterschied in der p16-Expression war zwischen den respondern und den nicht neoadjuvant behandelten Kontrollfällen signifikant ( $\mathrm{p}=0,03)$, da $83 \%$ der responder, aber nur $32 \%$ der Kontrollfälle eine hohe p16-Expression aufwiesen (Kamoshida et al. 
2004a). In der vorliegenden Arbeit werden diese Ergebnisse von Kamoshida et al. (2004a) durch die Korrelation der Höhe der p16-Expression und der Höhe des TRG an 156 Rektumresektaten (Kohorte AB) bestätigt ( $<<0,001$; siehe Abbildung 3.14).

Tabelle 4.1: Tumorregression nach der Japanese Classification of Colorectal Carcinoma und nach dem TRG nach Dworak (1997) im Vergleich

\begin{tabular}{|c|c|c|c|}
\hline \multicolumn{2}{|c|}{ Tumorregression nach der JCCC } & \multicolumn{2}{|c|}{ Tumorregressionsgrad nach Dworak (1997) } \\
\hline Grad 0 & Keine Regression & TRG 0 & Keine Regression \\
\hline Grad 1a & $\begin{array}{l}\text { Nekrose oder Verschwinden des Tumors } \\
\text { in weniger als } 1 / 3 \text { der Läsion }\end{array}$ & TRG 1 & $\begin{array}{l}\text { Dominante Tumormasse, eindeutige } \\
\text { Zeichen radiogener fibrotischer } \\
\text { Veränderungen/Vaskulopathie erkennbar }\end{array}$ \\
\hline Grad $1 b^{*}$ & $\begin{array}{l}\text { Nekrose oder Verschwinden des Tumors } \\
\text { in mehr als } 1 / 3 \text { der Läsion, aber weniger } \\
\text { als } 2 / 3 \text { der Läsion }\end{array}$ & TRG $2^{*}$ & $\begin{array}{l}\text { Fibrosen überwiegen im Präparat, leicht zu } \\
\text { identifizierende Tumorzellnester vorhanden }\end{array}$ \\
\hline Grad 2* & $\begin{array}{l}\text { Nekrose oder Verschwinden des Tumors } \\
\text { in mehr als } 2 / 3 \text { der Läsion, aber noch } \\
\text { vitale Tumorzellen erkennbar }\end{array}$ & TRG $3^{*}$ & $\begin{array}{l}\text { Dominante Fibrose mit oder ohne muköse } \\
\text { Substanz im Präparat, einzelne } \\
\text { mikroskopisch schwer zu identifizierende } \\
\text { Tumorzellen vorhanden }\end{array}$ \\
\hline Grad 3 & Keine vitalen Tumorzellen nachweisbar & TRG 4 & $\begin{array}{l}\text { Komplette Regression: keine vitalen } \\
\text { Tumorzellen nachweisbar, vollständige } \\
\text { Fibrose }\end{array}$ \\
\hline
\end{tabular}

*Da es in der von Dworak veröffentlichten Klassifikation ursprünglich keine Prozentangabe zum Ausmaß der Tumorfibrose gab, ist eine direkte Zuordnung der Grade $1 \mathrm{~b}$ und 2 der JCCC nicht möglich. Allerdings entsprechen die TRG 0, 1 und 4 den Graden 0, 1a und 3 der japanischen Klassifikation (Dworak et al. 1997; Kamoshida et al. 2004a).

Tabelle 4.2: Zusammenfassung der Unterschiede der Methodik zwischen der vorliegenden Arbeit, Kamoshida et al. (2004a) und Komuro et al. (2005)

\begin{tabular}{|c|c|c|c|}
\hline & \\
\hline & Diese Arbeit & Kamoshida et al. (2004a) & Komuro et al. (2005) \\
\hline Kollektiv & Rektumkarzinome & $\begin{array}{l}\text { Kolon- und } \\
\text { Rektumkarzinome }\end{array}$ & Rektumkarzinome \\
\hline \multicolumn{4}{|l|}{ Anzahl Resektate } \\
\hline neoadjuvant behandelt & 156 & 37 & 0 \\
\hline primär operiert & 98 & 31 & 0 \\
\hline \multicolumn{4}{|c|}{ Anzahl prätherapeutische Biopsien } \\
\hline neoadjuvant behandelt & 40 & 25 & 96 \\
\hline primär operiert & 0 & 17 & 0 \\
\hline $\begin{array}{l}\text { Art der } \\
\text { Vorbehandlung }\end{array}$ & $\begin{array}{l}\text { 5-FU + RT (50,4 Gy) oder } \\
5-F U \text { + Oxaliplatin + RT } \\
\text { (50,4 Gy) }\end{array}$ & 5-FU Ctx & RT mono (50 Gy) \\
\hline $\begin{array}{l}\text { Auswertung der p16- } \\
\text { Immunhistochemie }\end{array}$ & $\begin{array}{l}\text { Bildung eines p16- } \\
\text { Scores unter } \\
\text { Einbeziehung des } \\
\text { gefärbten } \\
\text { Karzinomanteils und der } \\
\text { Färbeintensität }\end{array}$ & $\begin{array}{l}\text { Einteilung in "low“- } \\
(<30 \%) \text { und "high“- } \\
\text { (>30\%) Expression } \\
\text { anhand des gefärbten } \\
\text { Tumoranteils ohne } \\
\text { Beachtung der } \\
\text { Färbeintensität }\end{array}$ & $\begin{array}{l}\text { Einteilung in negativ }(<5 \%) \\
\text { und positiv }(\geq 5 \%) \text { anhand } \\
\text { des gefärbten } \\
\text { Tumoranteils } \\
\text { ohne Beachtung der } \\
\text { Färbeintensität }\end{array}$ \\
\hline TRG-System & $\begin{array}{l}\text { nach Dworak (1997) und } \\
\text { zusätzlich in Prozent }\end{array}$ & $\begin{array}{l}\text { nach der Japanese } \\
\text { Classification of Colorectal } \\
\text { Carcinoma }\end{array}$ & $\begin{array}{l}\text { nach der Japanese } \\
\text { Research Society for } \\
\text { Cancer of the Colon and } \\
\text { Rectum }\end{array}$ \\
\hline
\end{tabular}

5-FU (5-Fluorouracil), RT (Radiotherapie), TRG (Tumorregressionsgrad). 
Alle drei Arbeiten untersuchten die Beziehung zwischen der p16-Expression in der prätherapeutischen Biopsie und der Tumorregression des dazugehörigen Resektates nach neoadjuvanter Therapie. Kamoshida et al. (2004a) verglichen 25 Tumorbiopsien von neoadjuvant behandelten und 17 Tumorbiopsien von primär operierten Patienten. Es zeigte sich kein Unterschied in der p16-Expression der Biopsien zwischen den Gruppen der responder, non-responder und der Kontrollgruppe (Kamoshida et al. 2004a). Trotz des größeren Biopsiekollektivs der vorliegenden Arbeit (40 vs. 25) konnte ebenfalls kein Zusammenhang zwischen der p16-Expression der Biopsie und dem TRG festgestellt werden ( $\mathrm{p}=0,15$ bzw. 0,61; siehe Abbildung 3.14). Komuro et al. (2005) untersuchten ein großes Kollektiv ( $\mathrm{n}=96)$ von prätherapeutischen Biopsien von darauffolgend präoperativ radiotherapierten Rektumkarzinomen. Die Arbeitsgruppe unterteilte den Effekt der RT auf die Rektumkarzinome gemäß der Japanese Research Society for Cancer of the Colon and Rectum in zwei Gruppen: eine strahlensensible Gruppe - definiert durch einen RT-induzierten Fibroseanteil von 2/3 oder mehr des Karzinoms - und eine zweite strahlenresistente Gruppe, definiert durch weniger als 2/3-Fibroseanteil des Karzinoms nach präoperativer RT. Eine positive p16-Expression (definiert als $\geq 5 \%$ der Karzinomzellen der prätherapeutischen Biopsie p16-positiv gefärbt) korrelierte dabei signifikant $(\mathrm{p}=0,033)$ mit einer Strahlensensibilität (Komuro et al. 2005).

Dieser von Komuro et al. (2005) beobachtete Zusammenhang zwischen der p16-Expression der prätherapeutischen Biopsie und einem Therapieerfolg, gemessen an der RT-induzierten, histopathologisch bestimmten Tumorregression, ist klinisch sehr interessant, da sich schon prätherapeutisch eine Aussage über den voraussichtlichen Therapieerfolg treffen ließe. Je höher die p16-Expression in der prätherapeutischen Biopsie ist, desto höher wäre nach der neoadjuvanten Therapie der TRG. Zu beachten ist allerdings, dass Komuro et al. (2005), die mit einem großen Biopsiekollektiv die Korrelation von Prognose und p16-Expression in der Biopsie untersuchten, zwar einen signifikanten Unterschied in der Tumorregression, aber keinen signifikanten Unterschied in prognostischen Parametern (OS und Zeit bis zum Auftreten eines Lokalrezidivs) zwischen p16negativen und p16-positiven Biopsien nachweisen konnten.

\subsubsection{Vor- und Nachteile der cellular senescence als Therapieeffekt}

Das vermeintlich beste - da unumkehrbare - Therapieziel scheint auf den ersten Blick der Zelltod durch Apoptose oder mitotische Katastrophe zu sein. Es verdichten sich jedoch Hinweise, dass insbesondere DNA-schädigende Therapien wie ionisierende Strahlung und auch Chemotherapeutika in vitro und in vivo nicht nur den Zelltod, sondern auch in erheblichem Maße einen Zellzyklusarrest in soliden Tumoren und Fibroblasten auslösen (Eriksson und Stigbrand 2010; Gewirtz et al. 2008; Shay und Roninson 2004; Suzuki et al. 2001; Suzuki und Boothman 2008). Damit wird cellular senescence heutzutage schon - wenn auch unbewusst - als Therapieeffekt genutzt. Die vorliegende Arbeit beschreibt eine RCT-induzierte z. T. starke p16 Expression in Rektumkarzinomzellen. Diese p16Expression kann als Surrogatparameter für eine Induktion von cellular senescence angesehen werden 
(siehe Kapitel 1.9). Auch im Mammakarzinomgewebe konnte in vivo eine deutliche Zunahme der p16Expression mit begleitender cellular senescence nach neoadjuvanter Chemotherapie im Gegensatz zu nicht neoadjuvant therapierten Tumoren gezeigt werden (te Poele et al. 2002). Eine Übersicht über die Therapieeffekte einer (Radio-)Chemotherapie und die Folgen einer eingeleiteten cellular senescence findet sich in Abbildung 4.4.

Die therapieassoziierte Einleitung einer cellular senescence des Tumors und des umgebenden Gewebes kann Vor- und Nachteile haben. Ein offensichtlicher Nachteil der Einleitung einer cellular senescence gegenüber der Einleitung eines Zelltodes scheint die weiterhin metabolisch aktive Persistenz von Malignomzellen zu sein (Shay und Roninson 2004). Ursprünglich wurde die cellular senescence zwar als irreversibler Zellzyklusarrest beschrieben, doch einige Autoren diskutieren, ob es sich bei der cellular senescence nicht eher um einen lang anhaltenden Zellzyklusarrest handelt, der durchaus reversibel ist (Beausejour et al. 2003; Gewirtz et al. 2008; Roberson et al. 2005). Zur Aufrechterhaltung dieses stabilen Zellzyklusarrestes sind eine erhöhte p16-Expression und ein intaktes p53 notwendig (Beausejour et al. 2003). Sollte eines dieser beiden Proteine von vornherein defekt sein oder im Verlauf durch Mutation vollständig verloren gehen, wäre ein instabiler Zellzyklusarrest die Folge, der in vitro z. B. durch eine aberrante Expression von $\mathrm{Cdc} 2 / \mathrm{CdK} 1$ reversibel ist (Roberson et al. 2005; Schmitt et al. 2002). Somit besteht bei einer onkologischen Therapie durch Induktion einer cellular senescene das Risiko, dass betroffene Malignomzellen wieder in einen aktiven Proliferationszustand eintreten und ein lokoregionäres oder fernmetastatisches Rezidiv verursachen können (Gewirtz et al. 2008).

Ein weiteres Problem der weiterhin aktiv metabolischen Tumorzellen ist auf den ersten Blick betrachtet eine fehlende Größenregression des Tumors. Im Mausmodell führte die Einleitung einer cellular senescence durch Radiotherapie, im Gegensatz zur Einleitung einer Apoptose, auch nach 11 Wochen Beobachtungszeit zu keiner deutlichen Tumorvolumenreduktion des aus einer KRK-Zelllinie entstandenen Malignoms (Waldman et al. 1997). Beim Menschen kann der Prozess der RTinduzierten Tumorregression sogar mehrere Monate bis Jahre andauern (Bataini et al. 1988; Cox und Kline 1983). Der Grund hierfür wird in der langsamen Tumormassenreduktion bei Vorliegen einer strahleninduzierten cellular senescence gesehen (Eriksson und Stigbrand 2010). Ein möglicher Mechanismus, wie es zu dieser Tumorreduktion kommt, ist die verzögerte Destruktion und Elimination des Tumors durch immunkompetente Zellen. Durch sezernierte Faktoren des SASP seneszenter Zellen können z. B. Makrophagen angelockt und zur Tumorelimination angeregt werden (Lujambio et al. 2013; Sagiv und Krizhanovsky 2013). Im Mausmodell des hepatozellulären Karzinoms konnte erstmals beobachtet werden, dass seneszente Zellen proinflammatorische Zytokine sezernieren (siehe Abbildung 4.4), die eine Tumorabräumung durch Natural-Killer-Zellen (Natürliche Killerzellen, NK-Zellen), neutrophile Granulozyten und Makrophagen vermitteln (Xue et al. 2007). Genauso konnte bei prämalignen seneszenten Maushepatozyten eine gesteigerte Umgebungsinfiltration durch Makrophagen, neutrophile Granulozyten, NK-Zellen, CD4+ und CD8+ 
Lymphozyten nachgewiesen werden (Kang et al. 2011). Zusätzlich zeigte sich sowohl in vitro als auch in vivo, dass NK-Zellen seneszente Zellen durch Perforinausschüttung und damit verbundenen Granzym B-induzierten Zelltod eliminieren (Sagiv et al. 2013). Zusammenfassend können seneszente Tumorzellen durch Veränderung ihrer extrazellulären Umgebung ihre eigene Phagozytose und Elimination durch das Immunsystem begünstigen (Xue et al. 2007). Eine Tumormassenreduktion durch Einleitung einer cellular senescence ist also grundsätzlich möglich. Welche Population der Immunzellen und in welchem Ausmaß diese angelockt werden, ist dabei abhängig vom seneszenten Zelltyp (Sagiv und Krizhanovsky 2013; Shelton et al. 1999).

Der SASP von seneszenten Zellen kann aber nicht nur tumorsuppressorische, wie durch das Anlocken von Zellen der Immunabwehr, sondern auch tumorfördernde Wirkung haben. Die extrazelluläre Matrix, die vorwiegend durch seneszente, stromale Fibroblasten erzeugt wird, hat einen entscheidenden Effekt auf Tumorentstehung und -progress (Krtolica und Campisi 2002). Seneszente Fibroblasten sezernieren proinflammatorische Zytokine, Chemokine, Wachstumsfaktoren, extrazelluläre Matrix und die extrazelluläre Matrix degradierende Metalloproteasen (siehe Abbildung 4.4) und haben somit in vitro auf ihre Umgebung einen tumorfördernden Effekt (Coppe et al. 2008; Coppe et al. 2010; Krtolica et al. 2001; Saretzki 2010). So fördern z. B. seneszente Stromazellen mit ihrem SASP das Wachstum von Prostatazellen in vitro (Bavik et al. 2006), eine epithelialmesenchymale Transition von Mammakarzinomzellen mit nachfolgender Basalmembraninvasion und Tumormetastasierung in vitro (Coppe et al. 2008) und eine Steigerung zellulärer Proliferation und Malignomentstehung in Zellen der Brustdrüse und der Lunge in Xenograft-Modellen in vivo (Barcellos-Hoff und Ravani 2000; Papadopoulou und Kletsas 2011). Wenn durch Chemotherapie und/oder Strahlentherapie auch die tumorumgebenden Stromazellen in eine cellular senescence übergehen können, so kann dies in vivo zu einer erneuten Tumorproliferation oder Rezidiventstehung führen (Shay und Roninson 2004; Suzuki und Boothman 2008). Unter Nutzung einer präoperativen multimodalen RCT ließ sich dieser Effekt beim Rektumkarzinom in vivo in den Auswertungen der vorliegenden Arbeit nicht beobachten. Es konnte weder eine zusätzliche RCT-induzierte stromale p16Expression als Zeichen einer vermehrten cellular senescence (siehe Kapitel 1.7.2) beobachtet werden noch zeigte sich ein Zusammenhang zwischen der Quantität seneszenter stromaler Zellen und Überlebensparametern (TTR, CSS; siehe Kapitel 4.1.6). Zusammenfassend kann der unter experimentellen Bedingungen gezeigte negative CTx- bzw. RT-assoziierte Effekt eines vermehrt seneszenten Stromas anhand der untersuchten Rektumkarzinomkohorten (Kohorte AB) klinisch nicht nachvollzogen werden.

Ebenso wie Fibroblasten können auch KRK-Tumorzellen selbst nach Induktion einer cellular senescence durch Doxorubicin in vitro tumorfördernde, wie z. B. antiapoptotische, mitogene, angiogenesefördernde und proteatische Proteine sezernieren (Chang et al. 2002). Auf der anderen Seite können seneszente Tumorzellen in vitro neben tumorfördernden auch tumorinhibitorische Proteine sezernieren, die das Wachstum der umliegenden Tumorzellen hemmen können (Chang et al. 
2002; Roninson 2003). Aufgrund der unzureichenden Datenlage im KRK in vivo ist ungeklärt, ob eher die tumorfördernde oder tumorhemmende Wirkung der sekretorischen Proteine des SASP überwiegt. Bei Betrachtung der Ergebnisse der vorliegenden Arbeit ist ein Überwiegen der tumorhemmenden Wirkung wahrscheinlich. Die signifikante Korrelation zwischen der Höhe der p16-Expression der Tumorzellen und dem TRG des Resektates (siehe Kapitel 3.5.4 und 4.1.13) ist gut vereinbar mit einem von den Tumorzellen selbst sezernierten tumorinhibitorischen SASP, der die Elimination des Tumors durch das Immunsystem begünstigt. Ein potentiell tumorfördernder Einfluss des seneszenten Stromas, wie er in der Literatur beschrieben wird, ist eher unwahrscheinlich, da die Menge der p16-positiven Stromazellen in der vorliegenden Arbeit keinen Einfluss auf die Prognose der Patienten hatte (siehe Kapitel 3.7.3). Zusätzlich kann ein negativer Effekt der RCT durch eine vermeintlich vermehrte Induktion von cellular senescence in stromalen Zellen verneint werden, da kein signifikanter Unterschied in der p16-Stromafärbung zwischen neoadjuvant behandelten und primär operierten Karzinomen beobachtet werden konnte (siehe Tabelle 3.3 und Kapitel 4.3.6.). Die p16-Induktion durch neoadjuvante RCT im Fall des Rektumkarzinoms scheint demnach vor allem Tumorzellen und kaum Stromazellen zu betreffen und einen vorwiegenden tumorsuppressorischen Effekt zu haben. In der Abbildung 4.4 werden die möglichen Folgen einer RCT und einer damit verbundenen cellular senescence schematisch dargestellt. 


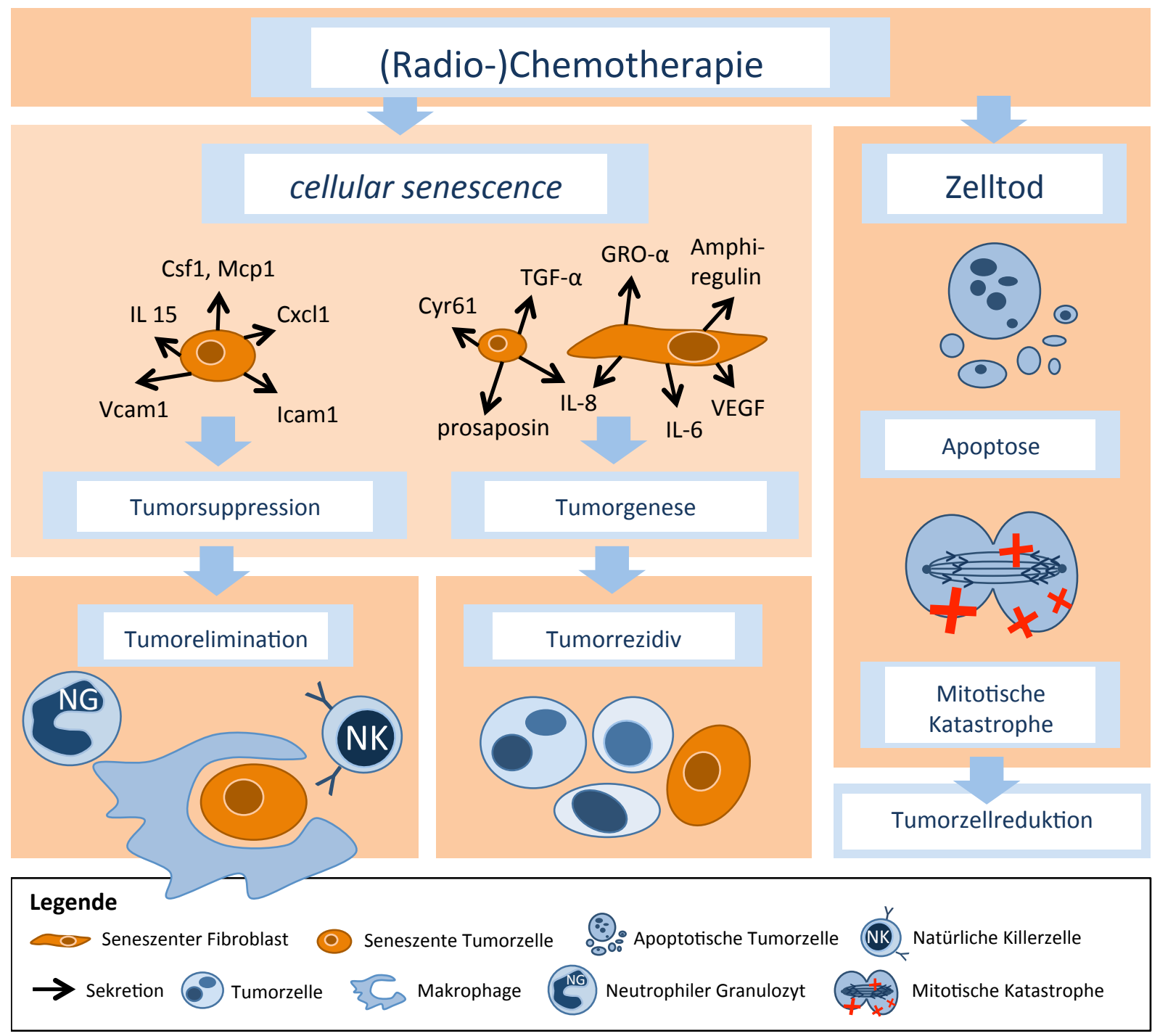

Abbildung 4.4: Auswirkungen einer (Radio-)Chemotherapie und der daraus folgenden cellular senescence Eigene schematische Darstellung. Eine (Radio-)Chemotherapie kann eine Tumorzellreduktion durch Einleitung einer Apoptose oder einer mitotischen Katastrophe bewirken, andererseits kann sie eine cellular senescence auslösen. Seneszente Zellen sezernieren Faktoren, die entweder eine tumorhemmende oder -fördernde Wirkung haben. Seneszente Tumorzellen sezernieren Faktoren, die Makrophagen (Csf1 and Mcp1), Neutrophile Granulozyten (Cxcl1) und Natürliche Killerzellen (IL 15) anlocken und so zur Tumorelimination beitragen (Xue et al. 2007). Demgegenüber haben ausgeschüttete Zytokine wie Cyr61, Prosaposin und TGF- $\alpha$ antiapoptotische, mitogene und angiogenetische Funktionen (Chang et al. 2002). Ebenso können seneszente Fibroblasten die Tumorgenese unterstützen durch Freigabe von u. a. IL-6 und IL-8 (Förderung der Tumorinvasion), GRO- $\alpha$ (Stimulation der Tumorzellproliferation z. B. im Mammakarzinom), VEGF (Stimulation der Tumorangiogenese) und Amphiregulin (Förderung der Zellproliferation im Prostatakarzinom) (Bavik et al. 2006; Coppe et al. 2008). VEGF (Vascular endothelial growth factor, Vaskulärer endothelialer Wachstumsfaktor), IL (Interleukin).

\subsubsection{Klinische Nutzung des Tumorsuppressorproteins p16}

Da der CDK-Inhibitor p16 während des Zellzyklus physiologisch den Übergang von der G- in die SPhase hemmt und eine cellular senescence einleiten und aufrechterhalten kann, besteht seit langem ein großes klinisches Interesse, ihn therapeutisch nutzbar zu machen (Serrano 1997). Therapeutisch wurden bereits selektive CDK-Inhibitoren als targeted therapy innerhalb klinischer Phase I- und IIStudien an Liposarkomen, fortgeschrittenen HER-2-negativen Mammakarzinomen und Mantelzelllymphomen getestet (Dickson 2014; Dickson et al. 2016; Finn et al. 2015; Leonard et al. 2012). Patientinnen mit Östrogenrezeptor-positiven und HER-2-negativen fortgeschrittenen Mammakarzinomen zeigten nach CDK-Inhibitor-Gabe im Prüfarm in Phase II- und Phase III-Studien 
ein signifikant längeres progressionsfreies Überleben im Vergleich zu den jeweiligen Kontrollgruppen (Finn et al. 2015; Finn et al. 2016). Weitere aktive klinische Phase I-III Studien mit dem 2016 in der Europäischen Union zugelassenen CDK-Inhibitor PD-0332991 (Handelsname: Palbociclib, Firma Pfizer Limited, Kent, Vereinigtes Königreich) zur Behandlung von KRK, Glioblastomen, Ovarial- und Prostatakarzinomen sind derzeit noch nicht abgeschlossen (Schroder und McDonald 2015).

Neben dem Einsatz von künstlichen CDK-Inhibitoren sollte auch die Induktion von cellular senescence durch konventionelle onkologische Therapien in den Fokus der Forschung rücken. In der onkologischen Standardtherapie eingesetzte Chemotherapeutika und RT induzieren ebenfalls eine cellular senescence (Gewirtz et al. 2008), die in vivo durch Beeinflussung des Immunsystems eine tumorablative Bedeutung haben kann (siehe Kapitel 4.1.14). Schmitt et al. (2002) zeigten als erste Arbeitsgruppe, dass eine CTx-assoziierte cellular senescence in vivo (im Lymphom-Mausmodell) einen positiven prognostischen Effekt besitzt. Die Mäuse, die aufgrund von Gendefekten keine cellular senescence ausbilden konnten, zeigten ein signifikant schlechteres Überleben gegenüber jenen Mäusen, die mit einer gesteigerten p16-Expression und einer damit verbundenen cellular senescence auf die CTx reagiert hatten (Schmitt et al. 2002). Anhand der eigenen Untersuchungsergebnisse an Rektumkarzinomgewebe wird verdeutlicht, dass eine neoadjuvante RCT die p16-Expression in Rektumkarzinomen induziert und der RCT-bedingte Tumorregressionsgrad mit der Höhe der p16Expression positiv korreliert. Dementsprechend kann die von der RCT induzierte, mit einer erhöhten p16-Expression verbundene cellular senescence einen positiven Effekt auf das Therapieansprechen haben.

Dieses Wissen sollte möglichst zeitnah in der Konzeption und Umsetzung klinischer Studien mit innovativen, an das individuelle Rezidiv-Risiko adaptierten multimodalen Therapiestrategien (präund/oder postoperativ) genutzt werden. Zudem könnten unter Einbeziehung anderer Biomarkerauswertungen aus dem Teilprojekt 5a (der KFO-179-2) durch die Ermittlung der p16Färbescores jene Patientenfälle retrospektiv identifiziert werden, die nach präoperativer RCT einen prognostisch ungünstigen TRG und eine niedrige p16-Expression als Zeichen eines Therapieversagens zeigten. Das Karzinomgewebe dieser Patientenfälle hat scheinbar die Fähigkeit verloren, auf eine iatrogene DNA-Schädigung (z.B. durch RCT) mit einer gesteigerten p16-Expression und nachfolgender cellular senescence $\mathrm{zu}$ reagieren. Weitergehende molekularbiologische Untersuchungen und vor allem komplexe biostatistische Analysen sollten es schon jetzt ermöglichen, derartige Patientenfälle a priori zu entdecken. Durch eine prädiktive Einschätzung des potentiellen Therapieansprechens könnten neoadjuvante Behandlungsformen intensiviert oder deeskaliert werden. Zudem könnte auch die postoperative multimodale Therapie schon sehr frühzeitig (spätestens postoperativ) auf die bisherige Karzinomreaktion fokussiert adaptiert werden im Sinne einer weiteren Therapie-Intensivierung, einer -Deeskalation oder sogar der Einleitung alternativer Behandlungsmaßnahmen (z.B. palliative oder rein supportive Maßnahmen). 


\subsubsection{6 p16 als prognostischer Marker}

Die prognostische Bedeutung der Expression des Tumorsuppressorproteins p16 in soliden Tumoren ist von großem Interesse. Im Mammakarzinom und im Prostatakarzinom konnte gezeigt werden, dass eine hohe p16-Expression der Tumorzellen innerhalb der Resektate mit einer schlechteren Prognose einhergeht (Han et al. 2001; Henshall et al. 2001). Dies wird auf die tumorfördernde Sekretion (siehe Kapitel 4.1.14) von seneszenten Zellen zurückgeführt (Roninson 2003). Aus oropharyngealen Plattenepithelkarzinomen ist bekannt, dass p16-positive Tumoren sowohl nach RCT als auch nach primärer Operation - auch unabhängig vom Nachweis einer HPV-Infektion - eine bessere Prognose (DFS und OS) haben als p16-negative Tumoren (Lewis et al. 2010; Rischin et al. 2010).

Die vorliegende Arbeit untersuchte die Korrelation zwischen dem p16-Score und Überlebensparametern. Weder in der neoadjuvant behandelten noch in der primär operierten Kohorte konnte zwischen p16-Score und TTR bzw. CSS eine signifikante Korrelation beobachtet werden (siehe Kapitel 3.7.1). In der Kohorte der neoadjuvant behandelten Patienten zeigte sich jedoch eine signifikante Korrelation zwischen der p16-Expression und dem TRG (siehe Kapitel 4.1.13). Die Höhe des TRG ist in der Literatur als Surrogatparameter für die weitere Prognose bekannt (siehe Kapitel 1.8) und korreliert mit dem DFS (Fokas et al. 2014). Daher kann - bei der vorliegenden signifikanten Korrelation der p16-Expression mit dem TRG - eigentlich auch eine Korrelation der p16-Expression mit Überlebensparametern erwartet werden, die die vorliegende Arbeit allerdings nicht zeigen konnte. $\mathrm{Da}$ diese Arbeit die erste Untersuchung ist, die die Korrelation der p16-Expression neoadjuvant behandelter Rektumkarzinome mit Überlebensparametern analysiert, werden weitere Studien zu diesem Thema benötigt.

Der Einfluss der p16-Expression im nicht vorbehandelten KRK auf die Prognose wurde in einigen dieser Diskussion zugrunde liegenden Studien untersucht. Die große Mehrzahl der Studien fand wie diese Arbeit keine signifikante Korrelation zwischen p16-Expression und den untersuchten prognostischen Parametern (Deschoolmeester et al. 2010; Kamoshida et al. 2004b; Lam et al. 2008; McKay et al. 2002; Norrie et al. 2003; Shima et al. 2011; Tada et al. 2003; von Stockmar-von Wangenheim et al. 2008). Lediglich zwei Arbeitsgruppen stellten für Patienten mit hoher p16Expression ein signifikant besseres Überleben (OS) fest (Lyall et al. 2006; Zhao et al. 2003). Lyall et al. (2006) analysierten mehrere Proteine immunhistochemisch und bildeten Clustergruppen, die sich durch ähnliche Proteinexpressionsmuster auszeichneten. Die Expression von p16 war hierbei in einer Gruppe von Patienten mit schlechter Prognose signifikant niedriger als in einer Gruppe mit guter Prognose. Hierbei waren allerdings die Fallzahlen in den jeweiligen Gruppen gering (Lyall et al. 2006). Im Gegensatz dazu zeigten zwei Arbeitsgruppen, dass eine hohe p16-Expression mit einem signifikant schlechteren Überleben (OS) korreliert (Cui et al. 2004; Wassermann et al. 2009). Cui et al. (2004) beobachteten zusätzlich bei Patienten mit einer p16-Überexpression (definiert als $>80 \%$ des Tumors gefärbt) eine signifikant höhere Lokalrezidivrate (Cui et al. 2004). Divergierende Ergebnisse verschiedener Studien lassen sich durch die unterschiedlichen immunhistochemischen 
Auswertungsverfahren erklären, wie z. B. die unterschiedlichen Definitionen einer negativen Färbung (siehe Kapitel 4.3.1) und die Untersuchung verschiedener Patientenkohorten (siehe Anhang, Tabelle 6.1). Aus den aktuell vorliegenden Daten lässt sich kein prognostischer Einfluss der p16-Expression im nicht vorbehandelten KRK ableiten; jedoch zeigt diese Arbeit, dass die p16-Expression im neoadjuvant behandelten Karzinom mit dem etablierten Prognoseparameter TRG korreliert (siehe Kapitel 3.5.4). 


\section{Zusammenfassung}

\subsection{Hintergrund und Zielsetzung}

Die neoadjuvante 5-FU-basierte Langzeit-Radiochemotherapie (gefolgt von einer totalen mesorektalen Exzision und adjuvanter Chemotherapie) hat sich im multimodalen Therapiekonzept bei lokal fortgeschrittenen Rektumkarzinomen aufgrund ihrer niedrigeren Lokalrezidivrate als Standard etabliert. Aufgrund der heterogenen Tumorbiologie zeigen Rektumkarzinome ein sehr variables Ansprechen auf eine neoadjuvante Radiochemotherapie (RCT), das von kompletter Tumorregression bis $\mathrm{zu}$ vollständiger Therapieresistenz reichen kann. Bisher kann der Grad des erwarteten Therapieansprechens für den einzelnen Patienten jedoch nicht vorhergesagt werden. Es werden Biomarker benötigt, die einerseits prätherapeutisch Patienten identifizieren können, die eine gegenüber der Standardtherapie intensiviertere Therapie benötigen, andererseits auch postoperativ eine individuelle Entscheidung für eine effektivere adjuvante Behandlungsform ermöglichen.

In der vorliegenden Dissertation wurde das Tumorsuppressorprotein p16 untersucht, welches als Vermittler eines Zellzyklusarrestes einen vielversprechenden Biomarker zur klinischen Therapiestratifizierung darstellt. Dafür wurde die Bedeutung der immunhistochemischen p16Expression einerseits in Resektaten von primär operierten Patienten und andererseits in Biopsien und Resektaten von vorbehandelten Patienten vor und nach neoadjuvanter RCT evaluiert.

\subsection{Material, Methoden und Patientenkollektiv}

Von den 261 Patienten lagen für die p16-Analysen insgesamt 40 prätherapeutische Biopsien und 156 Resektate von neoadjuvant therapierten Patienten sowie 98 Resektate von primär operierten Patienten vor. Als Grundlage für die Expressionsanalyse erfolgte eine immunhistochemische Färbung an Formalin-fixiertem und in Paraffin eingebettetem Material mittels eines spezifischen p16-Antikörpers. Aus der Färbeintensität und dem prozentual gefärbten Tumoranteil wurde ein p16-Score gebildet und für alle vorliegenden Biopsien und Tumorresektate bestimmt. Der p16-Score wurde jeweils separat für das normale Darmepithel, den Adenomanteil und den invasiven Anteil des Tumors gebildet. Zusätzlich wurde das p16-Expressionsmuster und die stromale p16-Expression untersucht. Sowohl für diese p16-Expressionsergebnisse als auch die jeweils ermittelten p16-Scores wurde ein potentieller statistischer Zusammenhang mit klinisch-pathologischen und Überlebensparametern (Time to recurrence (TTR), Cancer specific survival (CSS)) untersucht. Zusätzlich wurden vergleichende Analysen zwischen prätherapeutischen Biopsien und dem jeweiligen korrespondierenden Resektatgewebe nach neoadjuvanter RCT durchgeführt ( $\mathrm{n}=33)$.

\subsection{Ergebnisse}

Der p16-Score der Karzinomanteile ist in den neoadjuvant behandelten Resektaten signifikant höher als in den primär operierten Resektaten (Mittelwert 99,4 vs. 29,8, $n=254, p<0,001$ ). Der p16-Score der 
Adenomanteile liegt in den neoadjuvant behandelten Resektaten ebenfalls signifikant höher als in den primär operierten Resektaten $(\mathrm{n}=56, \mathrm{p}<0,001)$. Die $\mathrm{p} 16$-Expression des normalen Darmepithels korrelierte nicht mit der präoperativen Therapie $(n=192, p=0,4)$. In den neoadjuvant behandelten Resektaten lassen sich signifikant häufiger homogen angefärbte Tumorareale finden $(p<0,001)$. Der p16-Score des Karzinomanteils im Resektat korreliert mit dem Tumorregressionsgrad (TRG) in Prozent und in Graden ( $p=0,002$ bzw. $p<0,001$ ). Es besteht keine Korrelation des p16-Scores mit den anderen klinisch-pathologischen und Überlebensparametern (TTR und CSS). Es wurde jedoch eine Korrelation zwischen dem Grad der Stromafärbung und dem Patientenalter beobachtet $(p=0,02)$.

\subsection{Schlussfolgerungen und Ausblick}

Das Tumorsuppressorprotein p16 wurde im nicht neoadjuvant behandelten Rektumkarzinom im Vergleich zum normalen Darmepithel deutlich stärker exprimiert. Zudem induzierte eine neoadjuvante Radiochemotherapie eine noch höhere und homogenere p16-Expression als diese bei primär operierten Patienten beobachtet wurde. Neben der p16-Expression der Tumorzellen zeigte sich in dieser Arbeit auch eine Anfärbung der Stromazellen, die nicht von der Vorbehandlung abhängig war, aber mit dem Patientenalter korrelierte. Ein Zusammenhang mit den Überlebensparametern ergab sich nicht.

Die vorliegende Arbeit zeigte eine signifikante Korrelation der p16-Expression im Karzinomgewebe des Resektates nach neoadjuvanter RCT mit dem TRG. Dieses eindrucksvolle Ergebnis steht im Einklang mit Publikationen, die ebenfalls eine Korrelation zwischen der p16-Expression von mit alleiniger Chemotherapie vorbehandelten kolorektalen Karzinomen mit der Tumorregression bzw. sogar eine Korrelation zwischen der p16-Expression aus der prätherapeutischen Biopsie mit dem Therapieansprechen beobachteten (siehe Kapitel 4.1.12 und Kapitel 4.1.13).

Zusammenfassend betrachtet tragen die Ergebnisse der vorliegenden Arbeit dazu bei, dass der immunhistochemische Nachweis einer p16-Expression als therapiestratifizierender Biomarker sowohl vor als auch nach einer neoadjuvanten Radiochemotherapie genutzt werden kann. Patienten, bei denen aufgrund niedriger p16-Expression in der Biopsie oder im Resektat nach RCT kein ausreichendes Therapieansprechen erwartet wird, könnten in der Folge einer intensivierten oder zumindest modifizierten Behandlung zugeführt werden. Zur klinischen Implementierung einer derartigen Therapiestratifizierung bedarf es weiterer Studien mit hohen Patientenzahlen, aussagekräftigen Nachsorgeintervallen und langen Nachbeobachtungszeiträumen. Ziel wäre es, nicht nur die Korrelation der p16-Expression mit dem TRG zu reproduzieren, sondern auch einen direkten prognostischen Effekt, gemessen an TTR oder CSS zu beobachten. Grundlage für derartige Studien muss ein einheitliches Scoring-System der p16-Immunhistochemie und des TRGs sein. Diese Arbeit empfiehlt dafür einen p16-Score, der sowohl den positiv gefärbten Tumoranteil als auch die jeweilige Färbeintensität berücksichtigt, sowie die Angabe der Tumorregression in prozentualem Anteil am Gesamttumor. 


\section{Anhang}

Tabelle 6.1: Übersicht über die Veröffentlichungen, die die immunhistochemische p16-Expression im KRK untersucht haben

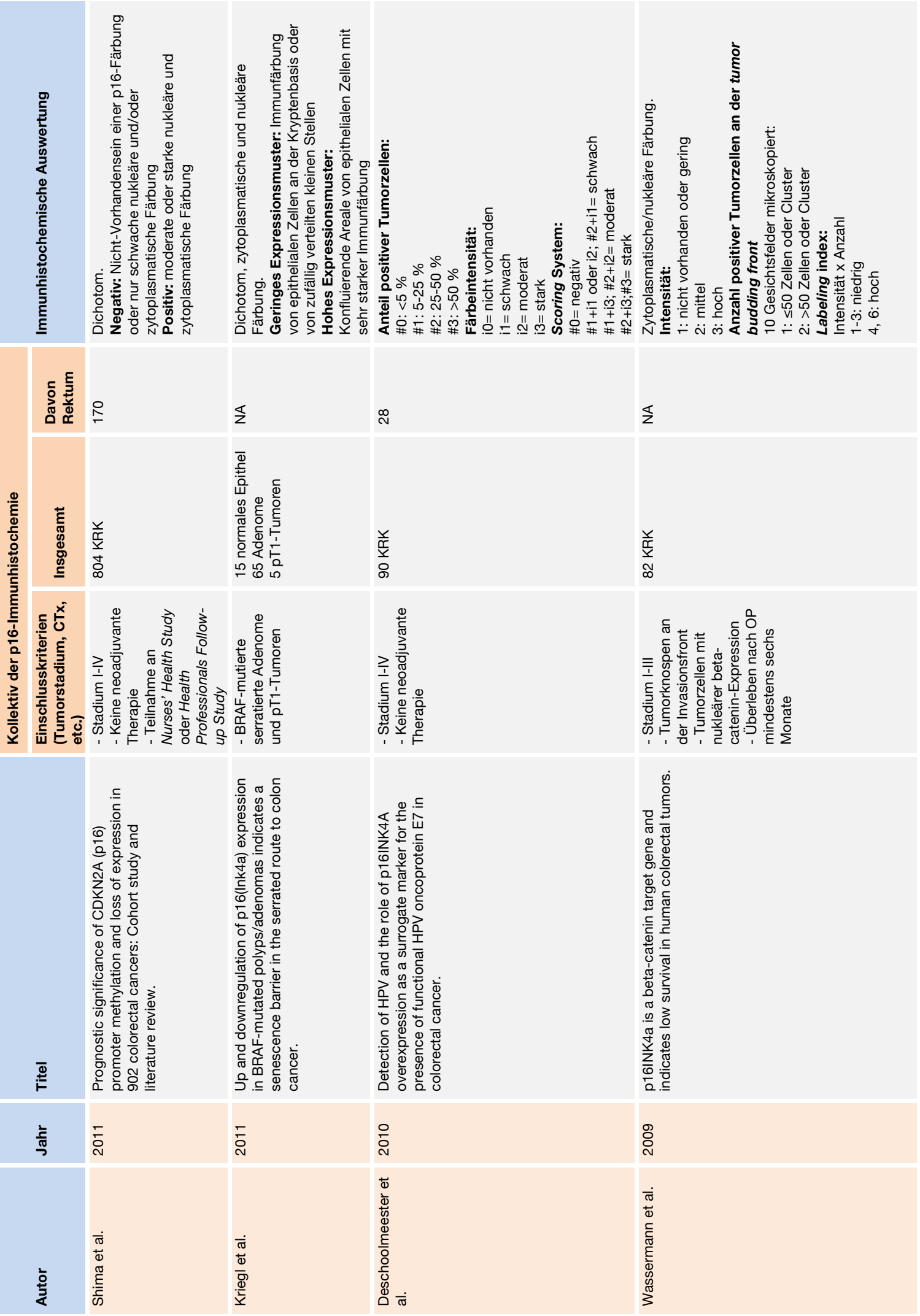




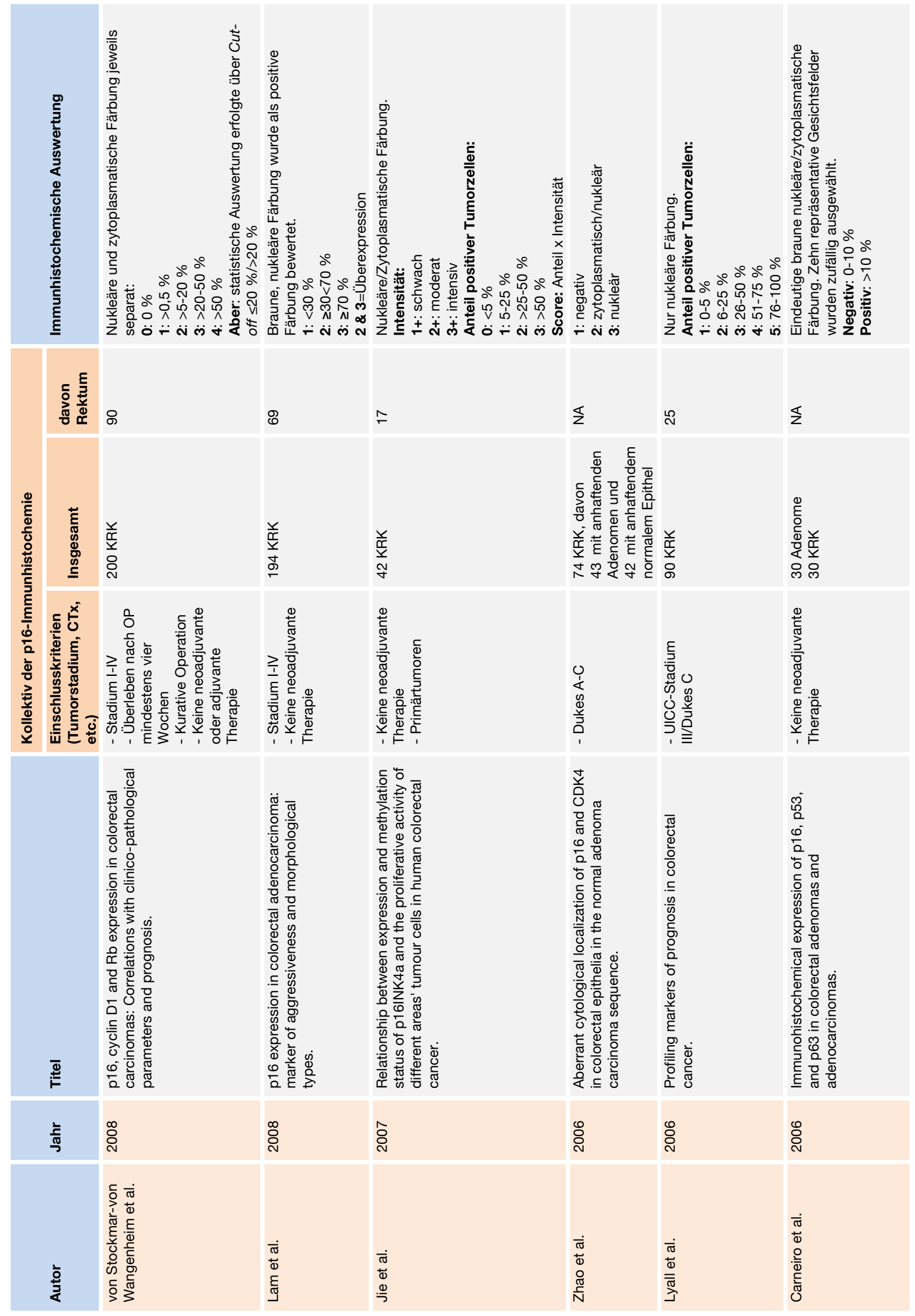




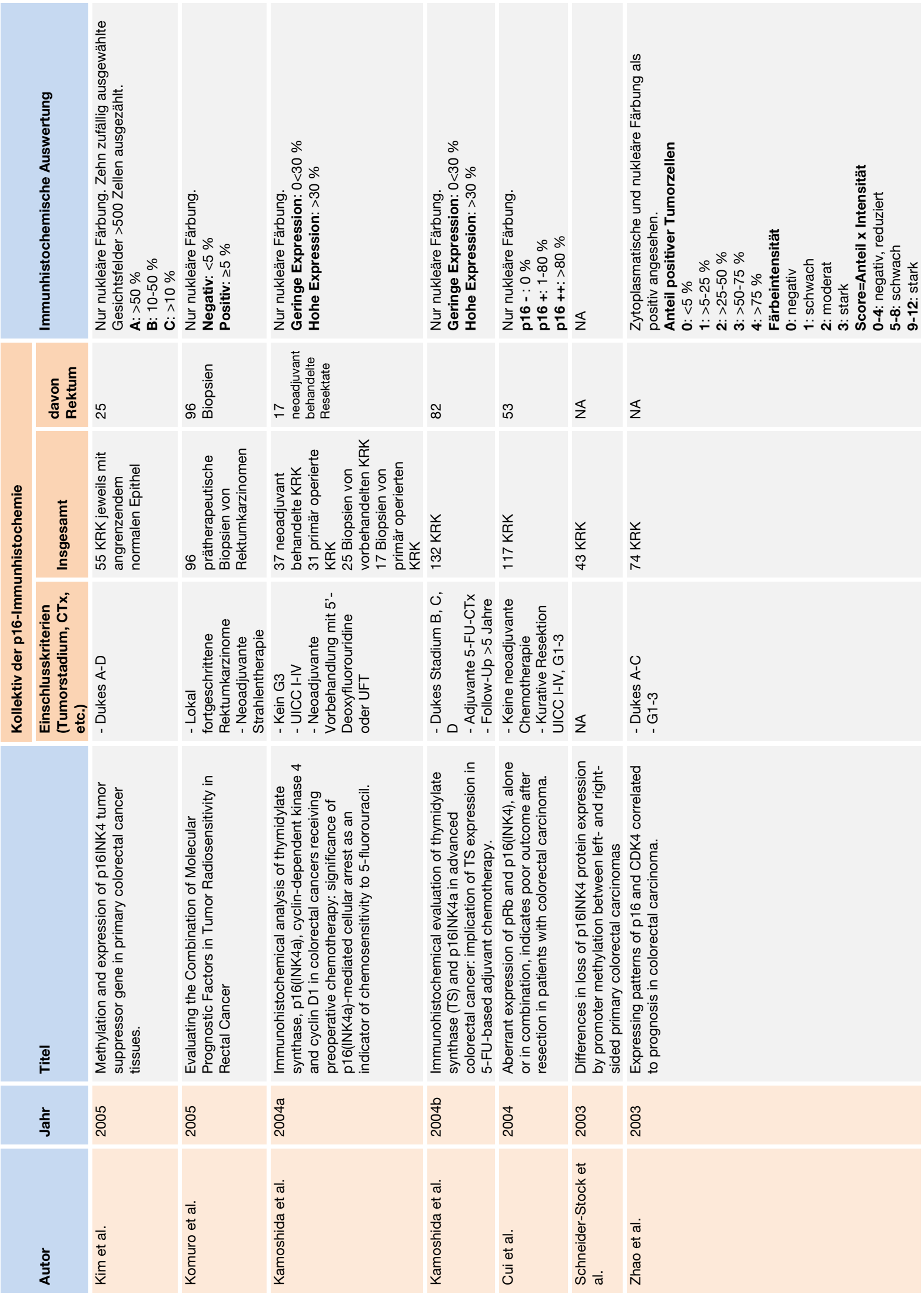




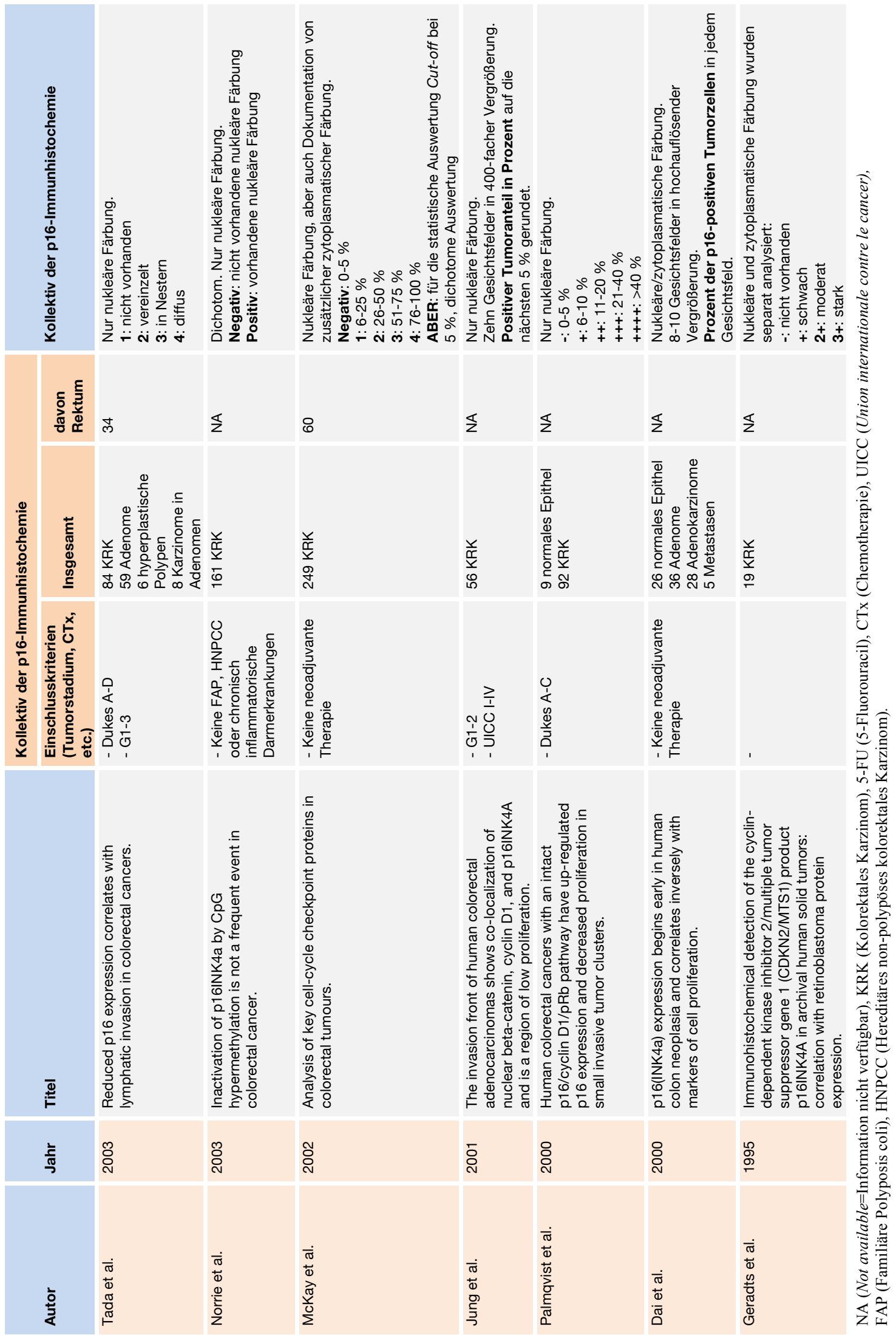




\section{Literaturverzeichnis}

Aarnio M, Mecklin JP, Aaltonen LA, Nystrom-Lahti M, Jarvinen HJ (1995): Life-time risk of different cancers in hereditary non-polyposis colorectal cancer (HNPCC) syndrome. Int J Cancer $\underline{64}$, $430-433$

Alcorta DA, Xiong Y, Phelps D, Hannon G, Beach D, Barrett JC (1996): Involvement of the cyclindependent kinase inhibitor p16 (INK4a) in replicative senescence of normal human fibroblasts. Proc Natl Acad Sci U S A 93, 13742-13747

Alspach E, Fu Y, Stewart SA (2013): Senescence and the pro-tumorigenic stroma. Crit Rev Oncog $\underline{18}, 549-558$

Arango D, Wilson AJ, Shi Q, Corner GA, Aranes MJ, Nicholas C, Lesser M, Mariadason JM, Augenlicht LH (2004): Molecular mechanisms of action and prediction of response to oxaliplatin in colorectal cancer cells. Br J Cancer 91, 1931-1946

Azumi N, Battifora H (1987): The distribution of vimentin and keratin in epithelial and nonepithelial neoplasms. A comprehensive immunohistochemical study on formalin- and alcohol-fixed tumors. Am J Clin Pathol 88, 286-296

Bang YJ, Van Cutsem E, Feyereislova A, Chung HC, Shen L, Sawaki A, Lordick F, Ohtsu A, Omuro Y, Satoh T, et al. (2010): Trastuzumab in combination with chemotherapy versus chemotherapy alone for treatment of HER2-positive advanced gastric or gastro-oesophageal junction cancer (ToGA): a phase 3, open-label, randomised controlled trial. Lancet $\underline{376}$, 687-697

Barcellos-Hoff MH, Ravani SA (2000): Irradiated mammary gland stroma promotes the expression of tumorigenic potential by unirradiated epithelial cells. Cancer Res $\underline{60}, 1254-1260$

Barillari P, Ramacciato G, De Angelis R, Gozzo P, Indinnimeo M, Valabrega S, Aurello P, Fegiz G (1990): Effect of preoperative colonoscopy on the incidence of synchronous and metachronous neoplasms. Acta Chir Scand 156, 163-166

Bataini JP, Belloir C, Mazabraud A, Pilleron JP, Cartigny A, Jaulerry C, Ghossein NA (1988): Desmoid tumors in adults: the role of radiotherapy in their management. Am J Surg 155, 754-760 
Bavik C, Coleman I, Dean JP, Knudsen B, Plymate S, Nelson PS (2006): The gene expression program of prostate fibroblast senescence modulates neoplastic epithelial cell proliferation through paracrine mechanisms. Cancer Res $\underline{66}, 794-802$

Baxter NN, Warren JL, Barrett MJ, Stukel TA, Doria-Rose VP (2012): Association between colonoscopy and colorectal cancer mortality in a US cohort according to site of cancer and colonoscopist specialty. J Clin Oncol 30, 2664-2669

Beausejour CM, Krtolica A, Galimi F, Narita M, Lowe SW, Yaswen P, Campisi J (2003): Reversal of human cellular senescence: roles of the p53 and p16 pathways. EMBO J 22, 4212-4222

Beets-Tan RG (2003): MRI in rectal cancer: the T stage and circumferential resection margin. Colorectal Dis $\underline{5}, 392-395$

Birgisson H, Wallin U, Holmberg L, Glimelius B (2011): Survival endpoints in colorectal cancer and the effect of second primary other cancer on disease free survival. BMC Cancer 11, 438

Bland JM, Altman DG (1998): Survival probabilities (the Kaplan-Meier method). BMJ 317, 1572

Bland JM, Altman DG (2004): The logrank test. BMJ $\underline{328,} 1073$

Bortz J, Lienert GA, Boehnke K: Verteilungsfreie Methoden in der Biostatistik. Springer, Berlin Heidelberg 2008

Brenner H, Stock C, Hoffmeister M (2014): Effect of screening sigmoidoscopy and screening colonoscopy on colorectal cancer incidence and mortality: systematic review and meta-analysis of randomised controlled trials and observational studies. BMJ 348, g2467

Brenner H, Altenhofen L, Kretschmann J, Rosch T, Pox C, Stock C, Hoffmeister M (2015): Trends in Adenoma Detection Rates During the First 10 Years of the German Screening Colonoscopy Program. Gastroenterology 149, 356-366 e351

Brenner H, Zwink N, Ludwig L, Hoffmeister M (2017): Should screening colonoscopy be offered from age 50? Dtsch Arztebl International 114, 94-100

Bringold F, Serrano M (2000): Tumor suppressors and oncogenes in cellular senescence. Exp Gerontol 35, 317-329 
Brule SY, Jonker DJ, Karapetis CS, O'Callaghan CJ, Moore MJ, Wong R, Tebbutt NC, Underhill C, Yip D, Zalcberg JR, et al. (2015): Location of colon cancer (right-sided versus left-sided) as a prognostic factor and a predictor of benefit from cetuximab in NCIC CO.17. Eur J Cancer 51, 14051414

Burd CE, Sorrentino JA, Clark KS, Darr DB, Krishnamurthy J, Deal AM, Bardeesy N, Castrillon DH, Beach DH, Sharpless NE (2013): Monitoring tumorigenesis and senescence in vivo with a p16(INK4a)-luciferase model. Cell 152, 340-351

Burri N, Shaw P, Bouzourene H, Sordat I, Sordat B, Gillet M, Schorderet D, Bosman FT, Chaubert P (2001): Methylation silencing and mutations of the p14ARF and p16INK4a genes in colon cancer. Lab Invest $\underline{81}, 217-229$

Burton DG, Krizhanovsky V (2014): Physiological and pathological consequences of cellular senescence. Cell Mol Life Sci 71, 4373-4386

Carneiro FP, Ramalho LN, Britto-Garcia S, Ribeiro-Silva A, Zucoloto S (2006):

Immunohistochemical expression of p16, p53, and p63 in colorectal adenomas and adenocarcinomas. Dis Colon Rectum 49, 588-594

Chan AK, Wong A, Jenken D, Heine J, Buie D, Johnson D (2005): Posttreatment TNM staging is a prognostic indicator of survival and recurrence in tethered or fixed rectal carcinoma after preoperative chemotherapy and radiotherapy. Int J Radiat Oncol Biol Phys $\underline{61}$, 665-677

Chang BD, Broude EV, Dokmanovic M, Zhu H, Ruth A, Xuan Y, Kandel ES, Lausch E, Christov K, Roninson IB (1999): A senescence-like phenotype distinguishes tumor cells that undergo terminal proliferation arrest after exposure to anticancer agents. Cancer Res $\underline{59}, 3761-3767$

Chang BD, Swift ME, Shen M, Fang J, Broude EV, Roninson IB (2002): Molecular determinants of terminal growth arrest induced in tumor cells by a chemotherapeutic agent. Proc Natl Acad Sci U S A $\underline{99}, 389-394$

Chapet O, Romestaing P, Mornex F, Souquet JC, Favrel V, Ardiet JM, d'Hombres A, Gerard JP (2005): Preoperative radiotherapy for rectal adenocarcinoma: Which are strong prognostic factors? Int J Radiat Oncol Biol Phys 61, 1371-1377 
Chaubert P, Gayer R, Zimmermann A, Fontolliet C, Stamm B, Bosman F, Shaw P (1997): Germline mutations of the p16INK4(MTS1) gene occur in a subset of patients with hepatocellular carcinoma. Hepatology 25, 1376-1381

Chen HS, Sheen-Chen SM (2000): Synchronous and "early" metachronous colorectal adenocarcinoma: analysis of prognosis and current trends. Dis Colon Rectum $\underline{43}, 1093-1099$

Chen Q, Ames BN (1994): Senescence-like growth arrest induced by hydrogen peroxide in human diploid fibroblast F65 cells. Proc Natl Acad Sci U S A 91, 4130-4134

Chen QM, Bartholomew JC, Campisi J, Acosta M, Reagan JD, Ames BN (1998): Molecular analysis of $\mathrm{H} \mathrm{O}$-induced senescent-like growth arrest in normal human fibroblasts: p53 and Rb control G1 arrest but not cell replication. Biochem J 332 ( Pt 1), 43-50

Chen QM (2000): Replicative senescence and oxidant-induced premature senescence. Beyond the control of cell cycle checkpoints. Ann N Y Acad Sci 908, 111-125

Cho E, Smith-Warner SA, Ritz J, van den Brandt PA, Colditz GA, Folsom AR, Freudenheim JL, Giovannucci E, Goldbohm RA, Graham S, et al. (2004): Alcohol intake and colorectal cancer: a pooled analysis of 8 cohort studies. Ann Intern Med 140, 603-613

Chuprin A, Gal H, Biron-Shental T, Biran A, Amiel A, Rozenblatt S, Krizhanovsky V (2013): Cell fusion induced by ERVWE1 or measles virus causes cellular senescence. Genes Dev 27, 2356-2366

Collado M, Blasco MA, Serrano M (2007): Cellular senescence in cancer and aging. Cell 130, 223233

Colussi D, Brandi G, Bazzoli F, Ricciardiello L (2013): Molecular pathways involved in colorectal cancer: implications for disease behavior and prevention. Int J Mol Sci 14, 16365-16385

Conradi LC, Bleckmann A, Schirmer M, Sprenger T, Jo P, Homayounfar K, Wolff HA, Rothe H, Middel P, Becker H, et al. (2011): Thymidylate synthase as a prognostic biomarker for locally advanced rectal cancer after multimodal treatment. Ann Surg Oncol 18, 2442-2452

Conradi LC, Styczen H, Sprenger T, Wolff HA, Rödel C, Nietert M, Homayounfar K, Gaedcke J, Kitz J, Talaulicar R, et al. (2013): Frequency of HER-2 positivity in rectal cancer and prognosis. Am J Surg Pathol 37, 522-531 
Coppe JP, Patil CK, Rodier F, Sun Y, Munoz DP, Goldstein J, Nelson PS, Desprez PY, Campisi J (2008): Senescence-associated secretory phenotypes reveal cell-nonautonomous functions of oncogenic RAS and the p53 tumor suppressor. PLoS Biol $\underline{6}, 2853-2868$

Coppe JP, Desprez PY, Krtolica A, Campisi J (2010): The senescence-associated secretory phenotype: the dark side of tumor suppression. Annu Rev Pathol 5, 99-118

Coppe JP, Rodier F, Patil CK, Freund A, Desprez PY, Campisi J (2011): Tumor suppressor and aging biomarker p16(INK4a) induces cellular senescence without the associated inflammatory secretory phenotype. J Biol Chem 286, 36396-36403

Cox JD, Kline RW (1983): Do prostatic biopsies 12 months or more after external irradiation for adenocarcinoma, Stage III, predict long-term survival? Int J Radiat Oncol Biol Phys 9, 299-303

Crook T, Tidy JA, Vousden KH (1991): Degradation of p53 can be targeted by HPV E6 sequences distinct from those required for p53 binding and trans-activation. Cell $\underline{67}, 547-556$

Cui X, Shirai Y, Wakai T, Yokoyama N, Hirano S, Hatakeyama K (2004): Aberrant expression of $\mathrm{pRb}$ and $\mathrm{p} 16(\mathrm{INK} 4)$, alone or in combination, indicates poor outcome after resection in patients with colorectal carcinoma. Hum Pathol 35, 1189-1195

Czito BG, Willett CG (2007): Contemporary management of rectal cancer: new standards, mounting questions, emerging challenges. Gastrointest Cancer Res $\underline{1}, 66-67$

Dai CY, Furth EE, Mick R, Koh J, Takayama T, Niitsu Y, Enders GH (2000): p16(INK4a) expression begins early in human colon neoplasia and correlates inversely with markers of cell proliferation. Gastroenterology 119, 929-942

Demaria M, Ohtani N, Youssef SA, Rodier F, Toussaint W, Mitchell JR, Laberge RM, Vijg J, Van Steeg H, Dolle ME, et al. (2014): An essential role for senescent cells in optimal wound healing through secretion of PDGF-AA. Dev Cell $\underline{31}, 722-733$

Deschoolmeester V, Van Marck V, Baay M, Weyn C, Vermeulen P, Van Marck E, Lardon F, Fontaine V, Vermorken JB (2010): Detection of HPV and the role of p16INK4A overexpression as a surrogate marker for the presence of functional HPV oncoprotein E7 in colorectal cancer. BMC Cancer 10, 117 
Detre S, Saclani Jotti G, Dowsett M (1995): A "quickscore" method for immunohistochemical semiquantitation: validation for oestrogen receptor in breast carcinomas. J Clin Pathol 48, 876-878

Dickson MA (2014): Molecular Pathways: CDK4 Inhibitors for Cancer Therapy. Clin Cancer Res 20, 3379-3383

Dickson MA, Schwartz GK, Keohan ML, D'Angelo SP, Gounder MM, Chi P, Antonescu CR, Landa J, Qin LX, Crago AM, et al. (2016): Progression-Free Survival Among Patients With WellDifferentiated or Dedifferentiated Liposarcoma Treated With CDK4 Inhibitor Palbociclib: A Phase 2 Clinical Trial. JAMA Oncol 2, 937-940

Dworak O, Keilholz L, Hoffmann A (1997): Pathological features of rectal cancer after preoperative radiochemotherapy. Int J Colorectal Dis $\underline{12}, 19-23$

Eaden JA, Abrams KR, Mayberry JF (2001): The risk of colorectal cancer in ulcerative colitis: a meta-analysis. Gut $\underline{48}, 526-535$

Edwards J, Mukherjee R, Munro AF, Wells AC, Almushatat A, Bartlett JM (2004): HER2 and COX2 expression in human prostate cancer. Eur J Cancer $\underline{40}, 50-55$

Emig R, Magener A, Ehemann V, Meyer A, Stilgenbauer F, Volkmann M, Wallwiener D, Sinn HP (1998): Aberrant cytoplasmic expression of the p16 protein in breast cancer is associated with accelerated tumour proliferation. Br J Cancer $\underline{78}, 1661-1668$

Eriksson D, Stigbrand T (2010): Radiation-induced cell death mechanisms. Tumour Biol 31, 363372

Eriksson JE, Dechat T, Grin B, Helfand B, Mendez M, Pallari HM, Goldman RD (2009):

Introducing intermediate filaments: from discovery to disease. J Clin Invest $\underline{119}, 1763-1771$

Fearon ER, Vogelstein B (1990): A genetic model for colorectal tumorigenesis. Cell $\underline{61,759-767}$

Fielding LP, Arsenault PA, Chapuis PH, Dent O, Gathright B, Hardcastle JD, Hermanek P, Jass JR, Newland RC (1991): Clinicopathological staging for colorectal cancer: an International Documentation System (IDS) and an International Comprehensive Anatomical Terminology (ICAT). J Gastroenterol Hepatol $\underline{6}, 325-344$ 
Finkel T, Holbrook NJ (2000): Oxidants, oxidative stress and the biology of ageing. Nature $\underline{408}$, 239-247

Finn RS, Crown JP, Lang I, Boer K, Bondarenko IM, Kulyk SO, Ettl J, Patel R, Pinter T, Schmidt M, et al. (2015): The cyclin-dependent kinase 4/6 inhibitor palbociclib in combination with letrozole versus letrozole alone as first-line treatment of oestrogen receptor-positive, HER2-negative, advanced breast cancer (PALOMA-1/TRIO-18): a randomised phase 2 study. Lancet Oncol 16, 2535

Finn RS, Martin M, Rugo HS, Jones S, Im SA, Gelmon K, Harbeck N, Lipatov ON, Walshe JM, Moulder S, et al. (2016): Palbociclib and Letrozole in Advanced Breast Cancer. N Engl J Med 375, $1925-1936$

Fitzpatrick-Lewis D, Ali MU, Warren R, Kenny M, Sherifali D, Raina P (2016): Screening for Colorectal Cancer: A Systematic Review and Meta-Analysis. Clin Colorectal Cancer 15, 298-313

Floriani I, Torri V, Rulli E, Garavaglia D, Compagnoni A, Salvolini L, Giovagnoni A (2010): Performance of imaging modalities in diagnosis of liver metastases from colorectal cancer: a systematic review and meta-analysis. J Magn Reson Imaging 31, 19-31

Fokas E, Liersch T, Fietkau R, Hohenberger W, Beissbarth T, Hess C, Becker H, Ghadimi M, Mrak $\mathrm{K}$, Merkel S, et al. (2014): Tumor regression grading after preoperative chemoradiotherapy for locally advanced rectal carcinoma revisited: updated results of the CAO/ARO/AIO-94 trial. J Clin Oncol $\underline{32}, 1554-1562$

Foulkes WD, Flanders TY, Pollock PM, Hayward NK (1997): The CDKN2A (p16) gene and human cancer. Mol Med 3, 5-20

Fraser JA, Reeves JR, Stanton PD, Black DM, Going JJ, Cooke TG, Bartlett JM (2003): A role for BRCA1 in sporadic breast cancer. Br J Cancer $\underline{88}$, 1263-1270

Frykholm GJ, Pahlman L, Glimelius B (2001): Combined chemo- and radiotherapy vs. radiotherapy alone in the treatment of primary, nonresectable adenocarcinoma of the rectum. Int J Radiat Oncol Biol Phys 50, 427-434 
Gaedcke J, Liersch T, Hess C, Becker H, Rödel C, Ghadimi BM (2011): [Rectal cancer: current status of multimodal therapy - when and how?]. Zentralbl Chir 136, 334-342

Gal H, Krizhanovsky V (2014): Cell fusion induced senescence. Aging (Albany NY) $\underline{6}, 353-354$

Geradts J, Kratzke RA, Niehans GA, Lincoln CE (1995): Immunohistochemical detection of the cyclin-dependent kinase inhibitor 2/multiple tumor suppressor gene 1 (CDKN2/MTS1) product p16INK4A in archival human solid tumors: correlation with retinoblastoma protein expression. Cancer Res 55, 6006-6011

Gewirtz DA, Holt SE, Elmore LW (2008): Accelerated senescence: an emerging role in tumor cell response to chemotherapy and radiation. Biochem Pharmacol 76, 947-957

Giovannucci E (2001): An updated review of the epidemiological evidence that cigarette smoking increases risk of colorectal cancer. Cancer Epidemiol Biomarkers Prev 10, 725-731

Goldgar DE, Easton DF, Cannon-Albright LA, Skolnick MH (1994): Systematic population-based assessment of cancer risk in first-degree relatives of cancer probands. J Natl Cancer Inst $\underline{86}, 1600$ 1608

Haller F, Agaimy A, Cameron S, Beyer M, Gunawan B, Happel N, Langer C, Ramadori G, von Heydebreck A, Fuzesi L (2010): Expression of p16INK4A in gastrointestinal stromal tumours (GISTs): two different forms exist that independently correlate with poor prognosis. Histopathology 56, 305-318

Halliwell B (2007): Biochemistry of oxidative stress. Biochem Soc Trans $\underline{35}, 1147-1150$

Hamilton SR, Aaltonen LA, Organization WH, Cancer IAfRo: Pathology and genetics of tumours of the digestive system. IARC Press Lyon 2000

Hamilton W, Round A, Sharp D, Peters TJ (2005): Clinical features of colorectal cancer before diagnosis: a population-based case-control study. Br J Cancer 93, 399-405

Han S, Ahn SH, Park K, Bae BN, Kim KH, Kim HJ, Kim YD, Kim HY (2001): P16INK4a protein expression is associated with poor survival of the breast cancer patients after CMF chemotherapy. Breast Cancer Res Treat 70, 205-212 
Hara E, Smith R, Parry D, Tahara H, Stone S, Peters G (1996): Regulation of p16CDKN2 expression and its implications for cell immortalization and senescence. Mol Cell Biol 16, 859-867

Harley CB, Futcher AB, Greider CW (1990): Telomeres shorten during ageing of human fibroblasts. Nature $345,458-460$

Haug U, Engel S, Verheyen F, Linder R (2014): Estimating colorectal cancer treatment costs: a pragmatic approach exemplified by health insurance data from Germany. PLoS One $\underline{9}$, e88407

Hayflick L, Moorhead PS (1961): The serial cultivation of human diploid cell strains. Exp Cell Res $\underline{25}, 585-621$

Heald RJ, Husband EM, Ryall RD (1982): The mesorectum in rectal cancer surgery - the clue to pelvic recurrence? Br J Surg 69, 613-616

Heald RJ, Ryall RD (1986): Recurrence and survival after total mesorectal excision for rectal cancer. Lancet $\underline{1}, 1479-1482$

Henshall SM, Quinn DI, Lee CS, Head DR, Golovsky D, Brenner PC, Delprado W, Stricker PD, Grygiel JJ, Sutherland RL (2001): Overexpression of the cell cycle inhibitor p16INK4A in highgrade prostatic intraepithelial neoplasia predicts early relapse in prostate cancer patients. Clin Cancer Res 7, 544-550

Herbig U, Jobling WA, Chen BP, Chen DJ, Sedivy JM (2004): Telomere shortening triggers senescence of human cells through a pathway involving ATM, p53, and p21(CIP1), but not p16(INK4a). Mol Cell 14, 501-513

Hewitson P, Glasziou P, Watson E, Towler B, Irwig L (2008): Cochrane systematic review of colorectal cancer screening using the fecal occult blood test (hemoccult): an update. Am J Gastroenterol 103, 1541-1549

Huxley RR, Ansary-Moghaddam A, Clifton P, Czernichow S, Parr CL, Woodward M (2009): The impact of dietary and lifestyle risk factors on risk of colorectal cancer: a quantitative overview of the epidemiological evidence. Int J Cancer 125, 171-180 
Ishikawa M, Fujii T, Saito M, Nindl I, Ono A, Kubushiro K, Tsukazaki K, Mukai M, Nozawa S (2006): Overexpression of p16 INK4a as an indicator for human papillomavirus oncogenic activity in cervical squamous neoplasia. Int J Gynecol Cancer 16, 347-353

Itahana K, Zou Y, Itahana Y, Martinez JL, Beausejour C, Jacobs JJ, Van Lohuizen M, Band V, Campisi J, Dimri GP (2003): Control of the replicative life span of human fibroblasts by p16 and the polycomb protein Bmi-1. Mol Cell Biol 23, 389-401

Jacob BJ, Moineddin R, Sutradhar R, Baxter NN, Urbach DR (2012): Effect of colonoscopy on colorectal cancer incidence and mortality: an instrumental variable analysis. Gastrointest Endosc $\underline{76}$, 355-364 e351

Jacobs JJ, de Lange T (2005): p16INK4a as a second effector of the telomere damage pathway. Cell Cycle $\underline{4}, 1364-1368$

Jie G, Zhixiang S, Lei S, Hesheng L, Xiaojun T (2007): Relationship between expression and methylation status of p16INK4a and the proliferative activity of different areas' tumour cells in human colorectal cancer. Int J Clin Pract 61, 1523-1529

Johns LE, Houlston RS (2001): A systematic review and meta-analysis of familial colorectal cancer risk. Am J Gastroenterol 96, 2992-3003

Jung A, Schrauder M, Oswald U, Knoll C, Sellberg P, Palmqvist R, Niedobitek G, Brabletz T, Kirchner T (2001): The invasion front of human colorectal adenocarcinomas shows co-localization of nuclear beta-catenin, cyclin D1, and p16INK4A and is a region of low proliferation. Am J Pathol $\underline{159}, 1613-1617$

Kahi CJ, Imperiale TF, Juliar BE, Rex DK (2009): Effect of screening colonoscopy on colorectal cancer incidence and mortality. Clin Gastroenterol Hepatol 7, 770-775; quiz 711

Kamb A, Gruis NA, Weaver-Feldhaus J, Liu Q, Harshman K, Tavtigian SV, Stockert E, Day RS, 3rd, Johnson BE, Skolnick MH (1994): A cell cycle regulator potentially involved in genesis of many tumor types. Science $264,436-440$

Kamoshida S, Matsuoka H, Shiogama K, Matsuyama A, Shimomura R, Inada K, Maruta M, Tsutsumi Y (2004a): Immunohistochemical analysis of thymidylate synthase, p16(INK4a), cyclindependent kinase 4 and cyclin D1 in colorectal cancers receiving preoperative chemotherapy: 
significance of p16(INK4a)-mediated cellular arrest as an indicator of chemosensitivity to 5fluorouracil. Pathol Int 54, 564-575

Kamoshida S, Matsuoka H, Ishikawa T, Maeda K, Shimomura R, Inada K, Tsutsumi Y (2004b): Immunohistochemical evaluation of thymidylate synthase (TS) and p16INK4a in advanced colorectal cancer: implication of TS expression in 5-FU-based adjuvant chemotherapy. Jpn J Clin Oncol 34, 594-601

Kang TW, Yevsa T, Woller N, Hoenicke L, Wuestefeld T, Dauch D, Hohmeyer A, Gereke M, Rudalska R, Potapova A, et al. (2011): Senescence surveillance of pre-malignant hepatocytes limits liver cancer development. Nature $\underline{479}, 547-551$

Karlseder J, Smogorzewska A, de Lange T (2002): Senescence induced by altered telomere state, not telomere loss. Science 295, 2446-2449

Kim BN, Yamamoto H, Ikeda K, Damdinsuren B, Sugita Y, Ngan CY, Fujie Y, Ogawa M, Hata T, Ikeda M, et al. (2005): Methylation and expression of p16INK4 tumor suppressor gene in primary colorectal cancer tissues. Int J Oncol 26, 1217-1226

Kirkegaard T, Edwards J, Tovey S, McGlynn LM, Krishna SN, Mukherjee R, Tam L, Munro AF, Dunne B, Bartlett JM (2006): Observer variation in immunohistochemical analysis of protein expression, time for a change? Histopathology $\underline{48}, 787-794$

Knudson AG, Jr. (1985): Hereditary cancer, oncogenes, and antioncogenes. Cancer Res $\underline{45}, 1437-$ 1443

Komuro Y, Watanabe T, Tsurita G, Muto T, Nagawa H (2005): Evaluating the combination of molecular prognostic factors in tumor radiosensitivity in rectal cancer. Hepatogastroenterology $\underline{52}$, $666-671$

Krebsfrüherkennungs-Richtlinien (2002): Richtlinien des Bundesausschusses der Ärzte und Krankenkassen über die Früherkennung von Krebserkrankungen („KrebsfrüherkennungsRichtlinien“). Fassung vom 26. April 1976, zuletzt geändert am 21. Juni 2002 (veröffentlicht im Bundesanzeiger Nr. 186 vom 5. Oktober 2002). Dtsch Arztebl 99, A-2650 / B-2258 / C-2122 
Kriegl L, Neumann J, Vieth M, Greten FR, Reu S, Jung A, Kirchner T (2011): Up and downregulation of $\mathrm{p} 16$ (Ink4a) expression in BRAF-mutated polyps/adenomas indicates a senescence barrier in the serrated route to colon cancer. Mod Pathol 24, 1015-1022

Krishnamurthy J, Torrice C, Ramsey MR, Kovalev GI, Al-Regaiey K, Su L, Sharpless NE (2004): Ink4a/Arf expression is a biomarker of aging. J Clin Invest 114, 1299-1307

Krizhanovsky V, Yon M, Dickins RA, Hearn S, Simon J, Miething C, Yee H, Zender L, Lowe SW (2008): Senescence of activated stellate cells limits liver fibrosis. Cell 134, 657-667

Krook JE, Moertel CG, Gunderson LL, Wieand HS, Collins RT, Beart RW, Kubista TP, Poon MA, Meyers WC, Mailliard JA, et al. (1991): Effective surgical adjuvant therapy for high-risk rectal carcinoma. N Engl J Med 324, 709-715

Krtolica A, Parrinello S, Lockett S, Desprez PY, Campisi J (2001): Senescent fibroblasts promote epithelial cell growth and tumorigenesis: a link between cancer and aging. Proc Natl Acad Sci U S A $\underline{98}, 12072-12077$

Krtolica A, Campisi J (2002): Cancer and aging: a model for the cancer promoting effects of the aging stroma. Int J Biochem Cell Biol 34, 1401-1414

Kwok H, Bissett IP, Hill GL (2000): Preoperative staging of rectal cancer. Int J Colorectal Dis 15, 920

Lam AK, Ong K, Giv MJ, Ho YH (2008): p16 expression in colorectal adenocarcinoma: marker of aggressiveness and morphological types. Pathology $\underline{40}, 580-585$

Larsson LG (2011): Oncogene- and tumor suppressor gene-mediated suppression of cellular senescence. Semin Cancer Biol 21, 367-376

Le ON, Rodier F, Fontaine F, Coppe JP, Campisi J, DeGregori J, Laverdiere C, Kokta V, Haddad E, Beausejour CM (2010): Ionizing radiation-induced long-term expression of senescence markers in mice is independent of p53 and immune status. Aging Cell $\underline{9}, 398-409$

Leonard JP, LaCasce AS, Smith MR, Noy A, Chirieac LR, Rodig SJ, Yu JQ, Vallabhajosula S, Schoder H, English P, et al. (2012): Selective CDK4/6 inhibition with tumor responses by PD0332991 in patients with mantle cell lymphoma. Blood 119, 4597-4607 
Levy M, Visokai V, Lipska L, Topolcan O (2008): Tumor markers in staging and prognosis of colorectal carcinoma. Neoplasma 55, 138-142

Lewis JS, Jr., Thorstad WL, Chernock RD, Haughey BH, Yip JH, Zhang Q, El-Mofty SK (2010): p16 positive oropharyngeal squamous cell carcinoma:an entity with a favorable prognosis regardless of tumor HPV status. Am J Surg Pathol 34, 1088-1096

Li J, Poi MJ, Tsai MD (2011): Regulatory mechanisms of tumor suppressor P16(INK4A) and their relevance to cancer. Biochemistry $\underline{50}, 5566-5582$

Li L, Story M, Legerski RJ (2001): Cellular responses to ionizing radiation damage. Int J Radiat Oncol Biol Phys 49, 1157-1162

Lieberman DA, Weiss DG, Bond JH, Ahnen DJ, Garewal H, Chejfec G (2000): Use of colonoscopy to screen asymptomatic adults for colorectal cancer. Veterans Affairs Cooperative Study Group 380. N Engl J Med 343, 162-168

Liersch T, Langer C, Jakob C, Muller D, Ghadimi BM, Siemer A, Markus PM, Fuzesi L, Becker H (2003): Präoperative Diagnostik beim lokal fortgeschrittenen Rektumkarzinom ( $>$ or $=\mathrm{T} 3$ oder $\mathrm{N}+$ ). Was leistet die Endosonographie gegenüber der Computertomographie im Staging und Restaging (nach neoadjuvanter Radio-/Chemotherapie)? Chirurg $\underline{74,}$, 224-234

Liersch T, Rothe H, Ghadimi BM, Becker H (2009): Therapie beim lokal fortgeschrittenen Rektumkarzinom. Chirurg 우, 281-293

Liersch T, Gaedcke J, Grade M, Sprenger T, Conradi L, Becker H, Ghadimi BM (2010): Molekulare Marker zur Responseprädiktion beim lokal fortgeschrittenen Rektumkarzinom. Der Onkologe 16, 779-788

Lin AW, Barradas M, Stone JC, van Aelst L, Serrano M, Lowe SW (1998): Premature senescence involving p53 and p16 is activated in response to constitutive MEK/MAPK mitogenic signaling. Genes Dev 12, 3008-3019

Liu X, Clements A, Zhao K, Marmorstein R (2006): Structure of the human Papillomavirus E7 oncoprotein and its mechanism for inactivation of the retinoblastoma tumor suppressor. J Biol Chem $\underline{281}, 578-586$ 
Longley DB, Harkin DP, Johnston PG (2003): 5-fluorouracil: mechanisms of action and clinical strategies. Nat Rev Cancer $\underline{3}, 330-338$

Loughran O, Malliri A, Owens D, Gallimore PH, Stanley MA, Ozanne B, Frame MC, Parkinson EK (1996): Association of CDKN2A/p16INK4A with human head and neck keratinocyte replicative senescence: relationship of dysfunction to immortality and neoplasia. Oncogene 13, 561-568

Lubbe SJ, Di Bernardo MC, Chandler IP, Houlston RS (2009): Clinical implications of the colorectal cancer risk associated with MUTYH mutation. J Clin Oncol 27, 3975-3980

Luengo-Fernandez R, Leal J, Gray A, Sullivan R (2013): Economic burden of cancer across the European Union: a population-based cost analysis. Lancet Oncol 14, 1165-1174

Lujambio A, Akkari L, Simon J, Grace D, Tschaharganeh DF, Bolden JE, Zhao Z, Thapar V, Joyce JA, Krizhanovsky V, et al. (2013): Non-cell-autonomous tumor suppression by p53. Cell 153, 449460

Lyall MS, Dundas SR, Curran S, Murray GI (2006): Profiling markers of prognosis in colorectal cancer. Clin Cancer Res 12, 1184-1191

Lynch HT, Smyrk TC (1998): Classification of familial adenomatous polyposis: a diagnostic nightmare. Am J Hum Genet $\underline{62}$, 1288-1289

Lynch HT, de la Chapelle A (2003): Hereditary colorectal cancer. N Engl J Med 348, 919-932

MacFarlane JK, Ryall RD, Heald RJ (1993): Mesorectal excision for rectal cancer. Lancet 341, 457460

Mainenti PP, Mancini M, Mainolfi C, Camera L, Maurea S, Manchia A, Tanga M, Persico F, Addeo P, D'Antonio D, et al. (2010): Detection of colo-rectal liver metastases: prospective comparison of contrast enhanced US, multidetector CT, PET/CT, and 1.5 Tesla MR with extracellular and reticuloendothelial cell specific contrast agents. Abdom Imaging $\underline{35}, 511-521$

Mantelli M, Barile M, Ciotti P, Ghiorzo P, Lantieri F, Pastorino L, Catricala C, Torre GD, Folco U, Grammatico P, et al. (2002): High prevalence of the G101W germline mutation in the CDKN2A (P16(ink4a)) gene in 62 Italian malignant melanoma families. Am J Med Genet 107, 214-221 
McKay JA, Douglas JJ, Ross VG, Curran S, Loane JF, Ahmed FY, Cassidy J, McLeod HL, Murray GI (2002): Analysis of key cell-cycle checkpoint proteins in colorectal tumours. J Pathol 196, 386393

Michaloglou C, Vredeveld LC, Soengas MS, Denoyelle C, Kuilman T, van der Horst CM, Majoor DM, Shay JW, Mooi WJ, Peeper DS (2005): BRAFE600-associated senescence-like cell cycle arrest of human naevi. Nature $\underline{436}, 720-724$

Minoo P, Zlobec I, Peterson M, Terracciano L, Lugli A (2010): Characterization of rectal, proximal and distal colon cancers based on clinicopathological, molecular and protein profiles. Int J Oncol $\underline{37}$, $707-718$

Murphree AL, Benedict WF (1984): Retinoblastoma: clues to human oncogenesis. Science 223, 1028-1033

Nagtegaal ID, van de Velde CJ, van der Worp E, Kapiteijn E, Quirke P, van Krieken JH, Cooperative Clinical Investigators of the Dutch Colorectal Cancer G (2002): Macroscopic evaluation of rectal cancer resection specimen: clinical significance of the pathologist in quality control. J Clin Oncol 20, 1729-1734

Nagtegaal ID, van de Velde CJ, Marijnen CA, van Krieken JH, Quirke P, Dutch Colorectal Cancer G, Pathology Review C (2005): Low rectal cancer: a call for a change of approach in abdominoperineal resection. J Clin Oncol 23, 9257-9264

Narisawa-Saito M, Kiyono T (2007): Basic mechanisms of high-risk human papillomavirus-induced carcinogenesis: roles of E6 and E7 proteins. Cancer Sci 98, 1505-1511

Nazemalhosseini Mojarad E, Kuppen PJ, Aghdaei HA, Zali MR (2013): The CpG island methylator phenotype (CIMP) in colorectal cancer. Gastroenterol Hepatol Bed Bench $\underline{6}, 120-128$

Nevins JR (2001): The Rb/E2F pathway and cancer. Hum Mol Genet 10, 699-703

Nilsson K, Landberg G (2006): Subcellular localization, modification and protein complex formation of the cdk-inhibitor p16 in Rb-functional and Rb-inactivated tumor cells. Int J Cancer 118 , $1120-1125$ 
Ning Y, Wang L, Giovannucci EL (2010): A quantitative analysis of body mass index and colorectal cancer: findings from 56 observational studies. Obes Rev 11, 19-30

Nobori T, Miura K, Wu DJ, Lois A, Takabayashi K, Carson DA (1994): Deletions of the cyclindependent kinase-4 inhibitor gene in multiple human cancers. Nature $\underline{368}, 753-756$

Norrie MW, Hawkins NJ, Todd AV, Meagher AP, O'Connor TW, Ward RL (2003): Inactivation of p16INK4a by CpG hypermethylation is not a frequent event in colorectal cancer. J Surg Oncol $\underline{84}$, $143-150$

Numata M, Morinaga S, Watanabe T, Tamagawa H, Yamamoto N, Shiozawa M, Nakamura Y, Kameda Y, Okawa S, Rino Y, et al. (2013): The clinical significance of SWI/SNF complex in pancreatic cancer. Int J Oncol $\underline{42}, 403-410$

Ohtani N, Yamakoshi K, Takahashi A, Hara E (2004): The p16INK4a-RB pathway: molecular link between cellular senescence and tumor suppression. J Med Invest 51, 146-153

Okamoto A, Demetrick DJ, Spillare EA, Hagiwara K, Hussain SP, Bennett WP, Forrester K, Gerwin B, Serrano M, Beach DH, et al. (1994): Mutations and altered expression of p16INK4 in human cancer. Proc Natl Acad Sci U S A 91, 11045-11049

Palmero I, McConnell B, Parry D, Brookes S, Hara E, Bates S, Jat P, Peters G (1997): Accumulation of p16INK4a in mouse fibroblasts as a function of replicative senescence and not of retinoblastoma gene status. Oncogene $\underline{15}, 495-503$

Palmqvist R, Rutegard JN, Bozoky B, Landberg G, Stenling R (2000): Human colorectal cancers with an intact $\mathrm{p} 16 /$ cyclin $\mathrm{D} 1 / \mathrm{pRb}$ pathway have up-regulated $\mathrm{p} 16$ expression and decreased proliferation in small invasive tumor clusters. Am J Pathol 157, 1947-1953

Papadopoulou A, Kletsas D (2011): Human lung fibroblasts prematurely senescent after exposure to ionizing radiation enhance the growth of malignant lung epithelial cells in vitro and in vivo. Int $\mathbf{J}$ Oncol 39, 989-999

Paparo F, Puppo C, Montale A, Bacigalupo L, Pascariello A, Clavarezza M, Binda C, Rollandi GA, Binda GA (2014): Comparison between magnetic resonance imaging and rigid rectoscopy in the preoperative identification of intra- and extraperitoneal rectal cancer. Colorectal Dis $\underline{16}$, O379-385 
Parrinello S, Coppe JP, Krtolica A, Campisi J (2005): Stromal-epithelial interactions in aging and cancer: senescent fibroblasts alter epithelial cell differentiation. J Cell Sci 118, 485-496

Pearson K (1900): X. On the criterion that a given system of deviations from the probable in the case of a correlated system of variables is such that it can be reasonably supposed to have arisen from random sampling. Philosophical Magazine Series 5 50, 157-175

Pelser C, Arem H, Pfeiffer RM, Elena JW, Alfano CM, Hollenbeck AR, Park Y (2014):

Prediagnostic lifestyle factors and survival after colon and rectal cancer diagnosis in the National Institutes of Health (NIH)-AARP Diet and Health Study. Cancer 120, 1540-1547

Perry WB, Connaughton JC (2007): Abdominoperineal resection: how is it done and what are the results? Clin Colon Rectal Surg 20, 213-220

Pilipshen SJ, Heilweil M, Quan SH, Sternberg SS, Enker WE (1984): Patterns of pelvic recurrence following definitive resections of rectal cancer. Cancer 53, 1354-1362

Poulogiannis G, Frayling IM, Arends MJ (2010): DNA mismatch repair deficiency in sporadic colorectal cancer and Lynch syndrome. Histopathology $\underline{56}, 167-179$

Pox C, Aretz S, Bischoff SC, Graeven U, Hass M, Heussner P, Hohenberger W, Holstege A, Hubner J, Kolligs F, et al. (2013): S3-Leitlinie Kolorektales Karzinom Version 1.0 - Juni 2013 AWMFRegisternummer: 021/007OL. Z Gastroenterol 51, 753-854

Pox CP, Altenhofen L, Brenner H, Theilmeier A, Von Stillfried D, Schmiegel W (2012): Efficacy of a nationwide screening colonoscopy program for colorectal cancer. Gastroenterology $\underline{142}, 1460-$ 1467 e 1462

Pulford KA, Rigney EM, Micklem KJ, Jones M, Stross WP, Gatter KC, Mason DY (1989): KP1: a new monoclonal antibody that detects a monocyte/macrophage associated antigen in routinely processed tissue sections. J Clin Pathol $\underline{42}, 414-421$

Puli SR, Reddy JB, Bechtold ML, Choudhary A, Antillon MR, Brugge WR (2009): Accuracy of endoscopic ultrasound to diagnose nodal invasion by rectal cancers: a meta-analysis and systematic review. Ann Surg Oncol 16, 1255-1265 
Purkayastha S, Athanasiou T, Tekkis PP, Constantinides V, Teare J, Darzi AW (2007): Magnetic resonance colonography vs computed tomography colonography for the diagnosis of colorectal cancer: an indirect comparison. Colorectal Dis $\underline{9}, 100-111$

Quaia E, D'Onofrio M, Palumbo A, Rossi S, Bruni S, Cova M (2006): Comparison of contrastenhanced ultrasonography versus baseline ultrasound and contrast-enhanced computed tomography in metastatic disease of the liver: diagnostic performance and confidence. Eur Radiol 16, 1599-1609

Read J, Wadt KA, Hayward NK (2016): Melanoma genetics. J Med Genet 53, 1-14

Reed JA, Loganzo F, Jr., Shea CR, Walker GJ, Flores JF, Glendening JM, Bogdany JK, Shiel MJ, Haluska FG, Fountain JW, et al. (1995): Loss of expression of the p16/cyclin-dependent kinase inhibitor 2 tumor suppressor gene in melanocytic lesions correlates with invasive stage of tumor progression. Cancer Res 55, 2713-2718

Ressler S, Bartkova J, Niederegger H, Bartek J, Scharffetter-Kochanek K, Jansen-Durr P, Wlaschek $\mathrm{M}$ (2006): p16INK4A is a robust in vivo biomarker of cellular aging in human skin. Aging Cell $\underline{5}$, 379-389

Ridgway PF, Darzi AW (2003): The role of total mesorectal excision in the management of rectal cancer. Cancer Control 10, 205-211

Rischin D, Young RJ, Fisher R, Fox SB, Le QT, Peters LJ, Solomon B, Choi J, O'Sullivan B, Kenny LM, et al. (2010): Prognostic significance of p16INK4A and human papillomavirus in patients with oropharyngeal cancer treated on TROG 02.02 phase III trial. J Clin Oncol 28, 4142-4148

Rizeq MN, van de Rijn M, Hendrickson MR, Rouse RV (1994): A comparative immunohistochemical study of uterine smooth muscle neoplasms with emphasis on the epithelioid variant. Hum Pathol 25, 671-677

RKI und GEKID: Krebs in Deutschland 2011/2012. 10. Ausgabe. Robert Koch-Institut (Hrsg.) und Gesellschaft der epidemiologischen Krebsregister in Deutschland e. V. (Hrsg.), Berlin 2015

Roberson RS, Kussick SJ, Vallieres E, Chen SY, Wu DY (2005): Escape from therapy-induced accelerated cellular senescence in p53-null lung cancer cells and in human lung cancers. Cancer Res $\underline{65}, 2795-2803$ 
Robles SJ, Adami GR (1998): Agents that cause DNA double strand breaks lead to p16INK4a enrichment and the premature senescence of normal fibroblasts. Oncogene 16, 1113-1123

Rödel C, Martus P, Papadoupolos T, Fuzesi L, Klimpfinger M, Fietkau R, Liersch T, Hohenberger W, Raab R, Sauer R, et al. (2005): Prognostic significance of tumor regression after preoperative chemoradiotherapy for rectal cancer. J Clin Oncol 23, 8688-8696

Rödel C, Liersch T, Hermann RM, Arnold D, Reese T, Hipp M, Furst A, Schwella N, Bieker M, Hellmich G, et al. (2007): Multicenter phase II trial of chemoradiation with oxaliplatin for rectal cancer. J Clin Oncol 25, 110-117

Rödel C, Liersch T, Becker H, Fietkau R, Hohenberger W, Hothorn T, Graeven U, Arnold D, LangWelzenbach M, Raab HR, et al. (2012): Preoperative chemoradiotherapy and postoperative chemotherapy with fluorouracil and oxaliplatin versus fluorouracil alone in locally advanced rectal cancer: initial results of the German CAO/ARO/AIO-04 randomised phase 3 trial. Lancet Oncol 13 , $679-687$

Rödel C, Graeven U, Fietkau R, Hohenberger W, Hothorn T, Arnold D, Hofheinz RD, Ghadimi M, Wolff HA, Lang-Welzenbach M, et al. (2015): Oxaliplatin added to fluorouracil-based preoperative chemoradiotherapy and postoperative chemotherapy of locally advanced rectal cancer (the German CAO/ARO/AIO-04 study): final results of the multicentre, open-label, randomised, phase 3 trial. Lancet Oncol 16, 979-989

Romagosa C, Simonetti S, Lopez-Vicente L, Mazo A, Lleonart ME, Castellvi J, Ramon y Cajal S (2011): p16(Ink4a) overexpression in cancer: a tumor suppressor gene associated with senescence and high-grade tumors. Oncogene 30, 2087-2097

Roninson IB (2003): Tumor cell senescence in cancer treatment. Cancer Res $\underline{63}$, 2705-2715

Rüschoff J, Dietel M, Baretton G, Arbogast S, Walch A, Monges G, Chenard MP, Penault-Llorca F, Nagelmeier I, Schlake W, et al. (2010): HER2 diagnostics in gastric cancer-guideline validation and development of standardized immunohistochemical testing. Virchows Arch 457, 299-307

Russo AA, Tong L, Lee JO, Jeffrey PD, Pavletich NP (1998): Structural basis for inhibition of the cyclin-dependent kinase Cdk6 by the tumour suppressor p16INK4a. Nature 395, 237-243 
Sagiv A, Krizhanovsky V (2013): Immunosurveillance of senescent cells: the bright side of the senescence program. Biogerontology 14, 617-628

Sagiv A, Biran A, Yon M, Simon J, Lowe SW, Krizhanovsky V (2013): Granule exocytosis mediates immune surveillance of senescent cells. Oncogene 32, 1971-1977

Samadder NJ, Jasperson K, Burt RW (2015): Hereditary and common familial colorectal cancer: evidence for colorectal screening. Dig Dis Sci 60, 734-747

Sano T, Oyama T, Kashiwabara K, Fukuda T, Nakajima T (1998a): Immunohistochemical overexpression of p16 protein associated with intact retinoblastoma protein expression in cervical cancer and cervical intraepithelial neoplasia. Pathol Int $\underline{48}, 580-585$

Sano T, Oyama T, Kashiwabara K, Fukuda T, Nakajima T (1998b): Expression status of p16 protein is associated with human papillomavirus oncogenic potential in cervical and genital lesions. Am J Pathol 153, 1741-1748

Saretzki G, Sitte N, Merkel U, Wurm RE, von Zglinicki T (1999): Telomere shortening triggers a p53-dependent cell cycle arrest via accumulation of G-rich single stranded DNA fragments. Oncogene 18, 5148-5158

Saretzki G (2010): Cellular senescence in the development and treatment of cancer. Curr Pharm Des $\underline{16}, 79-100$

Sarma DP (1988): Dukes' classification of rectal cancer. South Med J $\underline{81}$, 407-408

Sauer R, Fietkau R, Wittekind C, Rödel C, Martus P, Hohenberger W, Tschmelitsch J, Sabitzer H, Karstens JH, Becker H, et al. (2003): Adjuvant vs. neoadjuvant radiochemotherapy for locally advanced rectal cancer: the German trial CAO/ARO/AIO-94. Colorectal Dis 5, 406-415

Sauer R, Becker H, Hohenberger W, Rödel C, Wittekind C, Fietkau R, Martus P, Tschmelitsch J, Hager E, Hess CF, et al. (2004): Preoperative versus postoperative chemoradiotherapy for rectal cancer. N Engl J Med 351, 1731-1740

Sauer R, Liersch T, Merkel S, Fietkau R, Hohenberger W, Hess C, Becker H, Raab HR, Villanueva MT, Witzigmann H, et al. (2012): Preoperative versus postoperative chemoradiotherapy for locally 
advanced rectal cancer: results of the German CAO/ARO/AIO-94 randomized phase III trial after a median follow-up of 11 years. J Clin Oncol 30, 1926-1933

Sawicka M, Pawlikowski J, Wilson S, Ferdinando D, Wu H, Adams PD, Gunn DA, Parish W (2013): The specificity and patterns of staining in human cells and tissues of p16INK4a antibodies demonstrate variant antigen binding. PLoS One $\underline{8}$, e53313

Schmitt CA, Fridman JS, Yang M, Lee S, Baranov E, Hoffman RM, Lowe SW (2002): A senescence program controlled by p53 and p16INK4a contributes to the outcome of cancer therapy. Cell 109, 335-346

Schmoll HJ, Van Cutsem E, Stein A, Valentini V, Glimelius B, Haustermans K, Nordlinger B, van de Velde CJ, Balmana J, Regula J, et al. (2012): ESMO Consensus Guidelines for management of patients with colon and rectal cancer. a personalized approach to clinical decision making. Ann Oncol $\underline{23}, 2479-2516$

Schroder LB, McDonald KL (2015): CDK4/6 Inhibitor PD0332991 in Glioblastoma Treatment: Does It Have a Future? Front Oncol 5, 259

Serrano M, Hannon GJ, Beach D (1993): A new regulatory motif in cell-cycle control causing specific inhibition of cyclin D/CDK4. Nature 366, 704-707

Serrano M, Lin AW, McCurrach ME, Beach D, Lowe SW (1997): Oncogenic ras provokes premature cell senescence associated with accumulation of p53 and p16INK4a. Cell $\underline{88}, 593-602$

Serrano M (1997): The tumor suppressor protein p16INK4a. Exp Cell Res 237, 7-13

Shapiro GI, Rollins BJ (1996): p16INK4A as a human tumor suppressor. Biochim Biophys Acta $\underline{1242}, 165-169$

Shay JW, Roninson IB (2004): Hallmarks of senescence in carcinogenesis and cancer therapy. Oncogene 23, 2919-2933

Shelton DN, Chang E, Whittier PS, Choi D, Funk WD (1999): Microarray analysis of replicative senescence. Curr Biol 9, 939-945 
Sherr CJ, Roberts JM (1995): Inhibitors of mammalian G1 cyclin-dependent kinases. Genes Dev 9 , $1149-1163$

Sherr CJ, DePinho RA (2000): Cellular senescence: mitotic clock or culture shock? Cell 102, 407 410

Shima K, Nosho K, Baba Y, Cantor M, Meyerhardt JA, Giovannucci EL, Fuchs CS, Ogino S (2011): Prognostic significance of CDKN2A (p16) promoter methylation and loss of expression in 902 colorectal cancers: Cohort study and literature review. Int J Cancer 128, 1080-1094

Skalli O, Ropraz P, Trzeciak A, Benzonana G, Gillessen D, Gabbiani G (1986): A monoclonal antibody against alpha-smooth muscle actin: a new probe for smooth muscle differentiation. J Cell Biol 103, 2787-2796

Smith SR, Swift I, Gompertz H, Baker WN (1988): Abdominoperineal and anterior resection of the rectum with retrocolic omentoplasty and no drainage. Br J Surg 75, 1012-1015

Snover DC (2011): Update on the serrated pathway to colorectal carcinoma. Hum Pathol 42, 1-10

Sobin LH, Wittekind C, Cancer UIUA: TNM Classification of Malignant Tumours. Wiley 2002

Sobin LH, Gospodarowicz MK, Wittekind C: TNM Classification of Malignant Tumours. Wiley 2011

Soura E, Eliades PJ, Shannon K, Stratigos AJ, Tsao H (2016): Hereditary melanoma: Update on syndromes and management: Genetics of familial atypical multiple mole melanoma syndrome. J Am Acad Dermatol 74, 395-407

Sprenger T, Rothe H, Conradi LC, Beissbarth T, Kauffels A, Kitz J, Homayounfar K, Wolff H, Strobel P, Ghadimi M, et al. (2016): Stage-Dependent Frequency of Lymph Node Metastases in Patients With Rectal Carcinoma After Preoperative Chemoradiation: Results from the CAO/ARO/AIO-94 Trial and From a Comparative Prospective Evaluation With Extensive Pathological Workup. Dis Colon Rectum 59, 377-385

Sridhar J, Akula N, Pattabiraman N (2006): Selectivity and potency of cyclin-dependent kinase inhibitors. AAPS J $\underline{8}$, E204-221 
Stapley S, Peters TJ, Sharp D, Hamilton W (2006): The mortality of colorectal cancer in relation to the initial symptom at presentation to primary care and to the duration of symptoms: a cohort study using medical records. Br J Cancer 95, 1321-1325

Steiner MS, Wang Y, Zhang Y, Zhang X, Lu Y (2000): p16/MTS1/INK4A suppresses prostate cancer by both pRb dependent and independent pathways. Oncogene 19, 1297-1306

Stuart A: Kendall's Tau—I: Encyclopedia of Statistical Sciences. John Wiley \& Sons, Hoboken 2006

Styczen H, Nagelmeier I, Beissbarth T, Nietert M, Homayounfar K, Sprenger T, Boczek U, Stanek K, Kitz J, Wolff HA, et al. (2015): HER-2 and HER-3 expression in liver metastases of patients with colorectal cancer. Oncotarget $\underline{6}, 15065-15076$

Suzuki K, Mori I, Nakayama Y, Miyakoda M, Kodama S, Watanabe M (2001): Radiation-induced senescence-like growth arrest requires TP53 function but not telomere shortening. Radiat Res 155 , $248-253$

Suzuki M, Boothman DA (2008): Stress-induced premature senescence (SIPS) - influence of SIPS on radiotherapy -. J Radiat Res $\underline{49}, 105-112$

Tada T, Watanabe T, Kazama S, Kanazawa T, Hata K, Komuro Y, Nagawa H (2003): Reduced p16 expression correlates with lymphatic invasion in colorectal cancers. Hepatogastroenterology $\underline{50}$, $1756-1760$

te Poele RH, Okorokov AL, Jardine L, Cummings J, Joel SP (2002): DNA damage is able to induce senescence in tumor cells in vitro and in vivo. Cancer Res $\underline{62}$, 1876-1883

Toyota M, Ahuja N, Ohe-Toyota M, Herman JG, Baylin SB, Issa JP (1999): CpG island methylator phenotype in colorectal cancer. Proc Natl Acad Sci U S A $\underline{96}, 8681-8686$

Trakarnsanga A, Gonen M, Shia J, Nash GM, Temple LK, Guillem JG, Paty PB, Goodman KA, Wu A, Gollub M, et al. (2014): Comparison of tumor regression grade systems for locally advanced rectal cancer after multimodality treatment. J Natl Cancer Inst 106, pii: dju248

van Gijn W, Marijnen CA, Nagtegaal ID, Kranenbarg EM, Putter H, Wiggers T, Rutten HJ, Pahlman L, Glimelius B, van de Velde CJ (2011): Preoperative radiotherapy combined with total mesorectal 
excision for resectable rectal cancer: 12-year follow-up of the multicentre, randomised controlled TME trial. Lancet Oncol 12, 575-582

van Stolk RU, Beck GJ, Baron JA, Haile R, Summers R (1998): Adenoma characteristics at first colonoscopy as predictors of adenoma recurrence and characteristics at follow-up. The Polyp Prevention Study Group. Gastroenterology 115, 13-18

Ventura A, Kirsch DG, McLaughlin ME, Tuveson DA, Grimm J, Lintault L, Newman J, Reczek EE, Weissleder R, Jacks T (2007): Restoration of p53 function leads to tumour regression in vivo. Nature $445,661-665$

von Stockmar-von Wangenheim CA, Monig SP, Schneider PM, Landsberg S, Drebber U, Holscher AH, Dienes HP, Baldus SE (2008): p16, cyclin D1 and Rb expression in colorectal carcinomas: Correlations with clinico-pathological parameters and prognosis. Mol Med Rep 1, 27-32

Waldman T, Zhang Y, Dillehay L, Yu J, Kinzler K, Vogelstein B, Williams J (1997): Cell-cycle arrest versus cell death in cancer therapy. Nat Med $\underline{3}, 1034-1036$

Warnke RA, Pulford KA, Pallesen G, Ralfkiaer E, Brown DC, Gatter KC, Mason DY (1989): Diagnosis of myelomonocytic and macrophage neoplasms in routinely processed tissue biopsies with monoclonal antibody KP1. Am J Pathol 135, 1089-1095

Wassermann S, Scheel SK, Hiendlmeyer E, Palmqvist R, Horst D, Hlubek F, Haynl A, Kriegl L, Reu S, Merkel S, et al. (2009): p16INK4a is a beta-catenin target gene and indicates low survival in human colorectal tumors. Gastroenterology 136, 196-205 e192

Weinberg RA (1995): The retinoblastoma protein and cell cycle control. Cell $\underline{81}, 323-330$

West NP, Finan PJ, Anderin C, Lindholm J, Holm T, Quirke P (2008): Evidence of the oncologic superiority of cylindrical abdominoperineal excision for low rectal cancer. J Clin Oncol 26, 35173522

Willett W (1989): The search for the causes of breast and colon cancer. Nature 338, 389-394

Witkiewicz AK, Knudsen KE, Dicker AP, Knudsen ES (2011): The meaning of p16(ink4a) expression in tumors: functional significance, clinical associations and future developments. Cell Cycle 10, 2497-2503 
Worthley DL, Leggett BA (2010): Colorectal cancer: molecular features and clinical opportunities. Clin Biochem Rev 31, 31-38

Wu CL, Zukerberg LR, Ngwu C, Harlow E, Lees JA (1995): In vivo association of E2F and DP family proteins. Mol Cell Biol 15, 2536-2546

Xing X, Cai W, Shi H, Wang Y, Li M, Jiao J, Chen M (2013): The prognostic value of CDKN2A hypermethylation in colorectal cancer: a meta-analysis. Br J Cancer 108, 2542-2548

Xue W, Zender L, Miething C, Dickins RA, Hernando E, Krizhanovsky V, Cordon-Cardo C, Lowe SW (2007): Senescence and tumour clearance is triggered by p53 restoration in murine liver carcinomas. Nature $\underline{445}, 656-660$

Yates F (1934): Contingency Tables Involving Small Numbers and the $\chi^{2}$ Test. Supplement to the Journal of the Royal Statistical Society 1, 217-235

Yim EK, Park JS (2005): The role of HPV E6 and E7 oncoproteins in HPV-associated cervical carcinogenesis. Cancer Res Treat 37, 319-324

Zarbo RJ, Prasad AR, Regezi JA, Gown AM, Savera AT (2000): Salivary gland basal cell and canalicular adenomas: immunohistochemical demonstration of myoepithelial cell participation and morphogenetic considerations. Arch Pathol Lab Med 124, 401-405

Zauber AG, Lansdorp-Vogelaar I, Knudsen AB, Wilschut J, van Ballegooijen M, Kuntz KM (2008): Evaluating test strategies for colorectal cancer screening: a decision analysis for the U.S. Preventive Services Task Force. Ann Intern Med 149, 659-669

Zhao P, Hu YC, Talbot IC (2003): Expressing patterns of p16 and CDK4 correlated to prognosis in colorectal carcinoma. World J Gastroenterol 9, 2202-2206

Zhao P, Mao X, Talbot IC (2006): Aberrant cytological localization of p16 and CDK4 in colorectal epithelia in the normal adenoma carcinoma sequence. World J Gastroenterol 12, 6391-6396

zur Hausen H (1996): Papillomavirus infections-a major cause of human cancers. Biochim Biophys Acta $\underline{1288}$, F55-78 


\section{Danksagung}

Ich danke Herrn Prof. Dr. med. Torsten Liersch für die Ideengebung im Rahmen des TP5 der KFO-179/2, für das Überlassen des überaus interessanten Promotionsthemas, für die Betreuung während der Arbeit und seine stets konstruktiven, inhaltlich und wissenschaftlich umfassenden Anregungen sowie Anmerkungen.

Zudem danke ich Herrn PD Dr. med. Kia Homayounfar für die kurzzeitige Übernahme der Betreuung, die unkomplizierte und kollegiale Zusammenarbeit und sein wertvolles Feedback.

Ebenso danke ich Herrn Prof. Dr. med. Michael Ghadimi für die Möglichkeit, in seiner Klinik für Allgemein-, Viszeral- und Kinderchirurgie meine Promotion anzufertigen.

Ein herzlicher Dank geht an Frau Dr. med. Lena Conradi für die kontinuierliche Betreuung meiner Doktorarbeit, ihre stets motivierenden Worte, ihre Beharrlichkeit und ihre große Geduld.

Ein großer Dank gilt Frau Dr. med. Julia Kitz für die vielen Stunden, in denen sie mit mir Gewebeschnitte mikroskopiert hat, und für das Teilen ihres ungeheuren Fachwissens.

Ein besonderes Dankeschön geht an die gute Seele des Labors, Birgit Jünemann, für ihre hervorragende Arbeit, ihr großes Verständnis für die Nöte und Sorgen von Doktorand*innen und ihre psychologische Aufbauhilfe nach Rückschlägen aller Art.

Vielen Dank ebenfalls an Herrn Prof. Dr. rer. nat. Tim Beißbarth, der trotz des großen Zeitaufwands seinerseits nie die Geduld mit mir und meiner Arbeit verloren hat. Ich habe von ihm unschätzbar viel über medizinische Statistik und wissenschaftliches Arbeiten gelernt.

Danke auch an Larissa Geier, Susanne Klie, Johanna Kreutzer und Elke Stauffer aus dem Studiensekretariat und an Kathrin Stanek, die mir bei der Erhebung der Patientendaten mit Rat und Tat zur Seite standen. 